\title{
Quantification of Stabilization Efforts of Shoulder Muscles using Surface Electromyography
}

Hamad Nasser Alasim

Follow this and additional works at: https://researchrepository.wvu.edu/etd

\section{Recommended Citation}

Alasim, Hamad Nasser, "Quantification of Stabilization Efforts of Shoulder Muscles using Surface Electromyography" (2016). Graduate Theses, Dissertations, and Problem Reports. 5048.

https://researchrepository.wvu.edu/etd/5048

This Thesis is protected by copyright and/or related rights. It has been brought to you by the The Research Repository @ WVU with permission from the rights-holder(s). You are free to use this Thesis in any way that is permitted by the copyright and related rights legislation that applies to your use. For other uses you must obtain permission from the rights-holder(s) directly, unless additional rights are indicated by a Creative Commons license in the record and/ or on the work itself. This Thesis has been accepted for inclusion in WVU Graduate Theses, Dissertations, and Problem Reports collection by an authorized administrator of The Research Repository @ WVU. For more information, please contact researchrepository@mail.wvu.edu. 


\title{
Quantification of Stabilization Efforts of Shoulder Muscles using Surface Electromyography
}

\author{
Hamad Nasser Alasim \\ Thesis submitted to the Benjamin M. Statler College of \\ Engineering and Mineral Resources at \\ West Virginia University in partial fulfillment \\ of the requirement for the degree of
}

Master of Science
in
Industrial Engineering

Ashish D. Nimbarte, Ph.D., Chair

Majid Jaridi, Ph.D.

Xiaopeng Ning, Ph.D.

Department of Industrial and Management Systems Engineering

Morgantown, West Virginia

May, 2016

Keywords: shoulder, stability, concavity compression, musculoskeletal disorders

Copyright 2016 Hamad Nasser Alasim 


\section{ABSTRACT \\ Quantification of Stabilization Efforts of Shoulder Muscles using Surface Electromyography}

\section{Hamad Nasser Alasim}

Shoulder musculoskeletal disorders (MSDs) put a huge burden on both employers and employees due to lost work days, healthcare costs and human suffering. Static and heavy industrial work, submaximal repetitive movement and arm elevation are frequently associated with shoulder MSDs. Previous studies indicated that factors such as force exertion levels, posture and hand gripping can influence the activation and fatigability of shoulder muscles. In this study, we explored the inter-muscle difference in shoulder activation during isometric/static force exertions. We suspected that shoulder muscles' attempt to stabilize the glenohumeral joint using the concavity compression mechanism may explain differences in the muscle activation pattern during shoulder exertions. Ten right-hand dominant male participants performed a 60 second static shoulder exertion using three force levels (10, 7.5 and 5 lbs.) in five directions (back, down, left, right and up). Results showed that muscle activity and fatigability were affected by force level and force exertion direction. Muscle exertion and fatigability were highly affected by 10lbs. force exertion. The findings of this study suggest that, during static shoulder exertion, pulling in up and right directions result in the highest muscle activity and fatigability. 


\section{Acknowledgements}

I would like to express my deepest gratitude to my advisor, Dr. Ashish D. Nimbarte for the continuous encouragement, guidance and support toward my master's thesis. His guidance helped me in all the time on researching and writing this thesis. And his patience and support helped me overcome many crisis situations to finish this thesis. I would also like to thank my thesis committee: Dr. Majid Jaridi and Dr. Xiaopeng Ning, for their insightful comments and encouragements.

A special word of thanks goes to my parents, Nasser and Hind, for their continuous support and encouragement; and for their faith in me. I am also grateful for the love, encouragement, and tolerance of my wife Atheer, the woman who has made all the difference in my life. Without her support, I could not have completed this thesis. Finally, I dedicate this thesis to my parents and my lovely wife. 


\section{Table of Contents}

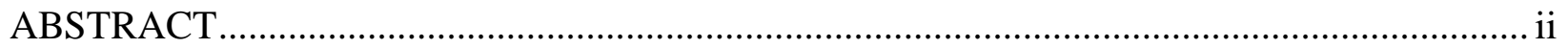

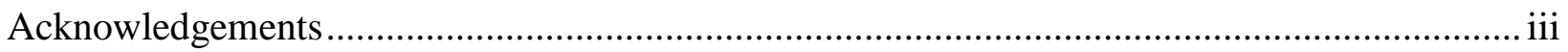

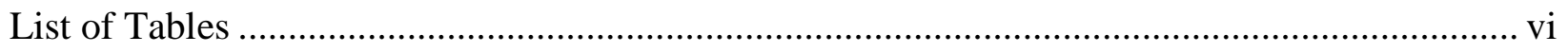

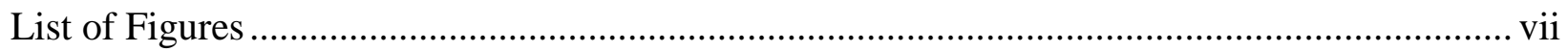

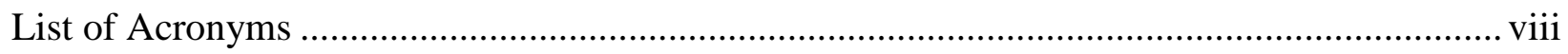

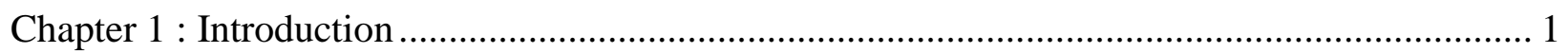

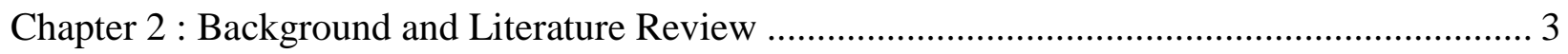

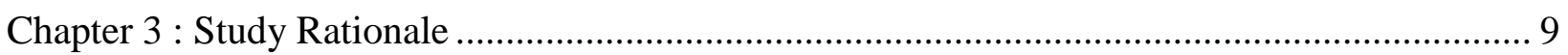

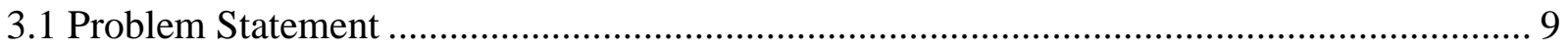

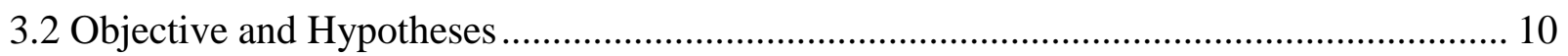

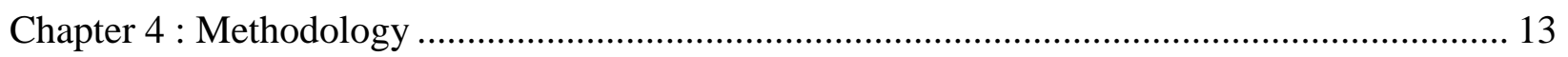

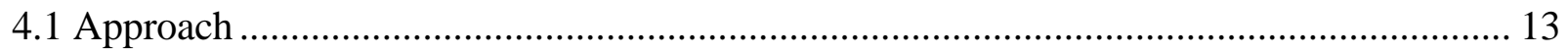

4.2 Participants .............................................................................................................. 13

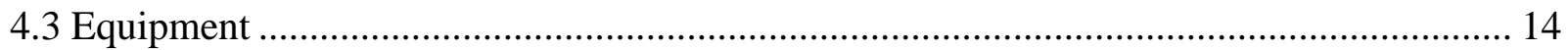

4.3.1 Custom-Made Force Exertion Device _........................................................................ 14

4.3.2 Surface Electromyography (SEMG) system .......................................................... 15

4.4 Experimental Design ............................................................................................. 16

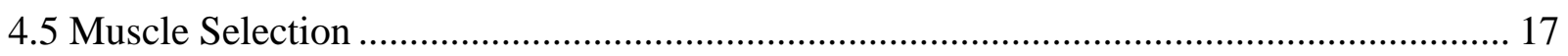

4.6 Experimental Data Collection Procedure ………………............................................. 18

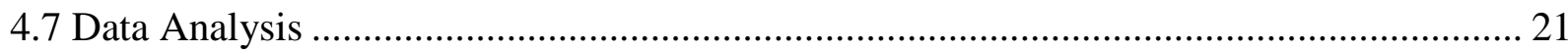

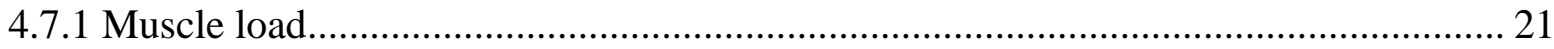

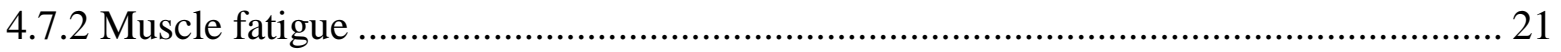

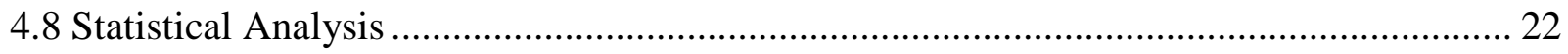




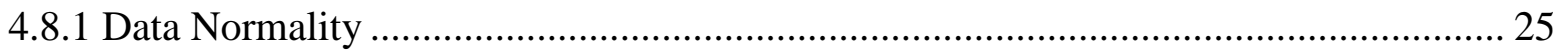

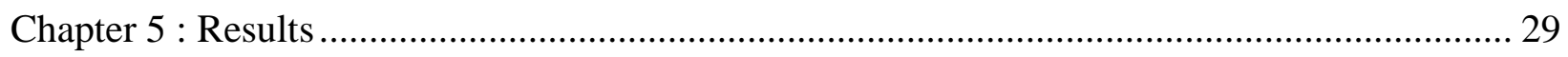

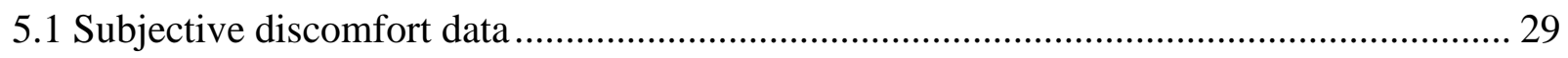

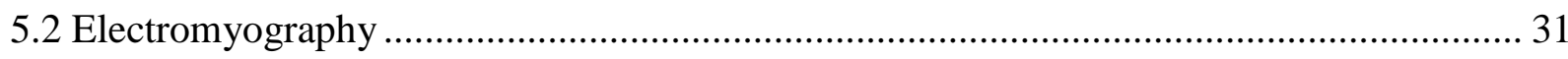

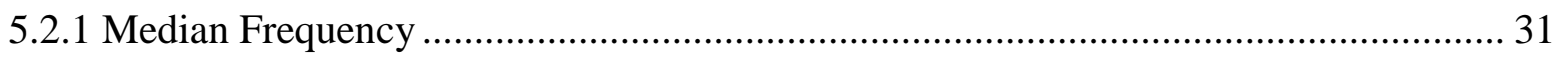

5.2.2 Normalized mean absolute values ............................................................. 42

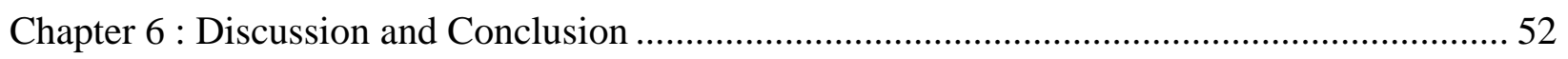

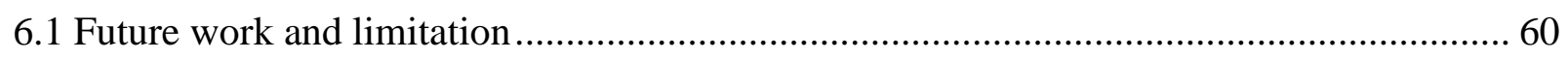

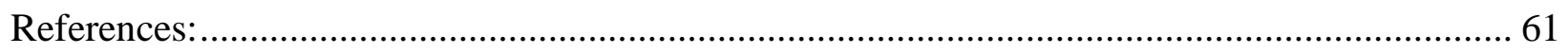

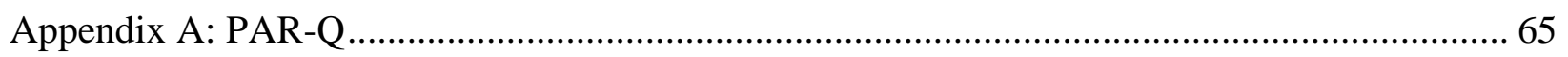

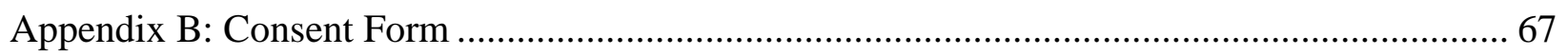

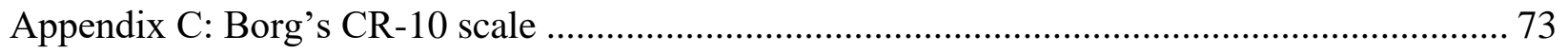

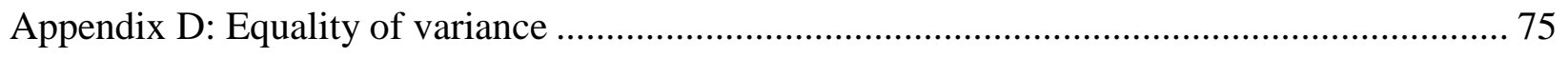

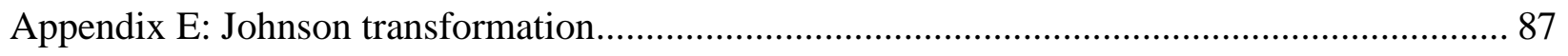

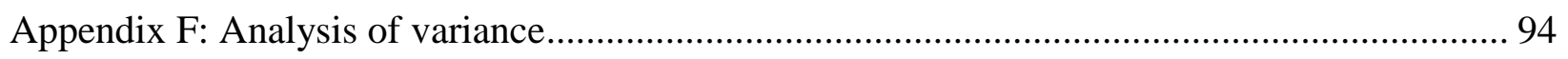

Appendix G: Kruskal-Wallis test........................................................................... 105

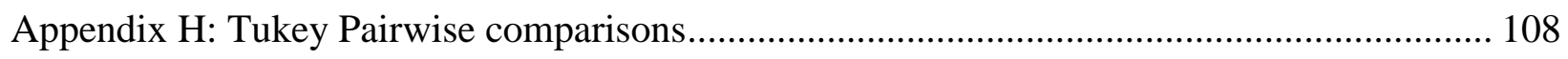

Appendix I: Subjective discomfort ratings raw data.................................................... 120

Appendix J: Median frequency slope raw data ............................................................ 122

Appendix K: Normalized mean absolute values raw data .............................................. 130 


\section{List of Tables}

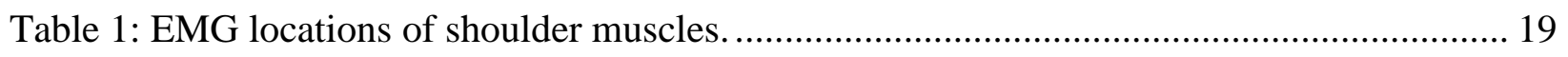

Table 2: MVC posture and action for each muscle............................................................... 20

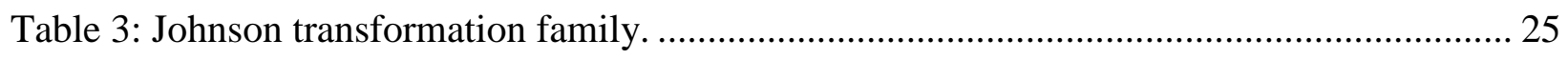

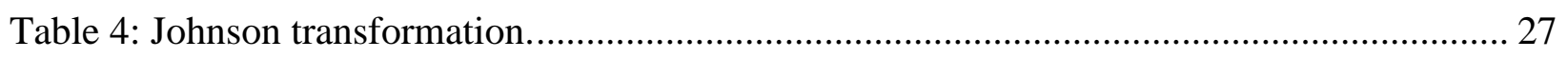

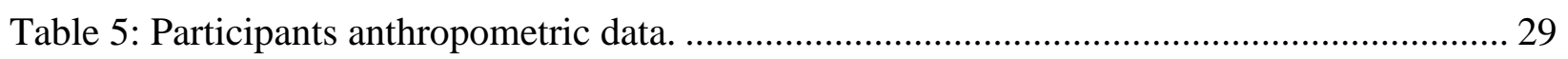

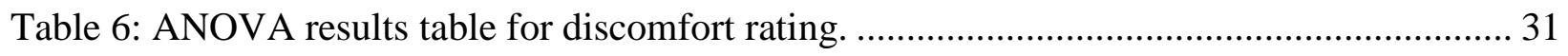

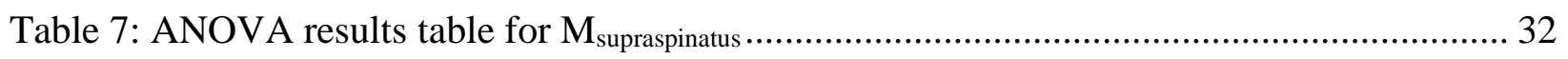

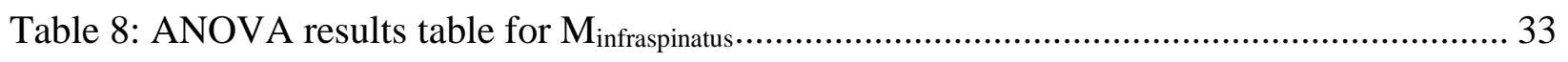

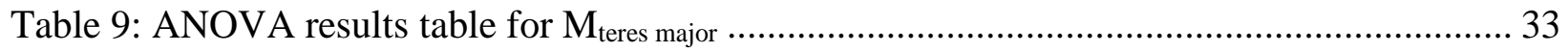

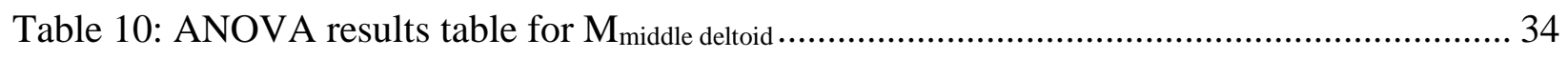

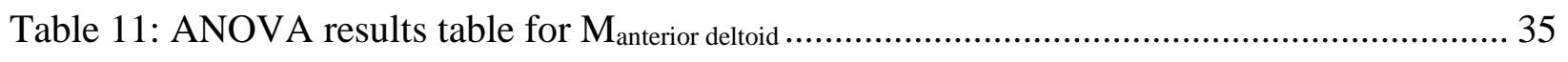

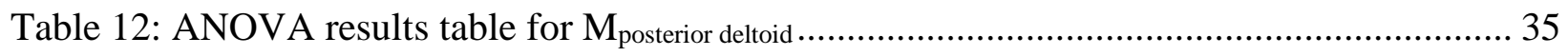

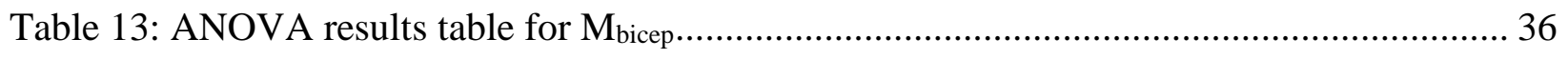

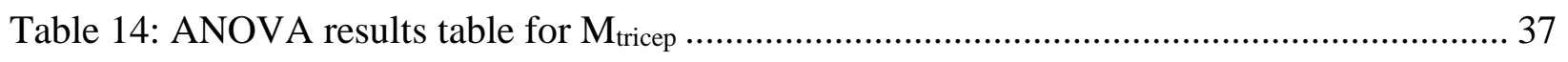

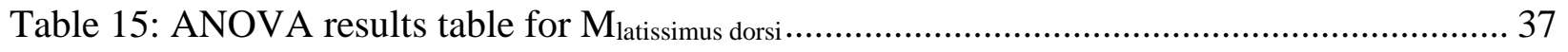

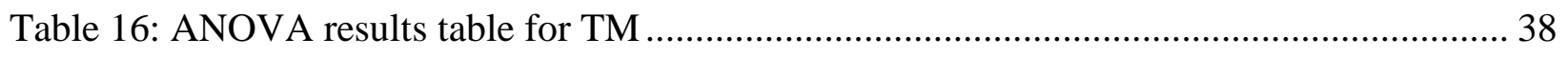

Table 17: Median frequency slope values mean, SD, main and interaction effect..................... 39

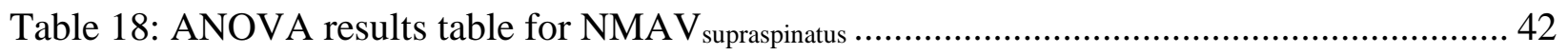

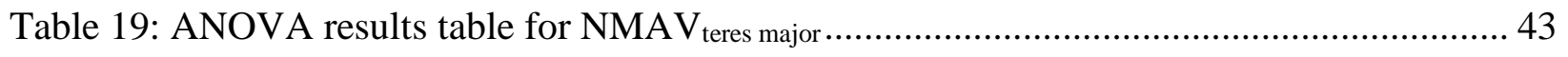

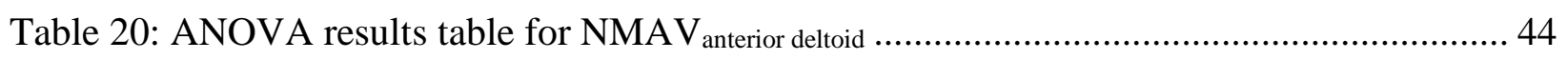

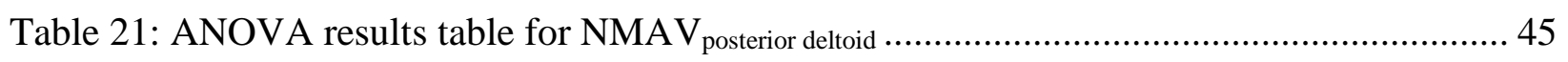

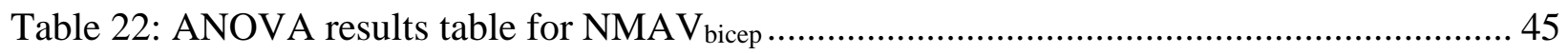

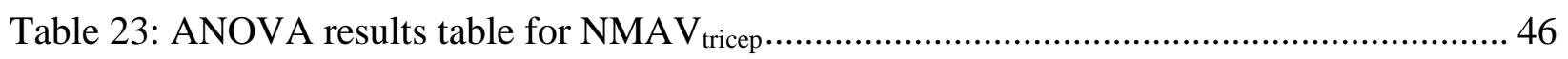

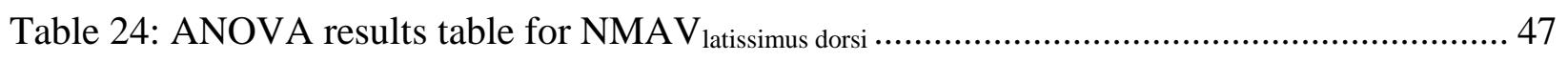

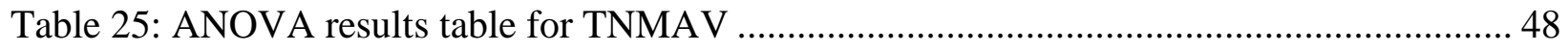

Table 26: Normalized mean absolute values, SD, main and interaction effect. ....................... 49

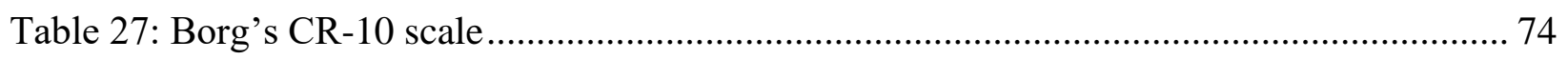

Table 28: Expected mean squares for $\mathrm{A}$ and $\mathrm{B}$ as fixed variables and $\mathrm{C}$ as a random variable ... 95

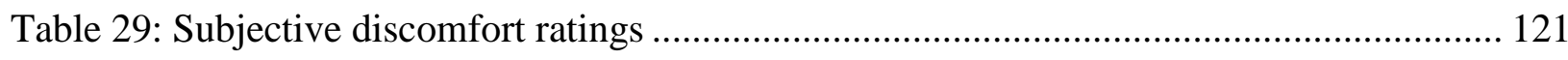




\section{List of Figures}

Figure 1: Human shoulder complex (Cutlip, 2004) ........................................................ 3

Figure 2: Concavity compression mechanism (Cutlip, 2014). .............................................. 4

Figure 3: Force magnitude for frontal and transverse plane. .............................................. 11

Figure 4: Experiment device while performing pulling right (PR) task ............................... 14

Figure 5: Upper view for experiment device shows (PR, PL and PB) tasks. ......................... 15

Figure 6: Telemyo 2400 T G2 EMG system receiver and transmitter. .................................. 15

Figure 7: Pre-amplified lead wires and Ag/AgCl snap/clips electrodes................................. 16

Figure 8: Equality of variance process illustration diagram. ............................................. 26

Figure 9: Subjective discomfort scores at different force levels and directions. Error bars

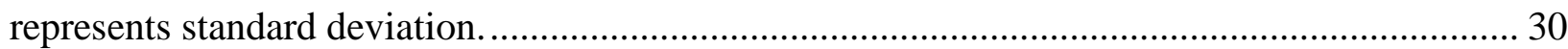

Figure 10: Raw data charts for median frequency slope values. Error bars represents standard

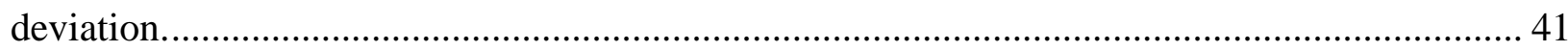

Figure 11: Raw data charts normalized mean absolute values. Error bars represents standard

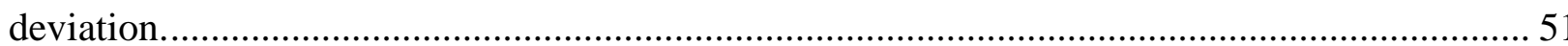




\section{List of Acronyms}

\begin{tabular}{|c|c|}
\hline MSD & Musculoskeletal Disorders \\
\hline GHJ & Glenohumeral joint \\
\hline ACJ & acromioclavicular joint \\
\hline SCJ & sternoclavicular joint \\
\hline MVC & Maximum Voluntary Contraction \\
\hline EMG & Electromyography \\
\hline SEMG & Surface electromyography \\
\hline PB & Pulling up \\
\hline PD & Pulling down \\
\hline PL & Pulling left \\
\hline PR & Pulling right \\
\hline PU & Pulling up \\
\hline MF & Median frequency \\
\hline M & Slope value \\
\hline $\mathrm{TM}$ & Total slope value \\
\hline MAV & Mean absolute value \\
\hline NMAV & Normalized mean absolute value \\
\hline TNMAV & Total normalized mean absolute value \\
\hline PAR-Q & Physical activity readiness questionnaire \\
\hline SD & Standard deviation \\
\hline ANOVA & Analysis of variance \\
\hline lbs. & Pound \\
\hline
\end{tabular}




\section{Chapter 1: Introduction}

Shoulder musculoskeletal disorders (MSDs) put a huge burden on both employers and employees due to lost work days, healthcare costs and human suffering. The Bureau of Labor Statistics (BLS) reported that in 2012 over 27,000 shoulder-related occupational injuries and illnesses caused a day or more away from work, with a median of 12 lost days (BLS, 2014). The cost per shoulder MSD claim varies from a few hundred to several thousand dollars. In a recent report on worker compensation data in the state of Maryland, it was reported that the cost per shoulder injury was higher, averaging $\$ 25,378$ per claim compared to the average cost of $\$ 22,447$ per lower back injury claim. Several Permanent Partial Disability (PPD) awards due to shoulder injuries were also reported, with costs ranging between \$253,230 (against Montgomery County Board of Education) and \$307,286 (against Browning Ferris Industries) (Warnken, 2012). The exact nature of the injuries was unknown for legal reasons.

Static and heavy industrial work, submaximal repetitive movement and arm elevation are some of the activities which are frequently associated with shoulder MSDs (Alizadehkhaiyat et al., 2011). Specialty trade contractors, food manufacturing, building material and garden equipment and supplies dealers, air transportation, warehousing and storage, nursing and residential care facilities are the occupations with the highest number of workers suffering from shoulder MSDs (BLS, 2014).

Most of the existing studies that deal with the prevention of shoulder MSDs primarily focus on evaluating the effects of stress (due to work-related factors such as force, posture and repetition) on internal shoulder strain measured using pain/discomfort, muscle activation and joint loading. A few such studies are reviewed in the next chapter. The results of these studies indicate that the 
shoulder strain is affected by a multitude of factors including the magnitude of force exertion, direction of force exertion, posture used, nature of exertion (static vs. dynamic) etc. All these studies are valuable and add to the body of knowledge on shoulder MSD prevention. However, there is a lack of research on workplace assessment/evaluation tools that can predict the risk of shoulder MSDs.

Developing a workplace assessment/evaluation tool for shoulder joints is challenging for several reasons. The shoulder is the most complex, yet most mobile, part of the human body, the joint is susceptible to injury due to repetitive submaximal exertion as well as heavy forceful arm exertion and there is a lack of research on how this joint is stabilized during physical workplace exertions. One study, focused on concavity compression, a shoulder stabilizing mechanism, to develop a strain index (Cutlip, 2014). A biomechanical model of the shoulder complex was used to develop the strain index. Biomechanical models provide good approximations; however, they exhibit several limitations due to their lack of physiological realism. Cutlip (2014) showed a reasonably strong relationship between the strain index and the ratings of perceived exertion. The purpose of this study was to further evaluate the role of concavity compression in shoulder stabilization using physiological data. Specifically, the activation pattern of the shoulder muscles was studied by using surface electromyography. 


\section{Chapter 2: Background and Literature Review}

The shoulder complex consists of three joints including the glenohumeral joint (GHJ), acromioclavicular joint (ACJ) and sternoclavicular joint (SCJ) (Figure 1). While most of these joints provide passive strength to the shoulder complex, the GHJ is responsible for the motion of the shoulder during workplace exertions. The GHJ is a ball-and-socket joint between the humeral head and the scapula's glenoid fossa. The surface of the glenoid fossa is only one third of the humeral head, meaning a small part of the humeral head is in contact with the glenoid fossa in any position of the joint. In order to maintain the stability of the GHJ, the humeral head must be held against the glenoid fossa. The shoulder muscles compress the humeral head while providing forces to compensate the moment due to the application of external force. This mechanism, which compresses the humeral head against the glenoid fossa, is called the concavity compression mechanism (Figure 2). The muscles have to resist the translational forces which push the humeral head away from the glenoid fossa to facilitate concavity compression.
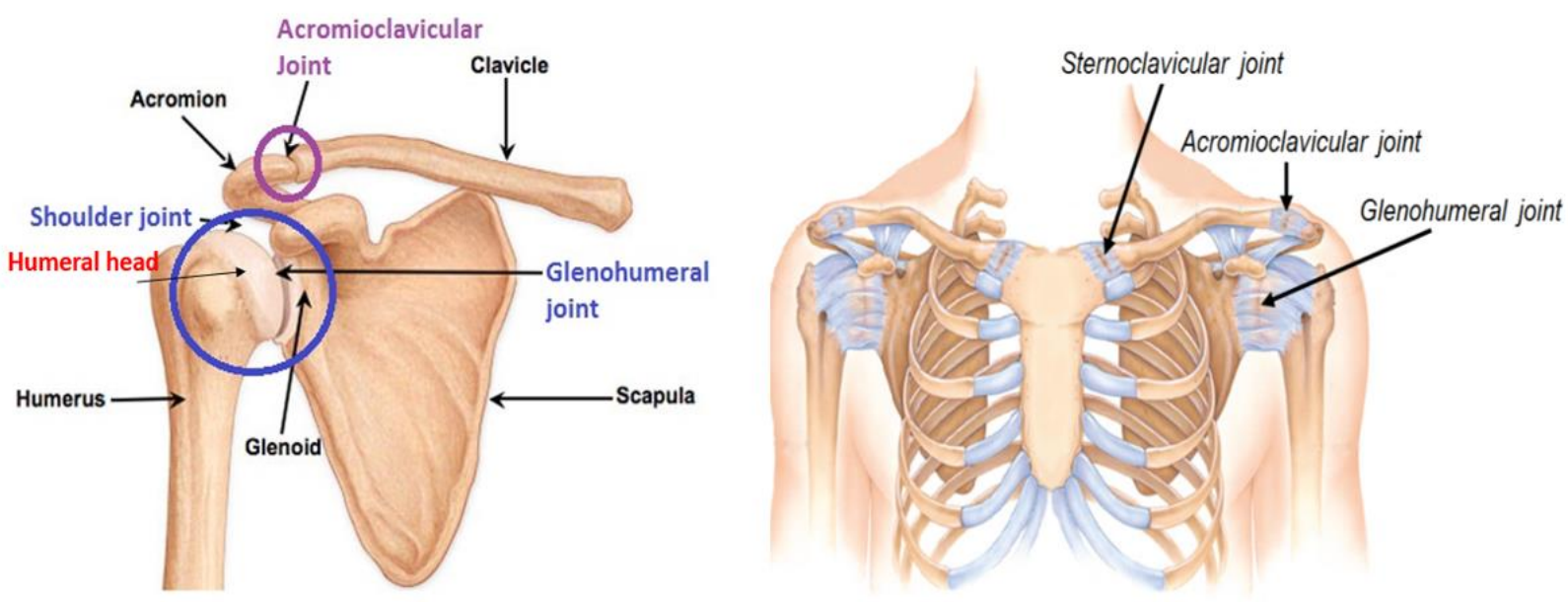

Figure 1: Human shoulder complex (Cutlip, 2004). 


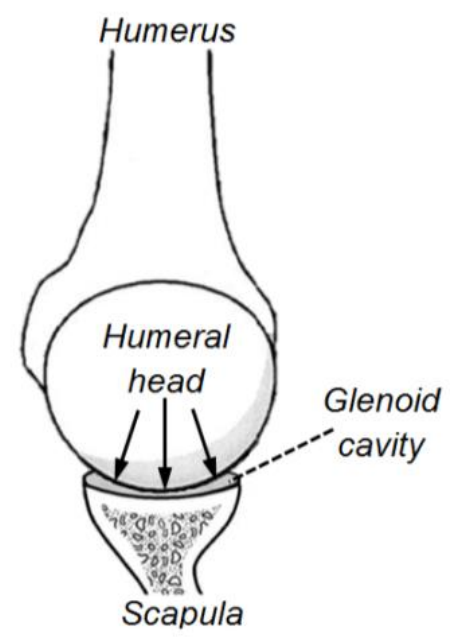

Figure 2: Concavity compression mechanism (Cutlip, 2014).

There are several muscles that are activated during exertions performed by the shoulder complex. The deltoid muscles (anterior, middle and posterior) are considered primary shoulder movers during elevation and abduction. The rotator cuff muscles include supraspinatus, infraspinatus, teres minor, teres major and subscapularis play a multifunctional role in achieving shoulder mobility and stability. They are referred as the dynamic ligaments of the GHJ (Müntener, 1982). The infraspinatus and subscapularis play major roles in scapular plane abduction, generating forces equal to three times the supraspinatus force (Escamilla et al., 2009). The biceps brachii and triceps brachii are the arm muscles that enter into the shoulder complex and facilitate upper and lower arm motions during shoulder exertions. The trapezius is a shoulder elevator muscle that also participates in the rotation of the scapula to extend the reach upwards.

Among these muscles, the rotator cuff muscles are considered the primary GHJ stabilizing muscles. These muscles not only facilitate the dynamic motion of the GHJ, but also add to the passive stability of the shoulder due to their location and orientation around the GHJ. The rotator cuff muscles are located closer to the center of GHJ rotation and act in association with the 
underlying capsular ligament structures to resist GHJ shear stresses. Individual rotator cuff muscles have independent actions that, in combination, contribute to the overall stability of the GHJ during the mid- and end-ranges of motion (Lugo et al., 2008). Wuelker et al., (1998) found that when forces from rotator cuff muscles decreased by $50 \%$, it will result in a roughly $50 \%$ increase in displacement of the humeral head anterior in response to external loading at all GHJ positions. Itoi et al. (1993) found that biceps brachii muscle activity could also assist in GHJ stability. Lee (2003) measured deltoid muscle activity interaction with GHJ stability. He found that in the scapular plane, and with $60^{\circ}$ of glenohumeral elevation, GHJ stability increased because of deltoid activity. In the coronal plane, with $60^{\circ}$ glenohumeral elevation, the GHJ stability decreased because of deltoid activity.

A few studies have looked at the activity of shoulder muscles by simulating static workplace exertions. Sporrong et al $(1995,1996)$ performed studies to evaluate the activity of shoulder muscles during hand gripping tasks. The muscles studied were the supraspinatus, infraspinatus, the middle portion of the deltoid and the descending part of the trapezius. Human participants performed hand gripping tasks at $30 \%$ and $50 \%$ of maximal voluntary contraction levels using a hand dynamometer in eight postures characterized by shoulder flexions of $30^{\circ}, 60^{\circ}$, $90^{\circ}$ and $120^{\circ}$ in the sagittal plane and abduction of $30^{\circ}, 60^{\circ}, 90^{\circ}$ and $120^{\circ}$ in the scapular plane. The EMG activity of the muscles was compared with and without hand gripping. It was observed that the hand gripping significantly increased the activity of the supraspinatus muscle in humeral flexion from and above $60^{\circ}$ degrees. A similar but smaller increase was observed for the infraspinatus muscle. For the deltoid muscles, an increase in activity was observed for positions lower than $90^{\circ}$; in higher arm positions, a decrease in activity was observed. The gripping task had no effect on the activity of the trapezius muscle. 
In a similar study, Antony and Keir (2010) evaluated the effect of load and gripping forces on the activity of shoulder muscles. Fifteen postures, characterized by abduction angles of $0^{\circ}, 30^{\circ}$, $60^{\circ}, 90^{\circ}$ and $120^{\circ}$ in the sagittal, frontal and mid-sagittal frontal planes, were studied. It was observed that the load in the hand increased activity of most of the shoulder muscles. During gripping exertion, an increase in activity was observed for the infraspinatus, trapezius, and biceps brachii muscles. A decrease in activity was observed among anterior and middle deltoid muscles. A similar conclusion regarding an increase in activity of the supraspinatus and infraspinatus muscles during a gripping task was also reported by Alizadehkhaiyat et al. (2011). In their study, muscle activity was measured in a standardized sitting and arm position using fine-wire electrodes during a controlled gripping task at 50\% of maximum voluntary contraction (MVC).

Brookham et al. (2010) studied the effect of different postures during light tool usage and forward pushing exertion on the activity of shoulder muscles. Fifteen postures characterized by shoulder flexion angles of $0^{\circ}, 60^{\circ}, 70^{\circ}, 80^{\circ}$ and $90^{\circ}$ in three shoulder rotations (humoral rotations), $-45^{\circ}, 0^{\circ}$ and $45^{\circ}$, were evaluated. The muscles studied were the right superior, middle and inferior trapezius, all deltoid portions, pectoralis major, infraspinatus and latissimus dorsi. To simulate hand tool use, a gripping task at $30 \% \mathrm{MVC}$ was performed and a force of $13 \pm 2 \mathrm{~N}$ was used for the forward pushing exertion. All tasks were performed in a seated position with shoulder abduction and elbow flexion maintained at $90^{\circ}$. In general, an increase in the shoulder flexion angle was associated with an increase in muscle activation. The postures with internal and external rotation influenced the activity of the inferior trapezius muscle more than other muscles.

Several other studies on shoulder muscle activation looked at fatigue development due to workplace alike exertions. Takala et al (1993) investigated the relationship between holding time and EMG changes. The study participants held a suspended weight using $90^{\circ}$ arm abduction in 
the sagittal plane until exhaustion. Male participants held a different weight than female participants (4 $\mathrm{kg}$ for men and $2.5 \mathrm{~kg}$ for women). Larger EMG changes were observed in male participants than in female participants. The infraspinatus and anterior deltoid muscles showed faster EMG changes and signs of fatigue than the upper trapezius. Minning et al. (2007) also reported similar findings regarding faster fatigue development of the deltoid muscle compared to other shoulder muscles. The upper trapezius, middle deltoid, serratus anterior and lower trapezius muscles were investigated in their study. The participants performed static lifting tasks at $90^{\circ}$ arm elevation using 60\% MVC load until exhaustion. Kai et al. (2012) compared the fatigability of the infraspinatus and deltoid muscles during resisted arm elevation (30\% MVC) performed at various postures in the sagittal and scapular planes. Faster fatigue development was observed for the infraspinatus in the sagittal plane than in the scapular plane.

Arwert et al., (1997) studied the relation between electromyography of shoulder muscles and force direction while performing static exertions. Fourteen muscles including supraspinatus, infraspinatus, teres major, all deltoid and latissimus dorsi were studied. Three postures were used: $90^{\circ}$ scapular shoulder abduction with $90^{\circ}$ elbow flexion and forearm in horizontal position; $90^{\circ}$ anteflexion of the humerus shoulder abduction with $90^{\circ}$ elbow flexion and forearm in horizontal position; $90^{\circ}$ anteflexion of the humerus shoulder abduction with $90^{\circ}$ elbow flexion and forearm in vertical position. $14 \mathrm{~N}$ was the exerted force for 3 seconds in all eight force directions $\left(0^{\circ}, 45^{\circ}\right.$ $\left., 90^{\circ}, 135^{\circ}, 180^{\circ}, 225^{\circ}, 270^{\circ}, 315^{\circ}\right)$. A relationship found between teres major and latissimus dorsi muscles since they have been activated simultaneously. Teres major and latissimus were active in downward and forward forces. Rotator cuff muscles and all deltoid muscles role in stabilizing the gienohumeral joint was obvious from the continues activation during exertion. 
In summary, existing studies indicate that factors such as force exertion level, posture and hand gripping influence the activation and fatigue of shoulder muscles. Different muscles exhibit different activation and fatigue patterns depending on the conditions of posture, force and hand gripping used. However, no previous study clearly explained the inter-muscle difference in the activation or fatigability pattern when subjected to different demands (work/exertion). It was suspected that shoulder muscles' attempt to stabilize the GHJ using concavity compression may explain the differences in muscle activation pattern during arm exertions. This forms the basis for conducting this study. In this study, the SEMG data recorded from shoulder muscles was examined to understand their role in stabilizing the shoulder using concavity compression. 


\section{Chapter 3: Study Rationale}

\subsection{Problem Statement}

The socioeconomic impact of shoulder MSDs is huge in terms of lost work days, lost productivity and healthcare costs. Shoulder MSDs are prevalent among workers in several occupations including, but not limited to, nursing, material handling, janitorial work, transportation and manufacturing. Despite the high socioeconomic impact and widespread occurrence of shoulder MSDs, currently no workplace assessment/evaluation tool exists that can predict the risk of developing these MSDs. Such a tool could prove beneficial to preventing workrelated shoulder MSDs. However, development of a workplace assessment/evaluation tool is a long, multi-step process.

The long-term goal of the research proposed in this study is to aid in the development of a workplace assessment/evaluation tool. Results of a previous study (Cutlip, 2014) showed some promise in utilizing concavity compression, a shoulder stabilizing mechanism, as a governing mechanism in developing such a tool; however, the problem with the previous study (or problem statement for this study) is that the findings heavily relied on the outputs of a biomechanical model and lacked comparison with true physiological data. Therefore, the purpose of this study is to further evaluate concavity compression as a suitable governing mechanism in developing a workplace assessment/evaluation tool by utilizing true physiological (muscle activation) data. 


\subsection{Objective and Hypotheses}

The main objective of this research is to study the shoulder muscle activation pattern during static arm exertions. The arm exertions were performed in five directions: pulling right (PR), pulling left (PL), pulling back (PB), pulling down (PD) and pulling up (PU). Three force exertion levels were used: $5 \mathrm{lbs}$, $7.5 \mathrm{lbs}$. and $10 \mathrm{lbs}$. The muscle activation pattern was used to quantify joint loading and fatigue development.

The following hypotheses were tested in this study:

Null hypotheses:

$\mathrm{H}_{01}$ : The direction of force exertion has no effect on the muscle activation pattern and fatigability.

$\mathrm{H}_{02}$ : The magnitude of force exertion has no effect on the muscle activation pattern and fatigability.

$\mathrm{H}_{03}$ : The direction and magnitude of force exertion have no interaction effect on the muscle activation pattern and fatigability.

Alternate hypotheses:

The results from a previous study (Cutlip, 2014) were summarized in Figure 3. The vectors in this figure represent locations of the resultant force vectors at the GHJ in the frontal and transverse planes. It can be observed from the figure that the orientation and magnitude of these vectors is affected by the direction of force exertion. Thus, based on these findings, the following alternate hypotheses will be tested:

$\mathrm{H}_{\mathrm{A} 1}$ : The direction of force exertion has an effect on the muscle activation pattern. Specifically, pulling exertions performed in the right direction will result in the highest muscle loading and faster fatigue development, followed by the exertions performed in the up and left directions. 


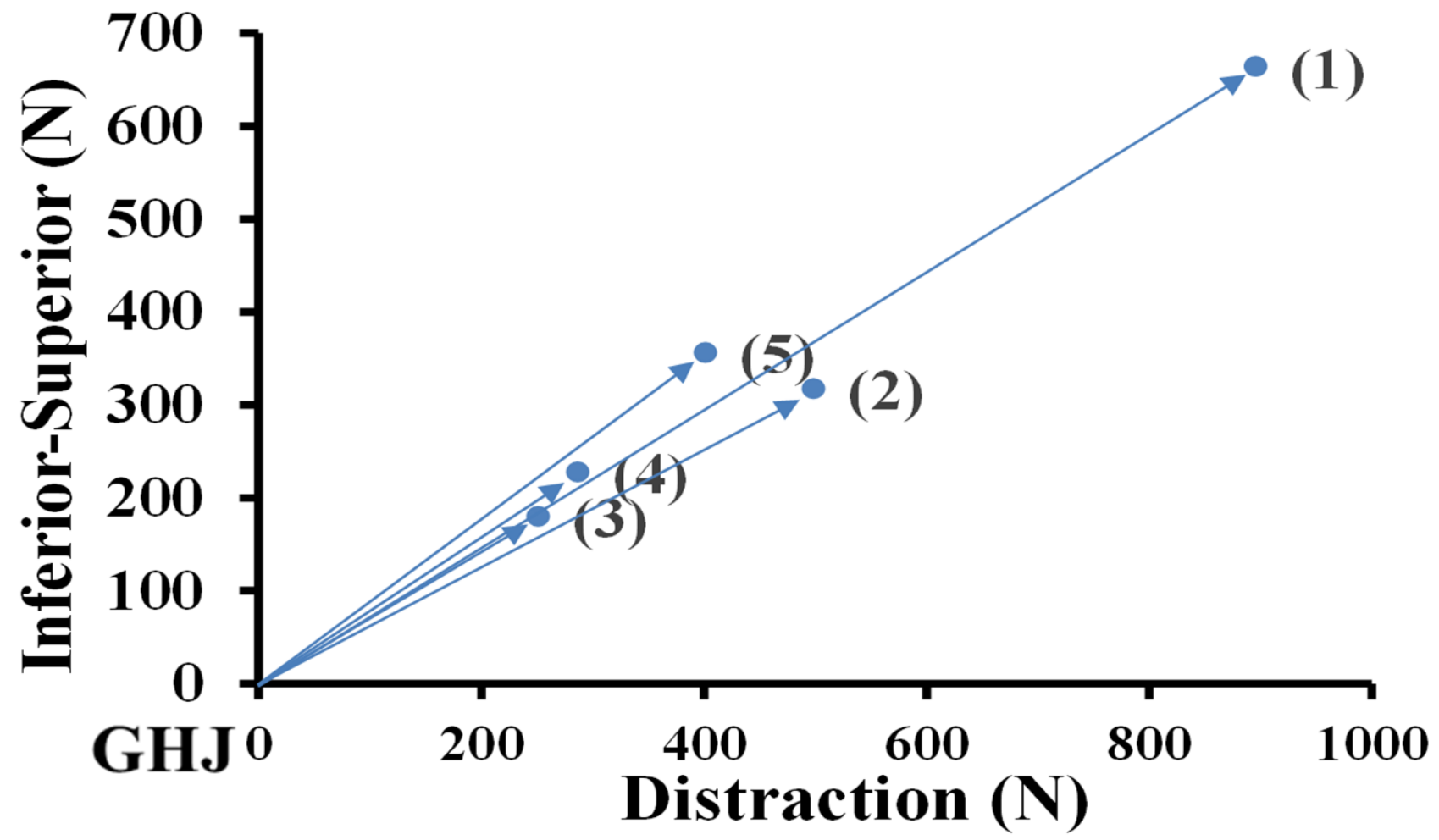

1) pulling right, 2) pulling left, 3) pulling back, 4) pulling down and 5) pulling up.

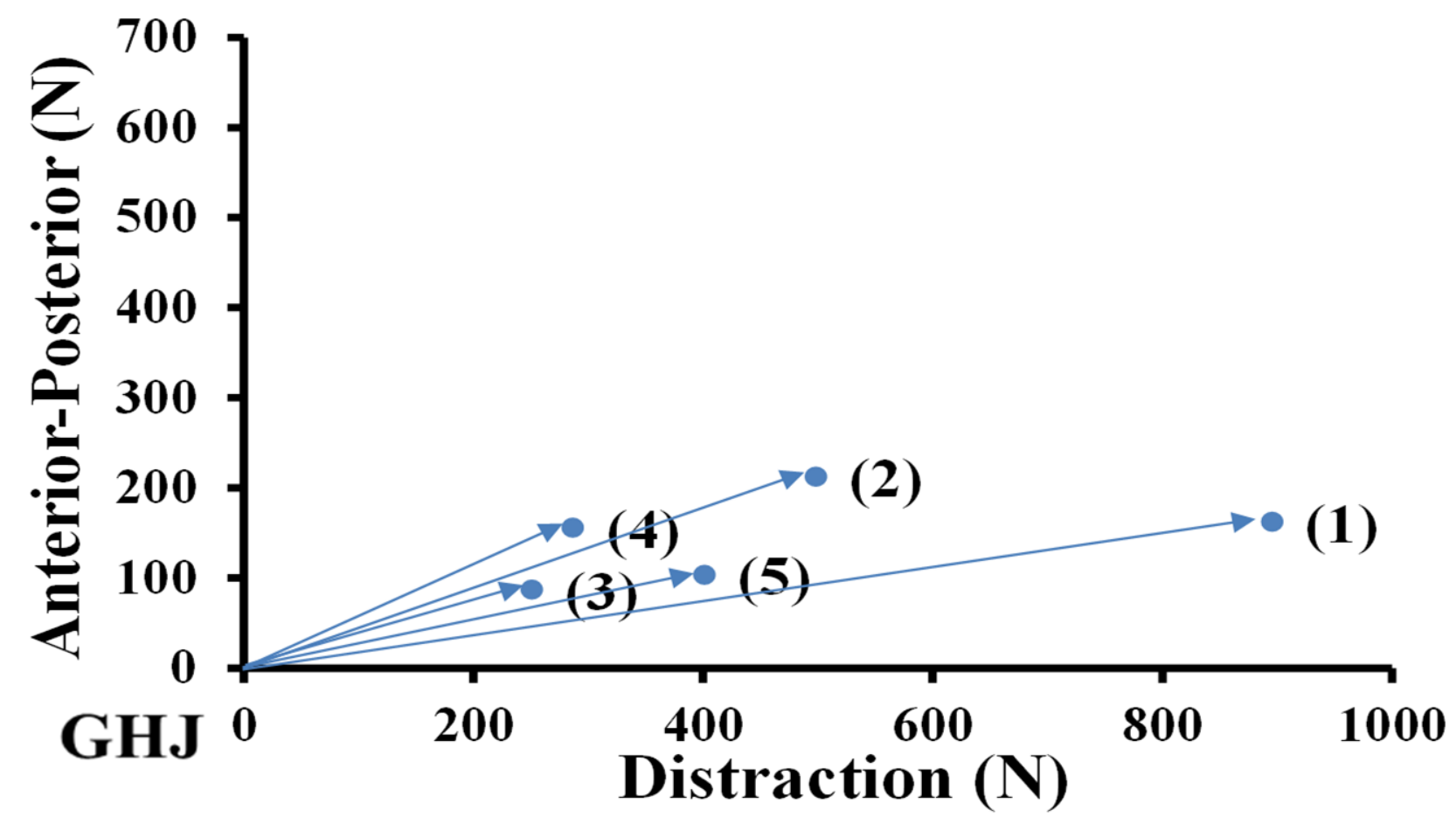

1) pulling right, 2) pulling left, 3) pulling back, 4) pulling down and 5) pulling up. 
The lowest muscle loading and slow fatigue development were observed for pulling exertions performed in the back and down directions.

$\mathrm{H}_{\mathrm{A} 2}$ : The magnitude of force exertion has an effect on the muscle activation pattern and fatigability.

$\mathrm{H}_{\mathrm{A} 3}$ : The direction and magnitude of force exertion have interaction effect on the muscle activation pattern and fatigability. 


\section{Chapter 4: Methodology}

\subsection{Approach}

A laboratory-based study was performed to quantify the effect of static arm exertions on the shoulder muscle activation pattern. Human subjects performed static arm exertions in five directions using three different weights. SEMG data was recorded from nine shoulder muscles. The SEMG data were used to quantify shoulder muscle loading and fatigue. The relationship between muscle loading and fatigue and the concavity compression vector were evaluated by testing the SEMG data.

\subsection{Participants}

Ten healthy, right-hand dominant male participants between the ages of 18 and 40 were recruited for the study. The primary inclusion criteria for this study required that the participants were free from any type of musculoskeletal, degenerative or neurological disorder and that they had neither a history of shoulder pain nor any current pain. The Physical Activity Readiness Questionnaire (PAR-Q, Canadian Society for Exercise Physiology) (Appendix A) was used to screen participants for cardiac and other health problems (e.g., dizziness, chest pain and heart trouble). Participants who met the inclusion criteria were asked to read and sign a consent form approved by the local Institutional Review Board (Appendix B). 


\subsection{Equipment}

\subsubsection{Custom-Made Force Exertion Device}

This device consists of a wooden chair equipped with a four-point harness to secure participants in a standard sitting posture. The chair was attached to a column and base assembly, and the column was fitted with a height-adjustable base. A peripheral assembly consisting of a set of perforated steel tubes was attached to this base, and several pulleys were mounted on the perforated steel tubes. Rope was used to hang weights of different magnitudes from the pulleys, and human participants pulled the other end of the rope using a D-handle. A set of perforated steel tubes and pulleys allow the experimenter to control the direction of pulling. Different weights can be attached to the rope to control the magnitude of force exertion. Figure 4 and Figure 5 can illustrate the experiment setup.

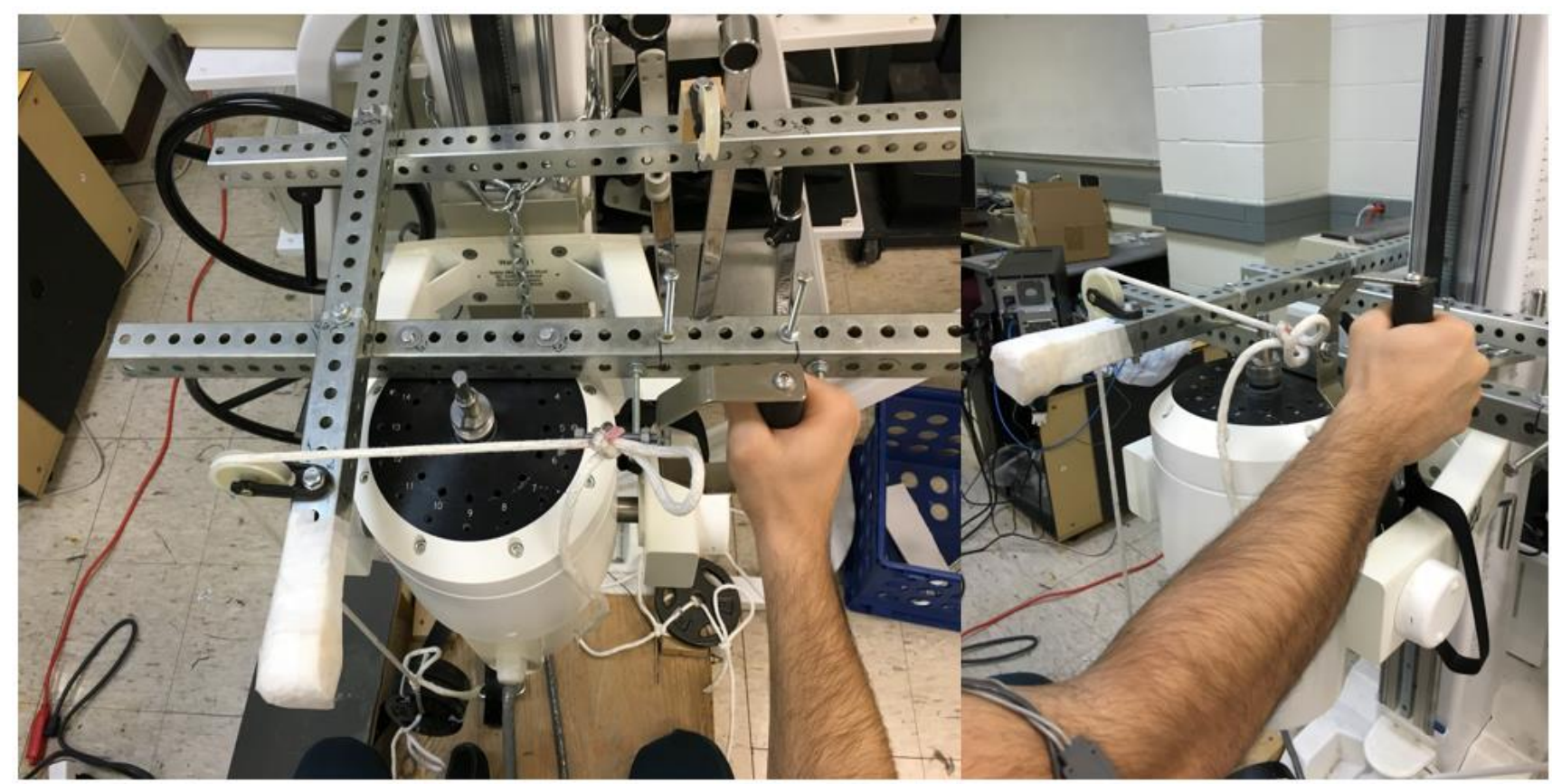

Figure 4: Experiment device while performing pulling right $(P R)$ task. 


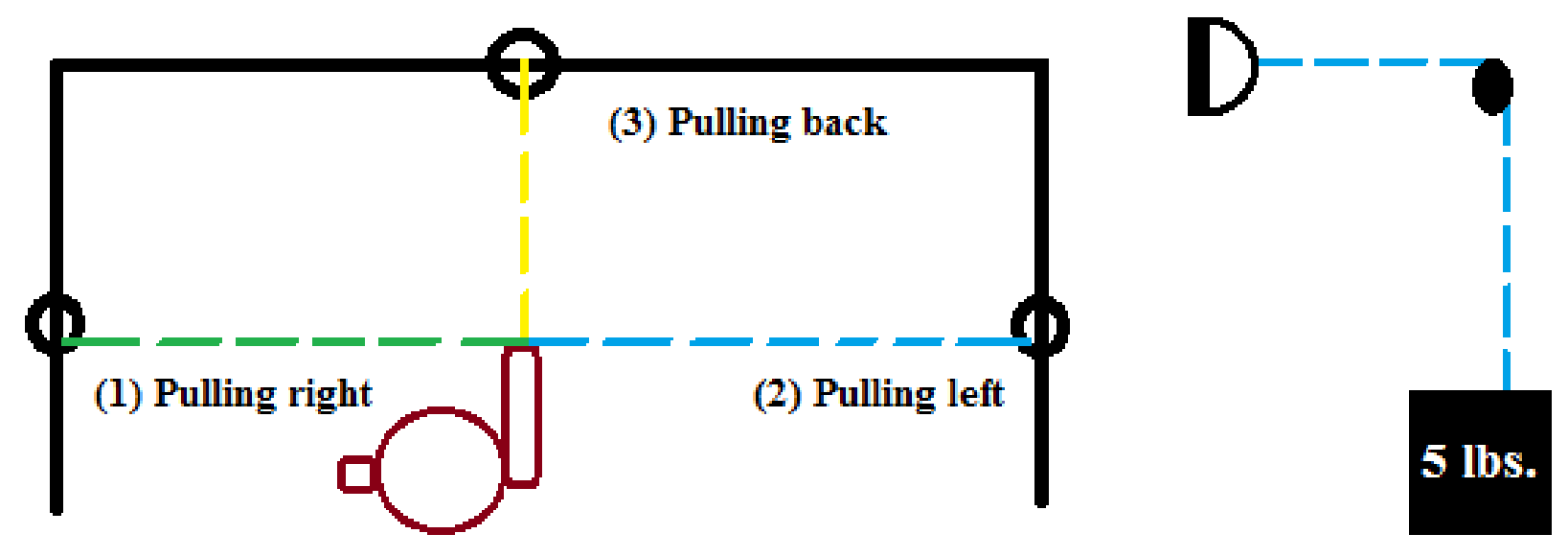

Figure 5: Upper view for experiment device shows (PR, PL and PB) tasks.

\subsubsection{Surface Electromyography (SEMG) system}

EMG signals were used to study muscle activation pattern by analyzing the electrical signal generated during muscular contractions (Acierno et al., 1995). EMG data can be recorded using surface or intramuscular EMG electrodes. The surface electrodes are employed when collecting data from superficial muscles. In the current study, surface electrodes were used to record EMG data from shoulder muscles.
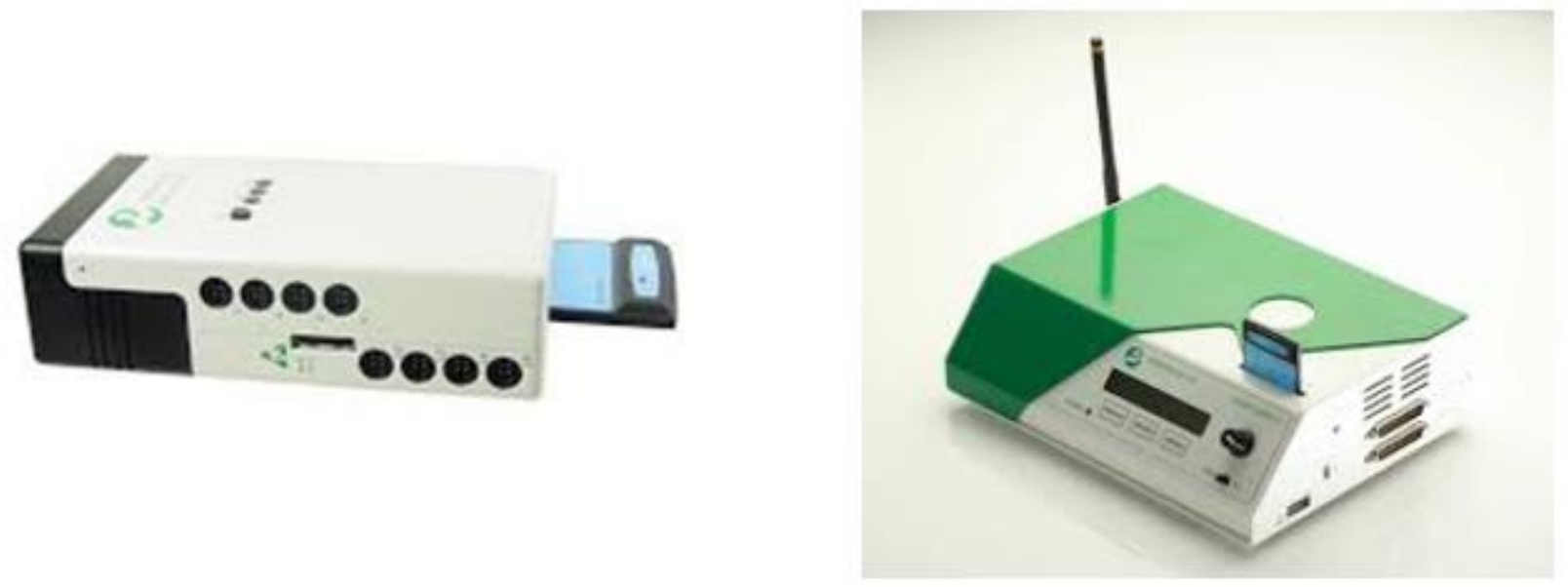

Figure 6: Telemyo 2400 T G2 EMG system receiver and transmitter. 
A Telemyo 2400 T G2 EMG system (Noraxon Inc., AZ, USA) was used for data collection. The system consists of a Telemyo 2400R G2 receiver (Figure 6), Telemyo 2400T G2 transmitter with 16 channels (Figure 6), pre-amplified lead wires (Figure 7) and disposable, self-adhesive $\mathrm{Ag} / \mathrm{AgCl}$ snap/clips electrodes (Figure 7). The bipolar Ag/AgCl pre-gelled surface electrodes were of $1 \mathrm{~cm}$ diameter, with an inter-electrode distance of $2 \mathrm{~cm}$. The pre amplifier on the lead wires has a band-pass of 10-1000 Hz (gain of 500), CMRR >100 dB and input impedance >100 M 2 . The electrodes were attached to the pre-amplified lead wires and then connected to the Telemyo 2400T G2 transmitter. The Telemyo 2400T G2 transmitter was mounted on the participants using a pouch and belt clip. The G2 transmitter transmitted the EMG data wirelessly to the Telemyo 2400R G2 receiver. The system can sample EMG data at a frequency of up to $1500 \mathrm{~Hz}$.
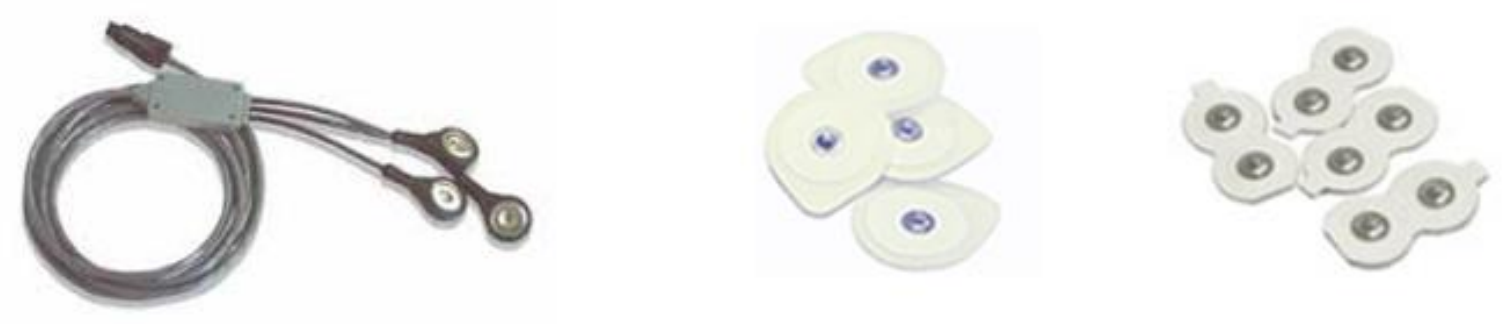

Figure 7: Pre-amplified lead wires and Ag/AgCl snap/clips electrodes.

\subsection{Experimental Design}

A two-factor replicated block design was used in this research. Factor 1, direction of force exertion, was treated at five levels: PR, PL, PB, PD and PU. Factor 2, force exertion level, was treated at three levels: 5 lbs., $7.5 \mathrm{lbs}$. and $10 \mathrm{lbs}$. 
The force exertion levels were obtained based on the findings of preliminary testing. During this testing we found that forces greater than $10 \mathrm{lbs}$. were very difficult to pull in certain directions. We also found that forces not greater than $2 \mathrm{lbs}$. were not perceived differently by the human participants. Therefore, a force difference of $2.5 \mathrm{lbs}$. was maintained between the force exertion levels. The duration of each exertion was controlled at 60 seconds. This trial length was determined based on the findings of the preliminary study. Over 60 seconds, the participants had trouble pulling in certain directions.

Two repetitions were collected for each experimental condition. Thus, each participant performed 30 experimental trials ( 5 directions $\times 3$ weights $\times 2$ repetitions). The trial order was randomized. Rest periods of up to two minutes were provided between experimental trials.

\subsection{Muscle Selection}

Based on previous SEMG studies on the shoulder complex and the role of individual muscles in shoulder stabilization, the following nine shoulder muscles were tested in this study: the supraspinatus, infraspinatus, teres major, anterior deltoid, middle deltoid, posterior deltoid, biceps, triceps and latissimus dorsi were studied. It is very important to select the appropriate muscles which have the highest activation in shoulder task. According to few studies that include shoulder static exertions and shoulder stability, the supraspinatus and infraspinatus were the major rotator cuff muscles. The deltoid, biceps and triceps muscles played important roles in stabilizing the shoulder joint during static arm exertions. (Hawkes et al., 2015; Itoi et al., 1993). 


\subsection{Experimental Data Collection Procedure}

After participants arrived to the laboratory, they were provided with a tour of the experimental setup. Equipment, data collection procedures and specifics of the experimental tasks were explained to the participants, and their signatures were obtained on a consent form approved by the local Institutional Review Board (Appendix B). A set of anthropometric measures such as height, weight and age were recorded for each participant. After that, EMG data collection preparation began. Participants prepared for EMG data collection by shaving the skin in the areas where SEMG electrodes were placed and then rubbing and cleaning the skin with $70 \%$ alcohol prior to the placement of the electrodes. Table 1 shows the electrode location for the shoulder muscles. Next, the MVCs were recorded for each muscle. Table 2 describes the exertion used to record the MVC for each muscle.

Participants then began the experimental trials. They were seated and secured into the wooden chair of the force exertion device using the four-point harness. A few practice trials were then performed to get the participants acquainted with the setup. During the actual trials, the position of the pulley, rope and D-handle were adjusted such that the participant could grasp it using a $15-20^{\circ}$ flexed elbow joint and a $70-80^{\circ}$ flexed shoulder joint. In each trial, participant was required to hold a D-shape handle attached to one of the weight levels which are $(10,7.5,5$ lb.) for 60 second with a $15^{\circ}-20^{\circ}$ flexed elbow joint and a $70^{\circ}-80^{\circ}$ flexed shoulder joint. participant performed this task in five different directions which are right, left, front, up and down. Each trial had two repetitions. A 2 minutes' rest time was provided between trials. A total of 30 trials were performed. The SEMG data was recorded continuously during the exertion. In addition, after the completion of each exertion, the participants were asked to numerically rate their perceived exertion using Borg's CR-10 scale (Appendix C). The Borg CR-10 scale contains 
two columns: one for subjective categories ranging from "nothing at all" to "extremely strong" and the other for numerical ratios ranging from 1 to 10 that are associated with the different categories.

Table 1: EMG locations of shoulder muscles.

\begin{tabular}{|c|c|c|}
\hline & Muscle & Electrodes position \\
\hline 1 & Supraspinatus & Midpoint and two fingers-breadths anterior to the scapular spine. \\
\hline 2 & Infraspinatus & $\begin{array}{l}\text { Midpoint and two fingers-breadths below and parallel to the } \\
\text { scapular spine. }\end{array}$ \\
\hline 3 & Teres Major & Middle of the muscle belly. \\
\hline 4 & Anterior deltoid & $\begin{array}{l}\text { Two to three fingers- breadths below the acromion process, over } \\
\text { the muscle belly, in line with the fibers. }\end{array}$ \\
\hline 5 & Middle deltoid & $\begin{array}{l}\text { Midline of the lateral surface of the arm, one fourth of the distance } \\
\text { between the acromion and the elbow. }\end{array}$ \\
\hline 6 & Posterior deltoid & $\begin{array}{l}\text { Two fingers-widths behind the angle of the acromion, over the } \\
\text { muscle belly, in line with the fibers. }\end{array}$ \\
\hline 7 & Biceps & Midpoint between the acromioclavicular and elbow joint. \\
\hline 8 & Triceps & Midpoint between acromion of the scapula and the ulna olecranon. \\
\hline 9 & Latissimus dorsi & $\begin{array}{l}\text { Approximately } 4 \mathrm{~cm} \text { below the inferior tip of the scapula, half the } \\
\text { distance between the spine and lateral edge of the torso. }\end{array}$ \\
\hline
\end{tabular}


Table 2: MVC posture and action for each muscle.

\begin{tabular}{|c|c|c|c|}
\hline & Muscle & MVC posture & MVC action \\
\hline 1 & Supraspinatus & $\begin{array}{c}\text { Arm will be abducted at } 20 \text { degrees } \\
\text { in frontal plane; elbow will be flexed } \\
\text { at } 90 \text { degrees; and no shoulder } \\
\text { flexion. }\end{array}$ & $\begin{array}{c}\text { Arm will be resisting the abduction, } \\
\text { while subject will sit on a chair and } \\
\text { will push against a wall. }\end{array}$ \\
\hline 2 & Infraspinatus & $\begin{array}{l}\text { Arm will be abducted at } 50 \text { degrees } \\
\text { in frontal plane; elbow will be flexed } \\
\text { at } 90 \text { degrees; and hand will be in } 90 \\
\text { degrees pronation. }\end{array}$ & $\begin{array}{l}\text { Arm will be resisting the External } \\
\text { rotation of the shoulder. }\end{array}$ \\
\hline 3 & Teres major & $\begin{array}{c}\text { Arm will be abducted at } 50 \text { degrees } \\
\text { in frontal plane; elbow will be flexed } \\
\text { at } 90 \text { degrees; and hand will be in } 90 \\
\text { degrees pronation. }\end{array}$ & $\begin{array}{l}\text { Arm will be resisting the Internal } \\
\text { rotation of the shoulder. }\end{array}$ \\
\hline 4 & $\begin{array}{l}\text { Anterior } \\
\text { deltoid }\end{array}$ & $\begin{array}{c}\text { Arm will be abducted at } 20 \text { degrees } \\
\text { in frontal plane; elbow will be flexed } \\
\text { at } 90 \text { degrees; and no shoulder } \\
\text { flexion. }\end{array}$ & $\begin{array}{l}\text { Arm will be resisting the horizontal } \\
\text { flexion. }\end{array}$ \\
\hline 5 & $\begin{array}{l}\text { Medial } \\
\text { deltoid }\end{array}$ & $\begin{array}{c}\text { Arm will be abducted at } 90 \text { degrees } \\
\text { in frontal plane; elbow will be flexed } \\
\text { at } 90 \text { degrees; and no shoulder } \\
\text { flexion. }\end{array}$ & Arm will be resisting the abduction. \\
\hline 6 & $\begin{array}{l}\text { Posterior } \\
\text { deltoid }\end{array}$ & $\begin{array}{c}\text { Arm will be abducted at } 20 \text { degrees } \\
\text { in frontal plane; elbow will be flexed } \\
\text { at } 90 \text { degrees; and no shoulder } \\
\text { flexion. }\end{array}$ & $\begin{array}{l}\text { Arm will be resisting the horizontal } \\
\text { extension. }\end{array}$ \\
\hline 7 & Biceps & $\begin{array}{l}\text { No shoulder abduction; elbow will be } \\
\text { flexed at } 90 \text { degrees; and hands will } \\
\text { be supinated at } 90 \text { degrees. }\end{array}$ & $\begin{array}{l}\text { Arm will be resisting the vertical } \\
\text { flexion. }\end{array}$ \\
\hline 8 & Triceps & $\begin{array}{l}\text { No shoulder abduction; elbow will be } \\
\text { flexed at } 90 \text { degrees; and hands will } \\
\text { be supinated at } 90 \text { degrees. }\end{array}$ & $\begin{array}{l}\text { Arm will be resisting the vertical } \\
\text { extension. }\end{array}$ \\
\hline 9 & $\begin{array}{l}\text { Latissimus } \\
\text { dorsi }\end{array}$ & $\begin{array}{l}\text { Arm straight, abduct } 30 \text { degrees in } \\
\text { the coronal plane, and internally } \\
\text { rotated } 45 \text { degrees. }\end{array}$ & Extension and internal rotation. \\
\hline
\end{tabular}




\subsection{Data Analysis}

The EMG data were processed to estimate the following dependent variables (muscle load, muscle fatigue and subjective discomfort rating):

\subsubsection{Muscle load}

The raw SEMG data were filtered using $10 \mathrm{~Hz}$ to $400 \mathrm{~Hz}$ band pass filter and a $60 \mathrm{~Hz}$ notch filter to eliminate noise. The signal was demeaned and full wave rectified. The resulting signal were averaged to determine mean absolute values (MAV). The MAV data were normalized using EMG recorded during MVC exertion to determine normalized MAV (NMAV). The total muscle load during an exertion were estimated using the following equation:

$$
N M A V_{\text {total }}=\sum_{i=1}^{9} N M A V_{i}
$$

Where, $N M A V_{i}$ is the normalized activation of the $\mathrm{i}^{\text {th }}$ muscle. A total of 9 muscles are evaluated in this study. In addition to the total NMAV which is the summation of all muscles, each individual muscle load was considered as a dependent variable too.

\subsubsection{Muscle fatigue}

The time domain EMG data were transformed to frequency domain using fast Fourier

transformation. Spectral analysis was performed using a window size of 5 seconds to estimate median frequency with a total of 12 windows. The median frequency data for each exertion was assumed to follow a linear regression data and fitted with linear regression line to estimate the 
slope of the line $\left(M_{i}\right)$ (Dedering et al., 1999; Strimpakos et al., 2005; Hummel et al., 2005; Oliveira et al., 2009; Alizadehkhaiyat et al., 2011). Total muscle fatigue was estimated using the following equation:

$$
M_{\text {total }}=\sum_{i=1}^{9} M_{i}
$$

In addition to the total $\mathrm{M}$ which is the summation of all muscles, each individual muscle M was considered as a dependent variable too.

For the dependent variable related to the subjective discomfort rating, data obtained from the individual participant after each trial was used.

\subsection{Statistical Analysis}

This research evaluates the total muscle load and fatigue of shoulder muscles during static arm exertions performed in five different directions under three weight conditions. The following statistical model was used to study the effect of independent variables (direction) and load (weight) on the dependent variables:

$$
y_{i j k l}=\mu+\alpha_{i}+\beta_{j}+\gamma_{k}+(\alpha \beta)_{i j}+\varepsilon_{i j k}\left\{\begin{array}{l}
i=1, \ldots, a \\
j=1, \ldots, b \\
k=1, \ldots, n \\
l=1,2
\end{array},\right.
$$


Where:

$y$ represents the dependent variables related to muscle load, fatigue and discomfort ratings.

$\mu$ is the overall mean common to all treatments.

$\alpha_{i}$ is the effect of exertion direction (PR, PL, PB, PD and PU), so $i=1,2,3,4,5$.

$\beta_{j}$ is the effect of load (weight) level at 5 lbs., 7.5 lbs., and 10 lbs., so $j=1,2,3$.

$\gamma_{k}$ is the effect of participants (block), and represents the number of participants recruited in the study. Ten participants were recruited in this study, so $k=1,2,3 \ldots 10$.

$(\alpha \beta)_{i j}$ is the interaction effect of exertion direction and load level.

$\varepsilon_{i j k}$ is a random error term.

In this model, the exertion direction $\left(\alpha_{i}\right)$ and weight level $\left(\beta_{j}\right)$ are treated as fixed factors. It was assumed that each factor and the two-way interaction factors have no effect on the muscle load and fatigue. That is:

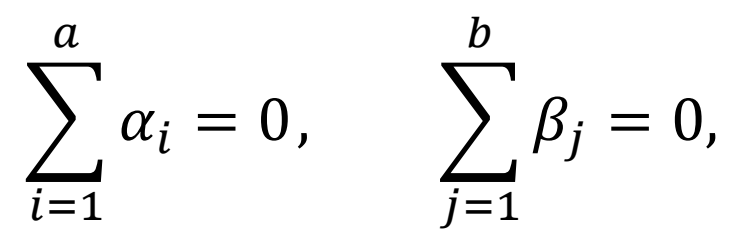

$$
\sum_{i=1}^{a} \sum_{j=1}^{b}(\alpha \beta)_{i j}=0
$$


Participants $\left(\gamma_{k}\right)$ were treated as a random factor that was assumed to be a normally and independently distributed (NID) $\left(0, \sigma_{y}^{2}\right)$ random variable. The random error $\left(\varepsilon_{i j k}\right)$ was also assumed to also follow $\mathrm{NID}\left(0, \sigma^{2}\right)$.

The appropriate $\mathrm{F}$ tests were applied in testing if the means of the fixed factor effects were equal to zero:

$$
\begin{gathered}
H_{0}: \alpha_{i}=0, \beta_{j}=0 \text { and }(\alpha \beta)_{i j}=0, \\
H_{1}: \text { at least one } \alpha_{i} \neq 0, \beta_{j} \neq 0 \text { and }(\alpha \beta)_{i j} \neq 0 .
\end{gathered}
$$

In addition, $\mathrm{F}$ tests were performed in testing the hypotheses of the random factor,

$H_{0}: \sigma_{\gamma}^{2}$. The Type I error probability, $\alpha=0.05$, and power of the test (1- $\left.\beta\right)$, which equals 0.90 , were chosen for hypotheses testing and sample size determination. These were previously discussed in section 4.2.

Significant effects were further evaluated by conducting a comparison between means using Tukey's Honestly Significant Difference (HSD) all-pairwise comparison test. For fixed factors, such as direction of force exertion and load, when the null hypothesis was rejected then the factors' effects were estimated using Minitab 17 statistical analysis software (Minitab Inc., PA, USA). 


\subsubsection{Data Normality}

The normality assumption for all dependent variables except for $M_{\text {supraspinatus }}$ data was found to be not true. Therefore, the equality of variance test was performed. The equality of variance test was true for most of the dependent variables except for $\mathrm{NMAV}_{\text {infraspinatus }}, \mathrm{NMAV}_{\text {middle }}$ deltoid, NMAV $\mathrm{V}_{\text {anterior deltoid, }} \mathrm{NMAV}_{\text {posterior deltoid, }} \mathrm{NMAV}_{\text {bicep }}, \mathrm{M}_{\text {teres major }}$ and TM. See appendix (D). The dependent variables that met the equality of variance was analyzed using general linear ANOVA. If the sufficiency of the linear model was not affirmed by using normal probability plots of residuals between the raw data and fitted values, the Johnson transformation was applied (Table

3, Figure 8). $\mathbf{M}_{\text {infraspinatus, }} \mathbf{M}_{\text {middle deltoid, }} \mathbf{M}_{\text {posterior deltoid, }} \mathrm{NMAV}_{\text {supraspinatus, }} \mathrm{NMAV}_{\text {teres major, }}$ $\mathrm{NMAV}_{\text {tricep }}$, and $\mathrm{NMAV}_{\text {latissimus dorsi }}$ data did not meet the data normality distribution.

Table 3: Johnson transformation family.

\begin{tabular}{cc}
\hline Johnson Family & Transformation Function \\
\hline SB & $\gamma+\eta \times \ln \left[\frac{(x-\varepsilon)}{(\lambda+\varepsilon-x)}\right]$ \\
& \\
SU & $\begin{array}{c}\gamma+\eta \times \sinh ^{-1}\left[\frac{(x-\varepsilon)}{\lambda}\right] \\
\text { Where, } \\
\sinh ^{-1}(x)=\ln \left[x+\sqrt{1+x^{2}}\right]\end{array}$ \\
SL & $\gamma+\eta \times \ln (x-\varepsilon)$ \\
\end{tabular}




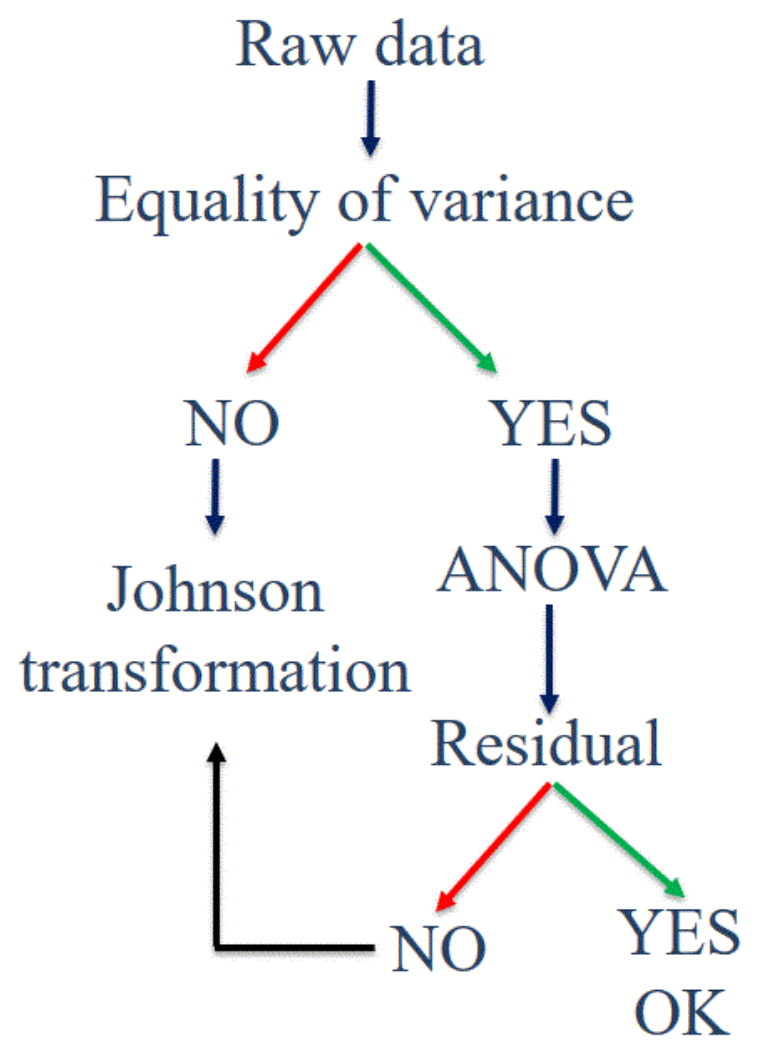

Figure 8: Illustration of the process used to perform statistical analysis.

Finally, the Johnson transformation was applied to the $\mathbf{M}_{\text {infraspinatus }}, \mathbf{M}_{\text {teres major }}, \mathbf{M}_{\text {middle deltoid, }}$ $\mathrm{M}_{\text {posterior deltoid, }} \mathrm{TM}, \mathrm{NMAV}$ supraspinatus, $\mathrm{NMAV}_{\text {teres major, }} \mathrm{NMAV}_{\text {anterior deltoid, }} \mathrm{NMAV}_{\text {posterior deltoid, }}$ $\mathrm{NMAV}_{\text {bicep }}, \mathrm{NMAV}_{\text {tricep }}$ and $\mathrm{NMAV}_{\text {latissimus dorsi }}$ data in order to achieve normality. A bounded (SB) type distribution Johnson transformation achieved normality for $\mathrm{M}_{\text {infraspinatus }}$, $\mathrm{NMAV}_{\text {supraspinatus, }} \mathrm{NMAV}_{\text {teres major }}, \mathrm{NMAV}_{\text {anterior deltoid, }} \mathrm{NMAV}_{\text {posterior deltoid, }} \mathrm{NMAV}_{\text {bicep }}$ and $\mathrm{NMAV}_{\text {latissimus dorsi }}$ data. Also, a bounded (SU) type distribution Johnson transformation achieved normality for $\mathbf{M}_{\text {teres major }}, \mathbf{M}_{\text {middle deltoid }}, \mathrm{M}_{\text {posterior deltoid, }}, \mathrm{TM}$ and $\mathrm{NMAV} \mathrm{V}_{\text {tricep }}$ data. Table 4 shows the optimal transformation function and parameter values for all transformed raw data. 


\begin{tabular}{|c|c|c|c|c|c|c|c|c|}
\hline & $\begin{array}{c}\text { Johnson } \\
\text { transfor } \\
\text { m type }\end{array}$ & $\begin{array}{c}\text { Johnson transformation } \\
\text { function }\end{array}$ & $\gamma$ & $\eta$ & $\varepsilon$ & $\lambda$ & $\begin{array}{l}\text { p-value } \\
\text { before } \\
\text { transfor } \\
\text { mation }\end{array}$ & $\begin{array}{l}\text { p-value after } \\
\text { transformatio } \\
n\end{array}$ \\
\hline$\underset{\text { Infraspinatus }}{M}$ & SB & $\begin{array}{l}-1.5766+1.09558 \\
\times \ln \left[\frac{(x+4.06686)}{(0.366255-x)}\right]\end{array}$ & -1.5766 & 1.09558 & 4.06686 & 0.366255 & $<0.005$ & 0.959094 \\
\hline $\begin{array}{c}\text { M } \\
\text { Teres major }\end{array}$ & SU & $\begin{array}{r}1.40006+1.26292 \\
\times \sinh ^{-1}\left[\frac{(x-0.0521897)}{0.380748}\right]\end{array}$ & 1.40006 & 1.26292 & 0.0521897 & 0.380748 & $<0.005$ & 0.439864 \\
\hline $\begin{array}{l}\text { M } \\
\text { Middle } \\
\text { deltoid }\end{array}$ & SU & $\begin{array}{c}1.22404+1.21468 \\
\times \sinh ^{-1}\left[\frac{(x-0.00676503)}{0.29702}\right]\end{array}$ & 1.22404 & 1.21468 & 0.00676503 & 0.29702 & $<0.005$ & 0.989716 \\
\hline $\begin{array}{c}\text { M } \\
\text { Posterior } \\
\text { deltoid }\end{array}$ & SU & $\begin{array}{c}1.28858+1.31359 \\
\times \sinh ^{-1}\left[\frac{(x-0.00203363)}{0.31806}\right]\end{array}$ & 1.28858 & 1.31359 & 0.00203363 & 0.31806 & $<0.005$ & 0.562281 \\
\hline $\begin{array}{c}\text { Total } \\
\mathbf{M}\end{array}$ & SU & $\begin{array}{c}2.347+1.39986 \\
\times \sinh ^{-1}\left[\frac{(x-0.166531)}{1.30482}\right]\end{array}$ & 2.347 & 1.39986 & 0.166531 & 1.30482 & $<0.005$ & 0.901577 \\
\hline $\begin{array}{c}\text { NMAV } \\
\text { Supraspinat } \\
\text { us }\end{array}$ & SB & $\begin{array}{l}3.15424+0.933155 \\
\times \ln \left[\frac{(x-0.131077))}{(196.205-x)}\right]\end{array}$ & 3.15424 & 0.933155 & 0.131077 & 196.205 & $<0.005$ & 0.622031 \\
\hline $\begin{array}{c}\text { NMAV } \\
\text { Teres major }\end{array}$ & SB & $\begin{array}{l}1.43894+0.847714 \\
\times \ln \left[\frac{(x-0.647975)}{(60.7376-x)}\right]\end{array}$ & 1.43894 & 0.847714 & 0.647975 & 60.7376 & $<0.005$ & 0.977591 \\
\hline $\begin{array}{l}\text { NMAV } \\
\text { Anterior } \\
\text { deltoid }\end{array}$ & SB & $\begin{array}{l}1.22166+0.481705 \\
\times \ln \left[\frac{(x-0.319075)}{(78.6941-x)}\right]\end{array}$ & 1.22166 & 0.481705 & 0.319075 & 78.6941 & $<0.005$ & 0.12699 \\
\hline $\begin{array}{l}\text { NMAV } \\
\text { Posterior } \\
\text { deltoid }\end{array}$ & SB & $\begin{array}{l}1.53906+0.604884 \\
\times \ln \left[\frac{(x-0.383474)}{(69.8451-x)}\right]\end{array}$ & 1.53906 & 0.604884 & 0.383474 & 69.8451 & $<0.005$ & 0.875149 \\
\hline $\begin{array}{l}\text { NMAV } \\
\text { Bicep }\end{array}$ & SB & $\begin{array}{l}1.2986+0.590796 \\
\times \ln \left[\frac{(x-0.303751)}{(58.6284-x)}\right]\end{array}$ & 1.2986 & 0.590796 & 0.303751 & 58.6284 & $<0.005$ & 0.473572 \\
\hline $\begin{array}{l}\text { NMAV } \\
\text { Tricep }\end{array}$ & SU & $\begin{array}{l}-1.8708+0.825356 \\
\times \sinh ^{-1}\left[\frac{(x-0.864504)}{0.862481}\right]\end{array}$ & -1.8708 & 0.825356 & 0.864504 & 0.862481 & $<0.005$ & 0.586 \\
\hline $\begin{array}{l}\text { NMAV } \\
\text { Latissimus } \\
\text { dorsi }\end{array}$ & SB & $\begin{array}{l}2.16552+0.987277 \\
\times \ln \left[\frac{(x-1.68571)}{(97.1743-x)}\right]\end{array}$ & 2.16552 & 0.987277 & 1.68571 & 97.1743 & $<0.005$ & 0.893428 \\
\hline
\end{tabular}


The transformed data met the normality and equality of variance assumption for most of the dependent variables. The results of the Johnson transformation are presented in Appendix E. However, NMAV (infraspinatus) and NMAV (middle deltoid) could not be transformed to normality using a Johnson transformation. Therefore, a nonparametric analysis was performed using Kruskall-Wallis test. 


\section{Chapter 5: Results}

Ten healthy, right-hand dominant male participants were recruited for this research. The average height, weight and age of the participants were $173.5 \pm 5.42 \mathrm{~cm}, 168.1 \pm 18.19 \mathrm{lbs}$. and $26.9 \pm 2.424$ years. Table 5 shows this anthropometric data for each participant.

Table 5: Participants anthropometric data.

\begin{tabular}{cccc}
\hline $\begin{array}{c}\text { Subject } \\
\text { number }\end{array}$ & $\begin{array}{c}\text { Height } \\
\text { (cm) }\end{array}$ & $\begin{array}{c}\text { Weight } \\
\text { (lbs.) }\end{array}$ & Age \\
\hline $\mathbf{1}$ & 175 & 163 & 31 \\
$\mathbf{2}$ & 170 & 189 & 30 \\
$\mathbf{3}$ & 170 & 150 & 27 \\
$\mathbf{4}$ & 178 & 162 & 28 \\
$\mathbf{5}$ & 173 & 180 & 24 \\
$\mathbf{6}$ & 180 & 185 & 24 \\
$\mathbf{7}$ & 182 & 195 & 27 \\
$\mathbf{8}$ & 173 & 140 & 27 \\
$\mathbf{9}$ & 164 & 162 & 27 \\
$\mathbf{1 0}$ & 170 & 155 & 24 \\
\hline Average & 174 & 168 & 27 \\
STD & 5.4 & 18.2 & 2.4 \\
\hline
\end{tabular}

\subsection{Subjective discomfort data}

Data for the individual subjective discomfort ratings are summarized in Appendix I. The mean scores of subjective discomfort for each force level showed an increasing trend towards the highest force level, which is $10 \mathrm{lbs}$ (Figure 9). The mean scores of subjective discomfort for direction showed that the PU and PR directions had the highest discomfort rating, followed by the PD direction. The PL and PB directions had the lowest discomfort ratings of all directions. A baseline discomfort of 1 (nothing at all) was recorded frequently at the $5 \mathrm{lbs}$. force level, and recorded in the PL and PB directions for different force levels. A mean discomfort of 4 (slight 
discomfort) was commonly reported at different force levels and different pulling directions. A mean subjective discomfort of 10 (very severe) was reported in the PU and PR directions. Some participants who reported a discomfort of 10 could not complete the trial, and stopped before reaching the 60 second mark. This situation occurred when participant was pulling $10 \mathrm{lbs}$. in the up direction, and it also occurred when pulling the same force level in the right direction.

\section{Subjective discomfort rating $95 \%$ CI for the Mean}

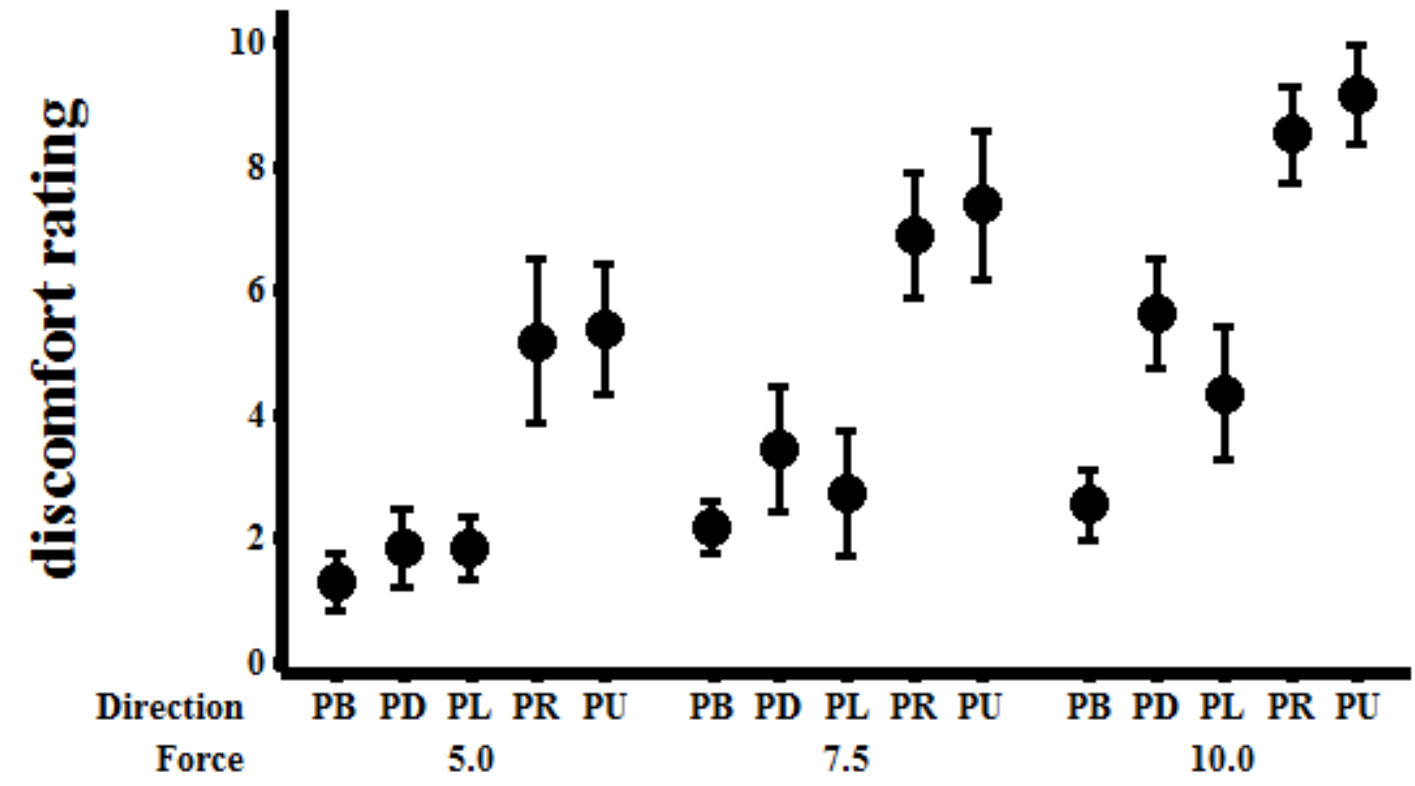

Figure 9: Subjective discomfort scores at different force levels and directions. Error bars represent standard deviations.

Further statistical analysis was performed on the subjective discomfort data to investigate whether the different force levels, different directions or the interaction between them had a significant effect on discomfort. ANOVA analysis showed that the main effect of force level was significant for the discomfort rating ( $\mathrm{p}$-value $\leq 0.001$ ), and the main effect of direction was significant for the discomfort rating (p-value $\leq 0.001)$ (Table 6). In addition, the interaction effect of force level and direction was significant for the discomfort rating ( $p$-value $\leq 0.001)$. Discomfort 
ratings for the PB, PD, PL, PR and PU directions increased by approximately $60 \%, 200 \%, 100 \%$, $60 \%$ and $80 \%$, respectively, at the $10 \mathrm{lbs}$. force level compared to the $5 \mathrm{lbs}$. force level. Results of post hoc analysis showed that at 5 lbs. force level, PU and PR directions were higher than PB, PD and PL directions. Similar results were found at the $7.5 \mathrm{lbs}$. force level. However, at $10 \mathrm{lbs}$. force level, PU and PR directions were higher than PD and PL directions, and PB direction was lower than PD and PL directions.

Table 6: ANOVA results table for discomfort rating.

\begin{tabular}{lccccc}
\hline Source & DF & Adj SS & Adj MS & F-Value & P-Value \\
\hline Subject & 9 & 119.86 & 13.318 & 18.51 & 0 \\
Force & 2 & 216.17 & 108.087 & 150.25 & 0 \\
Direction & 4 & 686.13 & 171.532 & 238.45 & 0 \\
Force*Direction & 8 & 25.39 & 3.174 & 4.41 & 0 \\
Error & 126 & 90.64 & 0.719 & & \\
Total & 149 & 1138.19 & & & \\
\hline
\end{tabular}

\subsection{Electromyography}

Electromyography data for supraspinatus, infraspinatus, teres major, anterior deltoid, middle deltoid, posterior deltoid, biceps, triceps and latissimus dorsi muscles were expressed in terms of median frequency $(\mathrm{M})$ and normalized mean absolute activation (NMAV) data.

\subsubsection{Median Frequency}

Median frequency data for each exertion was fitted with linear regression to estimate the slope of the line $\left(\mathrm{M}_{\mathrm{i}}\right)$. The slope values used for performing statistical analysis are presented in Appendix J. Table 17 shows the median frequency slope values and standard deviations, and it also shows the main and interaction effects for each muscle. Figure 10 shows the median frequency slope values for each muscle. 
For the supraspinatus muscle, ANOVA analysis showed that the main effect of the force level was significant ( $p$-value $\leq 0.001$ ), and the main effect of direction was also significant ( $p$ value $\leq 0.001)$. In addition, the interaction effect of force level and direction was significant (pvalue $=0.006)($ Table 7$)$. In all force exertion directions except BP, the slope value decreased by $100 \%$ or more at the $10 \mathrm{lbs}$. force level compared to the $5 \mathrm{lbs}$. force level. Results of post hoc analysis showed that at $5 \mathrm{lbs}$. force level, no differences were found between all force directions. Similar results were found for the $7.5 \mathrm{lbs}$. force level. However, at $10 \mathrm{lbs}$. force level, PU and PR directions were lower than PB, PD and PL directions.

Table 7: ANOVA results table for $M_{\text {supraspinatus }}$

\begin{tabular}{lccccc}
\hline Source & DF & Adj SS & Adj MS & F-Value & P-Value \\
\hline Subject & 9 & 0.9284 & 0.10316 & 1.65 & 0.108 \\
Force & 2 & 2.1716 & 1.0858 & 17.39 & 0 \\
Direction & 4 & 2.0556 & 0.5139 & 8.23 & 0 \\
Force*Direction & 8 & 1.4319 & 0.17899 & 2.87 & 0.006 \\
Error & 122 & 7.6195 & 0.06246 & & \\
Total & 145 & 14.2085 & & & \\
\hline
\end{tabular}

For the infraspinatus muscle, ANOVA analysis showed that the main effect of force level was significant ( $p$-value $\leq 0.001$ ), and the main effect of direction was also significant ( $p$-value $\leq$ 0.001). In addition, the interaction effect of force level and direction was significant ( $\mathrm{p}$-value = 0.047) (Table 8). The slope value for the PR and PU directions decreased by $50 \%$ and $150 \%$ respectively at the $10 \mathrm{lbs}$. force level compared to the $5 \mathrm{lbs}$. force level. On the other hand, slope values for the other directions had a smaller change at the $10 \mathrm{lbs}$. force level compared to the $5 \mathrm{lbs}$. force level. Results of post hoc analysis showed that at $5 \mathrm{lbs}$. force level, PU and PR directions were lower than PB, PD and PL directions. Similar results were found for the $7.5 \mathrm{lbs}$. force level. However, in at $10 \mathrm{lbs}$. force level, PL, PU and PR directions were lower than PB and PD directions. 
Table 8: ANOVA results table for $M_{\text {infraspinatus }}$

\begin{tabular}{lccccc}
\hline Source & DF & Adj SS & Adj MS & F-Value & P-Value \\
\hline Subject & 9 & 15.912 & 1.768 & 4.01 & 0 \\
Force & 2 & 11.729 & 5.8643 & 13.3 & 0 \\
Direction & 4 & 69.806 & 17.4514 & 39.56 & 0 \\
Force*Direction & 8 & 7.211 & 0.9014 & 2.04 & 0.047 \\
Error & 124 & 54.695 & 0.4411 & & \\
Total & 147 & 160.145 & & & \\
\hline
\end{tabular}

For the teres major muscle, ANOVA analysis showed that the main effect of force level was significant ( $p$-value $\leq 0.001$ ), and the main effect of direction was also significant ( $p$-value $\leq$ 0.001). In addition, the interaction effect of force level and direction was significant ( $\mathrm{p}$-value = 0.043) (Table 9). Slope value for the PR and PU directions decreased around $60 \%$ and $175 \%$ at the $10 \mathrm{lbs}$. force level compared to the $5 \mathrm{lbs}$. force level. On the other hand, slope values for the other directions had a smaller change at the $10 \mathrm{lbs}$. force level compared to the $5 \mathrm{lbs}$. force level. Post hoc analysis showed that at 5 lbs. force level, PL, PU and PR directions were lower than PB and PD directions. However, at $7.5 \mathrm{lbs}$. force level, PU and PR directions were lower than PB, PD and PL directions. Similar results were found for the $10 \mathrm{lbs}$. force level.

Table 9: ANOVA results table for $M_{\text {teres major }}$

\begin{tabular}{lccccc}
\hline Source & DF & Adj SS & Adj MS & F-Value & P-Value \\
\hline Subject & 9 & 7.207 & 0.8008 & 2.03 & 0.042 \\
Force & 2 & 10.899 & 5.4495 & 13.79 & 0 \\
Direction & 4 & 77.787 & 19.4468 & 49.21 & 0 \\
Force*Direction & 8 & 6.551 & 0.8189 & 2.07 & 0.043 \\
Error & 123 & 48.608 & 0.3952 & & \\
Total & 146 & 152.269 & & & \\
\hline
\end{tabular}

For the middle deltoid muscle, ANOVA analysis showed that the main effect of force level was significant ( $p$-value $\leq 0.001$ ), and the main effect of direction was also significant ( $p$-value $\leq$ 
0.001). In addition, the interaction effect of force level and direction was significant ( $\mathrm{p}$-value $=$ 0.015) (Table 10). Slope value for the PR and PU directions was decreased by approximately $350 \%$ and $125 \%$, respectively, at the $10 \mathrm{lbs}$. force level compared to the $5 \mathrm{lbs}$. force level. On the other hand, slope values for the other directions had a smaller change at the $10 \mathrm{lbs}$. force level compared to the $5 \mathrm{lbs}$. force level. Post hoc analysis showed that at $5 \mathrm{lbs}$. force level, PB, PL, PU and PR directions were lower than PD directions. At 7.5 lbs. force level, PB, PL, PU and PD directions were lower than PR directions. Similar results were found for the $10 \mathrm{lbs}$. force level.

Table 10: ANOVA results table for $M_{\text {middle deltoid }}$

\begin{tabular}{lccccc}
\hline Source & DF & Adj SS & Adj MS & F-Value & P-Value \\
\hline Subject & 9 & 27.051 & 3.0056 & 6.12 & 0 \\
Force & 2 & 15.652 & 7.8262 & 15.94 & 0 \\
Direction & 4 & 26.122 & 6.5305 & 13.3 & 0 \\
Force*Direction & 8 & 9.861 & 1.2326 & 2.51 & 0.015 \\
Error & 123 & 60.409 & 0.4911 & & \\
Total & 146 & 138.597 & & & \\
\hline
\end{tabular}

For the anterior deltoid muscle, ANOVA analysis showed that the main effect of force level was significant ( $\mathrm{p}$-value $\leq 0.001$ ), and the main effect of direction was also significant (pvalue $\leq$ 0.001) (Table 11). In addition, the interaction effect of force level and direction was significant ( $p$-value $=0.006$ ). Slope value for the PD, PR and PU directions was decreased by approximately $200 \%, 400 \%$ and $200 \%$, respectively, at the $10 \mathrm{lbs}$. force level compared to the 5 lbs. force level. On the other hand, slope values for the PB and PL directions had a smaller change at the $10 \mathrm{lbs}$. force level compared to the $5 \mathrm{lbs}$. force level. Post hoc analysis showed that at $5 \mathrm{lbs}$. force level, PU direction was lower than PB, PD, PL and PR directions. Similar results were found for the 7.5 and $10 \mathrm{lbs}$. force levels. 
Table 11: ANOVA results table for $M_{\text {anterior deltoid }}$

\begin{tabular}{lccccc}
\hline Source & DF & Adj SS & Adj MS & F-Value & P-Value \\
\hline Subject & 9 & 2.086 & 0.2317 & 1.72 & 0.091 \\
Force & 2 & 6.326 & 3.163 & 23.49 & 0 \\
Direction & 4 & 12.735 & 3.1838 & 23.64 & 0 \\
Force*Direction & 8 & 3.099 & 0.3874 & 2.88 & 0.006 \\
Error & 121 & 16.296 & 0.1347 & & \\
Total & 144 & 40.3 & & & \\
\hline
\end{tabular}

For the posterior deltoid muscle, ANOVA analysis showed that the main effect of force level was significant ( $\mathrm{p}$-value $\leq 0.001$ ), and the main effect of direction was also significant (pvalue $\leq 0.001)$ (Table 12). In addition, the interaction effect of force level and direction was significant $(\mathrm{p}$-value $=0.001)$. Slope value for the PD, PR and PU directions was decreased by approximately $100 \%, 400 \%$ and $90 \%$, respectively, at the $10 \mathrm{lbs}$. force level compared to the $5 \mathrm{lbs}$. force level. On the other hand, slope values for the PB and PL directions had a smaller change at the $10 \mathrm{lbs}$. force level compared to the $5 \mathrm{lbs}$. force level. Results of post hoc analysis showed that at $5 \mathrm{lbs}$. force level, no differences were found between all force directions. Similar results were found for the $7.5 \mathrm{lbs}$. force level. However, at $10 \mathrm{lbs}$. force level, PR direction was lower than PB, PD, PL and PU directions.

Table 12: ANOVA results table for $M_{\text {posterior deltoid }}$

\begin{tabular}{lccccc}
\hline Source & DF & Adj SS & Adj MS & F-Value & P-Value \\
\hline Subject & 9 & 11.05 & 1.228 & 2.3 & 0.02 \\
Force & 2 & 16.28 & 8.1388 & 15.22 & 0 \\
Direction & 4 & 12.04 & 3.0093 & 5.63 & 0 \\
Force*Direction & 8 & 14.57 & 1.8212 & 3.41 & 0.001 \\
Error & 121 & 64.69 & 0.5346 & & \\
Total & 144 & 118.79 & & & \\
\hline
\end{tabular}


For the bicep muscle, ANOVA analysis showed that the main effect of force level was significant ( $\mathrm{p}$-value $\leq 0.001$ ), and the main effect of direction was also significant ( $\mathrm{p}$-value $\leq$ 0.001). However, the interaction effect of force level and direction was not significant ( $\mathrm{p}$-value $=$ 0.401) (Table 13). Slope value for the PR, PD and PU directions was decreased by roughly $180 \%$, $100 \%$ and $100 \%$ for $10 \mathrm{lbs}$. force level compared to the $5 \mathrm{lbs}$. force level. On the other hand, slope values for the other directions had a smaller change at the $10 \mathrm{lbs}$. force level compared to the $5 \mathrm{lbs}$. force level. Post hoc analysis showed that at $10 \mathrm{lbs}$. force level was different than the other force levels. In addition, it showed that the PR and PD directions were lower than PB, PL and PU directions.

Table 13: ANOVA results table for $M_{\text {bicep }}$

\begin{tabular}{lccccc}
\hline Source & DF & Adj SS & Adj MS & F-Value & P-Value \\
\hline Subject & 9 & 1.6244 & 0.18049 & 1.87 & 0.064 \\
Force & 2 & 1.633 & 0.8165 & 8.45 & 0 \\
Direction & 4 & 2.9236 & 0.73091 & 7.56 & 0 \\
Force*Direction & 8 & 0.8145 & 0.10181 & 1.05 & 0.401 \\
Error & 116 & 11.2151 & 0.09668 & & \\
Total & 139 & 18.318 & & & \\
\hline
\end{tabular}

For the tricep muscle, ANOVA analysis showed that the main effect of force level was significant ( $\mathrm{p}$-value $\leq 0.001$ ), and the main effect of direction was also significant ( $\mathrm{p}$-value $\leq$ 0.001). In addition, the interaction effect of force level and direction was significant ( $\mathrm{p}$-value $\leq$ 0.001) (Table 14). Slope value for he PD, PR and PU directions was decreased by approximately $200 \%, 250 \%$ and $150 \%$, respectively, at the $10 \mathrm{lbs}$. force level compared to the $5 \mathrm{lbs}$. force level. On the other hand, slope values for the PB and PL directions had a smaller change at the $10 \mathrm{lbs}$. force level compared to the $5 \mathrm{lbs}$. force level. Results of post hoc analysis showed that in the at 5 lbs. force level, no differences were found between all force directions. However, at $7.5 \mathrm{lbs}$. force 
level, PU and PR directions were lower than PB, PD and PL directions. At $10 \mathrm{lbs}$. force level, PD and PU directions were lower than PB and PL directions, and PR direction was lower than PD and PU directions.

Table 14: ANOVA results table for $M_{\text {tricep }}$

\begin{tabular}{lccccc}
\hline Source & DF & Adj SS & Adj MS & F-Value & P-Value \\
\hline Subject & 9 & 5.966 & 0.66285 & 6.84 & 0 \\
Force & 2 & 4.766 & 2.38285 & 24.58 & 0 \\
Direction & 4 & 7.712 & 1.928 & 19.89 & 0 \\
Force*Direction & 8 & 2.965 & 0.3706 & 3.82 & 0 \\
Error & 124 & 12.021 & 0.09694 & & \\
Total & 147 & 33.468 & & & \\
\hline
\end{tabular}

For the latissimus dorsi muscle, ANOVA analysis showed that the main effect of force level was significant ( $\mathrm{p}$-value $\leq 0.001$ ), and the main effect of direction was also significant (pvalue $\leq 0.001)$. However, the interaction effect of force level and direction was not significant (pvalue $=0.09)($ Table 15$)$. Slope value for the PR and PU directions decreased by around $100 \%$ and $150 \%$, respectively, at the $10 \mathrm{lbs}$. force level compared to the $5 \mathrm{lbs}$. force level. On the other hand, slope values for the other directions had a smaller change at the $10 \mathrm{lbs}$. force level compared to the $5 \mathrm{lbs}$. force level. Post hoc analysis showed that the force level of $10 \mathrm{lbs}$. was different than the other force levels. In addition, post hoc analysis showed that the PR and PU directions were lower than PB, PD and PL directions.

Table 15: ANOVA results table for $M_{\text {latissimus dorsi }}$

\begin{tabular}{lccccc}
\hline Source & DF & Adj SS & Adj MS & F-Value & P-Value \\
\hline Subject & 9 & 4.971 & 0.5523 & 5.08 & 0 \\
Force & 2 & 1.814 & 0.9069 & 8.34 & 0 \\
Direction & 4 & 4.535 & 1.1336 & 10.42 & 0 \\
Force*Direction & 8 & 1.541 & 0.1926 & 1.77 & 0.09 \\
Error & 117 & 12.727 & 0.1088 & & \\
Total & 140 & 25.175 & & & \\
\hline
\end{tabular}


Finally, for total M, ANOVA analysis showed that the main effect of force level was significant ( $\mathrm{p}$-value $\leq 0.001$ ), and the main effect of direction was also significant ( $\mathrm{p}$-value $\leq$ 0.001). However, the interaction effect of force level and direction was not significant ( $\mathrm{p}$-value $=$ 0.377) (Table 16). Slope value for the PR and PU directions was decreased by roughly $150 \%$ for both at the $10 \mathrm{lbs}$. force level compared to the $5 \mathrm{lbs}$. force level. On the other hand, slope values for the PB, PD and PL directions had a smaller change at the 10lbs. force level compared to the 5 lbs. force level. Post hoc analysis showed that each force level was different than others. Moreover, post hoc analysis showed that PL direction was lower than PB and PD directions, and PR and PU were lower than PL direction.

Table 16: ANOVA results table for TM

\begin{tabular}{lccccc}
\hline Source & DF & Adj SS & Adj MS & F-Value & P-Value \\
\hline Subject & 9 & 15.051 & 1.6723 & 5.8 & 0 \\
Force & 2 & 27.483 & 13.7414 & 47.63 & 0 \\
Direction & 4 & 60.351 & 15.0879 & 52.3 & 0 \\
Force*Direction & 8 & 2.509 & 0.3136 & 1.09 & 0.377 \\
Error & 126 & 36.353 & 0.2885 & & \\
Total & 149 & 141.746 & & & \\
\hline
\end{tabular}




\begin{tabular}{|c|c|c|c|c|c|c|c|c|c|c|c|}
\hline \multirow{2}{*}{$\mathbf{M}$} & \multicolumn{3}{|c|}{ Load } & \multirow{2}{*}{$\begin{array}{c}\mathbf{P} \text { - } \\
\text { value }\end{array}$} & \multicolumn{5}{|c|}{ Direction } & \multirow{2}{*}{$\begin{array}{c}\text { P- } \\
\text { value }\end{array}$} & \multirow{2}{*}{$\begin{array}{c}\text { Interaction } \\
\text { P-value }\end{array}$} \\
\hline & 5 lbs. & $7.5 \mathrm{lbs}$. & 10 lbs. & & $\mathrm{PB}$ & $\mathrm{PD}$ & $\mathrm{PL}$ & PR & $\mathrm{PU}$ & & \\
\hline Supraspinatus & $\begin{array}{c}-0.1811 \\
( \pm 0.2479)\end{array}$ & $\begin{array}{c}-0.3531 \\
( \pm 0.2390)\end{array}$ & $\begin{array}{c}-0.4812 \\
( \pm 0.3647)\end{array}$ & $\leq 0.001$ & $\begin{array}{c}-0.1958 \\
( \pm 0.2914)\end{array}$ & $\begin{array}{c}-0.2981 \\
( \pm 0.3075)\end{array}$ & $\begin{array}{c}-0.3076 \\
( \pm 0.2610)\end{array}$ & $\begin{array}{c}-0.3422 \\
( \pm 0.2978)\end{array}$ & $\begin{array}{c}-0.5490 \\
( \pm 0.3090)\end{array}$ & $\leq \mathbf{0 . 0 0 1}$ & 0.006 \\
\hline Infraspinatus & $\begin{array}{c}-0.4239 \\
( \pm 0.4434)\end{array}$ & $\begin{array}{c}-0.5957 \\
( \pm 0.6116)\end{array}$ & $\begin{array}{c}-0.942 \\
( \pm 0.817)\end{array}$ & $\leq 0.001$ & $\begin{array}{c}-0.2742 \\
( \pm 0.2375)\end{array}$ & $\begin{array}{c}-0.1275 \\
( \pm 0.2755)\end{array}$ & $\begin{array}{c}-0.503 \\
( \pm 0.656)\end{array}$ & $\begin{array}{c}-1.107 \\
( \pm 0.593)\end{array}$ & $\begin{array}{c}-1.245 \\
( \pm 0.624)\end{array}$ & $\leq \mathbf{0 . 0 0 1}$ & 0.047 \\
\hline Teres major & $\begin{array}{c}-0.4303 \\
( \pm 0.4781)\end{array}$ & $\begin{array}{c}-0.591 \\
( \pm 0.713)\end{array}$ & $\begin{array}{c}-0.897 \\
( \pm 0.809)\end{array}$ & $\leq 0.001$ & $\begin{array}{c}-0.1862 \\
( \pm 0.2959)\end{array}$ & $\begin{array}{c}-0.2326 \\
( \pm 0.2839)\end{array}$ & $\begin{array}{c}-0.3371 \\
( \pm 0.3406)\end{array}$ & $\begin{array}{c}-1.167 \\
( \pm 0.668)\end{array}$ & $\begin{array}{c}-1.314 \\
( \pm 0.773)\end{array}$ & $\leq \mathbf{0 . 0 0 1}$ & 0.043 \\
\hline Mid deltoid & $\begin{array}{c}-0.2808 \\
( \pm 0.3760)\end{array}$ & $\begin{array}{c}-0.4549 \\
( \pm 0.4681)\end{array}$ & $\begin{array}{c}-0.6812 \\
( \pm 0.5722)\end{array}$ & $\leq 0.001$ & $\begin{array}{c}-0.355 \\
( \pm 0.552)\end{array}$ & $\begin{array}{c}-0.2030 \\
( \pm 0.2354)\end{array}$ & $\begin{array}{c}-0.4442 \\
( \pm 0.5087)\end{array}$ & $\begin{array}{c}-0.772 \\
( \pm 0.599)\end{array}$ & $\begin{array}{c}-0.6029 \\
( \pm 0.3713)\end{array}$ & $\leq \mathbf{0 . 0 0 1}$ & 0.015 \\
\hline Ant deltoid & $\begin{array}{c}-0.2613 \\
( \pm 0.3669)\end{array}$ & $\begin{array}{c}-0.4572 \\
( \pm 0.4619)\end{array}$ & $\begin{array}{c}-0.7709 \\
( \pm 0.6087)\end{array}$ & $\leq 0.001$ & $\begin{array}{c}-0.1747 \\
( \pm 0.3223)\end{array}$ & $\begin{array}{c}-0.2981 \\
( \pm 0.3469)\end{array}$ & $\begin{array}{c}-0.4613 \\
( \pm 0.2638)\end{array}$ & $\begin{array}{c}-0.4712 \\
( \pm 0.5436)\end{array}$ & $\begin{array}{c}-1.025 \\
( \pm 0.626)\end{array}$ & $\leq 0.001$ & 0.006 \\
\hline Post deltoid & $\begin{array}{c}-0.3025 \\
( \pm 0.2668)\end{array}$ & $\begin{array}{c}-0.3919 \\
( \pm 0.2796)\end{array}$ & $\begin{array}{c}-0.7373 \\
( \pm 0.5841)\end{array}$ & $\leq 0.001$ & $\begin{array}{c}-0.3261 \\
( \pm 0.2624)\end{array}$ & $\begin{array}{c}-0.3022 \\
( \pm 0.3376)\end{array}$ & $\begin{array}{c}-0.4856 \\
( \pm 0.2881)\end{array}$ & $\begin{array}{c}-0.718 \\
( \pm 0.681)\end{array}$ & $\begin{array}{c}-0.5716 \\
( \pm 0.4187)\end{array}$ & $\leq 0.001$ & 0.001 \\
\hline Bicep & $\begin{array}{c}-0.1331 \\
( \pm 0.2826)\end{array}$ & $\begin{array}{c}-0.2508 \\
( \pm 0.3223)\end{array}$ & $\begin{array}{c}-0.3911 \\
( \pm 0.4226)\end{array}$ & $\leq 0.001$ & $\begin{array}{c}-0.1324 \\
( \pm 0.2780)\end{array}$ & $\begin{array}{c}-0.3318 \\
( \pm 0.3421)\end{array}$ & $\begin{array}{c}-0.1012 \\
( \pm 0.2312)\end{array}$ & $\begin{array}{c}-0.5014 \\
( \pm 0.4965)\end{array}$ & $\begin{array}{c}-0.2463 \\
( \pm 0.2906)\end{array}$ & $\leq 0.001$ & 0.401 \\
\hline Tricep & $\begin{array}{c}-0.3144 \\
( \pm 0.2676)\end{array}$ & $\begin{array}{c}-0.4978 \\
( \pm 0.4385)\end{array}$ & $\begin{array}{c}-0.7485 \\
( \pm 0.5732)\end{array}$ & $\leq 0.001$ & $\begin{array}{c}-0.2645 \\
( \pm 0.2211)\end{array}$ & $\begin{array}{c}-0.4558 \\
( \pm 0.3771)\end{array}$ & $\begin{array}{c}-0.3021 \\
( \pm 0.3405)\end{array}$ & $\begin{array}{c}-0.821 \\
( \pm 0.604)\end{array}$ & $\begin{array}{c}-0.7486 \\
( \pm 0.4703)\end{array}$ & $\leq 0.001$ & $\leq 0.001$ \\
\hline Latissimus dorsi & $\begin{array}{c}-0.2079 \\
( \pm 0.3430)\end{array}$ & $\begin{array}{c}-0.2741 \\
( \pm 0.3901)\end{array}$ & $\begin{array}{c}-0.4565 \\
( \pm 0.4883)\end{array}$ & $\leq 0.001$ & $\begin{array}{c}-0.1829 \\
( \pm 0.2828)\end{array}$ & $\begin{array}{c}-0.1358 \\
( \pm 0.3258)\end{array}$ & $\begin{array}{c}-0.2451 \\
( \pm 0.4108)\end{array}$ & $\begin{array}{c}-0.4189 \\
( \pm 0.3007)\end{array}$ & $\begin{array}{c}-0.601 \\
( \pm 0.568)\end{array}$ & $\leq 0.001$ & 0.090 \\
\hline Total M & $\begin{array}{c}-2.455 \\
( \pm 1.610)\end{array}$ & $\begin{array}{c}-3.723 \\
( \pm 2.479)\end{array}$ & $\begin{array}{c}-6.020 \\
( \pm 3.866)\end{array}$ & $\leq \mathbf{0 . 0 0 1}$ & $\begin{array}{c}-1.980 \\
( \pm 1.330)\end{array}$ & $\begin{array}{c}-2.339 \\
( \pm 1.944)\end{array}$ & $\begin{array}{c}-3.090 \\
( \pm 1.371)\end{array}$ & $\begin{array}{c}-6.064 \\
( \pm 3.606)\end{array}$ & $\begin{array}{c}-6.855 \\
( \pm 3.178)\end{array}$ & $\leq 0.001$ & 0.377 \\
\hline
\end{tabular}



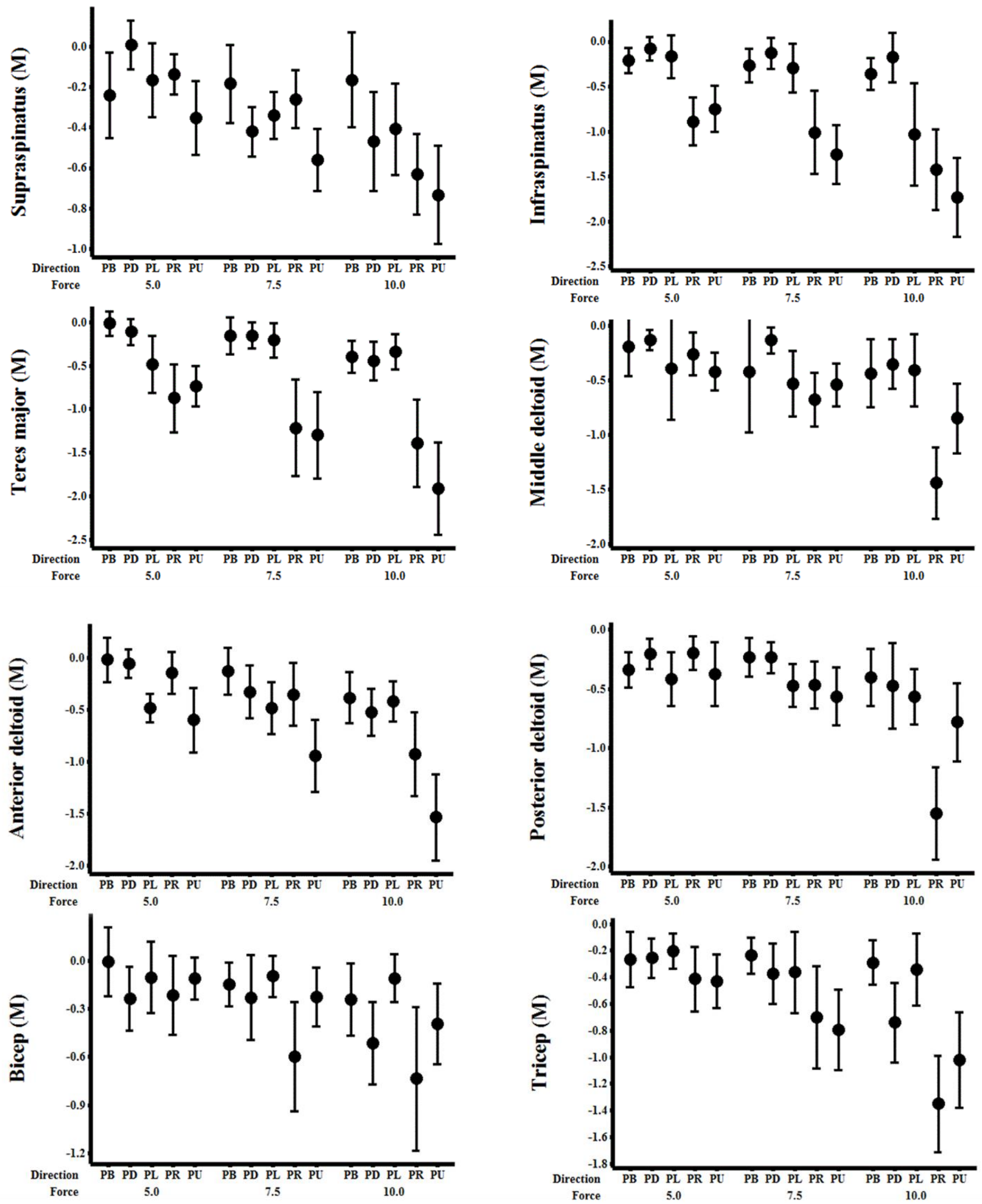

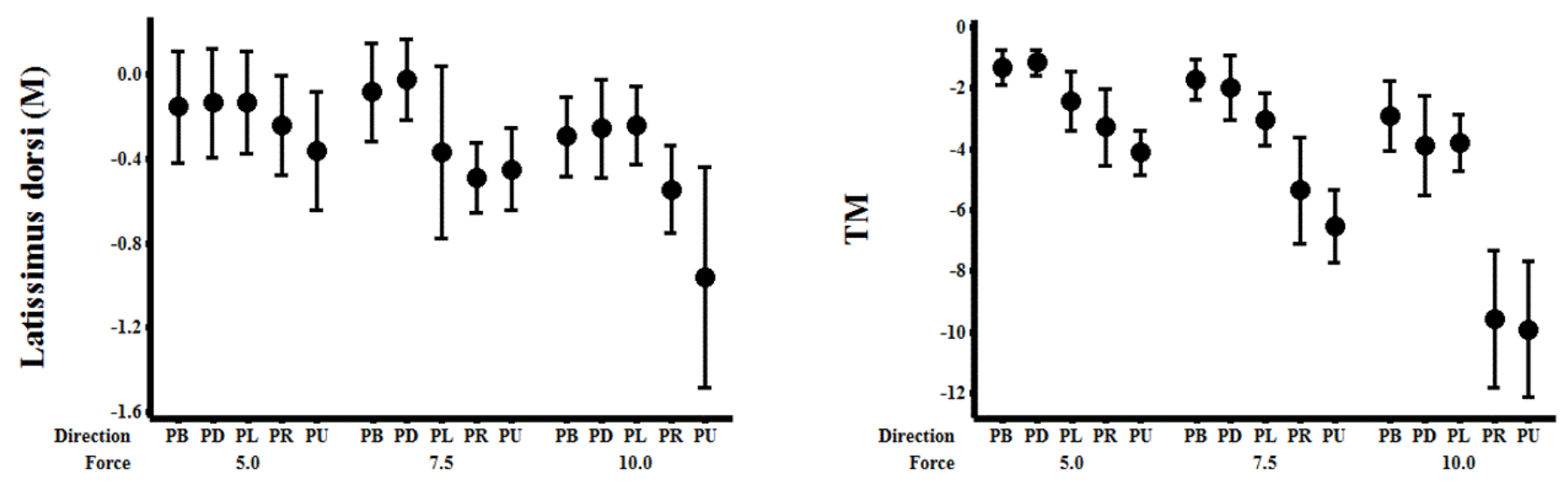

Figure 10: Raw data charts for median frequency slope values. Error bars represents standard deviation. 


\subsubsection{Normalized mean absolute values}

The raw data used for performing statistical analysis are presented in Appendix K. Table 26 shows the NMAVs and deviations, as well as the main and interaction effects for each muscle. Figure 11 shows the changes in NMAVs for each muscle.

For the supraspinatus muscle, ANOVA analysis showed that the main effect of the force level was significant ( $p$-value $\leq 0.001$ ), and the main effect of direction was also significant ( $p$ value $\leq$ 0.001). However, the interaction effect of force level and direction was not significant (pvalue $=0.984)($ Table 18$)$. Muscle activation for the PR and PU directions was increased by approximately $100 \%$ and $60 \%$, respectively, at the $10 \mathrm{lbs}$. force level compared to the $5 \mathrm{lbs}$. force level. On the other hand, muscle activation for the PB, PD and PL directions had a smaller change at the $10 \mathrm{lbs}$. force level compared to the $5 \mathrm{lbs}$. force level. Post hoc analysis showed that each force level was different than other force levels. In addition, post hoc analysis showed that the PR and PD directions were different than the PU and PL directions, and both of them were different than PB direction.

Table 18: ANOVA results table for NMA $V_{\text {supraspinatus }}$

\begin{tabular}{lccccc}
\hline Source & DF & Adj SS & Adj MS & F-Value & P-Value \\
\hline Subject & 9 & 33.893 & 3.7659 & 10.72 & 0 \\
Force & 2 & 16.855 & 8.4276 & 23.98 & 0 \\
Direction & 4 & 58.538 & 14.6345 & 41.64 & 0 \\
Force*Direction & 8 & 0.662 & 0.0828 & 0.24 & 0.984 \\
Error & 126 & 44.282 & 0.3514 & & \\
Total & 149 & 154.231 & & & \\
\hline
\end{tabular}

For the infraspinatus muscle, Kruskall-Wallis one-way analysis showed that the main effect of force level was significant ( $\mathrm{p}$-value $=0.003$ ), and the main effect of direction was also 
significant ( $\mathrm{p}$-value $\leq 0.001)$. Muscle activation for the PR and PU directions was increased by roughly $100 \%$ and $66 \%$, respectively, at the $10 \mathrm{lbs}$. force level compared to the $5 \mathrm{lbs}$. force level. On the other hand, muscle activation for the PB, PD and PL directions had a smaller change at the $10 \mathrm{lbs}$. force level compared to the $5 \mathrm{lbs}$. force level.

For the teres major muscle, ANOVA analysis showed that the main effect of force level was significant ( $p$-value $\leq 0.001$ ), and the main effect of direction was also significant ( $p$-value $\leq$ 0.001) (Table 19). However, the interaction effect of force level and direction was not significant $(\mathrm{p}$-value $=0.88)$. For all force exertion directions, muscle activation increased by roughly $100 \%$ at the $10 \mathrm{lbs}$. force level compared to the $5 \mathrm{lbs}$. force level. Post hoc analysis showed that each force level was different than other force levels. In addition, post hoc analysis showed that the PR, PB and PD directions were different than PU and PL directions.

Table 19: ANOVA results table for NMAV teres major

\begin{tabular}{lccccc}
\hline Source & DF & Adj SS & Adj MS & F-Value & P-Value \\
\hline Subject & 9 & 56.054 & 6.2282 & 19.71 & 0 \\
Force & 2 & 30.815 & 15.4075 & 48.76 & 0 \\
Direction & 4 & 9.015 & 2.2536 & 7.13 & 0 \\
Force*Direction & 8 & 1.171 & 0.1463 & 0.46 & 0.88 \\
Error & 126 & 39.814 & 0.316 & & \\
Total & 149 & 136.867 & & & \\
\hline
\end{tabular}

For the middle deltoid muscle, Kruskall-Wallis one-way analysis showed that the main effect of force level was significant ( $\mathrm{p}$-value $=0.011$ ), and the main effect of direction was significant ( $\mathrm{p}$-value $\leq 0.001)$. Muscle activation for the PR and PU directions was increased by roughly $200 \%$ and $100 \%$, respectively, at the $10 \mathrm{lbs}$. force level compared to the $5 \mathrm{lbs}$. force level. On the other hand, muscle activation for the PB, PD and PL directions had a smaller change at the $10 \mathrm{lbs}$. force level compared to the $5 \mathrm{lbs}$. force level. 
For the anterior deltoid muscle, ANOVA analysis showed that the main effect of force level was significant ( $p$-value $\leq 0.001$ ), and the main effect of direction was also significant ( $p$ value $\leq 0.001)$. However, the interaction effect of force level and direction was not significant (pvalue $=0.703)($ Table 20$)$. Muscle activation for the PR and PU directions was increased by roughly $150 \%$ and $50 \%$, respectively, at the $10 \mathrm{lbs}$. force level compared to the $5 \mathrm{lbs}$. force level. On the other hand, muscle activation for the PB and PL directions had a smaller change at the 10 lbs. force level compared to the $5 \mathrm{lbs}$. force level. Post hoc analysis showed that the force level of 5 lbs. was different than the other force levels. In addition, post hoc showed that each force exertion direction was different than the others. PU direction was the highest followed by PR direction, and PB and PD directions were lower than PL direction.

Table 20: ANOVA results table for NMAV $V_{\text {anterior deltoid }}$

\begin{tabular}{lccccc}
\hline Source & DF & Adj SS & Adj MS & F-Value & P-Value \\
\hline Subject & 9 & 7.186 & 0.7985 & 4.24 & 0 \\
Force & 2 & 3.85 & 1.9251 & 10.22 & 0 \\
Direction & 4 & 117.778 & 29.4444 & 156.26 & 0 \\
Force*Direction & 8 & 1.034 & 0.1293 & 0.69 & 0.703 \\
Error & 125 & 23.554 & 0.1884 & & \\
Total & 148 & 153.244 & & & \\
\hline
\end{tabular}

For the posterior deltoid muscle, ANOVA analysis showed that the main effect of force level was significant ( $\mathrm{p}$-value $\leq 0.001$ ), and the main effect of direction was also significant (pvalue $\leq 0.001)$. However, the interaction effect of force level and direction was not significant (pvalue $=0.29)($ Table 21$)$. Muscle activation for the PD, PR and PU directions was increased by roughly $100 \%, 150 \%$ and $70 \%$, respectively, at the $10 \mathrm{lbs}$. force level compared to the $5 \mathrm{lbs}$. force level. On the other hand, muscle activation for the PB and PL directions had a smaller change at the $10 \mathrm{lbs}$. force level compared to the $5 \mathrm{lbs}$. force level. Post hoc analysis showed that each force 
level was different than the other force levels. In addition, it showed that PR direction was the highest followed by PU and PD directions, and PB and PL directions were the lowest.

Table 21: ANOVA results table for NMAV $V_{\text {posterior deltoid }}$

\begin{tabular}{lccccc}
\hline Source & DF & Adj SS & Adj MS & F-Value & P-Value \\
\hline Subject & 9 & 19.467 & 2.163 & 8.61 & 0 \\
Force & 2 & 10.787 & 5.3937 & 21.48 & 0 \\
Direction & 4 & 93.375 & 23.3437 & 92.95 & 0 \\
Force*Direction & 8 & 2.461 & 0.3077 & 1.23 & 0.29 \\
Error & 125 & 31.392 & 0.2511 & & \\
Total & 148 & 154.262 & & & \\
\hline
\end{tabular}

For the bicep muscle, ANOVA analysis showed that the main effect of force level was significant ( $\mathrm{p}$-value $\leq 0.001$ ), and the main effect of direction was also significant ( $\mathrm{p}$-value $\leq$ 0.001). However, the interaction effect of force level and direction was not significant ( $\mathrm{p}$-value = 0.141) (Table 22). Muscle activation for the PL, PR and PU directions was increased by roughly $100 \%$ for all at the $10 \mathrm{lbs}$. force level compared to the $5 \mathrm{lbs}$. force level. On the other hand, muscle activation for the other directions had a smaller change at the $10 \mathrm{lbs}$. force level compared to the $5 \mathrm{lbs}$. force level. Post hoc analysis showed that the force level of $10 \mathrm{lbs}$. was different than other force levels. In addition, it showed that PU direction was the highest followed by PL direction, and PB and PD directions were the lower than PR direction.

Table 22: ANOVA results table for NMAV $V_{\text {bicep }}$

\begin{tabular}{lccccc}
\hline Source & DF & Adj SS & Adj MS & F-Value & P-Value \\
\hline Subject & 9 & 16.526 & 1.8362 & 12.32 & 0 \\
Force & 2 & 6.643 & 3.3214 & 22.29 & 0 \\
Direction & 4 & 96.475 & 24.1187 & 161.84 & 0 \\
Force*Direction & 8 & 1.867 & 0.2334 & 1.57 & 0.141 \\
Error & 126 & 18.778 & 0.149 & & \\
Total & 149 & 140.288 & & & \\
\hline
\end{tabular}


For the tricep muscle, ANOVA analysis showed that the main effect of force level was significant ( $\mathrm{p}$-value $\leq 0.001$ ), and the main effect of direction was also significant ( $\mathrm{p}$-value $\leq$ 0.001). In addition, the interaction effect of force level and direction was significant ( $\mathrm{p}$-value = 0.022) (Table 23). Muscle activation for the PD, PR and PU directions was increased by roughly $150 \%, 50 \%$ and $50 \%$, respectively, at the $10 \mathrm{lbs}$. force level compared to the $5 \mathrm{lbs}$. force level. On the other hand, muscle activation for the PB and PL directions had a smaller change at the $10 \mathrm{lbs}$. force level compared to the $5 \mathrm{lbs}$. force level. Post hoc analysis showed that at a force level of 10 lbs. the PB, PD and PL directions were different than the PR and PU directions. At a force level of $7.5 \mathrm{lbs}$. PU direction was different than other directions. At a force level of $5 \mathrm{lbs}$., no difference was found between the directions of force exertion. Results of post hoc analysis for interaction effect showed that at $5 \mathrm{lbs}$. force level, PD direction was higher than PR and PU directions, and PB and PL were the lowest. However, in the interaction between $7.5 \mathrm{lbs}$. force level and force directions, PD, PR and PU directions were higher than PL and PB directions. Similar results were found for the $10 \mathrm{lbs}$. force level.

Table 23: ANOVA results table for NMAV $V_{\text {tricep }}$

\begin{tabular}{lccccc}
\hline Source & DF & Adj SS & Adj MS & F-Value & P-Value \\
\hline Subject & 9 & 29.812 & 3.3124 & 12.25 & 0 \\
Force & 2 & 11.037 & 5.5185 & 20.4 & 0 \\
Direction & 4 & 64.21 & 16.0524 & 59.35 & 0 \\
Force*Direction & 8 & 5.082 & 0.6352 & 2.35 & 0.022 \\
Error & 126 & 34.078 & 0.2705 & & \\
Total & 149 & 144.218 & & & \\
\hline
\end{tabular}

For the latissimus dorsi muscle, ANOVA analysis showed that the main effect of force level was significant ( $\mathrm{p}$-value $\leq 0.001)$, and the main effect of direction was also significant ( $\mathrm{p}$ value $\leq 0.001)$. However, the interaction effect of force level and direction was not significant (p- 
value $=0.262)($ Table 24$)$. Muscle activation for the PB, PD, PR and PU directions was increased by roughly $100 \%, 175 \%, 100 \%$ and $50 \%$, respectively, at the $10 \mathrm{lbs}$. force level compared to the 5 lbs. force level. On the other hand, muscle activation for the PL direction had a smaller change at the $10 \mathrm{lbs}$. force level compared to the $5 \mathrm{lbs}$. force level. Post hoc analysis showed that each force level was different than the other force levels. In addition, it showed that the PL direction was lower than the PB, PU, PR and PD directions.

Table 24: ANOVA results table for NMAV latissimus dorsi

\begin{tabular}{lccccc}
\hline Source & DF & Adj SS & Adj MS & F-Value & P-Value \\
\hline Subject & 9 & 65.097 & 7.233 & 22.52 & 0 \\
Force & 2 & 28.879 & 14.4397 & 44.96 & 0 \\
Direction & 4 & 29.594 & 7.3986 & 23.04 & 0 \\
Force*Direction & 8 & 3.279 & 0.4099 & 1.28 & 0.262 \\
Error & 126 & 40.467 & 0.3212 & & \\
Total & 149 & 167.316 & & & \\
\hline
\end{tabular}

Finally, for TNMAV, ANOVA analysis showed that the main effect of force level was significant ( $\mathrm{p}$-value $\leq 0.001$ ), and the main effect of direction was also significant ( $\mathrm{p}$-value $\leq$ 0.001). In addition, the interaction effect of force level and direction was significant ( $p$-value $\leq$ 0.001) (Table 25). Muscle activation for the PD, PR and PU directions was increased by roughly $100 \%, 100 \%$ and $60 \%$, respectively, at the $10 \mathrm{lbs}$. force level compared to the $5 \mathrm{lbs}$. force level. On the other hand, muscle activation for the PL direction had a smaller change at the $10 \mathrm{lbs}$. force level compared to the $5 \mathrm{lbs}$. force level. Results of post hoc analysis showed that at $5 \mathrm{lbs}$. force level and force directions, PU and PR directions were higher than PB, PD and PL directions. Similar results were found for the 7.5 and $10 \mathrm{lbs}$. force levels. 
Table 25: ANOVA results table for TNMAV

\begin{tabular}{lccccc}
\hline Source & DF & Adj SS & Adj MS & F-Value & P-Value \\
\hline Subject & 9 & 70774 & 7863.7 & 12.47 & 0 \\
Force & 2 & 144207 & 72103.5 & 114.32 & 0 \\
Direction & 4 & 347382 & 86845.5 & 137.69 & 0 \\
Force*Direction & 8 & 35327 & 4415.9 & 7 & 0 \\
Error & 126 & 79470 & 630.7 & & \\
Total & 149 & 677160 & & & \\
\hline
\end{tabular}


Table 26: Normalized mean absolute values, SD, main and interaction effect.

\begin{tabular}{|c|c|c|c|c|c|c|c|c|c|c|c|}
\hline \multirow{2}{*}{ NMAV } & \multicolumn{3}{|c|}{ Load } & \multirow{2}{*}{$\begin{array}{c}\mathbf{P}- \\
\text { value }\end{array}$} & \multicolumn{5}{|c|}{ Direction } & \multirow{2}{*}{$\begin{array}{c}\text { P- } \\
\text { value }\end{array}$} & \multirow{2}{*}{$\begin{array}{l}\text { P-value for } \\
\text { Interaction }\end{array}$} \\
\hline & $5 \mathrm{lbs}$. & 7.5 lbs. & $10 \mathrm{lbs}$. & & $\mathrm{PB}$ & PD & $\mathrm{PL}$ & PR & $\mathrm{PU}$ & & \\
\hline Supraspinatus & $\begin{array}{c}10.72 \\
( \pm 9.71)\end{array}$ & $\begin{array}{c}12.40 \\
( \pm 11.48)\end{array}$ & $\begin{array}{c}16.85 \\
( \pm 17.93)\end{array}$ & $\leq 0.001$ & $\begin{array}{c}6.009 \\
( \pm 3.306)\end{array}$ & $\begin{array}{c}3.165 \\
( \pm 2.184)\end{array}$ & $\begin{array}{c}2.500 \\
( \pm 2.476)\end{array}$ & $\begin{array}{c}29.85 \\
( \pm 11.89)\end{array}$ & $\begin{array}{c}25.09 \\
( \pm 9.21)\end{array}$ & $\leq \mathbf{0 . 0 0 1}$ & 0.984 \\
\hline Infraspinatus & $\begin{array}{c}13.93 \\
( \pm 13.55)\end{array}$ & $\begin{array}{c}18.92 \\
( \pm 17.77)\end{array}$ & $\begin{array}{c}24.72 \\
( \pm 23.41)\end{array}$ & 0.003 & $\begin{array}{c}6.006 \\
( \pm 2.635)\end{array}$ & $\begin{array}{c}6.968 \\
( \pm 3.463)\end{array}$ & $\begin{array}{c}4.226 \\
( \pm 1.986)\end{array}$ & $\begin{array}{c}41.56 \\
( \pm 13.96)\end{array}$ & $\begin{array}{c}37.73 \\
( \pm 14.40)\end{array}$ & $\leq \mathbf{0 . 0 0 1}$ & - \\
\hline Teres major & $\begin{array}{c}6.713 \\
( \pm 5.392)\end{array}$ & $\begin{array}{c}10.79 \\
( \pm 8.33)\end{array}$ & $\begin{array}{c}16.57 \\
( \pm 12.87)\end{array}$ & $\leq 0.001$ & $\begin{array}{c}9.27 \\
( \pm 6.56)\end{array}$ & $\begin{array}{c}13.58 \\
( \pm 7.78)\end{array}$ & $\begin{array}{c}6.55 \\
( \pm 5.46)\end{array}$ & $\begin{array}{c}14.54 \\
( \pm 13.58)\end{array}$ & $\begin{array}{c}12.86 \\
( \pm 12.99)\end{array}$ & $\leq 0.001$ & 0.880 \\
\hline Mid deltoid & $\begin{array}{c}6.01 \\
( \pm 6.36)\end{array}$ & $\begin{array}{c}8.61 \\
( \pm 9.10)\end{array}$ & $\begin{array}{c}13.50 \\
( \pm 15.31)\end{array}$ & 0.011 & $\begin{array}{c}1.390 \\
( \pm 0.701)\end{array}$ & $\begin{array}{c}4.410 \\
( \pm 4.306)\end{array}$ & $\begin{array}{c}2.456 \\
( \pm 1.751)\end{array}$ & $\begin{array}{c}23.25 \\
( \pm 13.97)\end{array}$ & $\begin{array}{c}15.34 \\
( \pm 7.69)\end{array}$ & $\leq 0.001$ & - \\
\hline Ant deltoid & $\begin{array}{c}11.84 \\
( \pm 13.55)\end{array}$ & $\begin{array}{c}15.07 \\
( \pm 18.17)\end{array}$ & $\begin{array}{c}16.68 \\
( \pm 19.83)\end{array}$ & $\leq \mathbf{0 . 0 0 1}$ & $\begin{array}{c}1.201 \\
( \pm 0.975)\end{array}$ & $\begin{array}{c}1.903 \\
( \pm 1.202)\end{array}$ & $\begin{array}{c}9.40 \\
( \pm 6.66)\end{array}$ & $\begin{array}{c}19.71 \\
( \pm 13.41)\end{array}$ & $\begin{array}{c}42.58 \\
( \pm 12.28)\end{array}$ & $\leq 0.001$ & 0.703 \\
\hline Post deltoid & $\begin{array}{c}5.521 \\
( \pm 5.925)\end{array}$ & $\begin{array}{c}8.11 \\
( \pm 9.04)\end{array}$ & $\begin{array}{c}12.18 \\
( \pm 14.69)\end{array}$ & $\leq 0.001$ & $\begin{array}{c}3.159 \\
( \pm 2.301)\end{array}$ & $\begin{array}{c}6.74 \\
( \pm 5.57)\end{array}$ & $\begin{array}{c}1.581 \\
( \pm 1.602)\end{array}$ & $\begin{array}{c}23.98 \\
( \pm 12.47)\end{array}$ & $\begin{array}{c}8.05 \\
( \pm 9.12)\end{array}$ & $\leq 0.001$ & 0.290 \\
\hline Bicep & $\begin{array}{c}8.34 \\
( \pm 7.28)\end{array}$ & $\begin{array}{c}10.59 \\
( \pm 10.22)\end{array}$ & $\begin{array}{c}15.05 \\
( \pm 14.45)\end{array}$ & $\leq 0.001$ & $\begin{array}{c}4.324 \\
( \pm 2.418)\end{array}$ & $\begin{array}{c}1.823 \\
( \pm 1.020)\end{array}$ & $\begin{array}{c}15.55 \\
( \pm 6.54)\end{array}$ & $\begin{array}{c}6.281 \\
( \pm 3.063)\end{array}$ & $\begin{array}{c}28.66 \\
( \pm 9.93)\end{array}$ & $\leq 0.001$ & 0.141 \\
\hline Tricep & $\begin{array}{c}4.863 \\
( \pm 4.478)\end{array}$ & $\begin{array}{c}7.16 \\
( \pm 6.70)\end{array}$ & $\begin{array}{c}10.32 \\
( \pm 8.67)\end{array}$ & $\leq \mathbf{0 . 0 0 1}$ & $\begin{array}{c}2.706 \\
( \pm 2.004)\end{array}$ & $\begin{array}{c}16.45 \\
( \pm 9.70)\end{array}$ & $\begin{array}{c}3.867 \\
( \pm 2.336)\end{array}$ & $\begin{array}{c}9.70 \\
( \pm 5.40)\end{array}$ & $\begin{array}{c}5.136 \\
( \pm 2.471)\end{array}$ & $\leq 0.001$ & 0.022 \\
\hline Latissimus dorsi & $\begin{array}{c}7.824 \\
( \pm 6.015)\end{array}$ & $\begin{array}{c}10.516 \\
( \pm 6.271)\end{array}$ & $\begin{array}{c}15.26 \\
( \pm 9.22)\end{array}$ & $\leq 0.001$ & $\begin{array}{c}13.16 \\
( \pm 8.18)\end{array}$ & $\begin{array}{c}12.27 \\
( \pm 7.86)\end{array}$ & $\begin{array}{c}4.697 \\
( \pm 1.626)\end{array}$ & $\begin{array}{c}13.20 \\
( \pm 8.95)\end{array}$ & $\begin{array}{c}12.68 \\
( \pm 7.39)\end{array}$ & $\leq 0.001$ & 0.262 \\
\hline Total NMAV & $\begin{array}{c}75.76 \\
( \pm 50.41)\end{array}$ & $\begin{array}{c}102.0 \\
( \pm 66.9)\end{array}$ & $\begin{array}{c}138.9 \\
( \pm 89.7)\end{array}$ & $\leq 0.001$ & $\begin{array}{c}47.23 \\
( \pm 17.50)\end{array}$ & $\begin{array}{c}65.94 \\
( \pm 29.73)\end{array}$ & $\begin{array}{c}50.82 \\
( \pm 18.76)\end{array}$ & $\begin{array}{c}180.7 \\
( \pm 66.0)\end{array}$ & $\begin{array}{c}183.0 \\
( \pm 51.9)\end{array}$ & $\leq 0.001$ & $\leq 0.001$ \\
\hline
\end{tabular}



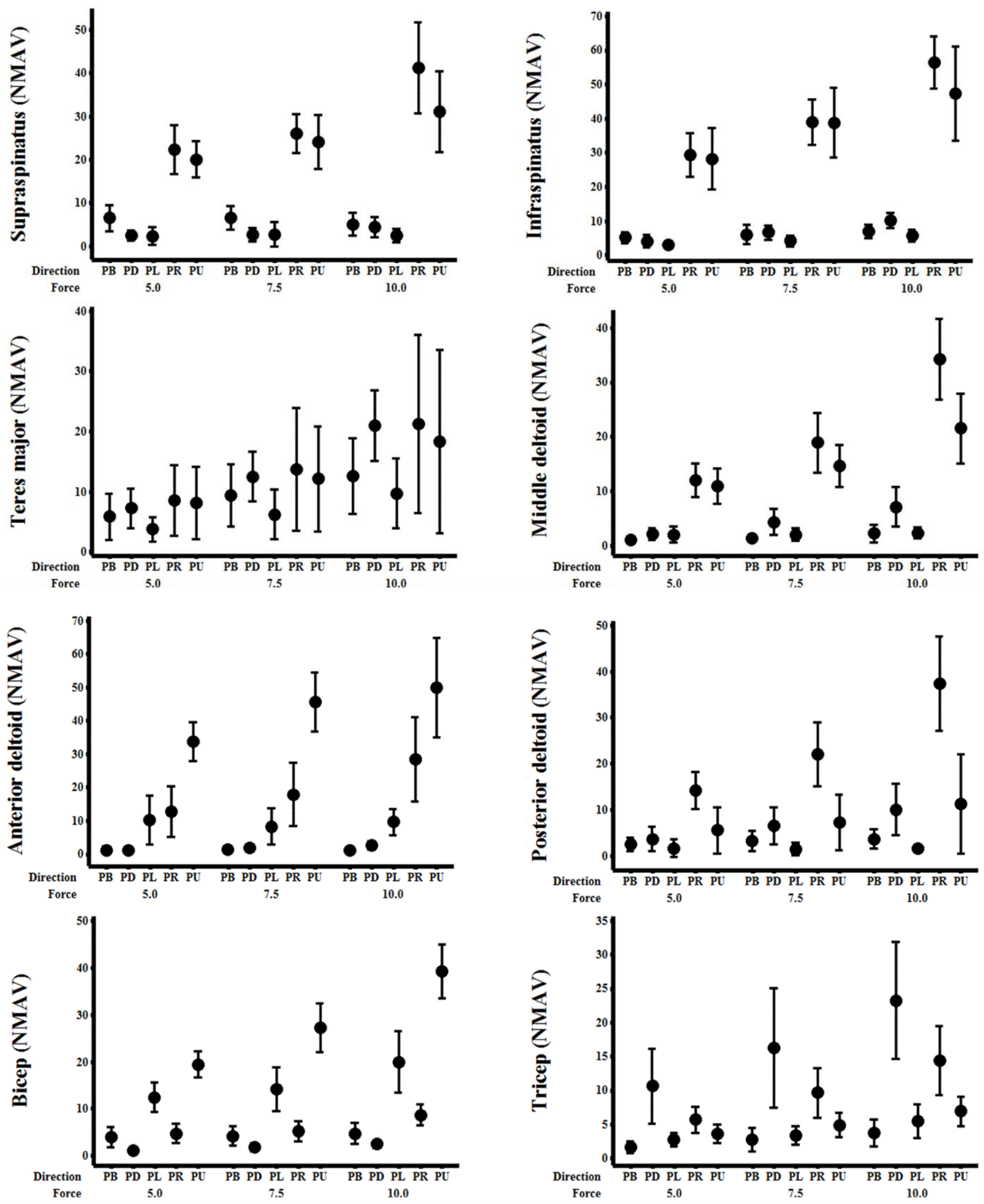

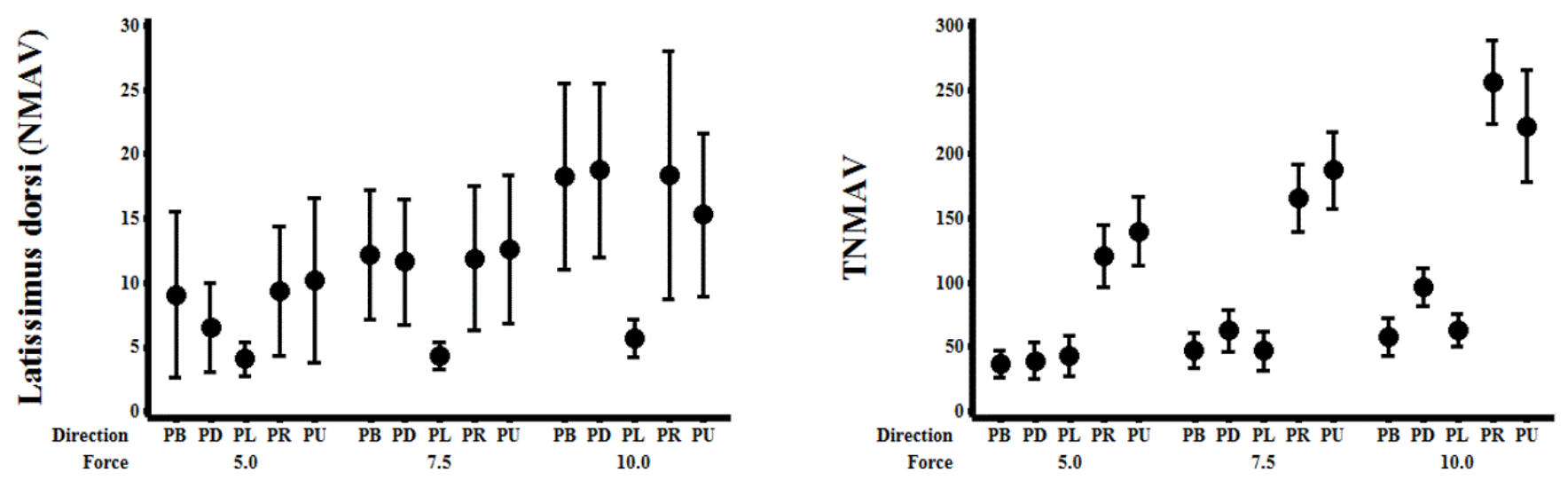

Figure 11: Raw data charts normalized mean absolute values. Error bars represents standard deviation. 


\section{Chapter 6: Discussion and Conclusion}

In this study, the activation pattern of the shoulder muscles was examined using SEMG under different force exertion demands. We suspected that shoulder muscles' attempt to stabilize the GHJ using concavity compression may explain the differences in muscle activation pattern during arm exertions. The results indicate that the level of force exertion had an effect on the muscle activation pattern. The $5 \mathrm{lbs}$. force level had the smallest effect on muscle activation and fatigability, followed by the $7.5 \mathrm{lbs}$. force level. The $10 \mathrm{lbs}$. force level had the highest effect on muscle activation and fatigability. In fact, several of the participants could not complete all $10 \mathrm{lbs}$. force level exertions trials. The discomfort ratings were also affected by the level of force exertion. The 5 lbs. force level had the smallest effect on discomfort rating, followed by the $7.5 \mathrm{lbs}$. force level. The $10 \mathrm{lbs}$. force level had the highest effect on discomfort ratings.

The results also indicate that the direction of force exertion had an effect on the muscle activation pattern. The PB and PL directions of force exertion had the smallest effect on muscle activation, followed by the PD direction. The PR and PU directions of force exertion had the largest effect on muscle activation. In addition, the directions of force exertion had an effect on muscle fatigability. The PB direction of force exertion had the smallest effect on muscle fatigability, followed by the PD and PL directions. The PR and PU directions of force exertion had the highest effect on muscle fatigability. In fact, several of the participants could not complete all PR and PU direction force exertion trials. The discomfort ratings were also affected by the direction of force exertion. The PB and PL directions of force exertion had the smallest effect on discomfort rating, followed by the PD direction. The PR and PU directions of force exertion had 
the highest effect on discomfort rating. The interaction between direction and level of force exertion was also significant for the muscle activation, muscle fatigability, and discomfort rating.

High muscles activation on PR and PU directions were common in both rotator cuff muscles and non-rotator cuff muscles. Among rotator cuff muscles, PR and PU directions caused the highest muscle activation for all force levels. On the other hand, PB, PD and PL caused almost the same lower muscle activation for all force levels. In $10 \mathrm{lbs}$. force level, supraspinatus and infraspinatus muscle activation at PR and PU directions was higher than muscle activation at PB, PD and PL directions by a range of $350 \%$ to $500 \%$. In addition to PR and PU directions, PD direction caused high muscle activation for teres major muscle. Teres major muscle activation in PR, PU and PD force directions and $10 \mathrm{lbs}$ force levels increased by $100 \%$ compared to the muscle activation in PR, PU and PD directions and the $5 \mathrm{lbs}$. force level. Among non-rotator cuff muscles, PR and PU directions (or at least one of them) caused the highest muscle activation for all force levels. On the other hand, PB, PD, PL caused in general the lowest muscle activation for all force levels. In 10 lbs. force level, middle deltoid and anterior deltoid muscle activation at PR and PU directions was higher than muscle activation at PB, PD and PL directions by a range of $200 \%$ to 500\%. Posterior deltoid muscle activation at PR direction was higher than muscle activation at PB, PD, PL and PU directions by 300\%. For bicep and tricep muscles, muscle activation was high at PU and PD directions, respectively. And it was higher than muscle activation at other force directions by $150 \%$. Latissimus dorsi muscle activation was the same for all directions except the PL direction. Findings of study, in terms of muscle activation for different direction is comparable with a study performed by Arwert et al., 1997. Similar to our findings Arwert et al., (1997) also reported the highest activation of teres major and latissimus dorsi muscles in pulling down direction. On the other hand, Arwert et al., (1997) found that supraspinatus' highest activation 
was in pulling up direction compared to the pulling right direction found in our study. Also, they found that infraspinatus was activated in all direction and in our study, infraspinatus was found to be mainly activated in pulling up and pulling right directions. This difference in experimental setup could be the reason for this. In the study performed by Arwert et al., (1997), they did not use a hand grip instead they directly connected strain-gauge two-dimensional force transducer to participants' elbow.

Similarly, high muscles fatigability on PR and PU directions were common in both rotator cuff muscles and non-rotator cuff muscles. Among rotator cuff muscles, PR and PU directions caused the highest muscles fatigue for all force levels. On the other hand, in general PB, PD and PL caused almost the same small muscles fatigue for all force levels. In $10 \mathrm{lbs}$. force level, supraspinatus and teres major muscles fatigue at PR and PU directions was higher than PB, PL and PD directions by a range of $100 \%$ to $200 \%$. For infraspinatus muscle, PL, PR and PU directions was higher than PB and PD directions by 200\%. Among non-rotator cuff muscles, PR and PU directions (or at least one of them) caused the highest negative slope for all force levels. On the other hand, PB, PD, PL caused in general the small negative slope for all force levels. middle deltoid, posterior deltoid and tricep muscles fatigue at PR direction was higher than PB, PL, PD and PU directions by $200 \%$. For anterior deltoid, muscle fatigue at PR and PU directions was higher than PB, PL and PD directions by a range of $100 \%$ to $200 \%$. Finally, latissimus dorsi muscle fatigue in PU direction was higher than PB, PL, PD and PR directions by $200 \%$.

The alternate hypotheses tested in this study were based on a biomechanical modelling study performed by Cutlip (2014). When the biomechanical results were compared with the physiological result from this study, they are found to be in good agreement. The results in Cutlip (2014) were that the PL exertion direction had the highest muscle biomechanical demand followed 
by the PU and PL directions. The lowest muscle biomechanical demand was observed in the PD and PB directions. The relationship between the direction of force exertion and muscle fatigability was also affected by the level of force exertion.

It is clear that the PR and PU exertion directions had the highest muscle activation and caused the largest negative slopes. In the PR and PU directions, rotator muscles have to resist the translational forces which push the humeral head away from the glenoid fossa to facilitate concavity compression. In other words, while participants were trying to pull in left direction, the reaction forces pushed their humeral head away from the glenoid fossa. To prevent joint instability, rotator cuff muscles contribute to pulling the humeral head back to the glenoid fossa. Blasier et al. (1992) reported that each of the rotator cuff muscles significantly contributed to GHJ stability, with no significant difference between one another.

Rotator cuff muscles in the PR and PU directions had higher muscle activation compared to other directions of force exertion at the same force level. It is well-known that glenohumeral joint stability is a primary job for the supraspinatus and infraspinatus muscles; therefore, in order to maintain joint stability and to contribute to concavity compression, muscle activity is expected to increase with hand exertions. Sigholm et al. (1984) and Sporrong et al. $(1995,1996)$ had similar findings regarding the supraspinatus and infraspinatus muscle activation during hand exertions. In Sporrong et al. $(1995,1996)$, it was observed that hand gripping significantly increased the activity of the supraspinatus muscle in humeral flexion from and above $60^{\circ}$. A similar, but lesser, increase was observed for the infraspinatus muscle. However, in the latter case there were no signs of muscles fatigue during hand gripping tasks.

Some of the non-rotator cuff muscle such as middle deltoid and posterior deltoid muscles had high muscle activation and exhibited the largest negative slopes in the PR and PU exertion 
directions. However, the anterior deltoid's largest muscle activation and largest negative slope were in the PU direction. The activation of deltoid muscle was affected by the exertion direction, and thus contributed to concavity compression in stabilizing the GHJ. This is in agreement with the findings of Sigholm et al. (1984). They found that, while holding a $2 \mathrm{~kg}$ load in the shoulder abduction posture or shoulder flexion posture, deltoid muscle activity increased. Even though the deltoid muscles play an important role in shoulder abduction (Kronberg et al., 1990), they also contribute to GHJ stability, especially the middle deltoid and posterior deltoid muscles. On the other hand, some studies have found a muscle activity reduction for deltoid muscles in correlation with the increase in infraspinatus muscle activity (MacDonell and Keir, 2005). However, those previous studies tested the muscles in different shoulder flexion angles and/or different shoulder abduction angles, which could affect the muscle activation (Sporrong et al., 1996). Also, bicep muscle activation in the PR direction supports the findings of Itoi et al. (1993). They found that biceps brachii muscle activity could also assist in GHJ stability.

The action of shoulder muscles can be characterized into three vectors which are compressive force, anterior-posterior shear force and superior-inferior shear force. Despite the fact that compressive forces work to push the humeral head into the glenoid fossa for stabilizing the GHJ, anterior-posterior shear force and superior-inferior shear force can contribute to stabilize the GHJ or destabilize it (Labriola et al., 2005). That means that not all activated muscles in pulling up and pulling right directions are contributed in GHJ stability. Some of shoulder muscles may be considered as destabilized muscles such as deltoid muscles. Lee and An (2002), have found out that deltoid muscle activity contributes to GHJ stability based on shoulder abduction plane. Deltoid muscle activity contributed to increase GHJ stability in a 60 degree of shoulder abduction in mid-sagittal frontal plane. On the other hand, deltoid muscle activity contributed to 
decrease GHJ stability in a 60 degree of shoulder abduction in the frontal plane. Labriola et al., (2005) studied the contribution of individual shoulder muscle in GHJ stability by using a model. When supraspinatus, infraspinatus, or teres minor muscles magnitude was increased, the action vectors were less anteriorly directed, which contribute to improve GHJ stability. On the other hand, GHJ stability tend to decrease when activation vector was more anteriorly directed with increases in deltoid muscle activation. However, subscapularis, teres major and latissimus dorsi muscles had no effects on activation vector for the resultant force.

The highest fatigue for all muscles was found to be in PR and PU exertion directions at the $10 \mathrm{lbs}$. force level, where the negative slope value was equal to -11 . This was followed by the PR and PU exertion directions and the 7.5 lbs. force level, which produced a negative slope value of -6. The slope values for other exertion directions at the $10 \mathrm{lbs}$. force level were almost the same as the slope value in the PR and PU exertion directions at the $5 \mathrm{lbs}$. force level, which was equal to -4. The slope value for the PD and PL exertion directions at the $10 \mathrm{lbs}$. force level was equal to -3 , followed by the PB exertion direction at the $10 \mathrm{lbs}$. force level, which had a negative slope value equal to -1 . In addition, the highest fatigue for a specific muscle found was for the teres major. The slope value for the teres major was roughly equal to -2 for interactions at both the PR and PU exertion directions at the $10 \mathrm{lbs}$. force level. This was followed by the infraspinatus muscle's slope value, which was approximately equal to -1.75 for interactions in the PL, PR and PU exertion directions at the $10 \mathrm{lbs}$. force level. The middle deltoid, posterior deltoid and tricep had their highest negative slope value (-1.5) in the PR exertion direction at the $10 \mathrm{lbs}$. force level. For the tricep, the slope value for the PD exertion direction at the $10 \mathrm{lbs}$. force level was equal to -0.8 , smaller than the PR and PU fatigues. This means that, even though muscles exert more in other directions, the PR and PU directions had the highest fatigability. The anterior deltoid and 
latissimus dorsi had almost the same negative slope values, at -1.5 and -1.1 respectively, for the PR exertion direction at the $10 \mathrm{lbs}$. force level.

A relationship was found between muscle fatigability and MVC in different directions for several of the muscles. However, fatigability cannot be predicted based on muscle activation. For example: the posterior deltoid muscle had the highest negative slope value for the PR direction, followed by the PU direction. At the same time, this muscle had the highest muscle activity in the PR direction, followed by the PU direction. On the other hand, the tricep muscle had the highest negative slope value in the PR direction, followed by the PU direction, but it had the highest muscle activity in the PD direction.

A relationship was also found between subjective (discomfort) and objective (EMG) data. Participants' discomfort ratings supported both the muscle activation and fatigability results, and they considered the PR and PU directions at the $10 \mathrm{lbs}$. force level to be the most strenuous exertion. In fact, some of the participants could not complete some of the PR and PU direction force exertion trials. The PR and PU directions at the $7.5 \mathrm{lbs}$. force level were considered to be the second most strenuous exertions. Furthermore, participants' discomfort ratings show that the $\mathrm{PD}$ and PL directions at the $10 \mathrm{lbs}$. force level and the PR and PU directions at the $5 \mathrm{lbs}$. force level produced almost the same level of discomfort. A similar finding was made in muscle activation and fatigability results.

In occupational application, an MVC of $30 \%$ or more is considered to be occupationally hazardous. Only two exertion directions resulted in this level of activation. The PR and PU exertion directions had $30 \%$ muscle activation or more, and can thus be considered the most hazardous directions. In the PR direction at the $10 \mathrm{lbs}$. force level, the supraspinatus, infraspinatus, middle deltoid and posterior deltoid muscles exert more than $30 \%$ MVC. In the PU direction at 
$10 \mathrm{lbs}$. force level, the supraspinatus, infraspinatus and bicep muscles exert more than 30\% MVC. In the PU direction at each of the force levels, the anterior deltoid muscles exert more than $30 \%$ MVC. In the PR and PU directions at the $7.5 \mathrm{lbs}$. force level, the infraspinatus muscle exerted more than $30 \%$ MVC.

Muscle co-contraction improves joint stability in the human body, especially during in dynamic force exertions (Xu, 2014). Some studies (Van der Helm, 1994; Happee and Van der Helm, 1995) indicate that the concavity compression mechanism in the GHJ is basically muscle co-contraction, particularly when the reaction/resultant force of shoulder muscles is pushing the humeral head to the glenoid fossa to stabilize the GHJ and prevent it from dislocating. Forster et al. (2004) define muscle co-contraction as the occurrence of antagonistic muscle activity. The activity of agonist and antagonistic muscle groups and arm abduction angle play important roles in muscle co-contraction during dynamic exertions; however, the shoulder elevation plane has no influence on muscle co-contraction (Xu et al., 2014; Antony et al., 2010). Muscle co-contraction is hard to predict in static muscle exertions and therefore cannot be used to explain findings of this current study. 


\subsection{Future work and limitation}

Shoulder muscles' action can be characterized into three vectors which are compressive force, anterior-posterior shear force and superior-inferior shear force. The compressive forces work to push the humeral head into the glenoid fossa for stabilizing the GHJ. Future studies should investigate the exact compressive forces direction that provide GHJ stability by pushing glenhumeral head to the glenoid fossa.

One of the limitation we had in this study is gender diversity. Only male participants were used for data collection in this study. Inclusion of female participant could provide additional insight into the gender specific strategies used by the shoulder muscles to stabilize the joint. Resting time of 2 minutes was provided between trials. It is possible that 2 minutes may not have been enough for participants to fully recover from the preceding exertion. Future studies should better control/study the effect of gender and rest period on fatigability and overall stability of the shoulder complex. 


\section{References:}

Bureau, U. S., \& Statistics, L. (2014). Occupational Injuries and Illnesses: a pilot study of jobtransfer or work-restriction cases, 2012, (April), 1-38.

Warnken, B. (2012). The Comp Pinkbook. Maryland: 27Legal, LLC (2012).

Garg, A., Hegmann, K., \& Kapellusch, J. (2006). Short-cycle overhead work and shoulder girdle muscle fatigue. International Journal of Industrial Ergonomics, 36(6), 581-597. http://doi.org/10.1016/j.ergon.2006.02.002

Alizadehkhaiyat, O., Fisher, A. C., Kemp, G. J., Vishwanathan, K., \& Frostick, S. P. (2011). Shoulder muscle activation and fatigue during a controlled forceful hand grip task. Journal of Electromyography and Kinesiology, 21(3), 478-482.

http://doi.org/10.1016/j.jelekin.2011.03.002

Cutlip, K., (2014). Stability of the Shoulder Complex during Manual Exertions Engineering and Mineral Resources at Stability of the Shoulder Complex during Manual Exertions, (August) Masters' Thesis, IMSE Department, WVU.

Müntener, M. (1982). Functional anatomy of the shoulder girdle. Helvetica Chirurgica Acta, 48(5), 523-532. http://doi.org/10.2519/jospt.1993.18.1.342

Escamilla, R. F., Yamashiro, K., Paulos, L., \& Andrews, J. R. (2009). Shoulder muscle activity and function in common shoulder rehabilitation exercises. Sports Medicine, 39(8), 663-685. http://doi.org/10.2165/00007256-200939080-00004

Lugo, R., Kung, P., \& Ma, C. B. (2008). Shoulder biomechanics. European Journal of Radiology, 68(1), 16-24. http://doi.org/10.1016/j.ejrad.2008.02.051

Wuelker, N., korell, M. S., \& Thren, K. (1998). Dynamic glenohumeral Shoulder and Elbow Surgery Board of Trustees 7(1), 43-52.

Itoi, E., Kuechle, D. K., Newman, S. R., Morrey, B. F., \& An, K. N. (1993). Stabilising function of the biceps in stable and unstable shoulders. The Journal of Bone and Joint Surgery. British Volume, 75(4), 546-550.

Lee, H. (2003). Evaluation of shoulder proprioception following muscle fatigue, 18, 843-847. http://doi.org/10.1016/S0268-0033(03)00151-7

Sporrong, H., Palmerud, G., \& Herberts, P. (1995). Influences of handgrip on shoulder muscle activity. European Journal of Applied Physiology and Occupational Physiology, 71(6), 485-492. http://doi.org/10.1007/BF00238549 
Sporrong, H., Palmerud, G., \& Herberts, P. (1996). Hand grip increases shoulder muscle activity, An EMG analysis with static hand contractions in 9 subjects. Acta Orthopaedica Scandinavica, 67(5), 485-490. http://doi.org/10.3109/17453679608996674

Antony, N. T., \& Keir, P. J. (2010). Effects of posture, movement and hand load on shoulder muscle activity. Journal of Electromyography and Kinesiology, 20(2), 191-198. http://doi.org/10.1016/j.jelekin.2009.04.010

Brookham, R. L., Wong, J. M., \& Dickerson, C. R. (2010). Upper limb posture and submaximal hand tasks influence shoulder muscle activity. International Journal of Industrial Ergonomics, 40(3), 337-344. http://doi.org/10.1016/j.ergon.2009.11.006

Takala, E. P., Nieminen, H., \& Lammi, H., (1993). Electromographic changes in the static holding test of the arm. International Journal of Industrial Ergonomics, 12, 85-90.

Minning, S., Eliot, C. a., Uhl, T. L., \& Malone, T. R. (2007). EMG analysis of shoulder muscle fatigue during resisted isometric shoulder elevation. Journal of Electromyography and Kinesiology, 17(2), 153-159. http://doi.org/10.1016/j.jelekin.2006.01.008

Arwert, H. J., de Groot, J., Van Woensel, W. W., \& Rozing, P. M. (n.d.). Electromyography of shoulder muscles in relation to force direction. Journal of Shoulder and Elbow Surgery / American Shoulder and Elbow Surgeons ... [et Al.], 6(4), 360-370. http://doi.org/10.1016/S1058-2746(97)90004-5

Kai, Y., Gotoh, M., Nagata, K., \& Shiba, N. (2012). Infraspinatus fatigue during resisted arm elevation with isometric contraction: An electromyographic study. Journal of Shoulder and Elbow Surgery, 21(8), 1104-1109. http://doi.org/10.1016/j.jse.2011.07.021

Acierno, S.P., Baratta, R.V., and Solomonow, M., (1995). A practical guide to electromyography for biomechanics. Louisiana State University.

Hawkes, D. H., Alizadehkhaiyat, O., Kemp, G. J., Fisher, a. C., Roebuck, M. M., \& Frostick, S. P. (2015). Electromyographic assessment of muscle fatigue in massive rotator cuff tear. Journal of Electromyography and Kinesiology, 25(1), 93-99. http://doi.org/10.1016/j.jelekin.2014.09.010

Dedering, Å., Németh, G., \& Harms-Ringdahl, K. (1999). Correlation between electromyographic spectral changes and subjective assessment of lumbar muscle fatigue in subjects without pain from the lower back. Clinical Biomechanics, 14(2), 103-111. http://doi.org/10.1016/S0268-0033(98)00053-9

Strimpakos, N., Georgios, G., Eleni, K., Vasilios, K., \& Jacqueline, O. (2005). Issues in relation to the repeatability of and correlation between EMG and Borg scale assessments of neck muscle fatigue. Journal of Electromyography and Kinesiology: Official Journal of the International Society of Electrophysiological Kinesiology, 15(5), 452-65. http://doi.org/10.1016/j.jelekin.2005.01.007 
Hummel, a, Läubli, T., Pozzo, M., Schenk, P., Spillmann, S., \& Klipstein, a. (2005).

Relationship between perceived exertion and mean power frequency of the EMG signal from the upper trapezius muscle during isometric shoulder elevation. European Journal of Applied Physiology, 95(4), 321-6. http://doi.org/10.1007/s00421-005-0014-7

Oliveira, A. D. S. C., \& Gonçalves, M. (2009). EMG amplitude and frequency parameters of muscular activity: effect of resistance training based on electromyographic fatigue threshold. Journal of Electromyography and Kinesiology: Official Journal of the International Society of Electrophysiological Kinesiology, 19(2), 295-303. http://doi.org/10.1016/j.jelekin.2007.07.008

Sigholm, G., Herberts, P., Almström, C., \& Kadefors, R. (1984). Electromyographic analysis of shoulder muscle load. Journal of Orthopaedic Research : Official Publication of the Orthopaedic Research Society, 1(4), 379-86. http://doi.org/10.1002/jor.1100010406

Kronberg M, Nemeth G, Brostrom LA. Muscle activity and coordination in the normal shoulder. An electromyographic study. Clin Orthop Relat Res 1990;257:76-85.

MacDonell, C. W., \& Keir, P. J. (2005). Interfering effects of the task demands of grip force and mental processing on isometric shoulder strength and muscle activity. Ergonomics, 48(15), 1749-1769. http://doi.org/10.1080/00140130500319757

Blasier, R. B. (1992). Anterior shoulder stability: Contributions of rotator cuff forces and the capsular ligaments in a cadaver model. Journal of shoulder and elbow surgery, 1(3), 140150.doi:10.1016/1058-2746(92)90091-G

Labriola, J. E., Lee, T. Q., Debski, R. E., \& McMahon, P. J. (2005). Stability and instability of the glenohumeral joint: the role of shoulder muscles. Journal of Shoulder and Elbow Surgery / American Shoulder and Elbow Surgeons ... [et Al.], 14(1 Suppl S), 32S-38S. http://doi.org/10.1016/j.jse.2004.09.014

Lee SB, An KN. Dynamic glenohumeral stability provided by three heads of the deltoid muscle. Clin Orthop 2002;400:40-7.

Xu, X., McGorry, R. W., \& Lin, J. H. (2014). A regression model predicting isometric shoulder muscle activities from arm postures and shoulder joint moments. Journal of Electromyography and Kinesiology, 24, 419-429. http://doi.org/10.1016/j.jelekin.2014.02.004

Van der Helm, F.C.T., 1994. Analysis of the kinematic and dynamic behaviour of the shoulder mechanism. J. Biomech. 27, 527-550.

Happee, R., Van der Helm, F.C.T., 1995. The control of shoulder muscles during goal directed movements, an inverse dynamic analysis. J. Biomech. 28, 1179-1191. 
Forster, E., Simon, U., Augat, P., \& Claes, L. (2004). Extension of a state-of-the-art optimization criterion to predict co-contraction. Journal of Biomechanics, 37(4), 577-581. http://doi.org/10.1016/j.jbiomech.2003.09.003 
Appendix A: PAR-Q 
(A Questionnaire for People Aged 15 to 69)

Regular physical activity is fun and healthy, and increasingly more people are starting to become more active every day. Being more active is very safe for most people. However, some people should check with their doctor before they start becoming much more physically active.

If you are planning to become much more physically active than you are now, start by answering the seven questions in the box below. If you are between the ages of 15 and 69 , the PAR-Q will tell you if you should check with your doctor before you start. If you are over 69 years of age, and you are not used to being very active, check with your doctor.

Common sense is your best guide when you answer these questions. Please read the questions carefully and answer each one honestly: check YES or NO.

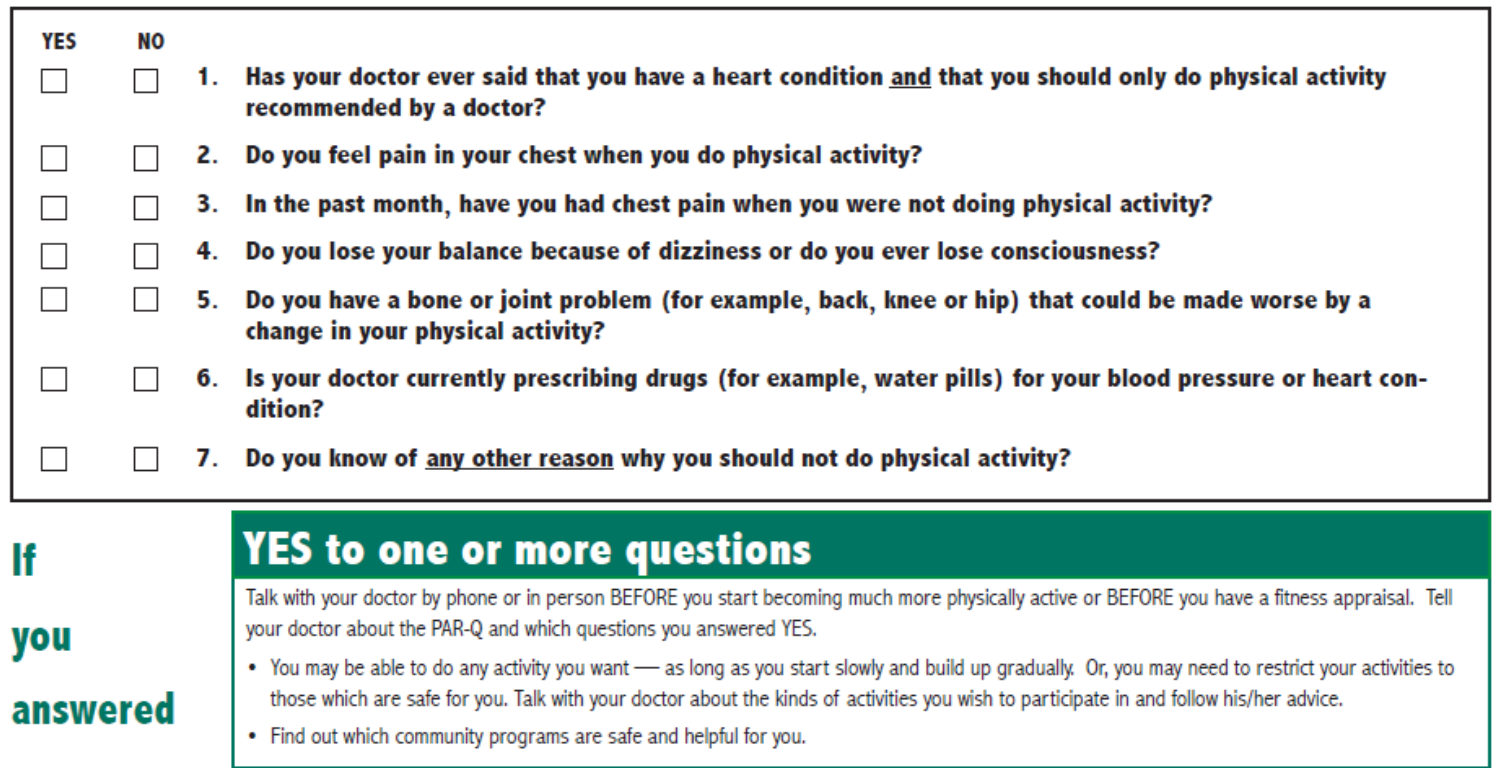

\section{NO to all questions}

If you answered NO honestly to all PAR-Q questions, you can be reasonably sure that you can: - start becoming much more physically active - begin slowly and build up gradually. This is the safest and easiest way to go.

- take part in a fitness appraisal - this is an excellent way to determine your basic fitness so that you can plan the best way for you to live actively. It is also highly recommended that you have your blood pressure evaluated. If your reading is over $144 / 94$, talk with your doctor before you start becoming much more physically active.
DELAY BECOMING MUCH MORE ACTIVE:

- if you are not feeling well because of a temporary illness such as a cold or a fever - wait until you feel better; or

- if you are or may be pregnant - talk to your doctor before you start becoming more active.

PLEASE NOTE: If your health changes so that you then answer YES to any of the above questions, tell your fitness or health professional. Ask whether you should change your physical activity plan.

Informed Use of the PAR-Q: The Canadian Society for Exercise Physiology, Health Canada, and their agents assume no liability for persons who undertake physical activity, and if in doubt after completing this questionnaire, consult your doctor prior to physical activity

No changes permitted. You are encouraged to photocopy the PAR-Q but only if you use the entire form.

NOTE: If the PAR-Q is being given to a person before he or she participates in a physical activity program or a fitness appraisal, this section may be used for legal or administrative purposes.

"I have read, understood and completed this questionnaire. Any questions I had were answered to my full satisfaction."

NAME

SIGNATURE

SIGNATURE OF PARENT

or GUARDIAN (for participants under the age of majority)

DATE

WTTNESS

Note: This physical activity clearance is valid for a maximum of $\mathbf{1 2}$ months from the date it is completed and becomes invalid if your condition changes so that you would answer YES to any of the seven questions. 


\section{Appendix B: Consent Form}




\title{
Only Minimal Risk Consent Information and HIPAA Form
}

\author{
Principal Investigator \\ Dr. Ashish Nimbarte \\ Department \\ ENGINEERING-Industrial and Management Systems Engineering \\ Protocol Number \\ 1511900923 \\ Study Title \\ Effect of force and direction on shoulder complex \\ Co-Investigator(s) \\ Hamad Alasim \\ Sponsor (if any) \\ N/A
}

\section{Contact Persons}

In the event you experience any side effects or injury related to this research, you should contact Dr. Ashish Nimbarte at (304) 293-9473. If you have any questions, concerns, or complaints about this research, you can contact Dr. Ashish Nimbarte (304)293-9473.

For information regarding your rights as a research subject, to discuss problems, concerns, or suggestions related to the research, to obtain information or offer input about the research, contact the Office of Research Compliance at (304) 293-7073.

In addition, if you would like to discuss problems, concerns, have suggestions related to research, or would like to offer input about the research, contact the Office of Research Integrity and Compliance at 304-293-7073.

\section{Introduction}

You, , have been asked to participate in this research study, which has been explained to you by Mr. Hamad. This study is being conducted by Dr. Ashish Nimbarte (PhD) and Hamad Alasim in the Department of Industrial and Management System Engineering at West Virginia University.

\section{Purpose(s) of the Study}

The purpose of this study is to find out if static hand load exertions in five different directions, which are front, right, left, up and down direction, can develop shoulder fatigue and shoulder instability.

\section{Description of Procedures}

Upon arrival, the procedures of the experiment will be explained to you in detail and you will be asked to sign an informed consent form. Next, basic anthropometric data including age, body weight, height and elbow height will be measured. You will be then given a 10 minutes training session in order to become familiar with the tasks to be performed and also to warm-up your shoulder muscles. Surface EMG electrodes will be placed over the skin at the following muscles: supraspinatus, infraspinatus, teres major, anterior deltoid, middle deltoid, posterior deltoid, biceps and triceps. You will

be asked to perform maximum voluntary contraction (MVC) exertions in order to measure the maximum exertion using EMG from all selected muscles. Each maximum voluntary contraction trial will be five seconds long and a one-minute rest 
period will be provided between exertions in order to reduce the chance of fatigue and injury. Then you will move to the testing area and perform designated tasks. In each trial you are required to hold a D-shape handle attached to one of the weight levels which are $\left(10,7.5,5 \mathrm{lb}\right.$.) for 60 second with a $15^{\circ}-20^{\circ}$ flexed elbow joint and a $70^{\circ}-80^{\circ}$ flexed shoulder joint. You will perform this task in five different directions which are right, left, front, up and down. Each trial will have two repetitions. A 3 minutes' rest time is will be provided between trials. A total of 30 trials will be performed. After the completion of each task, you will be asked to numerically rate your perceived exertion caused by the hand load exertion using Borg's CR-10 scale. The Borg CR-10 scale contains two columns, one for subjective categories ranging from "nothing at all" to "extremely strong" and the other for numerical ratios ranging on a scale of 0 to 10 that are associated with the different categories. The purpose of performing static hand load exertions during those trials was to generate fatigue in the shoulder muscles. During performing static hand load exertions, you will be seated in the wooden chair in upright position and buckle up with the four-point harness to prevent any upper body movement which could interfere with the data collection.

\section{Discomforts}

There is a minimal risk for shoulder muscles strain and fatigue while performing the maximum exertions. Therefore, you will be required to complete a warm up before these tasks and sufficient rest between trials.

\section{Alternatives}

You do not have to participate in this study.

\section{Benefits}

You may not receive any direct benefit from this study. The knowledge gained from this study may eventually benefit others.

\section{Financial Considerations}

You will not receive any compensation for participation in the study and will not incur any costs related to the study. It is very important for you to understand that neither the investigator nor WVU or it associated affiliates has the funds set aside to pay for the cost work wages or any care or treatment that might be necessary because you get hurt or sick taking part in this study. Any injuries that may result from this study would not be eligible for workers' Compensation as this is not a job related injury. Understand that any treatments necessary will be billed to the participant or to your personal health insurance, and you may wish to consult your insurance provider before participating in this study.

\section{Confidentiality}

Any information about you that is obtained as a result of your participation in this research will be kept as confidential as legally possible. Your research records and test results, just like hospital records, may be subpoenaed by court order or may be inspected by the study sponsor or federal regulatory authorities (including the FDA if applicable) without your additional consent.

\section{Voluntary Participation}


Participation in this study is voluntary. You are free to withdraw your consent to participate in this study at any time.

Refusal to participate or withdrawal will not affect [your class standing or grades, as appropriate] and will involve no penalty to you. Refusal to participate or withdrawal will not affect your future care, or your employee status at West Virginia University.

In the event new information becomes available that may affect your willingness to participate in this study, this information will be given to you so that you can make an informed decision about whether or not to continue your participation.

You have been given the opportunity to ask questions about the research, and you have received answers concerning areas you did not understand.

Upon signing this form, you will receive a copy.

I willingly consent to participate in this research.

\section{Signatures}

Signature of Subject

$\begin{array}{lll}\text { Printed Name } & \text { Date Time }\end{array}$

The participant has had the opportunity to have questions addressed. The participant willingly agrees to be in the study.

Signature of Investigator or Co-Investigator

Printed Name

Date

Time 


\section{West VrrginiaUniversity. \\ Office of Research Integrity and Compliance \\ 836 CHESNUT RIDEE ROND MOAGANTOWN, WV 25606}

\section{Approval Letter Expedited}

\section{Action Date}

To

From

Approval Date

Expiration Date

Subject

Protocol Number

Title
02/02/2016

Ashish Nimbarte

WVU Office of Research Integrity and Compliance

02/02/2016

02/01/2017

Protocol Approval Letter

1511900923

Effect of Force and Direction on shoulder Complex

The above-referenced research study was reviewed by the West Virginia University Institutional Review Board IRB and was approved in accordance with 46 CFR 46.101b.

It has been determined that this study is of minimal risk and meets the criteria as defined by the expedited categories listed below:

- Category 4. Collection of data through noninvasive procedures (not involving general anesthesia or sedation) routinely employed in clinical practice, excluding procedures involving x-rays or microwaves. Where medical devices are employed, they must be cleared/approved for marketing. (Studies intended to evaluate the safety and effectiveness of the medical device are not generally eligible for expedited review, including studies of cleared medical devices for new indications.) Examples: (a) physical sensors that are applied either to the surface of the body or at a distance and do not involve input of significant amounts of energy into the subject or an invasion of the subjects privacy; (b) weighing or testing sensory acuity; (c) magnetic resonance imaging; (d) electrocardiography, electroencephalography, thermography, detection of naturally occurring radioactivity, electroretinography, ultrasound, diagnostic infrared imaging, doppler blood flow, and echocardiography; (e) moderate exercise, muscular strength testing, body composition assessment, and flexibility testing where appropriate given the age, weight, and health of the individual.

- Category 7. Research on individual or group characteristics or behavior (including, but not limited to, research on perception, cognition, motivation, identity, language, communication, cultural beliefs or practices, and social behavior) or research employing survey, interview, oral history, focus group, program evaluation, human factors evaluation, or quality assurance methodologies. [NOTE: Some research in this category may be exempt from the DHHS regulations for the protection of human subjects. See Exempt Categories and 45 CFR 46.101(b)(2) and (b)(3). This listing refers only to research that is not exempt.] 
Documents reviewed and/or approved as part of this submission:

Subject Name.pdf: 2016-01-20-05:00

Hamad's Consent OMR pdf: 2016-01-25-05:00

Dear Dr.pdf: 2016-01-25-05:00

Documents for use in this study are available in the WVUkc system in the Notes and Attachments section of your protocol.

The Office of Research Integrity and Compliance is here to provide assistance to you from the initial submission of an IRB protocol and all subsequent activity. Please feel free to contact us by phone at 304.293 .7073 with any question you may have. Thank you.

WVU Office of Research Integrity and Compliance

Date:02/02/2016

Signed:

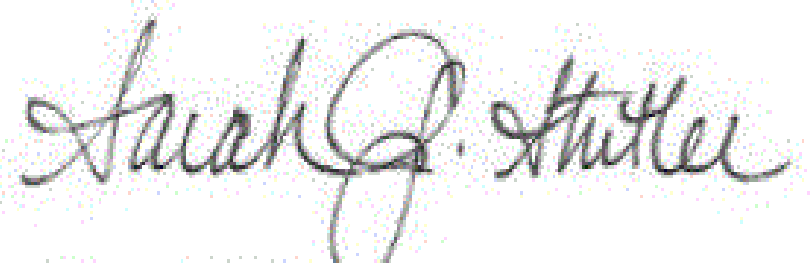

\section{Sarah Stutler \\ IRB Administrator ving regulations apply:}

1. Unanticipated or serious adverse events/side effects encountered in this research study must be reported to the IRB within five (5) days via the Notify IRB action.

2. Any modifications to the study protocol or informed consent form must be reviewed and approved by the IRB prior to implementation via submission of an amendment.

3. You may not use a modified informed consent form until it has been approved and validated by the IRB. 
Appendix C: Borg's CR-10 scale 
Table 27: Borg's CR-10 scale

\begin{tabular}{cc}
\hline Number & Severity \\
\hline $\mathbf{1}$ & Nothing at all \\
$\mathbf{2}$ & Just Noticeable \\
$\mathbf{3}$ & Very Slight \\
$\mathbf{4}$ & Slight \\
$\mathbf{5}$ & Slight Moderate \\
$\mathbf{6}$ & Moderate \\
$\mathbf{7}$ & Some difficulty \\
$\mathbf{8}$ & Moderate Severe \\
$\mathbf{9}$ & Severe \\
$\mathbf{1 0}$ & Very Severe \\
\hline
\end{tabular}


Appendix D: Equality of variance 
Test for Equal Variances: discomfort vs Force, Direction

Multiple comparison intervals for the standard deviation, $\alpha=0.05$

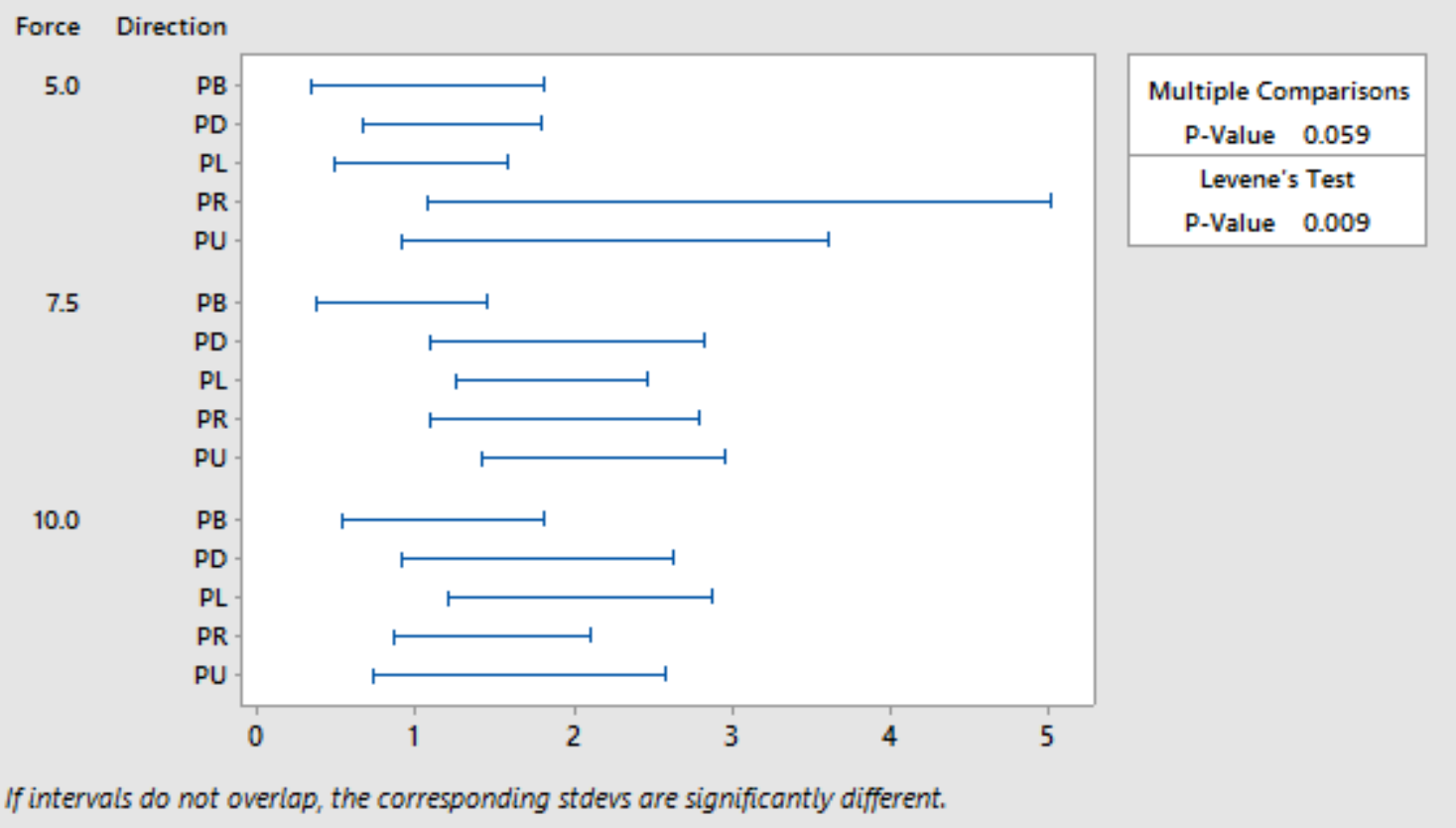

Equality of variance test for discomfort rating

\section{Test for Equal Variances: Supraspinatus vs Force, Direction}

Multiple comparison intervals for the standard deviation, $\alpha=0.05$

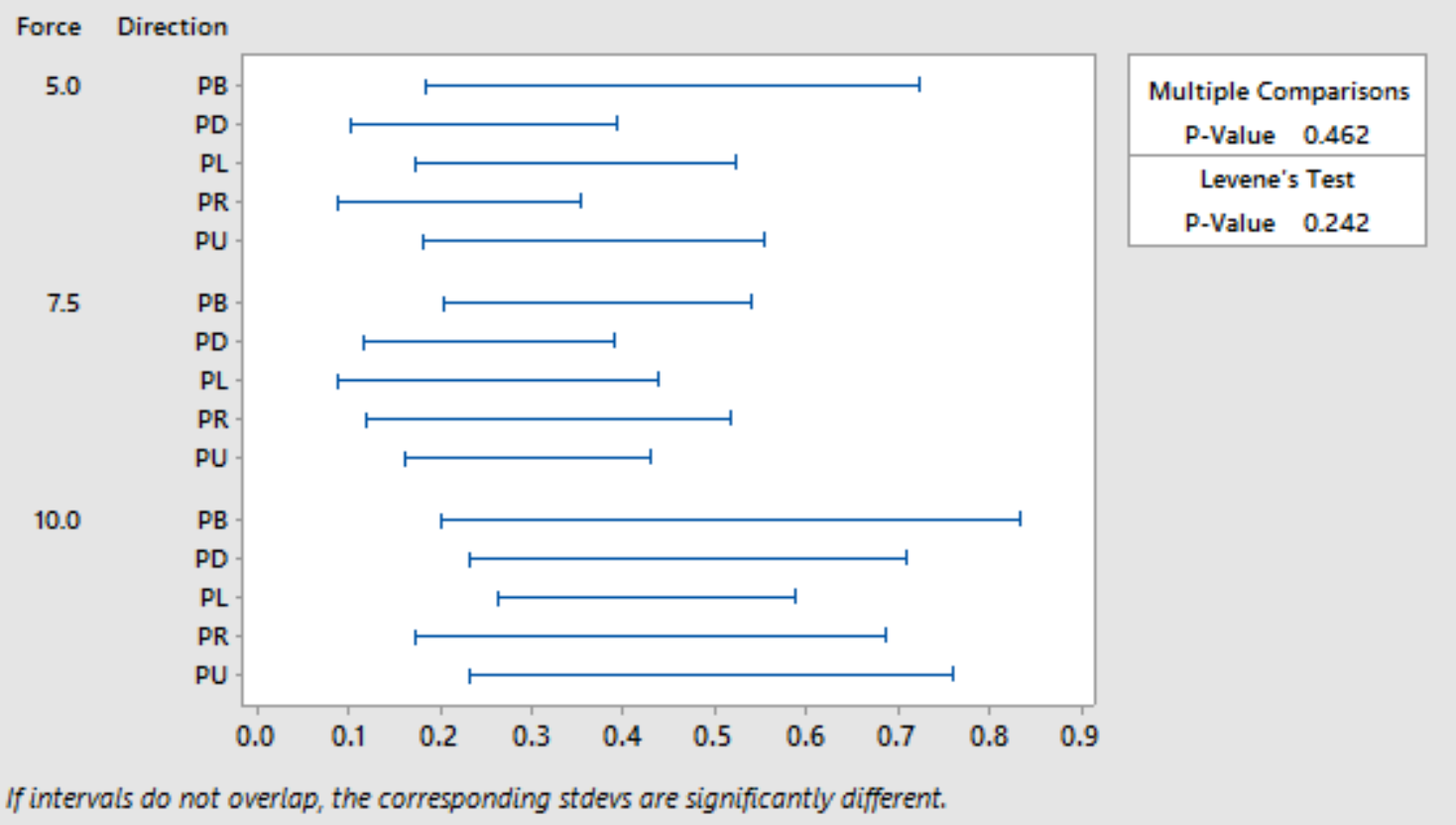

Equality of variance test for $\mathrm{M}$ (supraspinatus) 
Test for Equal Variances: Infraspinatus vs Force, Direction

Multiple comparison intervals for the standard deviation, $\alpha=0.05$

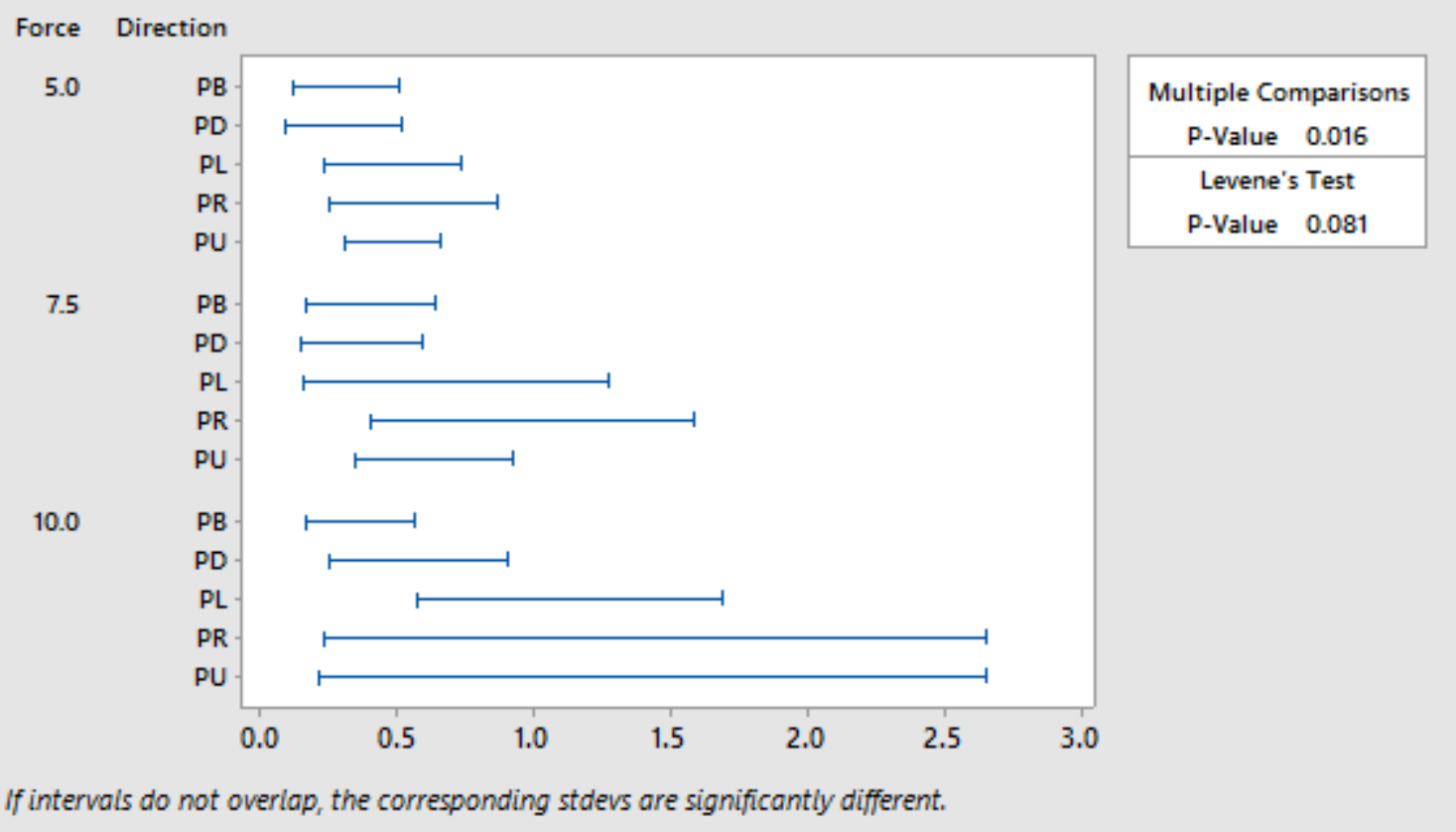

Equality of variance test for M (infraspinatus)

\section{Test for Equal Variances: Teres major vs Force, Direction}

Multiple comparison intervals for the standard deviation, $\alpha=0.05$

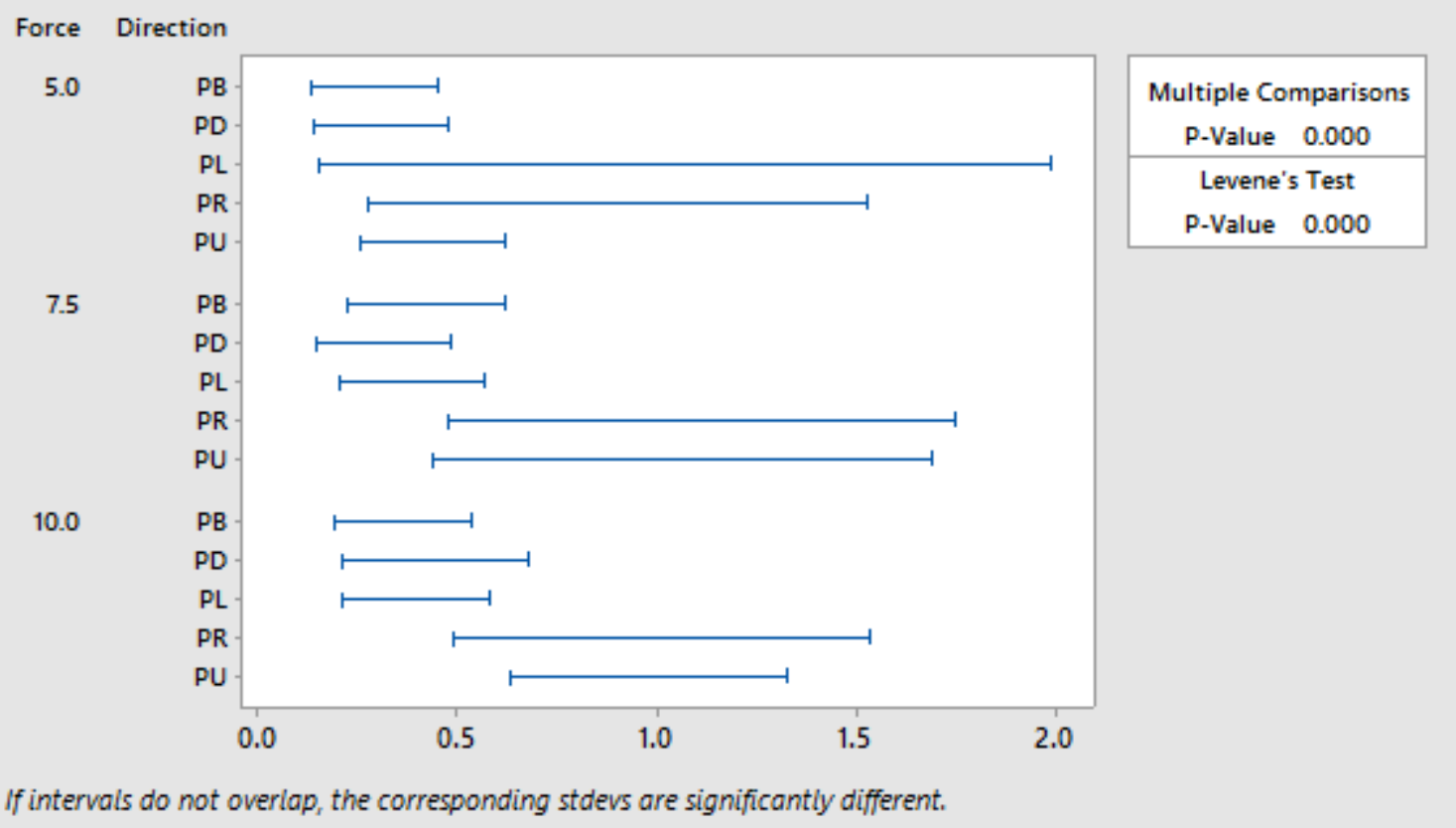

Equality of variance test for M (teres major) 
Test for Equal Variances: Mid deltoid vs Force, Direction

Multiple comparison intervals for the standard deviation, $\alpha=0.05$

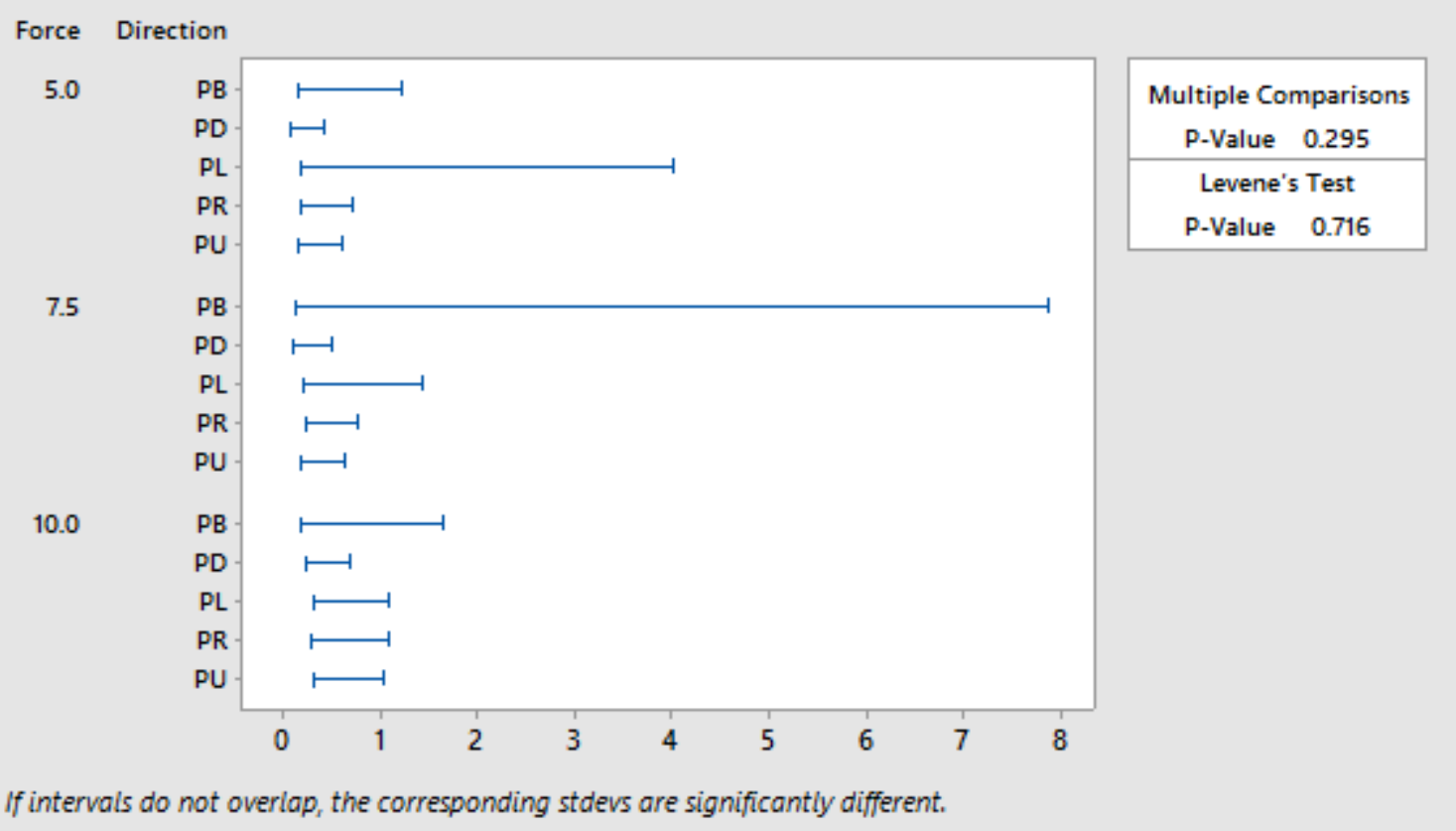

Equality of variance test for $\mathrm{M}$ (middle deltoid)

\section{Test for Equal Variances: Ant deltoid vs Force, Direction}

Multiple comparison intervals for the standard deviation, $\alpha=0.05$

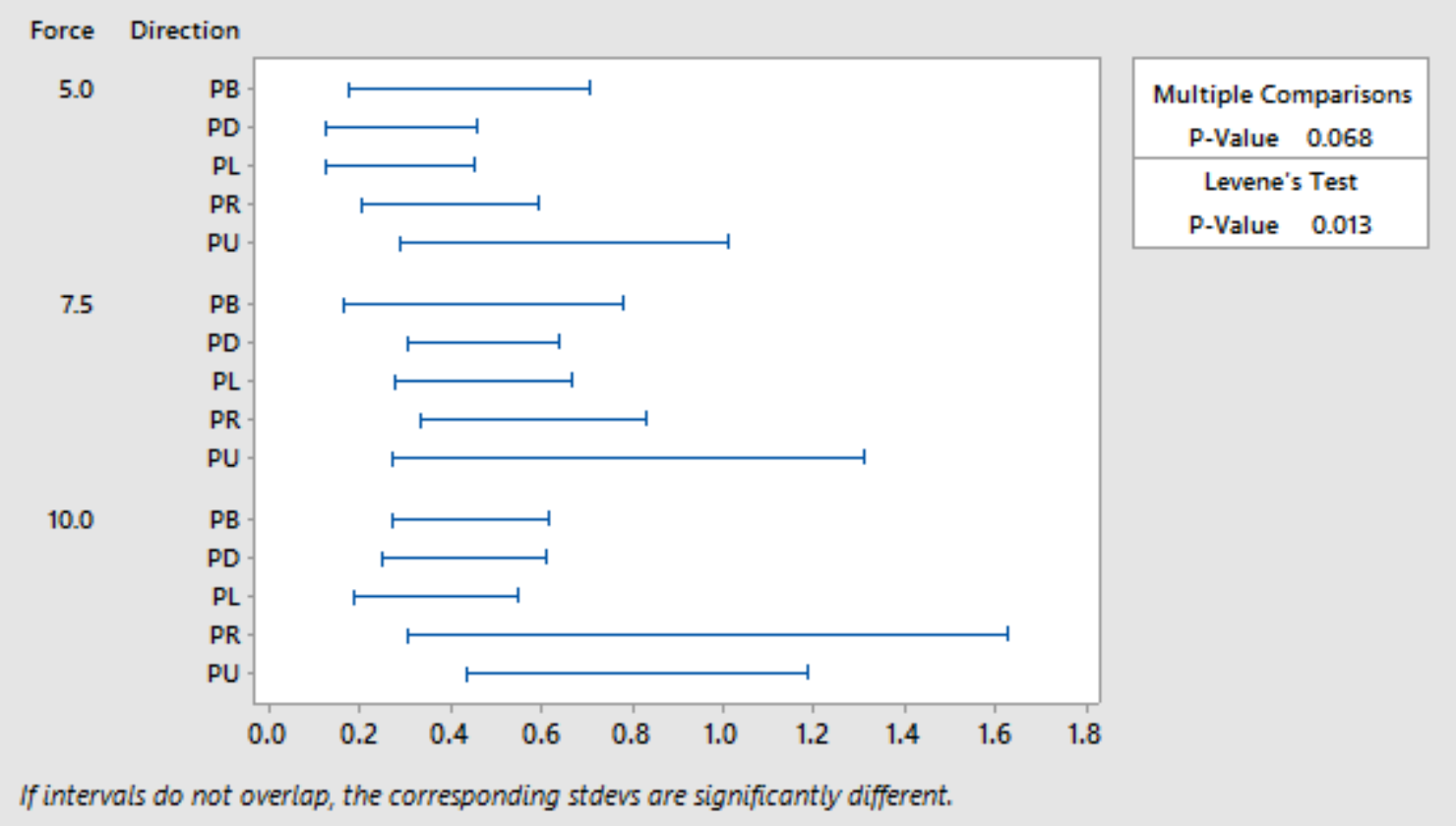

Equality of variance test for M (anterior deltoid) 


\section{Test for Equal Variances: Post deltoid vs Force, Direction}

\section{Multiple comparison intervals for the standard deviation, $\alpha=0.05$}

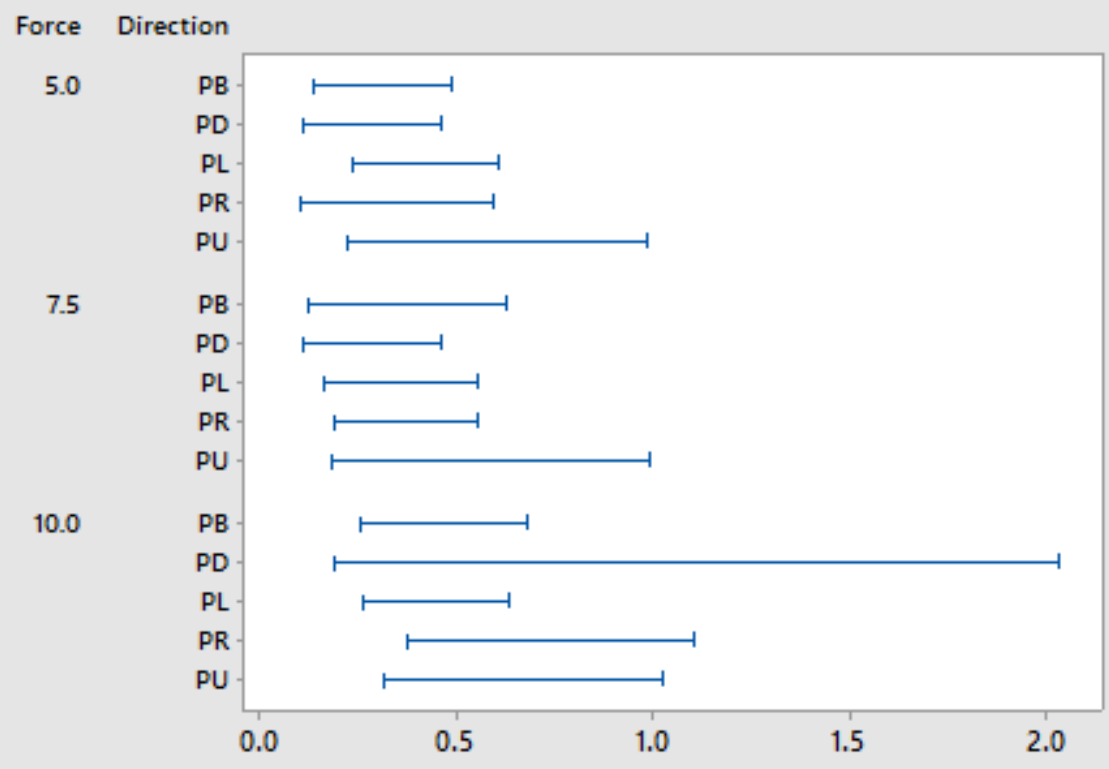

If intervals do not overlap, the corresponding stdevs are significantly different.

Equality of variance test for M (posterior deltoid)

\section{Test for Equal Variances: Bicep vs Force, Direction}

\section{Multiple comparison intervals for the standard deviation, $\alpha=0.05$}

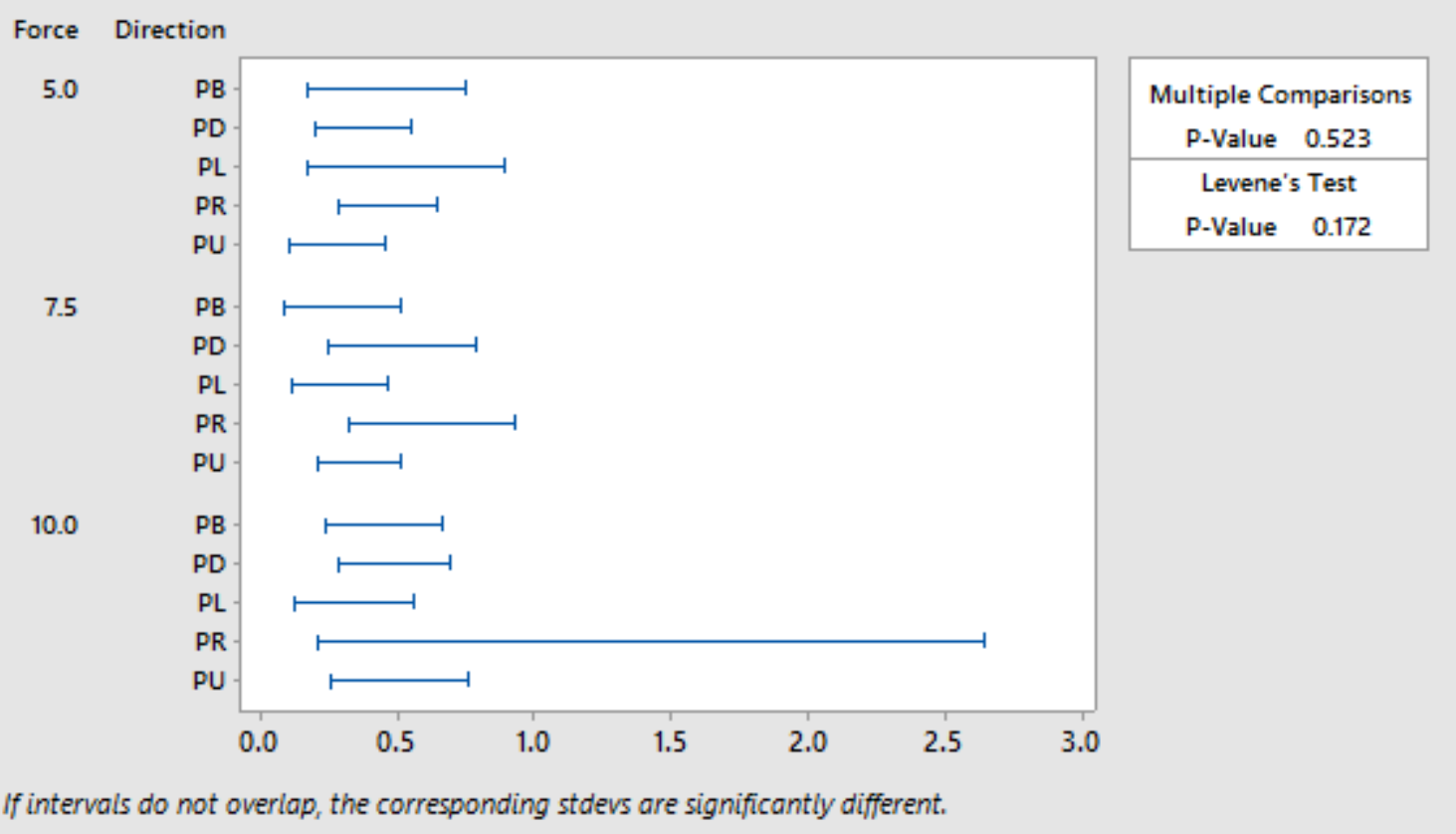

Equality of variance test for M (bicep) 
Test for Equal Variances: Tricep vs Force, Direction

Multiple comparison intervals for the standard deviation, $\alpha=0.05$

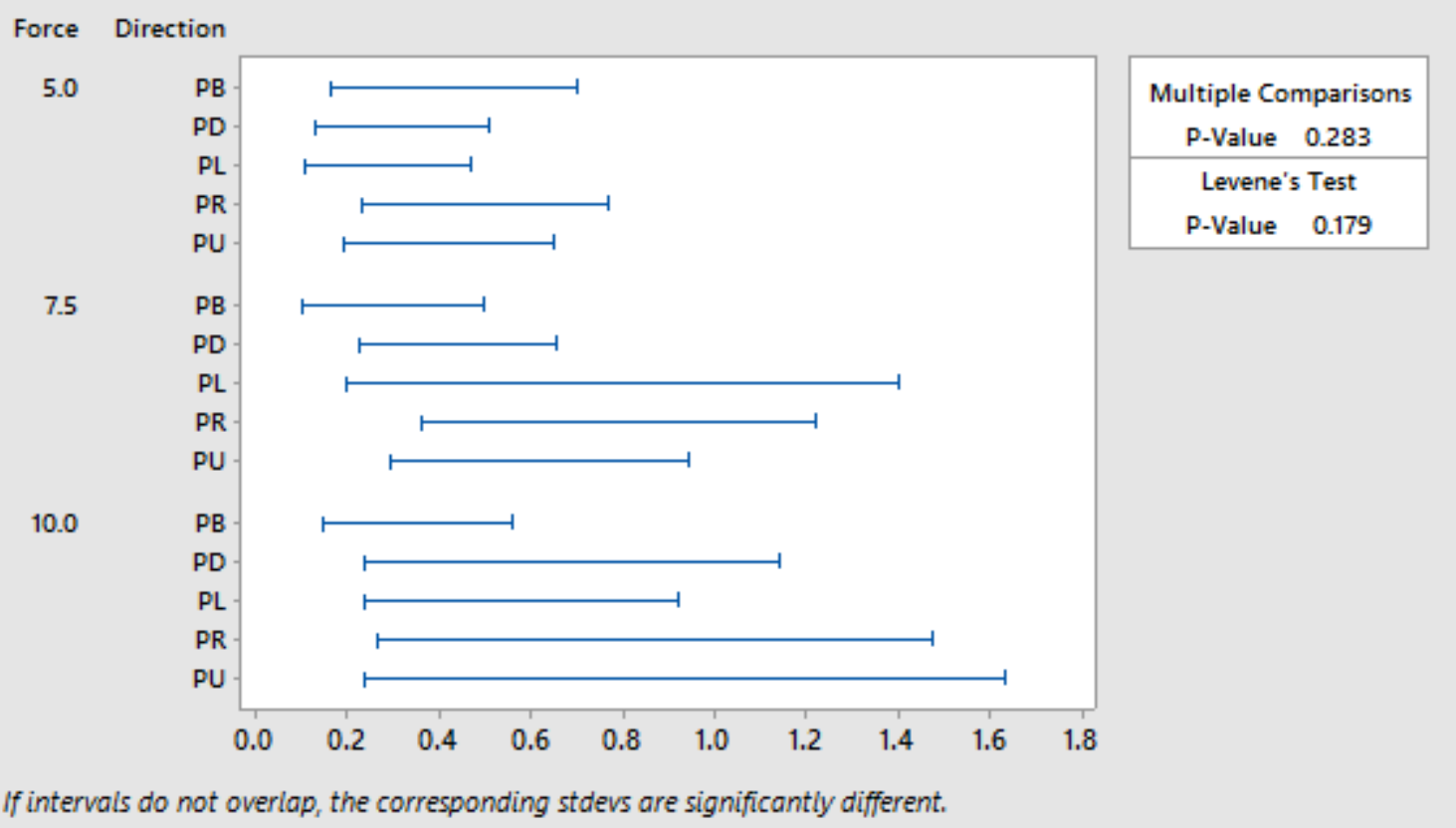

Equality of variance test for M (tricep)

Test for Equal Variances: Latissimus dorsi vs Force, Direction

Multiple comparison intervals for the standard deviation, $\alpha=0.05$

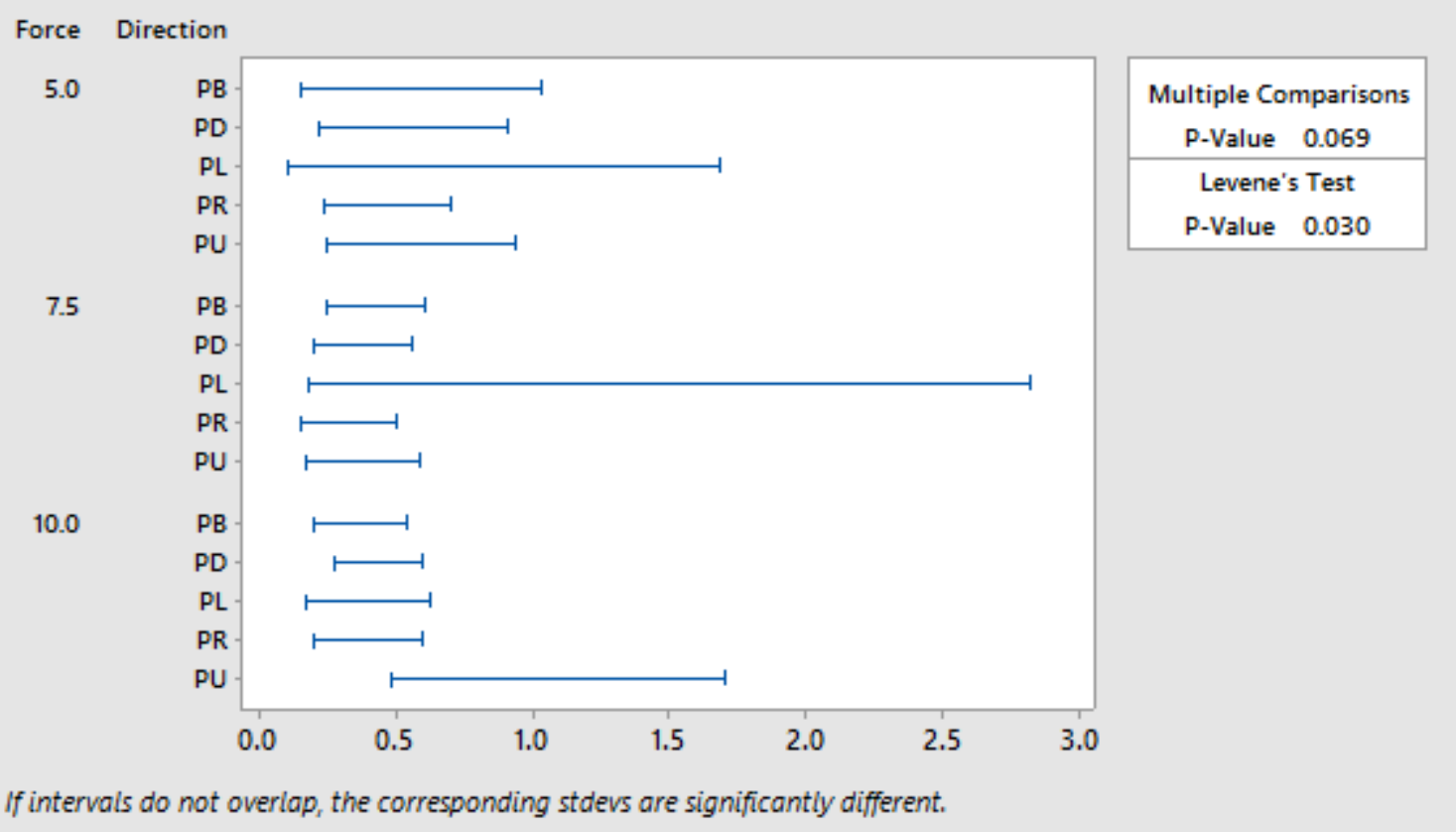

Equality of variance test for M (latissimus dorsi) 
Test for Equal Variances: TM vs Force, Direction

Multiple comparison intervals for the standard deviation, $\alpha=0.05$

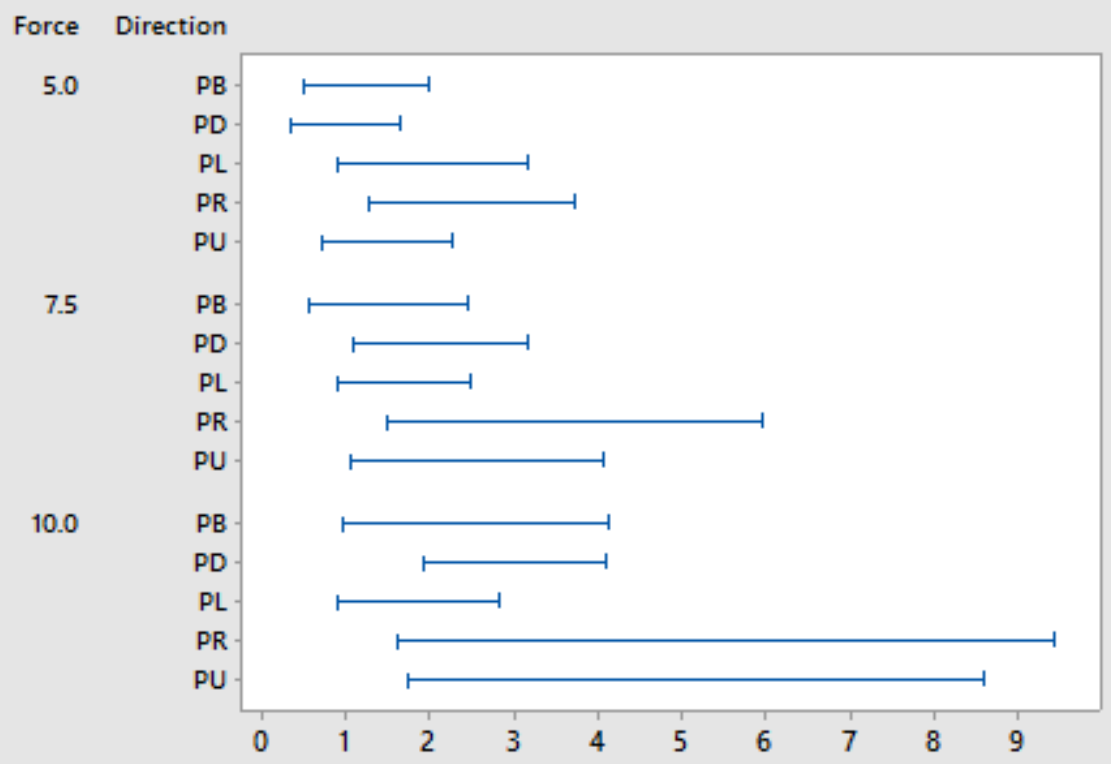

Multiple Comparisons P-Value 0.010

Levene's Test

P-Value 0.002

If intervals do not overlap, the corresponding stdevs are significantly different.

Equality of variance test for TM

\section{Test for Equal Variances: Supraspinatus vs Force, Direction}

Multiple comparison intervals for the standard deviation, $\alpha=0.05$

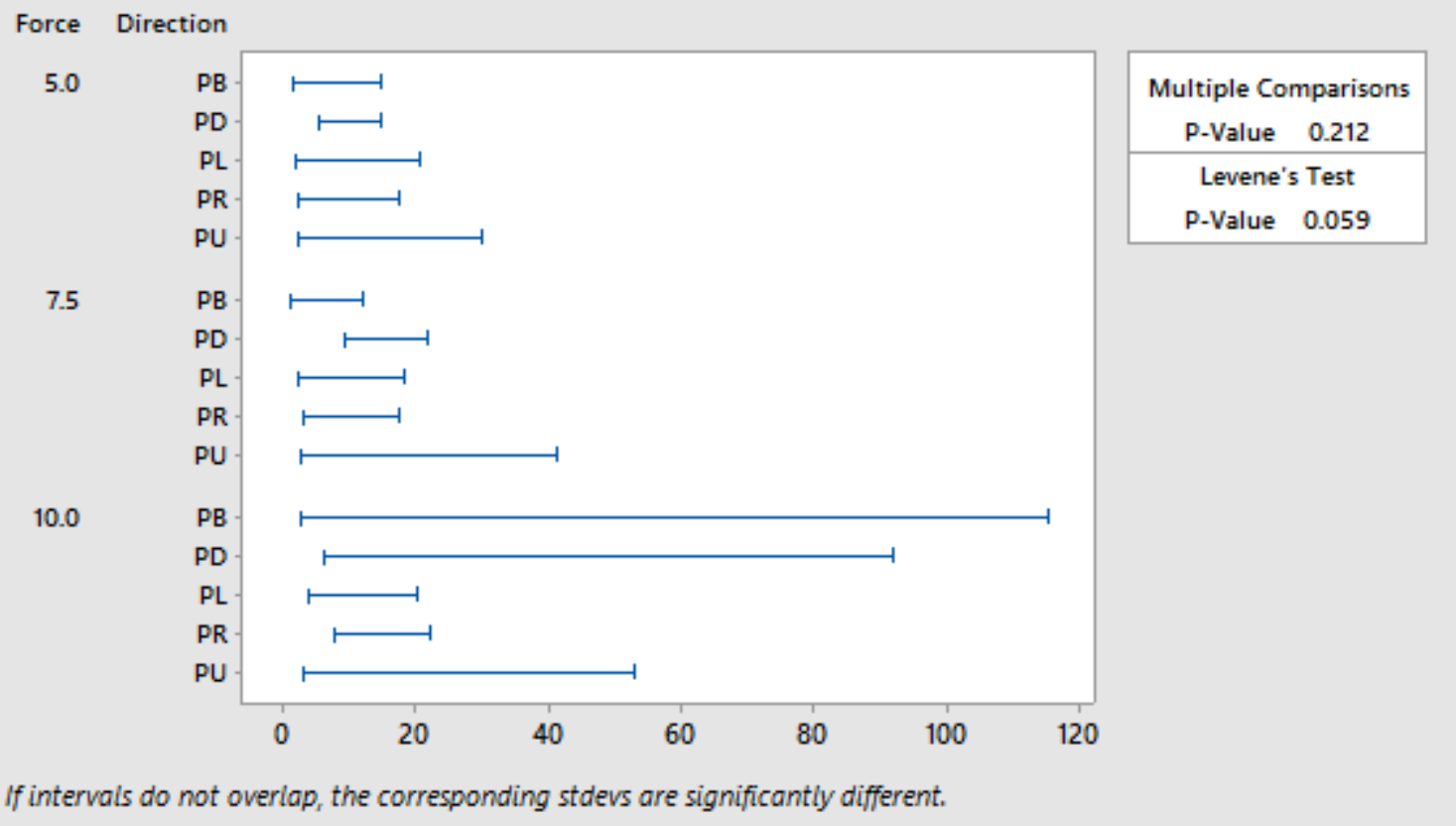

Equality of variance test for NMAV (supraspinatus) 
Test for Equal Variances: Infraspinatus vs Force, Direction

Multiple comparison intervals for the standard deviation, $\alpha=0.05$

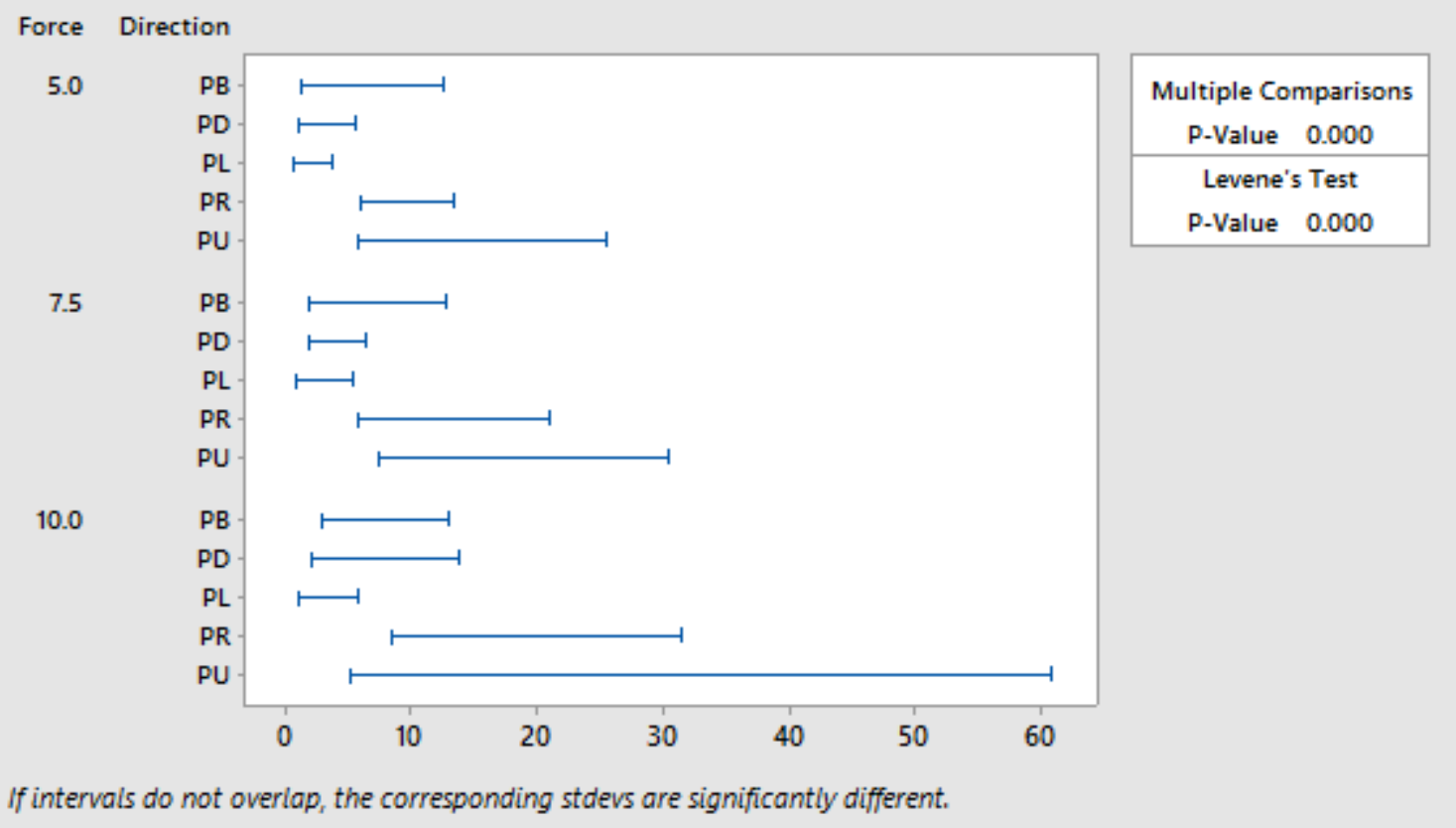

Equality of variance test for NMAV (infraspinatus)

\section{Test for Equal Variances: Teres major vs Force, Direction}

Multiple comparison intervals for the standard deviation, $\alpha=0.05$

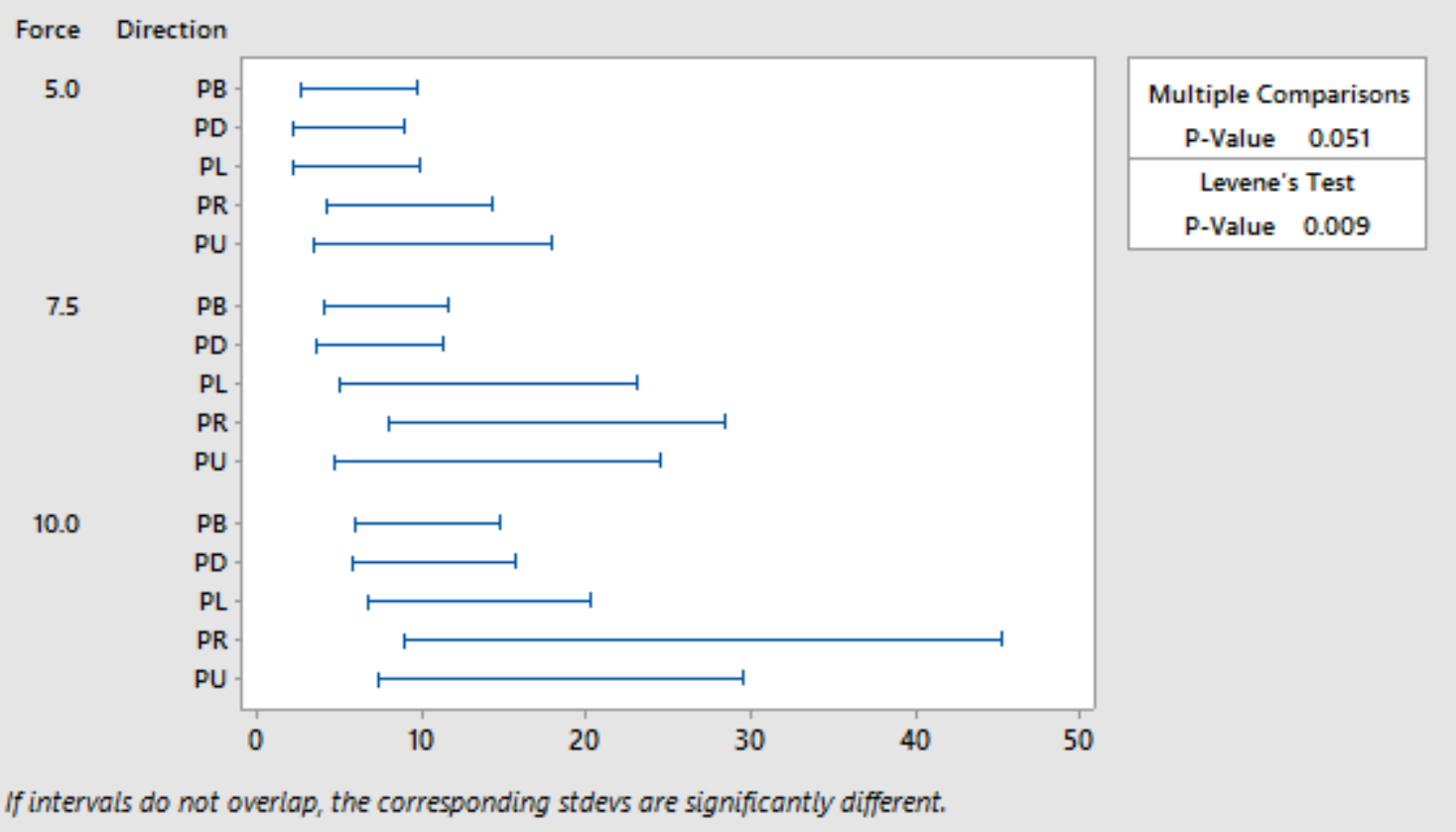

Equality of variance test for NMAV (teres major) 


\section{Test for Equal Variances: Mid deltoid vs Force, Direction}

\section{Multiple comparison intervals for the standard deviation, $\alpha=0.05$}

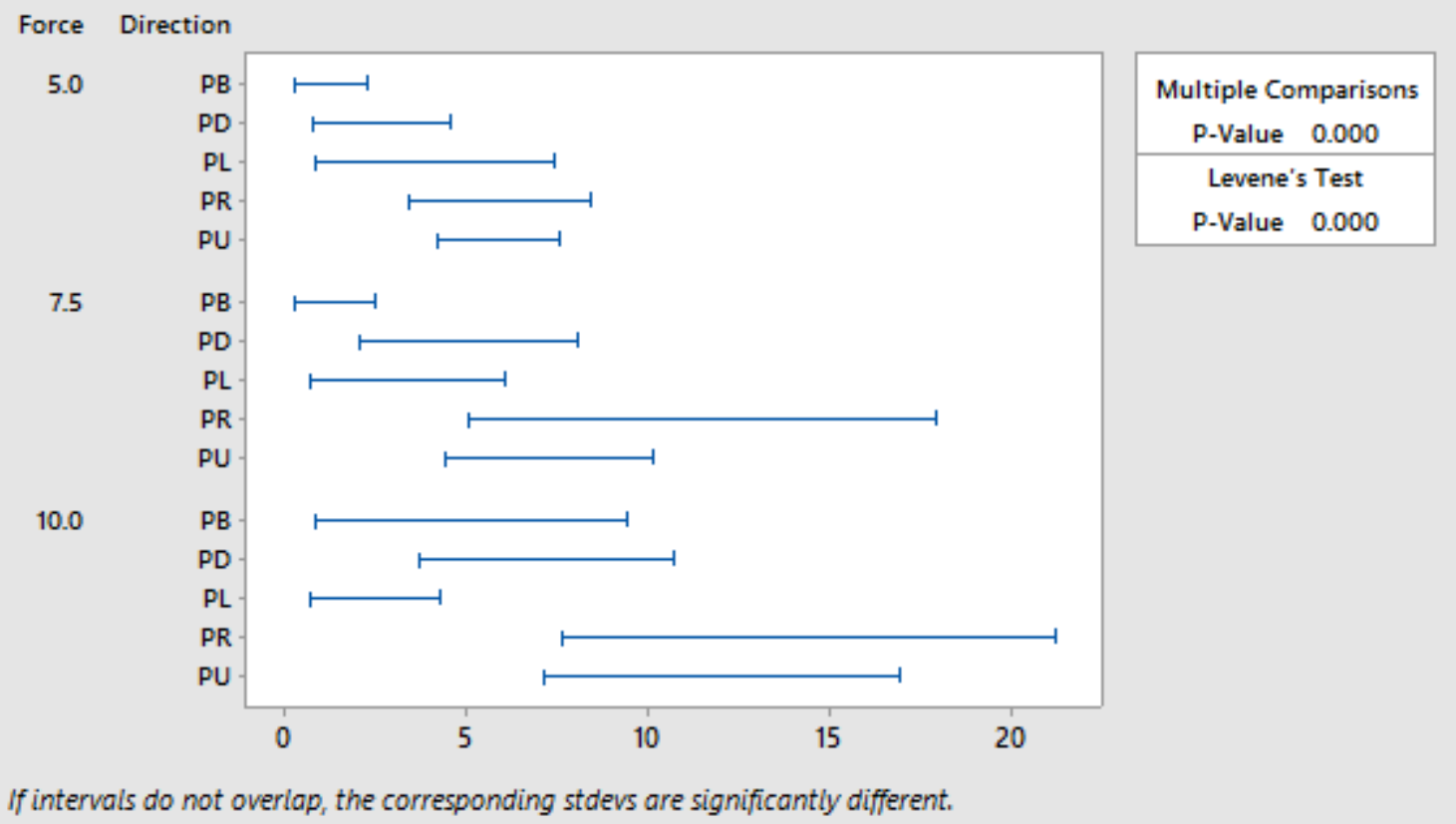

Equality of variance test for NMAV (middle deltoid)

\section{Test for Equal Variances: Ant deltoid vs Force, Direction}

\section{Multiple comparison intervals for the standard deviation, $\alpha=0.05$}

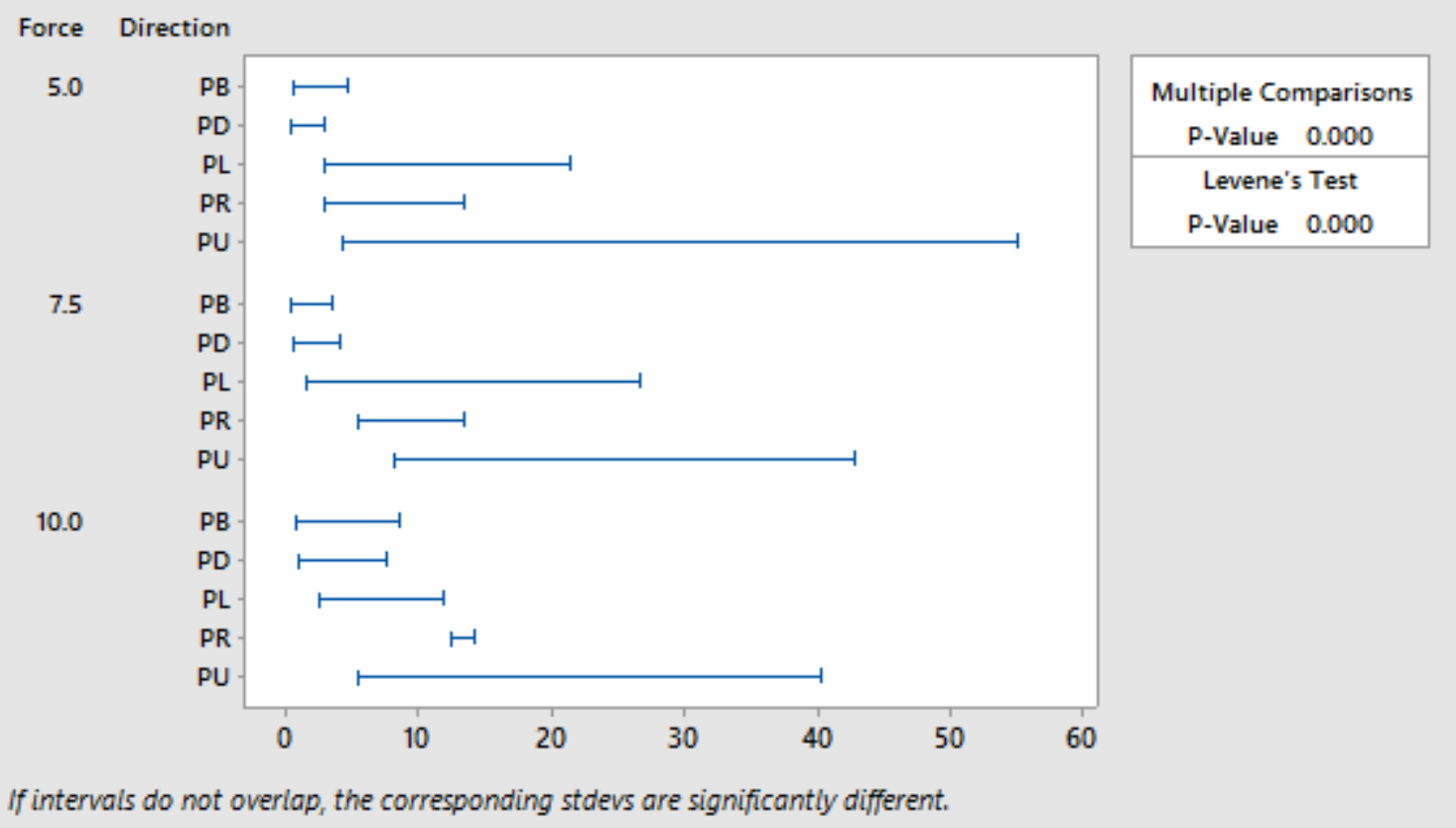

Equality of variance test for NMAV (anterior deltoid) 


\section{Test for Equal Variances: Post deltoid vs Force, Direction}

Multiple comparison intervals for the standard deviation, $\alpha=0.05$

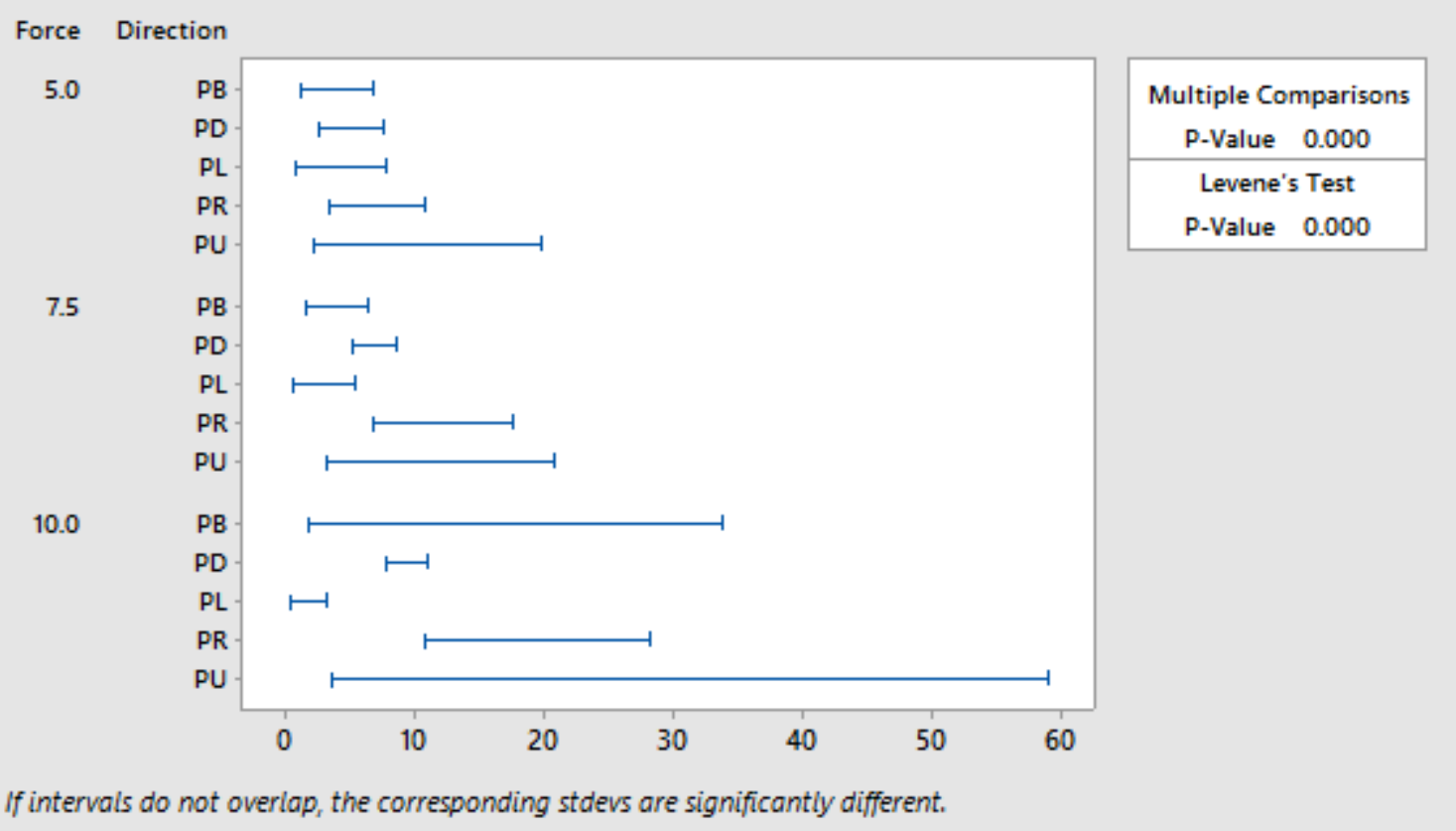

Equality of variance test for NMAV (posterior deltoid)

\section{Test for Equal Variances: Bicep vs Force, Direction}

Multiple comparison intervals for the standard deviation, $\alpha=0.05$

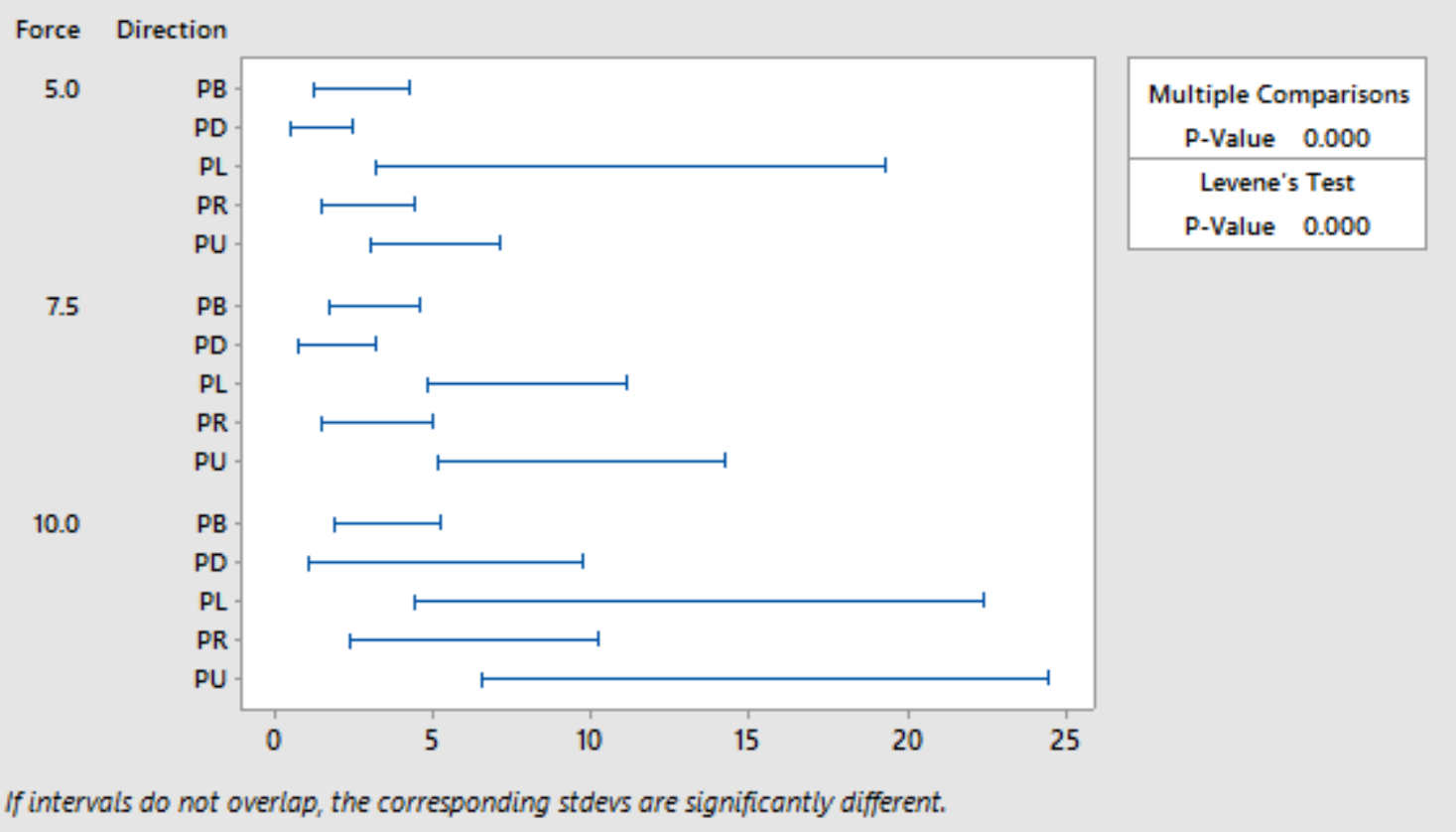

Equality of variance test for NMAV (bicep) 
Test for Equal Variances: Tricep vs Force, Direction

Multiple comparison intervals for the standard deviation, $\alpha=0.05$

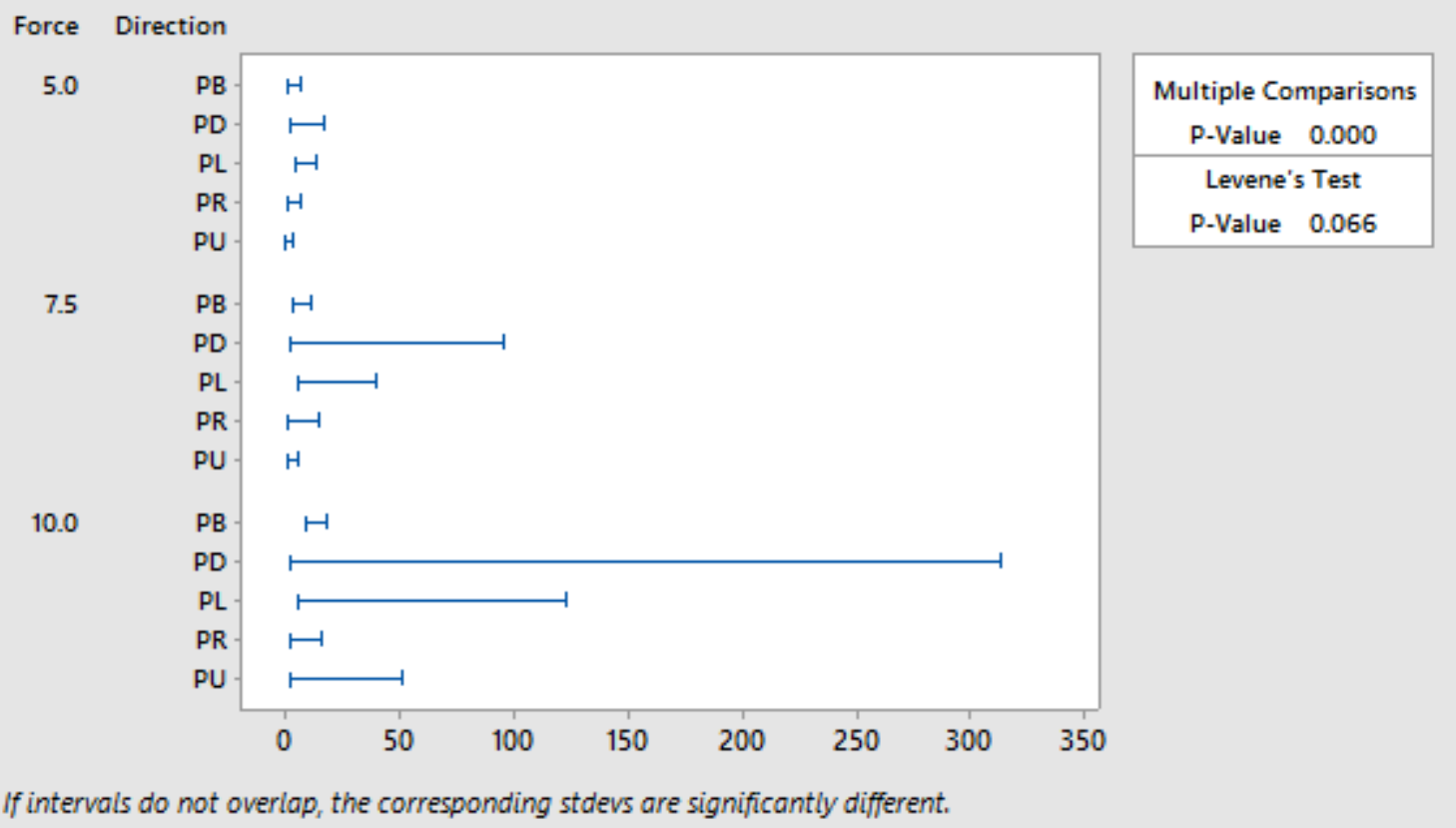

Equality of variance test for NMAV (tricep)

Test for Equal Variances: Latissimus dorsi vs Force, Direction

Multiple comparison intervals for the standard deviation, $\alpha=0.05$

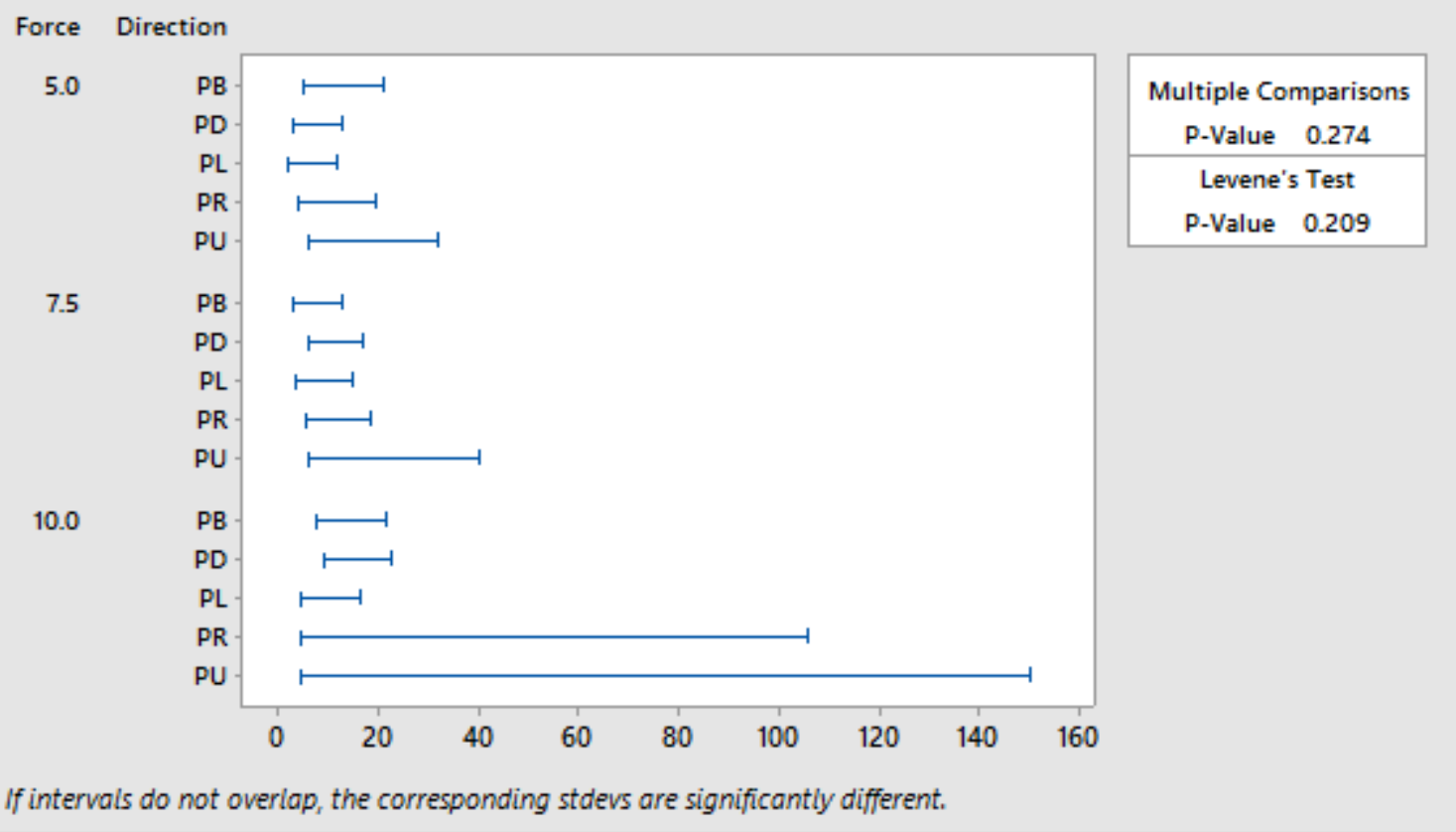

Equality of variance test for NMAV (latissimus dorsi) 
Test for Equal Variances: TNMAV vs Force, Direction

Multiple comparison intervals for the standard deviation, $\alpha=0.05$

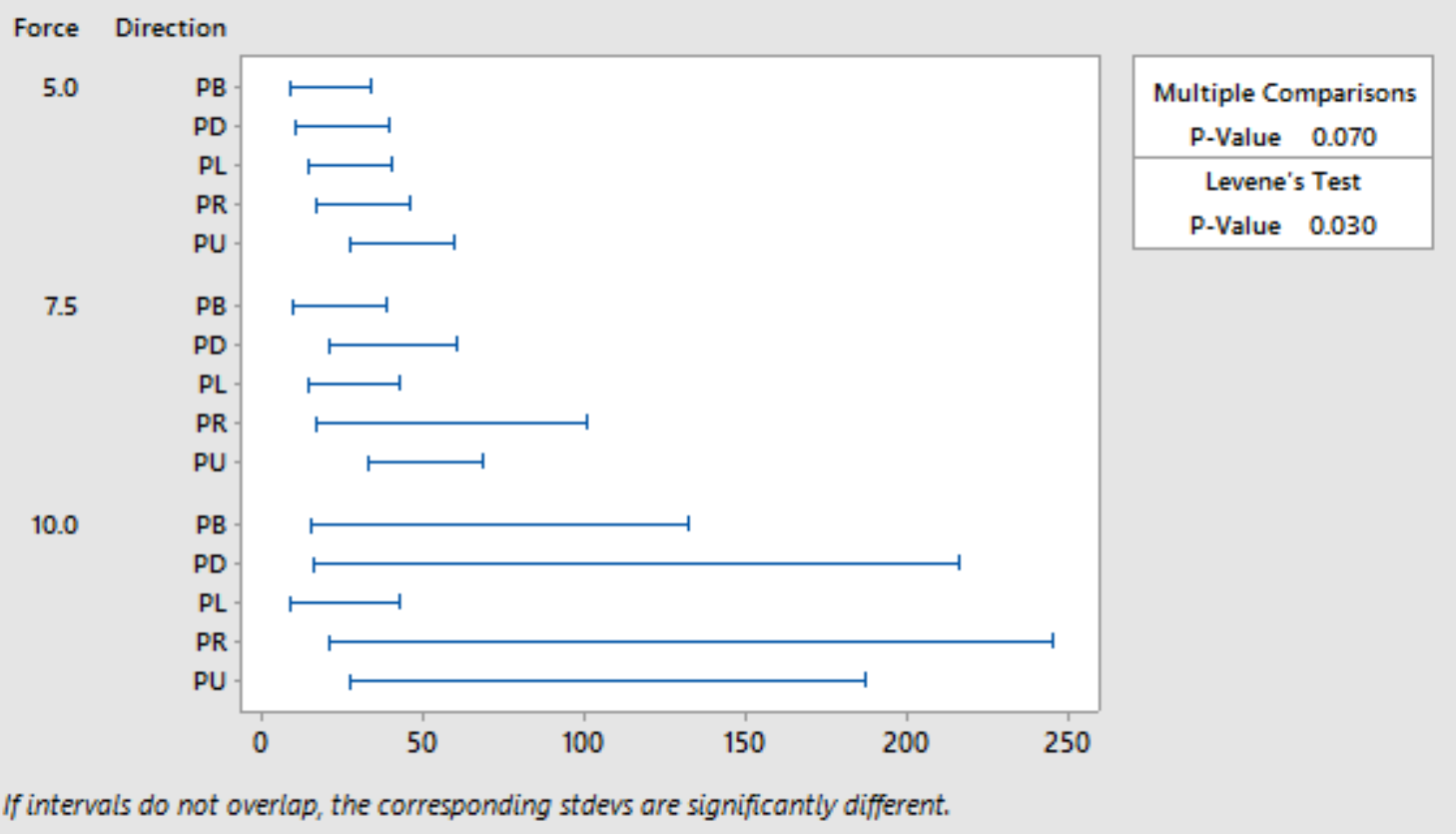

Equality of variance test for TNMAV 
Appendix E: Johnson transformation 


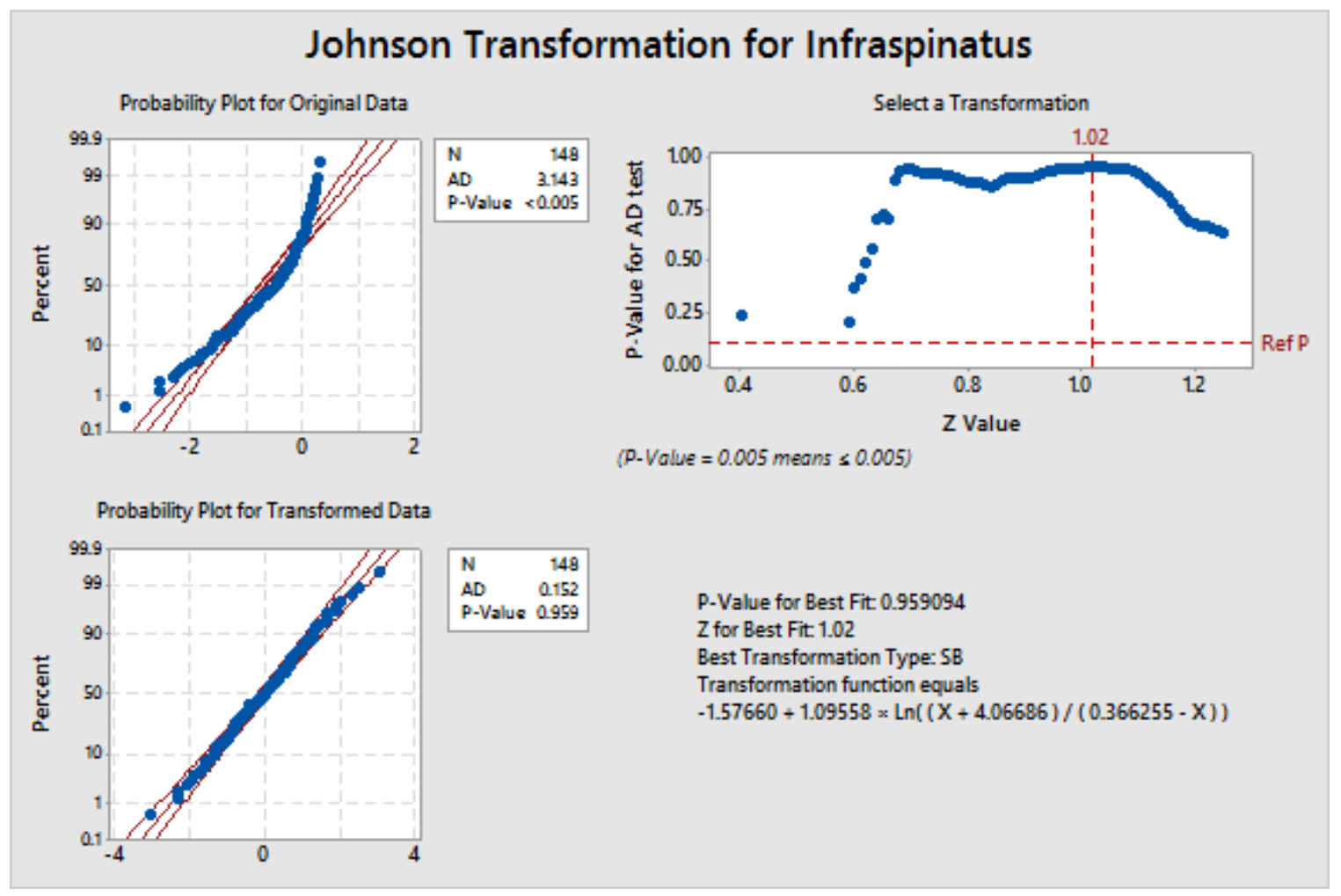

Johnson transformation for M (infraspinatus)

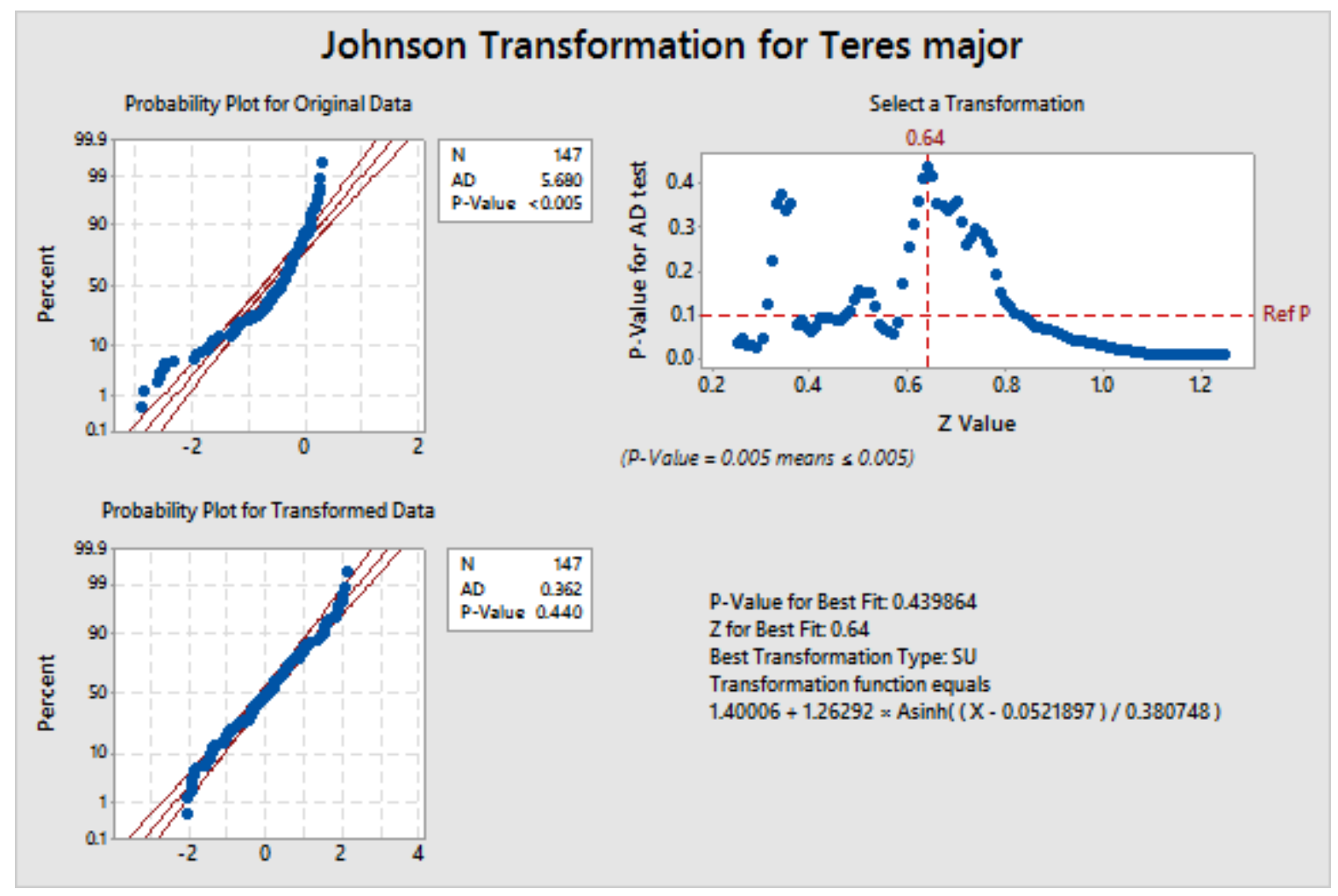

Johnson transformation for M (Teres major) 


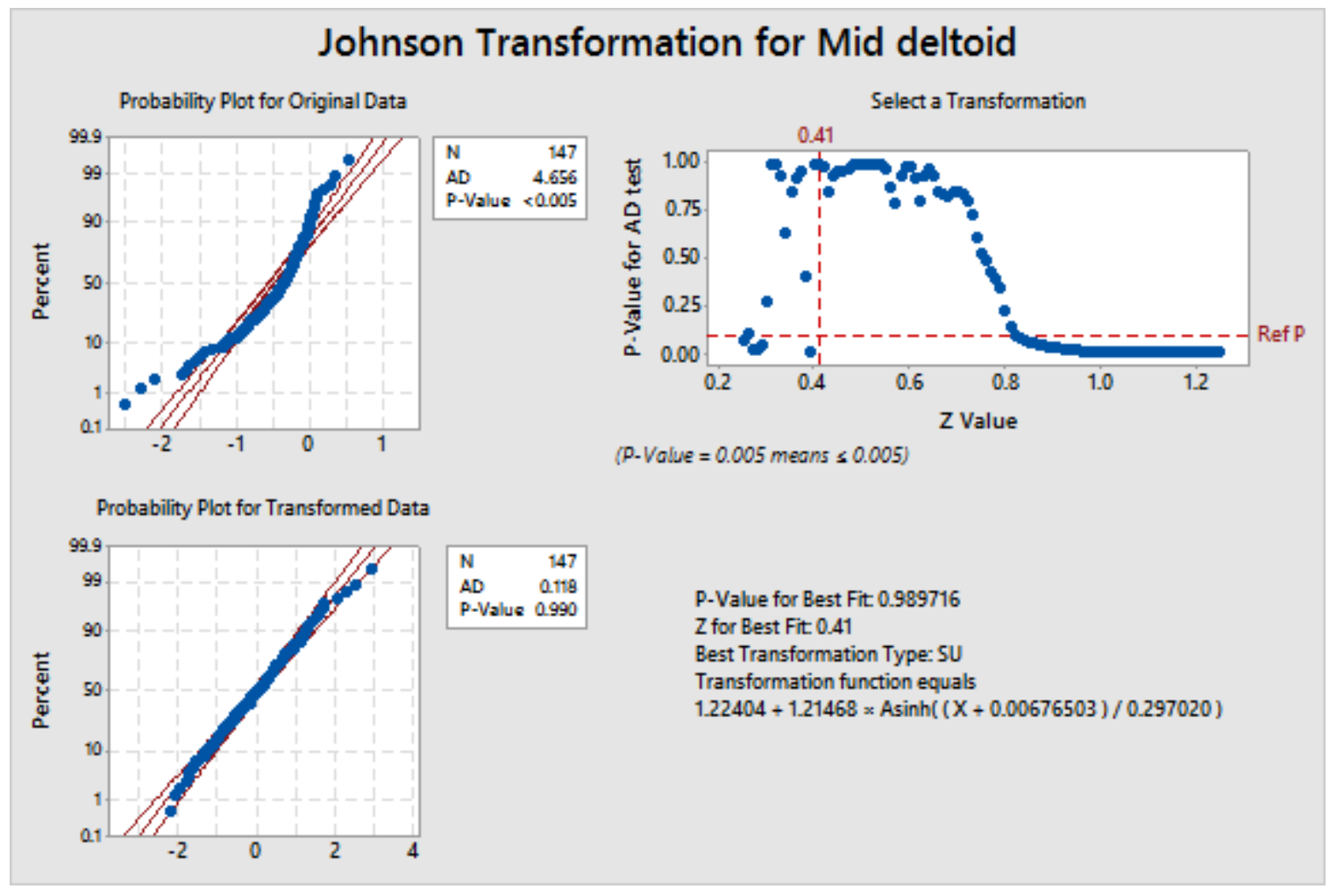

Johnson transformation for M (middle deltoid)

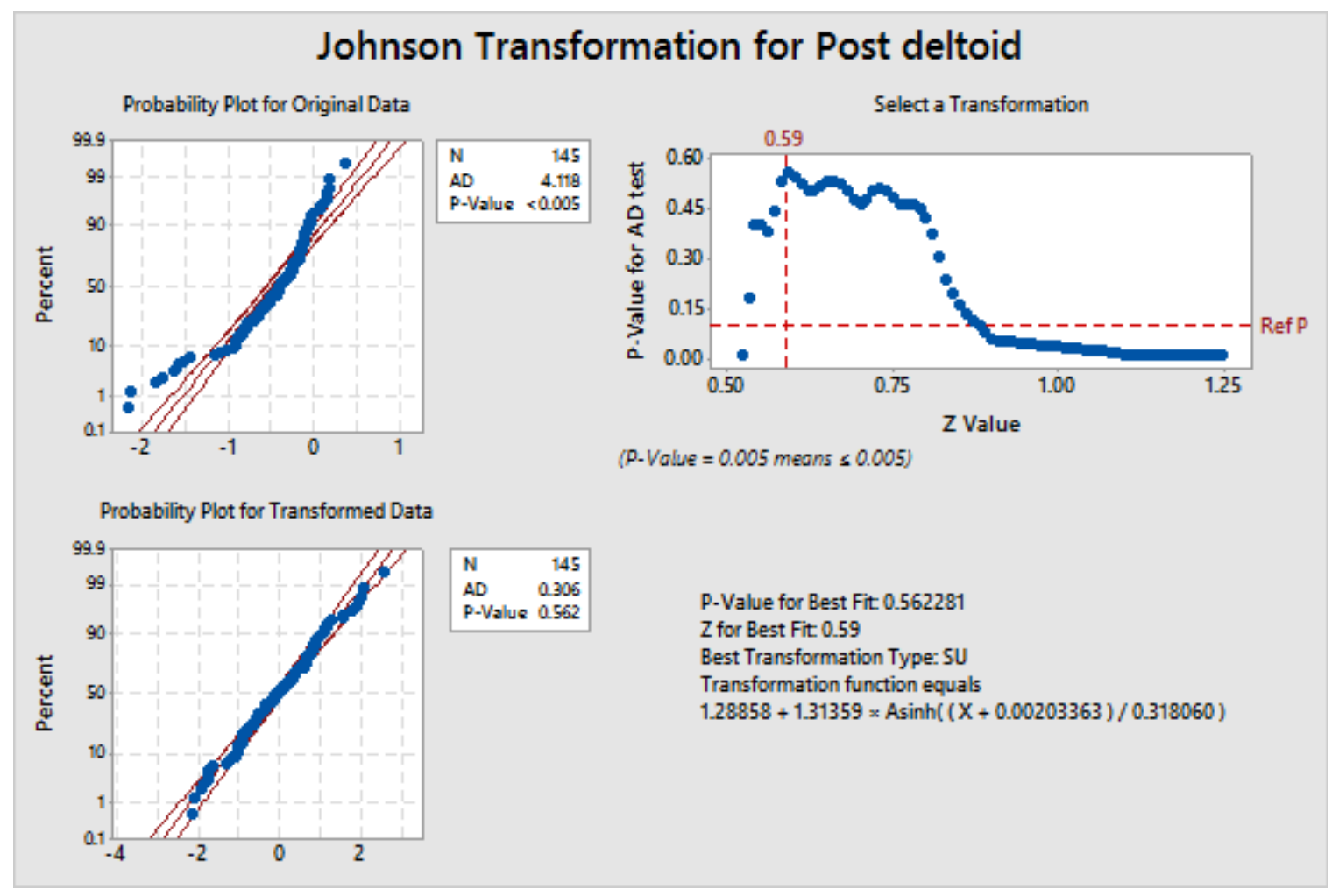

Johnson transformation for M (posterior deltoid) 


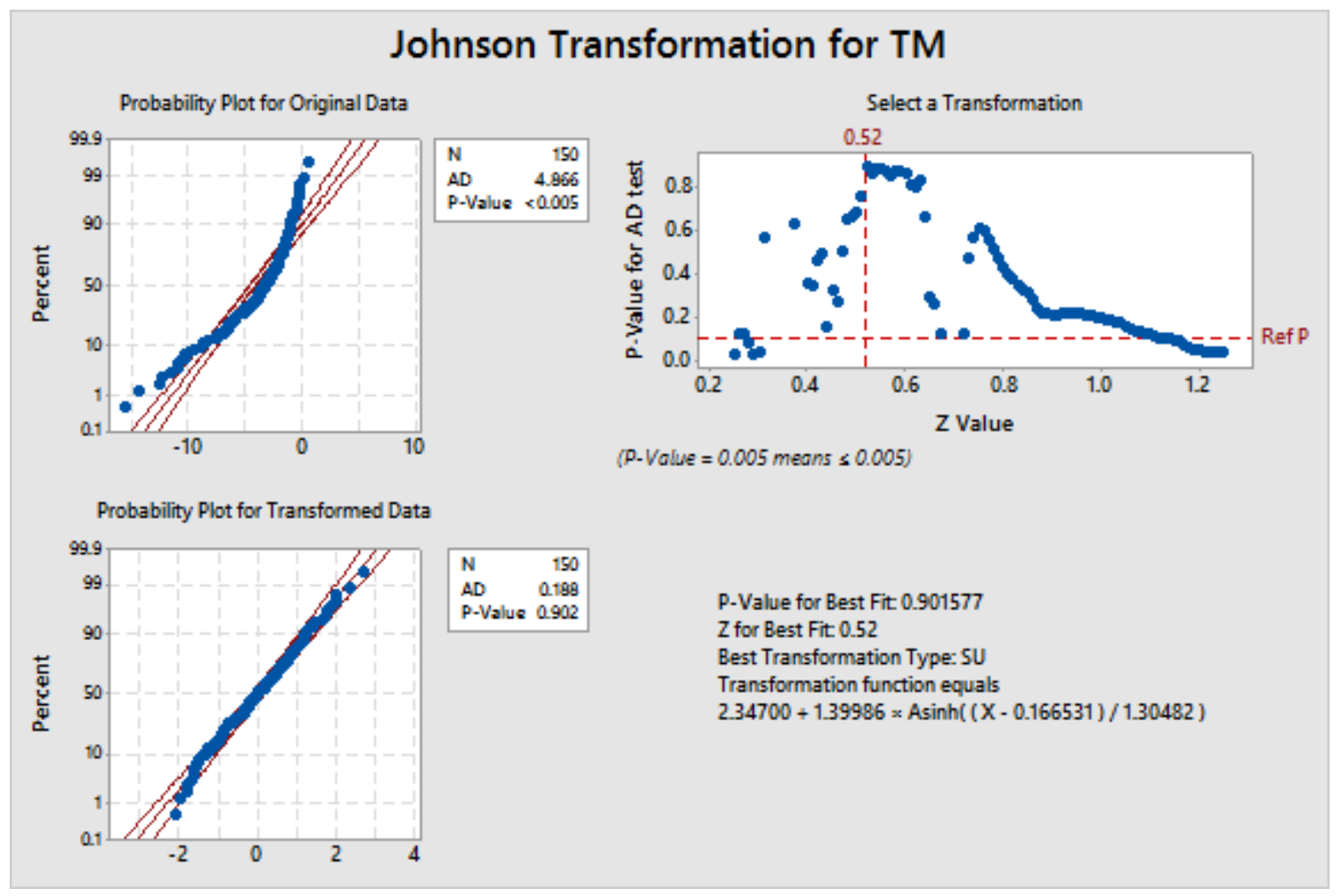

Johnson transformation for TM

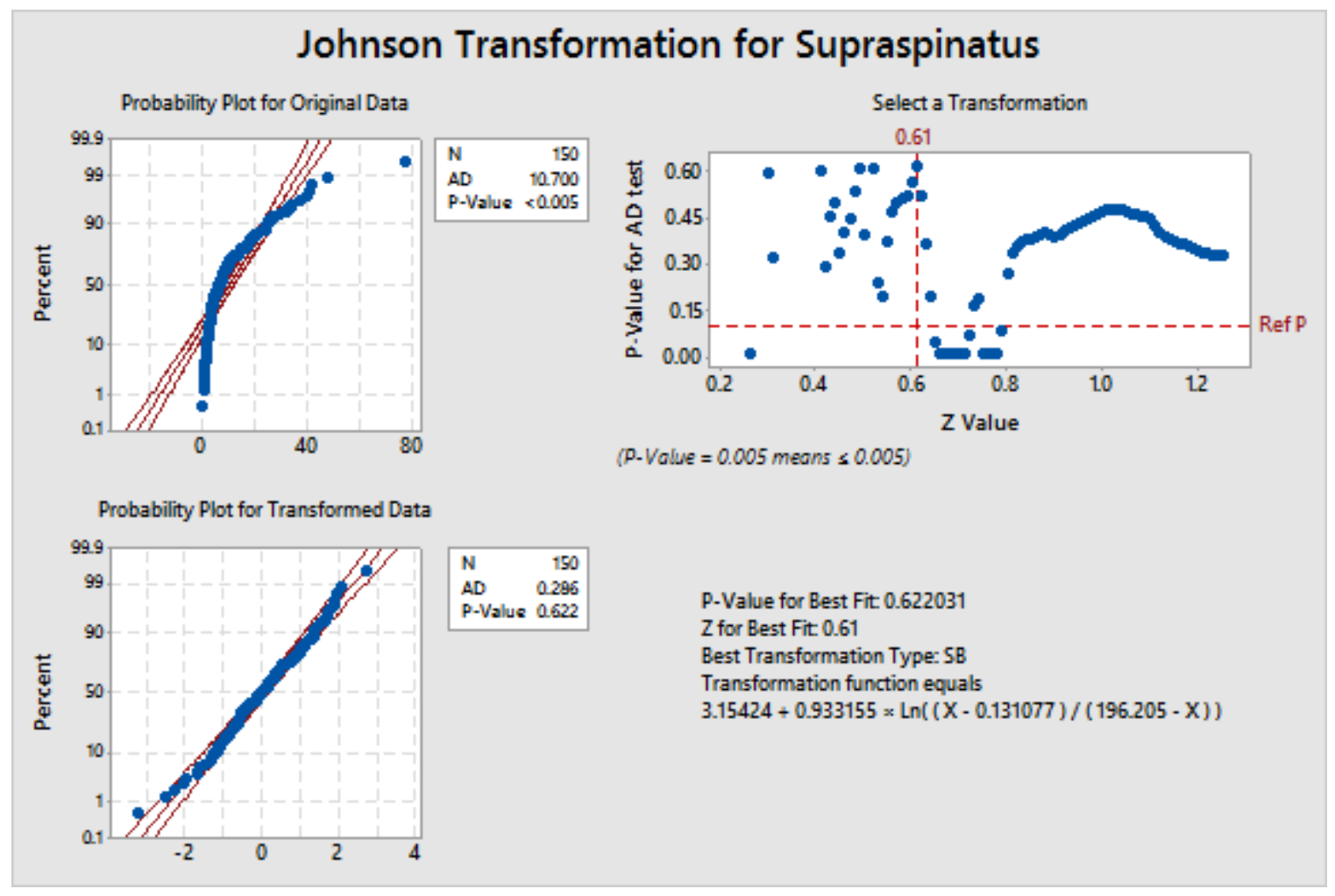

Johnson transformation for NMAV (supraspinatus) 


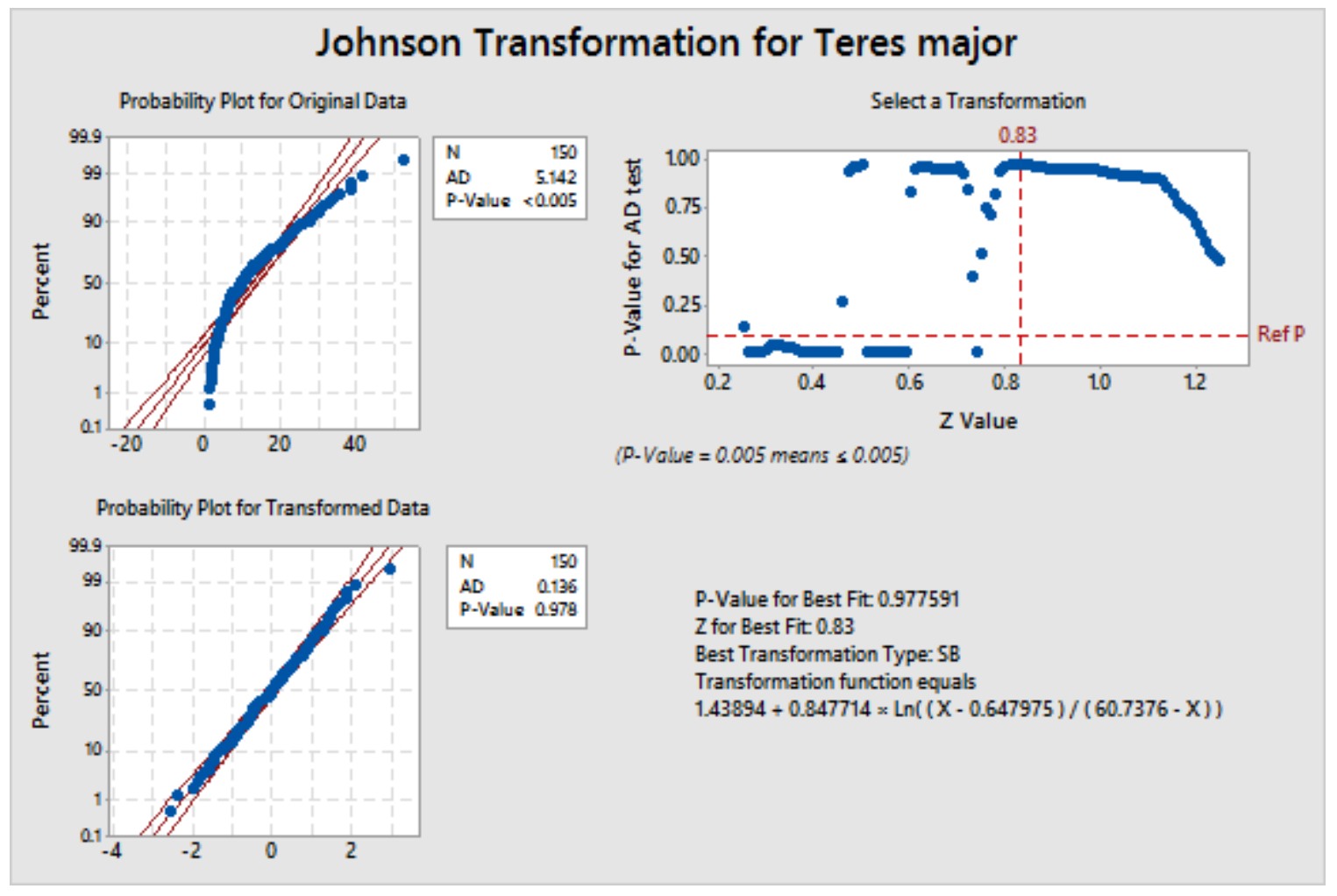

Johnson transformation for NMAV (trese major)

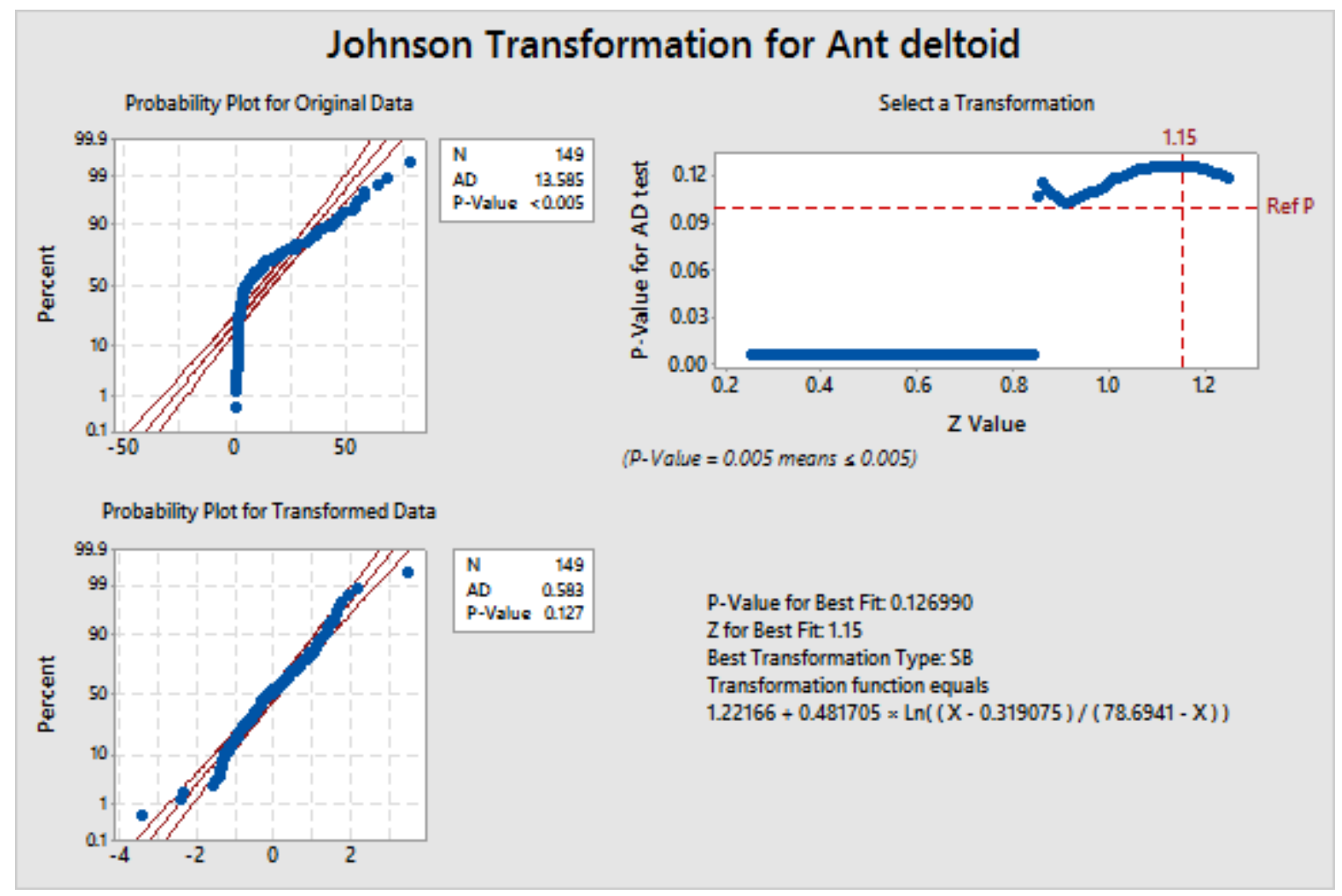

Johnson transformation for NMAV (anterior deltoid) 


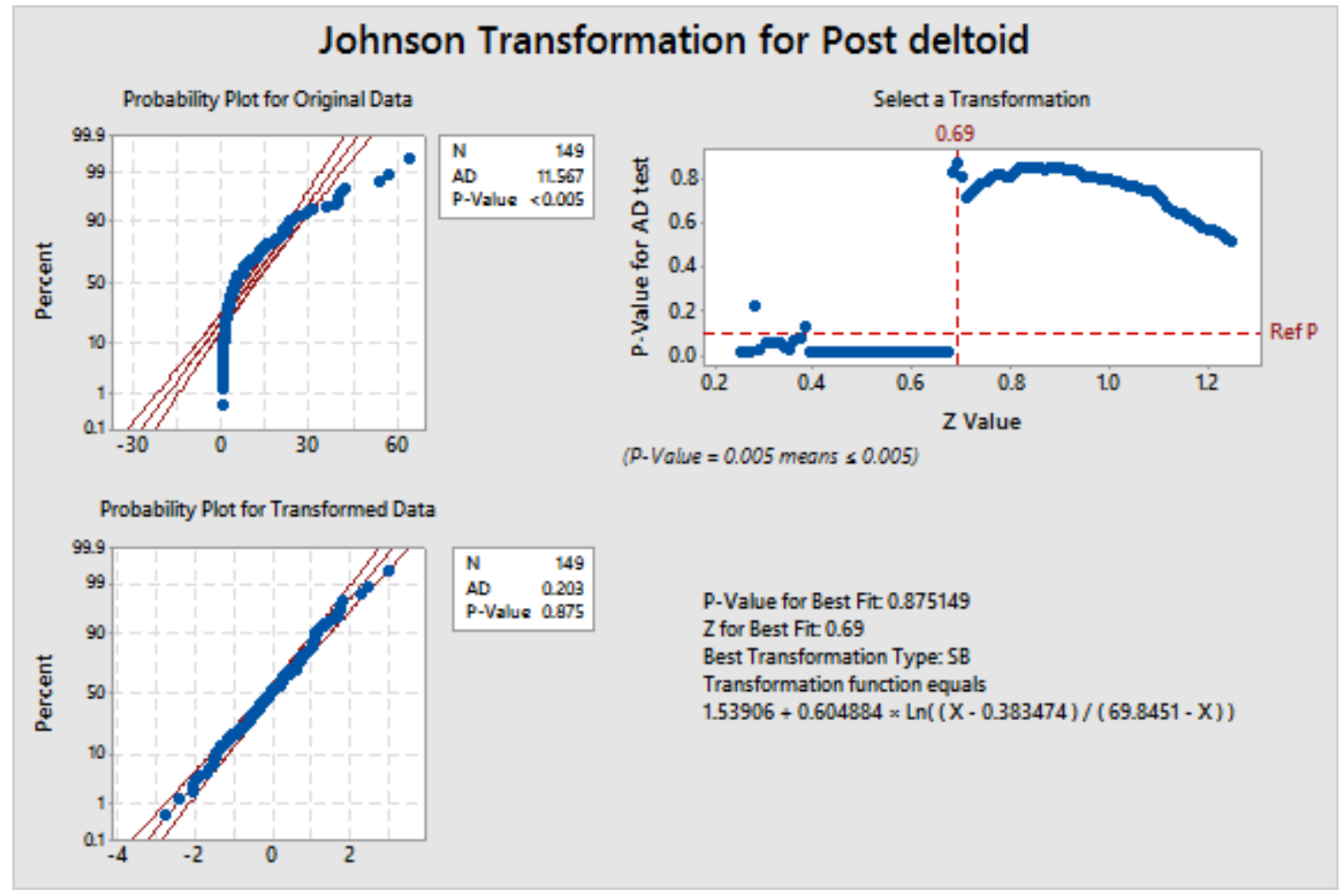

Johnson transformation for NMAV (posterior deltoid)

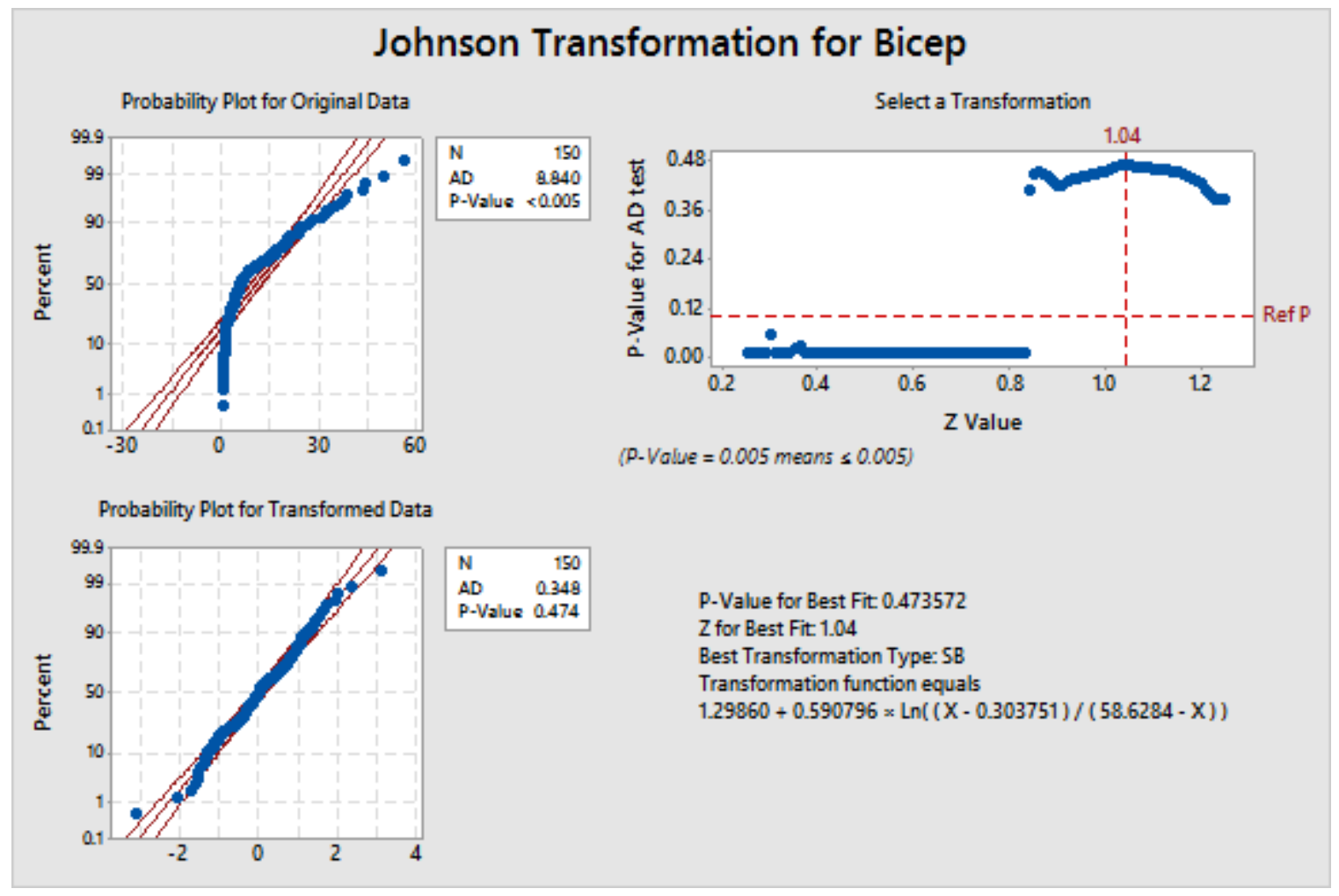

Johnson transformation for NMAV (bicep) 


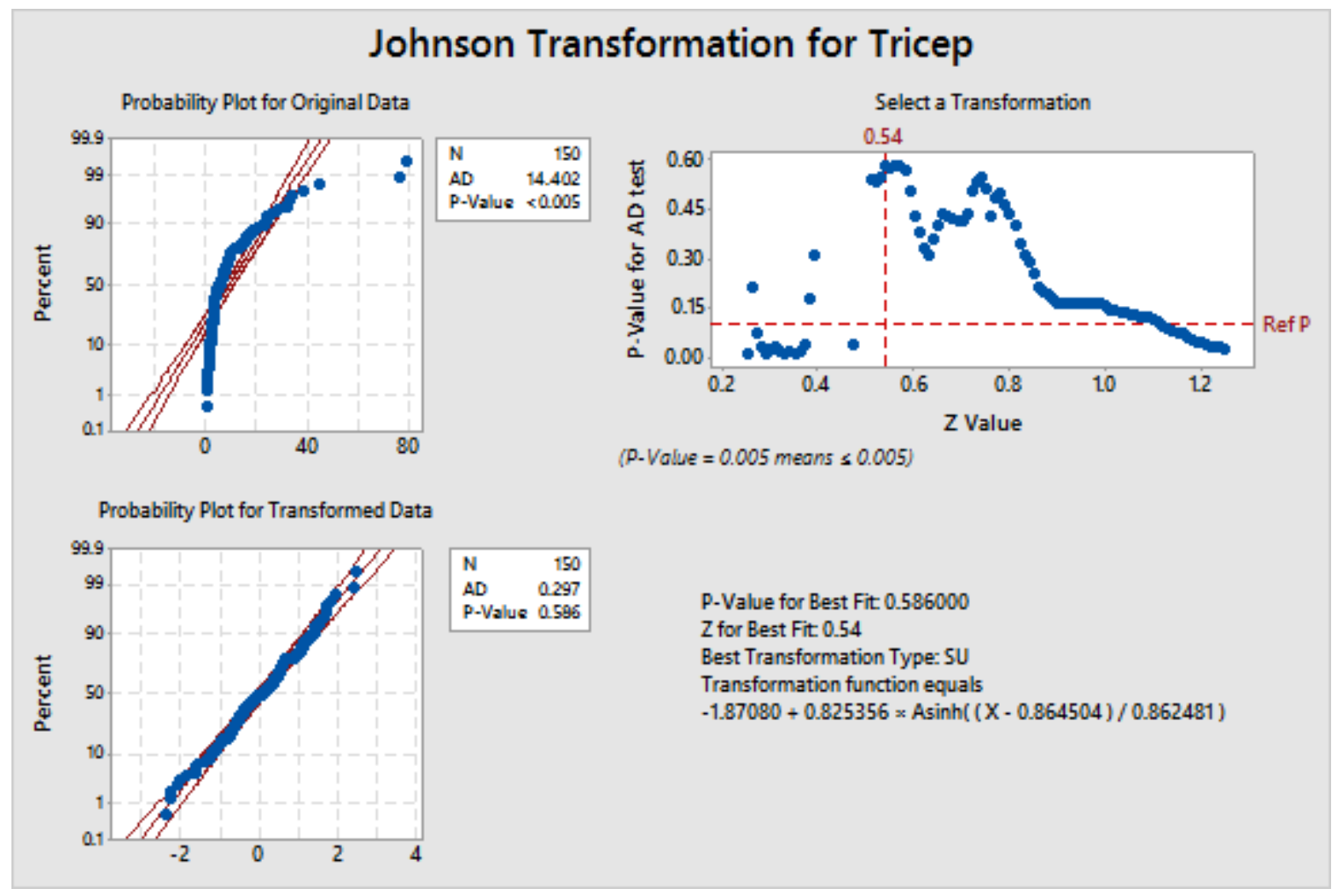

Johnson transformation for NMAV (tricep)

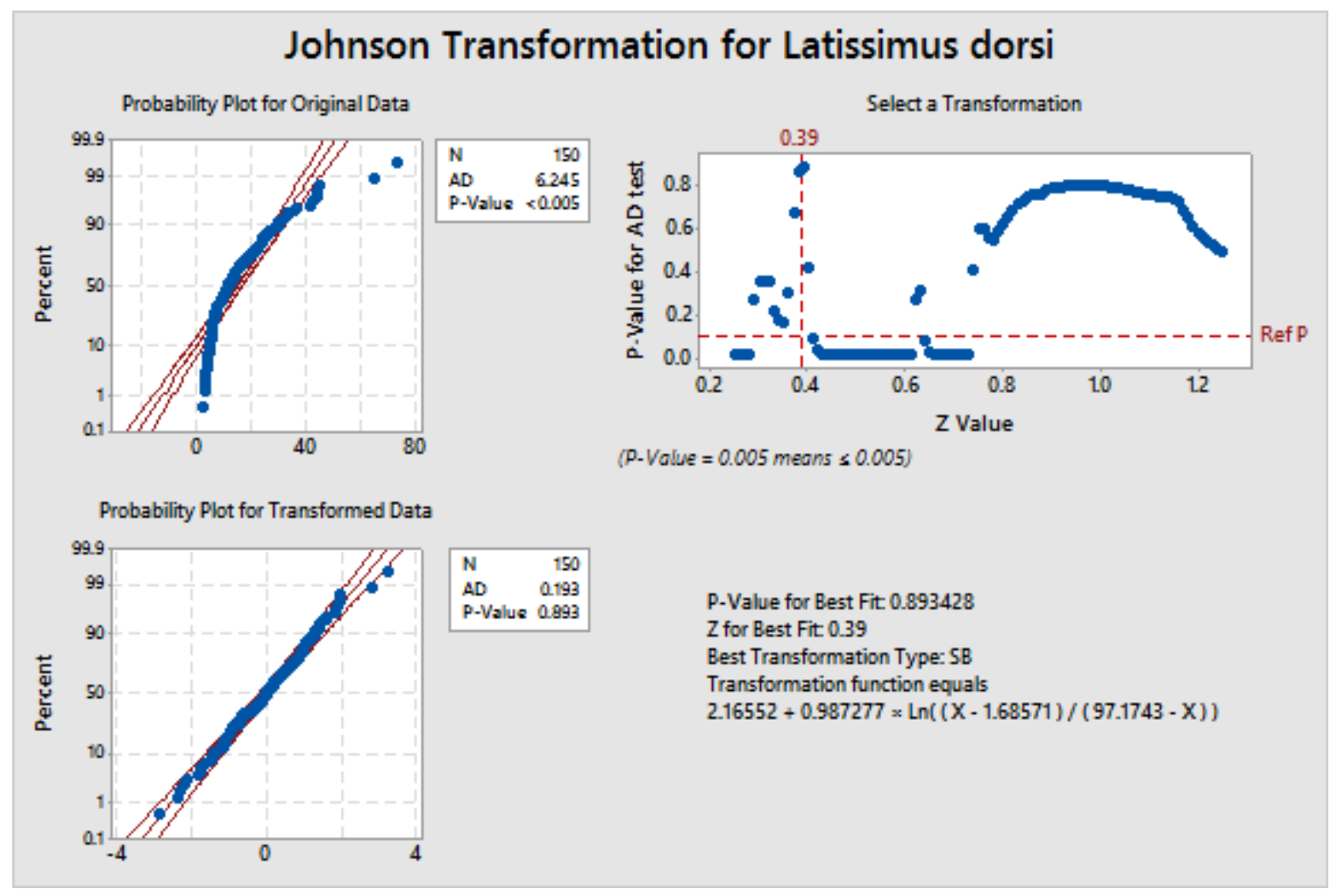

Johnson transformation for NMAV (latissimus dorsi) 
Appendix F: Analysis of variance 


\begin{tabular}{llllll}
\hline & $\mathrm{F}$ & $\mathrm{F}$ & $\mathrm{R}$ & $\mathrm{R}$ & \\
& $a$ & $b$ & $c$ & $n$ & $\mathrm{E}(M S)$ \\
\hline Factor & $i$ & $j$ & $k$ & $l$ & $\sigma^{2}+b n \sigma_{\tau \gamma}^{2}+b c n \sum \frac{\tau_{i}^{2}}{(a-1)}$ \\
\hline$\tau_{i}$ & 0 & $b$ & $c$ & $n$ & $\sigma^{2}+a n \sigma_{\beta \gamma}^{2}+a c n \sum \frac{\beta_{j}^{2}}{(b-1)}$ \\
\hline$\beta_{j}$ & $a$ & 0 & $c$ & $n$ & $\sigma^{2}+a b n \sigma_{\gamma}^{2}$ \\
\hline$\gamma_{k}$ & $a$ & $b$ & 1 & $n$ & $\sigma^{2}+n \sigma_{\tau \beta \gamma}^{2}+c n \sum \sum \frac{(\tau \beta)_{i j}^{2}}{(a-1)(b-1)}$ \\
\hline$(\tau \beta)_{i j}$ & 0 & 0 & $c$ & $n$ & $\sigma^{2}+b n \sigma_{\tau \gamma}^{2}$ \\
\hline$(\tau \gamma)_{i k}$ & 0 & $b$ & 1 & $n$ & $\sigma^{2}+a n \sigma_{\beta \gamma}^{2}$ \\
\hline$(\beta \gamma)_{j k}$ & $a$ & 0 & 1 & $n$ & $\sigma^{2}+n \sigma_{\tau \beta \gamma}^{2}$ \\
\hline$(\tau \beta \gamma)_{i j k}$ & 0 & 0 & 1 & $n$ & $\sigma^{2}$ \\
\hline$\varepsilon_{(i j k)}$ & 1 & 1 & 1 & 1 & $\sigma^{2}$ \\
\hline
\end{tabular}

General Linear Model: discomfort rating versus sub, Force, Direction

\begin{tabular}{|c|c|c|c|c|c|c|}
\hline Factor & Type & Leve & Value & & & \\
\hline sub & Random & & 1,2 , & $3,4,5$ & $6,7,8$, & 10 \\
\hline Force & Fixed & & 5.0 & $7.5,10.0$ & & \\
\hline Direction & Fixed & & $\mathrm{PB}$, & $D, P L, P R$, & $\mathrm{PU}$ & \\
\hline Analysis of & Varian & & & & & \\
\hline Source & & $\mathrm{DF}$ & Adj SS & Adj MS & F-Value & P-Value \\
\hline sub & & 9 & 119.86 & 13.318 & 18.51 & 0.000 \\
\hline Force & & 2 & 216.17 & 108.087 & 150.25 & 0.000 \\
\hline Direction & & 4 & 686.13 & 171.532 & 238.45 & 0.000 \\
\hline Force*Dir & ection & 8 & 25.39 & 3.174 & 4.41 & 0.000 \\
\hline Error & & 126 & 90.64 & 0.719 & & \\
\hline Total & & 149 & 1138.19 & & & \\
\hline
\end{tabular}

Model Summary
0.848154
S R $\quad$ Rq
$R-s q(a d j)$
$\mathrm{R}-\mathrm{sq}$ (pred)
$0.84815492 .04 \% \quad 90.58 \% \quad 88.71 \%$ 


\section{General Linear Model: MF (Supraspinatus) versus sub, Force, Direction}

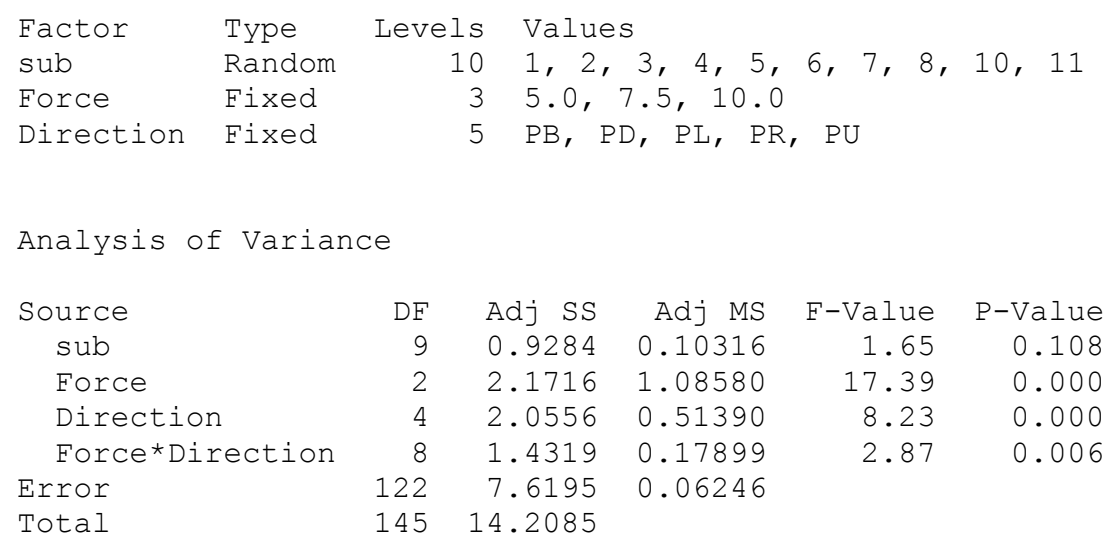

Model Summary

$\begin{array}{rrrr}S & R-s q & R-s q(a d j) & R-s q(p r e d) \\ 0.249910 & 46.37 \% & 36.26 \% & 23.34 \%\end{array}$

\section{General Linear Model: MF (Infraspinatus) versus sub, Force, Direction}

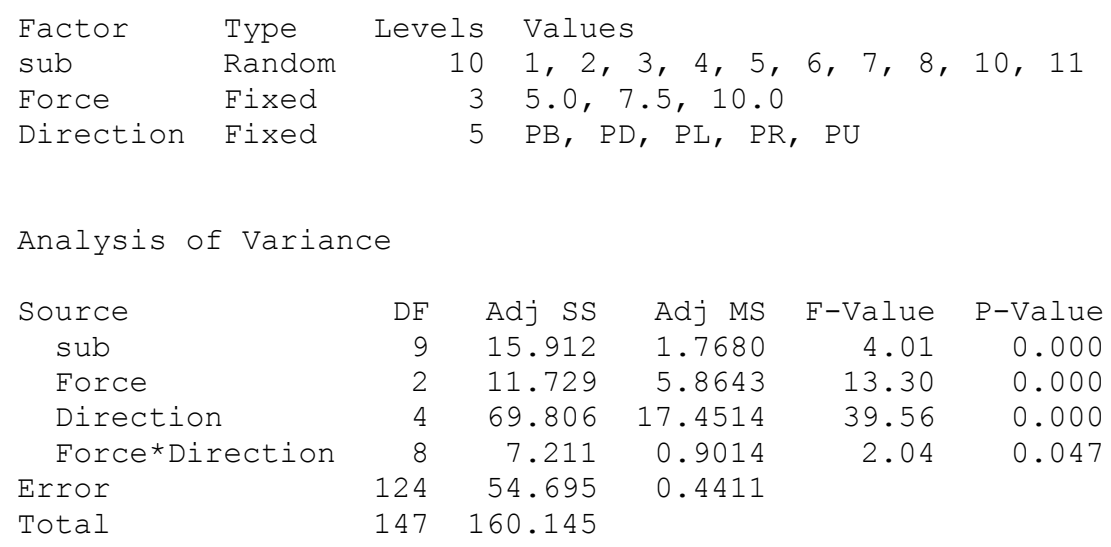

Model Summary

$\begin{array}{rrrr}S & R-s q & R-s q(a d j) & R-s q(p r e d) \\ 0.664148 & 65.85 \% & 59.51 \% & 51.39 \%\end{array}$


General Linear Model: MF (Teres major) versus sub, Force, Direction

\begin{tabular}{|c|c|c|c|c|c|c|}
\hline Factor & Type & Leve & Value & & & \\
\hline sub & Random & & 1,2 , & $3,4,5$, & $6,7,8$, & 10 \\
\hline Force & Fixed & & 5.0 & $7.5,10.0$ & & \\
\hline Direction & Fixed & & $\mathrm{PB}$, $\mathrm{F}$ & $D$, $P L, P R$, & $\mathrm{PU}$ & \\
\hline Analysis of & Varia & & & & & \\
\hline Source & & $\mathrm{DF}$ & Adj $S S$ & Adj MS & F-Value & P-Value \\
\hline sub & & 9 & 7.207 & 0.8008 & 2.03 & 0.042 \\
\hline Force & & 2 & 10.899 & 5.4495 & 13.79 & 0.000 \\
\hline Direction & & 4 & 77.787 & 19.4468 & 49.21 & 0.000 \\
\hline Force*Dir & ection & 8 & 6.551 & 0.8189 & 2.07 & 0.043 \\
\hline Error & & 123 & 48.608 & 0.3952 & & \\
\hline Total & & 146 & 152.269 & & & \\
\hline
\end{tabular}

Model Summary

$\begin{array}{rrrr}S & R-s q & R-s q(a d j) & R-s q(p r e d) \\ 0.628639 & 68.08 \% & 62.11 \% & 54.37 \%\end{array}$

\section{General Linear Model: MF (Mid deltoid) versus sub, Force, Direction}

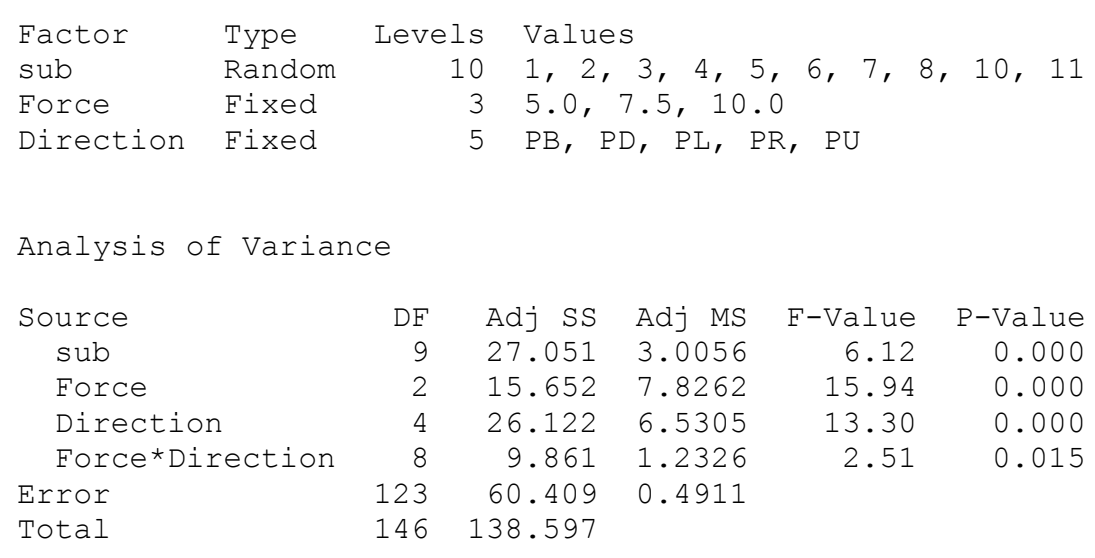

Model Summary

$\begin{array}{rrrr}S & R-s q & R-s q(a d j) & R-s q(p r e d) \\ 0.700804 & 56.41 \% & 48.26 \% & 37.91 \%\end{array}$


General Linear Model: MF (Ant deltoid) versus sub, Force, Direction

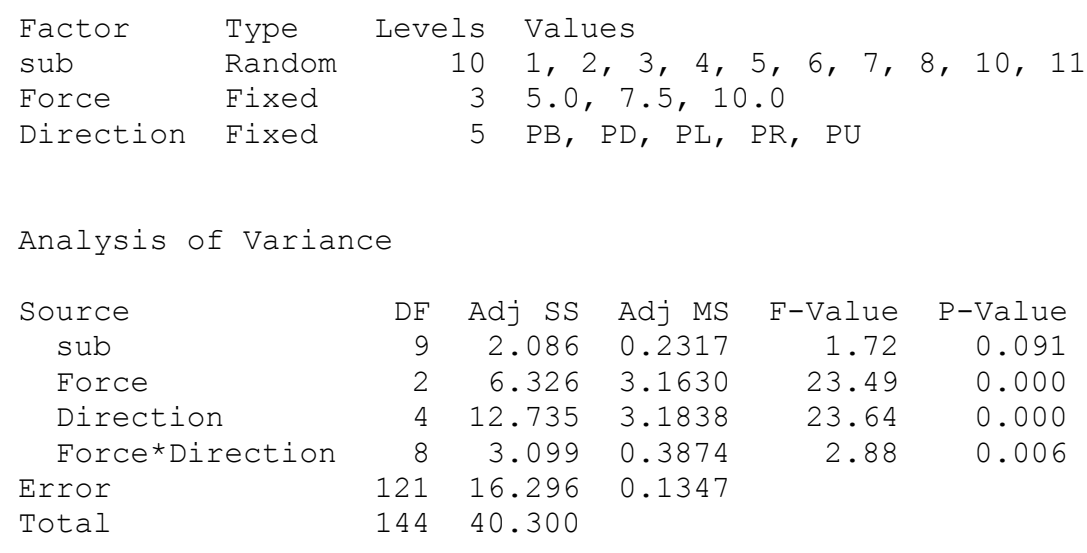

Model Summary

$\begin{array}{rrrr}S & R-s q & R-s q(\text { adj) } & \text { R-sq(pred) } \\ 0.366981 & 59.56 \% & 51.88 \% & 41.96 \%\end{array}$

General Linear Model: MF (Post deltoid) versus sub, Force, Direction

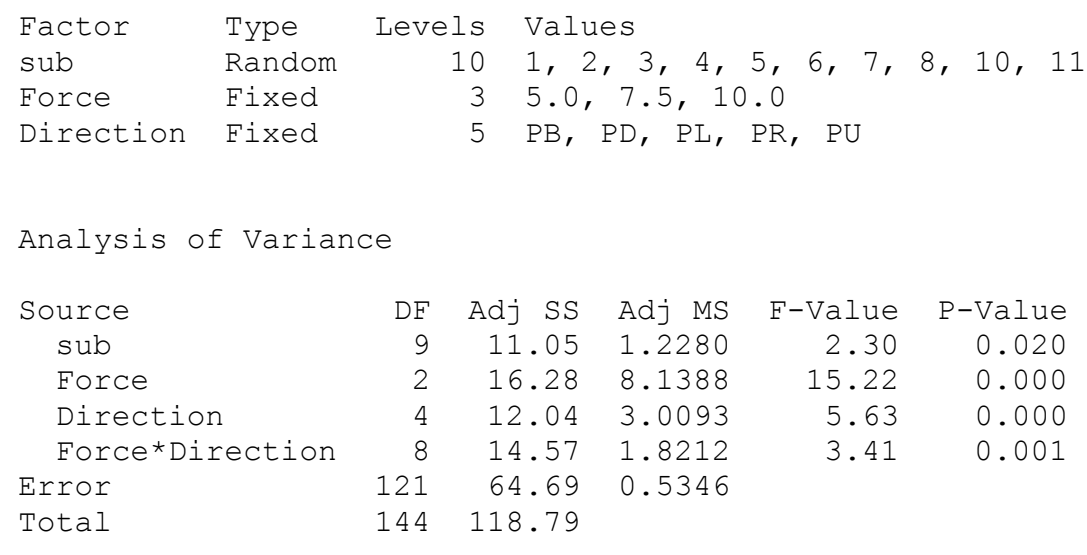

Model Summary
$\begin{array}{rrrr}S & R-s q & R-s q(a d j) & R-s q(p r e d) \\ 0.731167 & 45.54 \% & 35.19 \% & 22.02 \%\end{array}$ 


\section{General Linear Model: MF (Bicep) versus sub, Force, Direction}

\begin{tabular}{|c|c|c|c|c|c|c|}
\hline Factor & Type & Levels & \multicolumn{2}{|c|}{ Values } & & \\
\hline sub & Random & & 1,2 & $3,4,5$, & $6,7,8$, & 10 \\
\hline Force & Fixed & & 5.0, & $7.5,10.0$ & & \\
\hline Direction & Fixed & & $\mathrm{PB}$ & $D, P L, P R$, & $\mathrm{PU}$ & \\
\hline Analysis of & $=\operatorname{Variar}$ & & & & & \\
\hline Source & & $\mathrm{DF}$ & Adj SS & Adj $\mathrm{MS}$ & F-Value & P-Value \\
\hline sub & & 9 & 1.6244 & 0.18049 & 1.87 & 0.064 \\
\hline Force & & 2 & 1.6330 & 0.81650 & 8.45 & 0.000 \\
\hline Direction & & 4 & 2.9236 & 0.73091 & 7.56 & 0.000 \\
\hline Force*Dir & cection & 8 & 0.8145 & 0.10181 & 1.05 & 0.401 \\
\hline Error & & 116 & 11.2151 & 0.09668 & & \\
\hline Total & & 139 & 18.3180 & & & \\
\hline
\end{tabular}

Model Summary

$\begin{array}{rrrr}S & R-s q & R-s q(\text { adj) } & \text { R-sq(pred) } \\ 0.310937 & 38.78 \% & 26.64 \% & 10.77 \%\end{array}$

General Linear Model: MF (Tricep) versus sub, Force, Direction

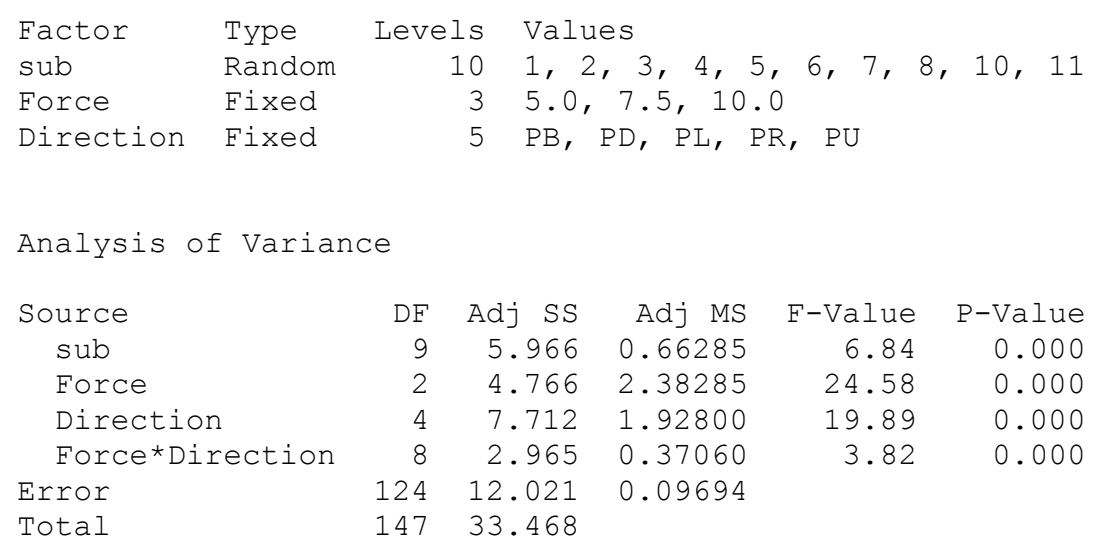

Model Summary
$0.31135^{3}$
$\mathrm{R}-\mathrm{sq}$
$R-s q(a d j)$
$\mathrm{R}-\mathrm{sq}$ (pred)
$64.08 \%$
$57.42 \%$
$48.94 \%$ 
General Linear Model: MF (Latissimus dorsi) versus sub, Force, Direction

\begin{tabular}{|c|c|c|c|c|c|}
\hline \multirow{3}{*}{$\begin{array}{l}\text { Factor } \\
\text { sub } \\
\text { Force }\end{array}$} & Levels & \multicolumn{4}{|c|}{ Values } \\
\hline & & 1,2 & $, 3,4$, & $5,6,7$, & 10 \\
\hline & & 5.0, & $7.5,10$ & .0 & \\
\hline Direction & & $\mathrm{PB}$ & PD, $P L$, & $\mathrm{PR}$ & \\
\hline Analysis of Varian & & & & & \\
\hline Source & $\mathrm{DF}$ & Adj $S S$ & Adj $\mathrm{MS}$ & F-Value & P-Value \\
\hline sub & 9 & 4.971 & 0.5523 & 5.08 & 0.000 \\
\hline Force & 2 & 1.814 & 0.9069 & 8.34 & 0.000 \\
\hline Direction & 4 & 4.535 & 1.1336 & 10.42 & 0.000 \\
\hline Force*Direction & 8 & 1.541 & 0.1926 & 1.77 & 0.090 \\
\hline Error & 117 & 12.727 & 0.1088 & & \\
\hline Total & 140 & 25.175 & & & \\
\hline
\end{tabular}

Model Summary

$\begin{array}{rrrr}S & R-s q & R-s q(\text { adj) } & \text { R-sq(pred) } \\ 0.329811 & 49.45 \% & 39.51 \% & 27.00 \%\end{array}$

General Linear Model: TM versus sub, Force, Direction

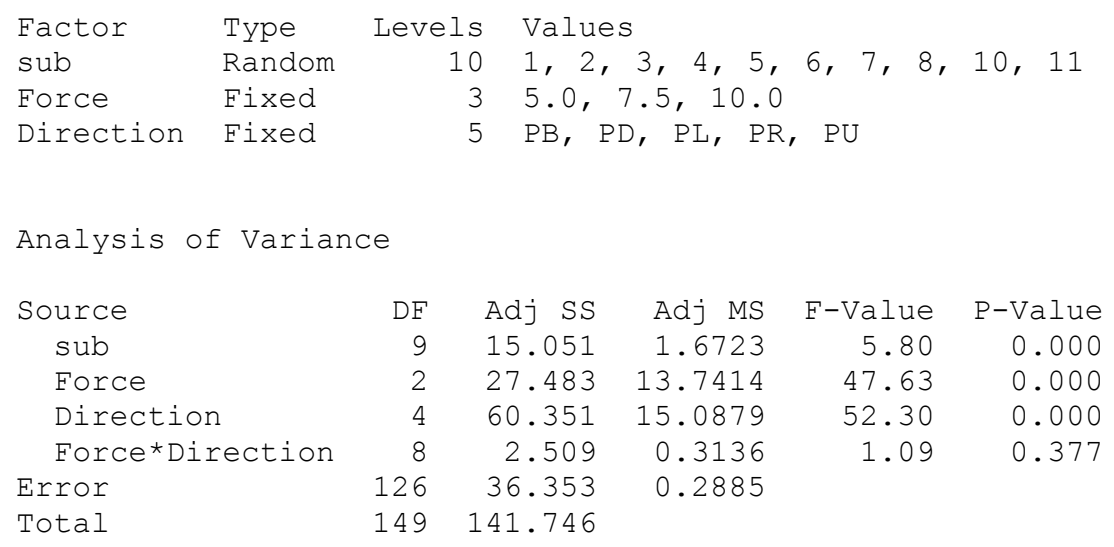

Model Summary
$\begin{array}{rrrr}S & R-s q & R-s q(\text { adj) } & R-s q(p r e d) \\ 0.537135 & 74.35 \% & 69.67 \% & 63.65 \%\end{array}$ 


\section{General Linear Model: NMAV (Supraspinatus) versus sub, Force, Direction}

\begin{tabular}{|c|c|c|c|c|c|c|}
\hline Factor & Type & Leve & Value & & & \\
\hline sub & Random & & 1,2, & $3,4,5$ & $6,7,8$, & 10,11 \\
\hline Force & Fixed & & 5.0 & $7.5,10.0$ & & \\
\hline Direction & Fixed & & $P B$, $\quad \mathrm{F}$ & $D, P L, P R$, & PU & \\
\hline Analysis of & Varian & & & & & \\
\hline Source & & $\mathrm{DF}$ & Adj $S S$ & Adj MS & F-Value & P-Value \\
\hline sub & & 9 & 33.893 & 3.7659 & 10.72 & 0.000 \\
\hline Force & & 2 & 16.855 & 8.4276 & 23.98 & 0.000 \\
\hline Direction & & 4 & 58.538 & 14.6345 & 41.64 & 0.000 \\
\hline Force*Dir & ection & 8 & 0.662 & 0.0828 & 0.24 & 0.984 \\
\hline Error & & 126 & 44.282 & 0.3514 & & \\
\hline Total & & 149 & 154.231 & & & \\
\hline
\end{tabular}

Model Summary

$\begin{array}{rrrr}S & R-s q & R-s q(a d j) & R-s q(p r e d) \\ 0.592827 & 71.29 \% & 66.05 \% & 59.31 \%\end{array}$

\section{General Linear Model: NMAV (Teres major) versus sub, Force, Direction}

\begin{tabular}{|c|c|c|c|c|c|c|}
\hline Factor & Type & Leve & Value & & & \\
\hline sub & Random & & 1,2 & $3,4,5$ & $6,7,8$, & 10,11 \\
\hline Force & Fixed & & 5.0 & $7.5,10.0$ & & \\
\hline Direction & Fixed & & $\mathrm{PB}$, & $\mathrm{D}, \mathrm{PL}, \mathrm{PR}$, & $\mathrm{PU}$ & \\
\hline Analysis of & $=$ Variar & & & & & \\
\hline Source & & $\mathrm{DF}$ & Adj $S S$ & Adj MS & F-Value & P-Value \\
\hline sub & & 9 & 56.054 & 6.2282 & 19.71 & 0.000 \\
\hline Force & & 2 & 30.815 & 15.4075 & 48.76 & 0.000 \\
\hline Direction & & 4 & 9.015 & 2.2536 & 7.13 & 0.000 \\
\hline Force*Dir & cection & 8 & 1.171 & 0.1463 & 0.46 & 0.880 \\
\hline Error & & 126 & 39.814 & 0.3160 & & \\
\hline Total & & 149 & 136.867 & & & \\
\hline
\end{tabular}

Model Summary

$\begin{array}{rrrr}S & R-s q & R-s q(a d j) & R-s q(p r e d) \\ 0.562122 & 70.91 \% & 65.60 \% & 58.77 \%\end{array}$


General Linear Model: NMAV (Ant deltoid) versus sub, Force, Direction

\begin{tabular}{|c|c|c|c|c|c|c|}
\hline Factor & Type & Leve & Valu & & & \\
\hline sub & Random & & 1,2 & $3,4,5$, & $6,7,8$, & 10,11 \\
\hline Force & Fixed & & 5.0, & $7.5,10.0$ & & \\
\hline Direction & Fixed & & $\mathrm{PB}$ & $P D, P L, P R$, & $\mathrm{PU}$ & \\
\hline Analysis of & Variar & & & & & \\
\hline Source & & $\mathrm{DF}$ & Adj $S S$ & Adj MS & F-Value & P-Value \\
\hline sub & & 9 & 7.186 & 0.7985 & 4.24 & 0.000 \\
\hline Force & & 2 & 3.850 & 1.9251 & 10.22 & 0.000 \\
\hline Direction & & 4 & 117.778 & 29.4444 & 156.26 & 0.000 \\
\hline Force*Dir & ection & 8 & 1.034 & 0.1293 & 0.69 & 0.703 \\
\hline Error & & 125 & 23.554 & 0.1884 & & \\
\hline Total & & 148 & 153.244 & & & \\
\hline
\end{tabular}

Model Summary

$\begin{array}{rrrr}S & R-s q & R-s q(a d j) & R-s q(p r e d) \\ 0.434092 & 84.63 \% & 81.80 \% & 78.17 \%\end{array}$

General Linear Model: NMAV (Post deltoid) versus sub, Force, Direction

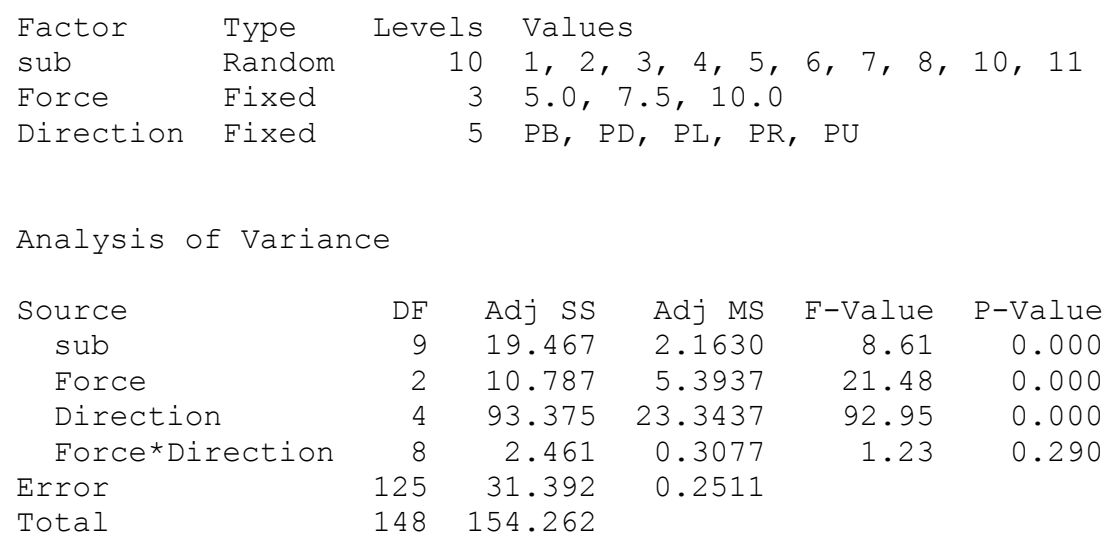

Model Summary

$\begin{array}{rrrr}S & R-s q & R-s q(a d j) & R-s q(\text { pred) } \\ 0.501132 & 79.65 \% & 75.91 \% & 71.06 \%\end{array}$ 


\section{General Linear Model: NMAV (Bicep) versus sub, Force, Direction}

\begin{tabular}{|c|c|c|c|c|c|c|}
\hline Factor & Type & Leve & Valu & & & \\
\hline sub & Random & & 1,2 & $3,4,5$, & $6,7,8$, & 10,11 \\
\hline Force & Fixed & & 5.0 & $7.5,10.0$ & & \\
\hline Direction & Fixed & & $\mathrm{PB}$ & $D$, $P L, P R$, & PU & \\
\hline Analysis of & Variar & & & & & \\
\hline Source & & $\mathrm{DF}$ & Adj $S S$ & Adj MS & F-Value & P-Value \\
\hline sub & & 9 & 16.526 & 1.8362 & 12.32 & 0.000 \\
\hline Force & & 2 & 6.643 & 3.3214 & 22.29 & 0.000 \\
\hline Direction & & 4 & 96.475 & 24.1187 & 161.84 & 0.000 \\
\hline Force*Dir & ection & 8 & 1.867 & 0.2334 & 1.57 & 0.141 \\
\hline Error & & 126 & 18.778 & 0.1490 & & \\
\hline Total & & 149 & 140.288 & & & \\
\hline
\end{tabular}

Model Summary

$\begin{array}{rrrr}S & R-s q & R-s q(a d j) & R-s q(p r e d) \\ 0.386042 & 86.61 \% & 84.17 \% & 81.03 \%\end{array}$

\section{General Linear Model: NMAV (Tricep) versus sub, Force, Direction}

\begin{tabular}{|c|c|c|c|c|c|c|}
\hline Factor & Type & Leve & Value & & & \\
\hline sub & Random & & 1,2 , & $3,4,5$, & $6,7,8$, & 10 \\
\hline Force & Fixed & & 5.0 & $7.5,10.0$ & & \\
\hline Direction & Fixed & & $\mathrm{PB}, \quad \mathrm{E}$ & $D$, $P L, P R$, & PU & \\
\hline Analysis of & Variar & & & & & \\
\hline Source & & $\mathrm{DF}$ & Adj $S S$ & Adj MS & F-Value & P-Value \\
\hline sub & & 9 & 29.812 & 3.3124 & 12.25 & 0.000 \\
\hline Force & & 2 & 11.037 & 5.5185 & 20.40 & 0.000 \\
\hline Direction & & 4 & 64.210 & 16.0524 & 59.35 & 0.000 \\
\hline Force*Dir & ection & 8 & 5.082 & 0.6352 & 2.35 & 0.022 \\
\hline Error & & 126 & 34.078 & 0.2705 & & \\
\hline Total & & 149 & 144.218 & & & \\
\hline
\end{tabular}

Model Summary

$\begin{array}{rrrr}S & R-s q & R-s q(a d j) & R-s q(p r e d) \\ 0.520057 & 76.37 \% & 72.06 \% & 66.51 \%\end{array}$


General Linear Model: NMAV (Latissimus dorsi) versus sub, Force, Direction

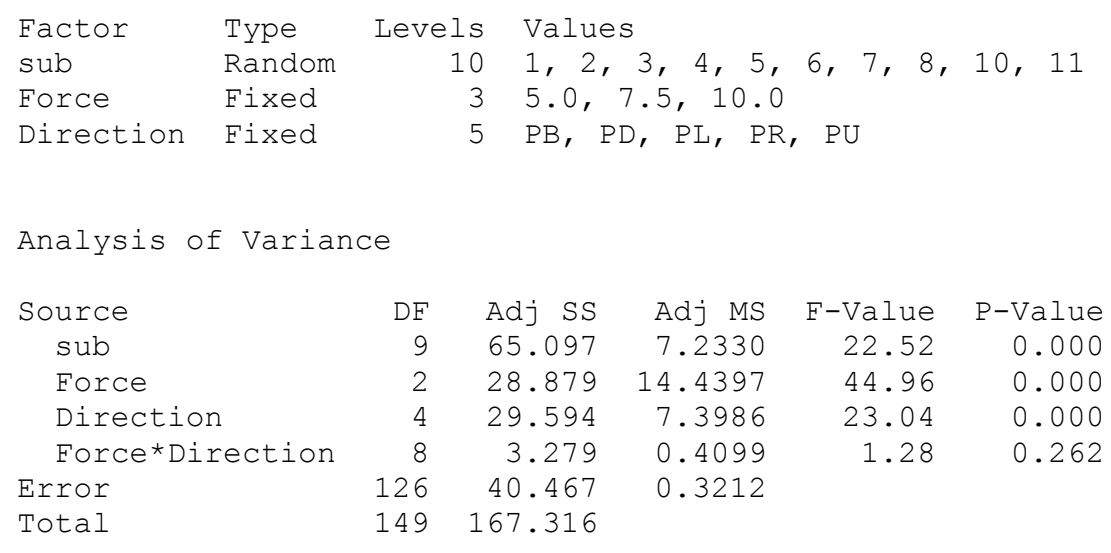

Model Summary

$\begin{array}{rrrr}S & R-s q & R-s q(\text { adj) } & \text { R-sq(pred) } \\ 0.566715 & 75.81 \% & 71.40 \% & 65.72 \%\end{array}$

General Linear Model: TNMAV versus sub, Force, Direction

\begin{tabular}{|c|c|c|c|c|c|}
\hline Factor & Type & Valu & es & & \\
\hline sub & Random & 1,2 & $, 3,4,5$ & 6,7, & 10,11 \\
\hline Force & Fixed & 5.0, & $7.5,10$. & & \\
\hline Direction & Fixed & $\mathrm{PB}$ & $P D, P L, P$ & R, $\mathrm{PU}$ & \\
\hline Analysis of & Variance & & & & \\
\hline Source & $\mathrm{DF}$ & Adj SS & Adj MS & F-Value & P-Value \\
\hline sub & 9 & 70774 & 7863.7 & 12.47 & 0.000 \\
\hline Force & 2 & 144207 & 72103.5 & 114.32 & 0.000 \\
\hline Direction & 4 & 347382 & 86845.5 & 137.69 & 0.000 \\
\hline Force*Dir & rection & 35327 & 4415.9 & 7.00 & 0.000 \\
\hline Error & 126 & 79470 & 630.7 & & \\
\hline Total & 149 & 677160 & & & \\
\hline
\end{tabular}

Model Summary

$\begin{array}{rrrr}S & R-s q & R-s q(\text { adj) } & \text { R-sq(pred) } \\ 25.1140 & 88.26 \% & 86.12 \% & 83.37 \%\end{array}$ 
Appendix G: Kruskal-Wallis test 


\section{Kruskal-Wallis Test: NMAV (Infraspinatus) versus Force}

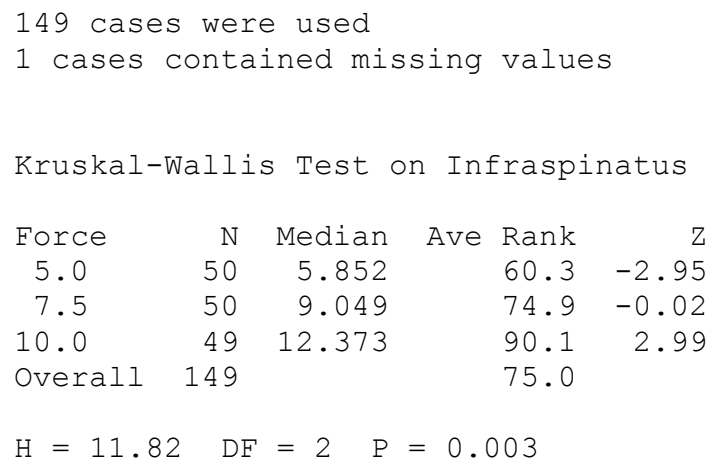

Kruskal-Wallis Test: NMAV (Infraspinatus) versus Direction

\begin{tabular}{|c|c|c|c|c|c|}
\hline \multicolumn{2}{|c|}{ Kruskal-Wallis } & \multirow{2}{*}{$\begin{array}{l}\text { Test on } \\
\text { Median }\end{array}$} & \multicolumn{3}{|c|}{ Infraspinatus } \\
\hline Direction & $\mathrm{N}$ & & Ave & Rank & Z \\
\hline $\mathrm{PB}$ & 30 & 5.526 & & 53.5 & -3.06 \\
\hline $\mathrm{PD}$ & 30 & 7.377 & & 55.7 & -2.74 \\
\hline PL & 30 & 3.705 & & 27.7 & -6.72 \\
\hline PR & 30 & 38.300 & & 122.0 & 6.67 \\
\hline $\mathrm{PU}$ & 29 & 36.337 & & 117.6 & 5.92 \\
\hline Overall & 149 & & & 75.0 & \\
\hline
\end{tabular}


Kruskal-Wallis Test: NMAV (Middle deltoid) versus Force

\begin{tabular}{lrrrr}
\multicolumn{4}{l}{ Kruskal-Wallis Test on Mid deltoid } \\
$\begin{array}{lrrrr}\text { Force } & \text { N } & \text { Median } & \text { Ave Rank } & \text { Z } \\
5.0 & 50 & 2.849 & 62.7 & -2.55 \\
7.5 & 50 & 4.828 & 75.0 & -0.10 \\
10.0 & 50 & 7.610 & 88.8 & 2.65 \\
\text { Overall } & 150 & & 75.5 & \\
\text { H }=9.00 & \text { DF }=2 \quad \mathrm{P}=0.011\end{array}$
\end{tabular}

Kruskal-Wallis Test: NMAV (Middle deltoid) versus Direction

\begin{tabular}{|c|c|c|c|c|c|}
\hline Direction & $\mathrm{N}$ & Median & Ave & Rank & Z \\
\hline $\mathrm{PB}$ & 30 & 1.150 & & 33.0 & -5.99 \\
\hline $\mathrm{PD}$ & 30 & 2.965 & & 63.4 & -1.70 \\
\hline PL & 30 & 1.781 & & 44.6 & -4.36 \\
\hline$P R$ & 30 & 19.127 & & 123.3 & 6.73 \\
\hline $\mathrm{PU}$ & 30 & 15.216 & & 113.2 & 5.31 \\
\hline Overall & 150 & & & 75.5 & \\
\hline$=105.05$ & $\mathrm{DF}$ & $=4$ & & & \\
\hline
\end{tabular}


Appendix H: Tukey Pairwise comparisons 
Comparisons for MF (Supraspinatus)

Tukey Pairwise Comparisons: Response $=$ MF (Supraspinatus), Term = Force*Direction

\begin{tabular}{|c|c|c|c|c|c|c|c|}
\hline Force*Direction & $\mathrm{N}$ & Mean & & & oup & ing & \\
\hline $5.0 \mathrm{PD}$ & 9 & 0.010713 & A & & & & \\
\hline $5.0 \mathrm{PR}$ & 10 & -0.135945 & A & B & & & \\
\hline $10.0 \mathrm{~PB}$ & 10 & -0.163085 & A & B & & & \\
\hline $5.0 \mathrm{PL}$ & 9 & -0.170668 & A & B & $\mathrm{C}$ & & \\
\hline $7.5 \mathrm{~PB}$ & 10 & -0.182940 & A & B & $\mathrm{C}$ & & \\
\hline $5.0 \mathrm{~PB}$ & 10 & -0.241495 & A & B & $\mathrm{C}$ & & \\
\hline $7.5 \mathrm{PR}$ & 10 & -0.259485 & A & B & C & $\mathrm{D}$ & \\
\hline $7.5 \mathrm{PL}$ & 9 & -0.320884 & A & B & C & $\mathrm{D}$ & \\
\hline $5.0 \mathrm{PU}$ & 10 & -0.352615 & A & B & $\mathrm{C}$ & $\mathrm{D}$ & $\mathrm{E}$ \\
\hline $10.0 \mathrm{PL}$ & 10 & -0.407525 & & B & $\mathrm{C}$ & $\mathrm{D}$ & $\mathrm{E}$ \\
\hline $7.5 \mathrm{PD}$ & 10 & -0.420215 & & B & $\mathrm{C}$ & D & $\mathrm{E}$ \\
\hline $10.0 \mathrm{PD}$ & 9 & -0.450856 & & B & $\mathrm{C}$ & $\mathrm{D}$ & $\mathrm{E}$ \\
\hline $7.5 \mathrm{PU}$ & 10 & -0.561455 & & & C & D & $\mathrm{E}$ \\
\hline $10.0 \mathrm{PR}$ & 10 & -0.631245 & & & & D & $\mathrm{E}$ \\
\hline $10.0 \mathrm{PU}$ & 10 & -0.732980 & & & & & $\mathrm{E}$ \\
\hline
\end{tabular}

\section{Comparisons for MF (Infraspinatus)}

Tukey Pairwise Comparisons: Response = MF (Infraspinatus), Term = Force* Direction

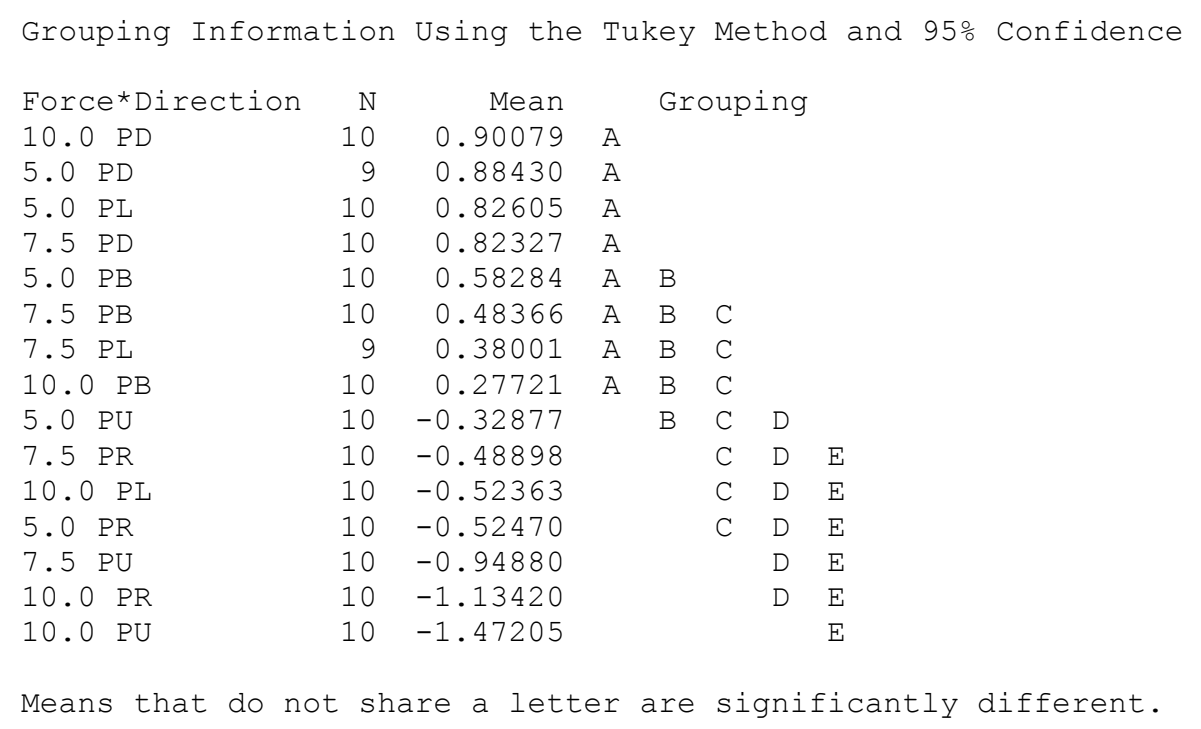




\section{Comparisons for MF (Teres major)}

Tukey Pairwise Comparisons: Response $=$ MF (Teres major), Term = Force*Direction

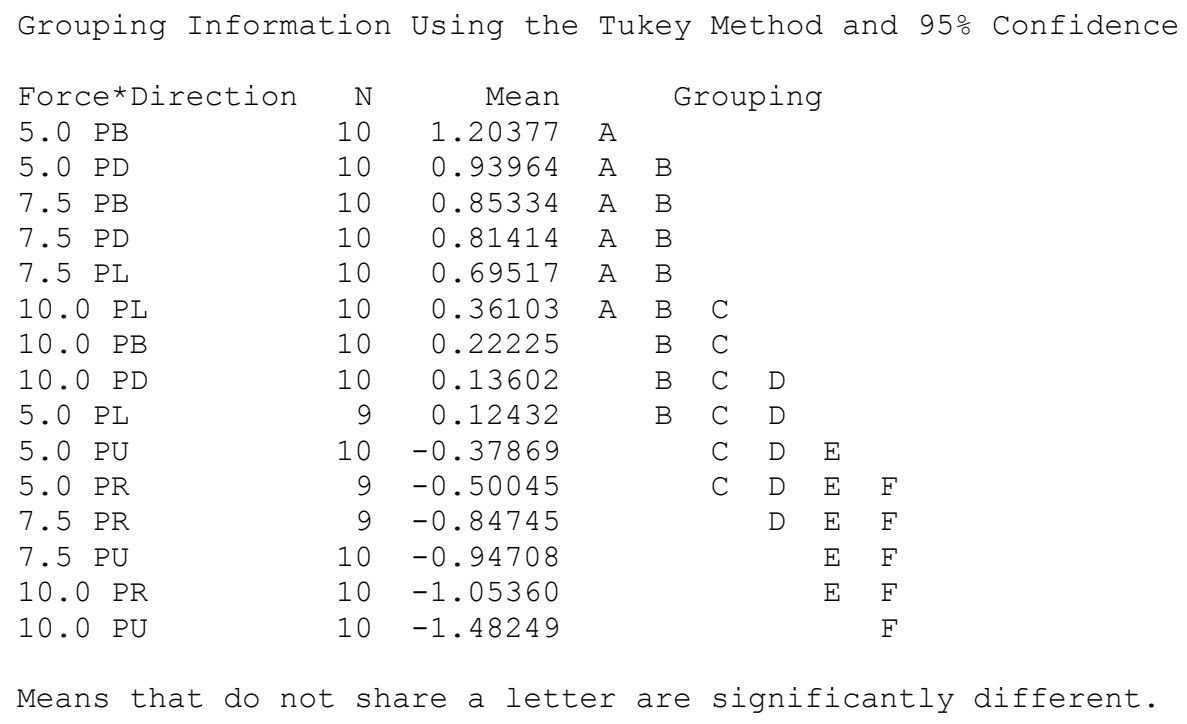

\section{Comparisons for MF (Mid deltoid)}

Tukey Pairwise Comparisons: Response $=$ MF (Mid deltoid), Term $=$ Force* Direction

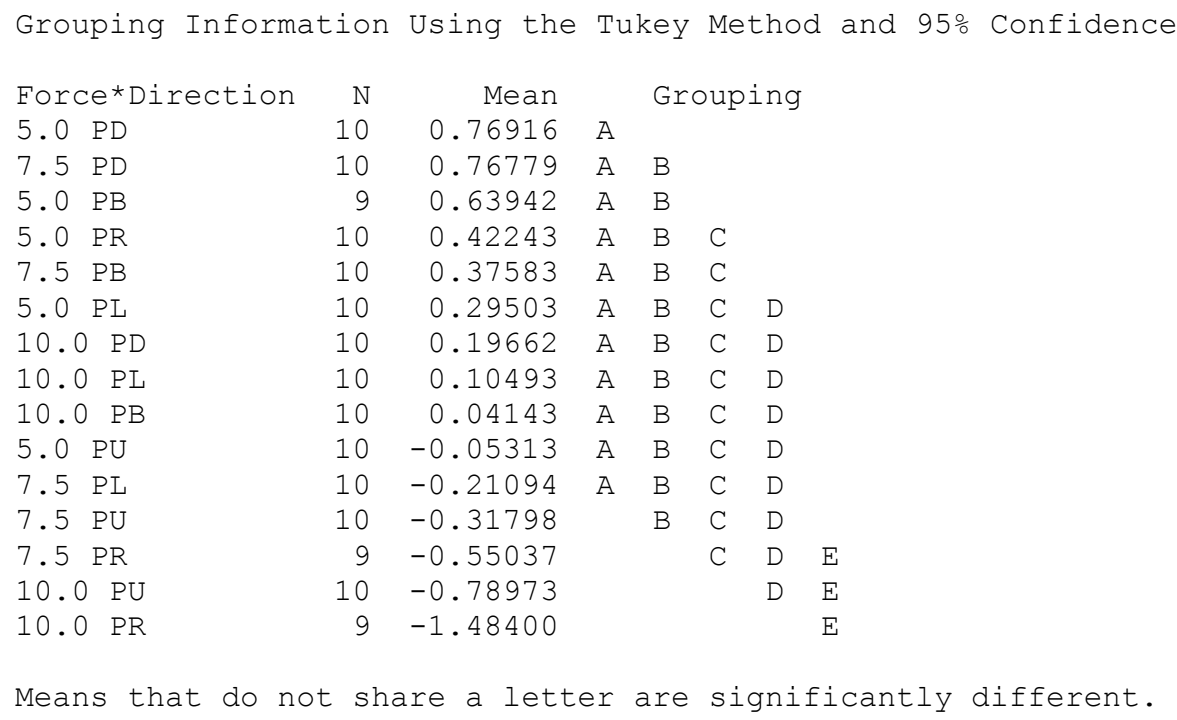


Comparisons for MF (Ant deltoid)

Tukey Pairwise Comparisons: Response $=$ MF (Ant deltoid), Term $=$ Force*Direction

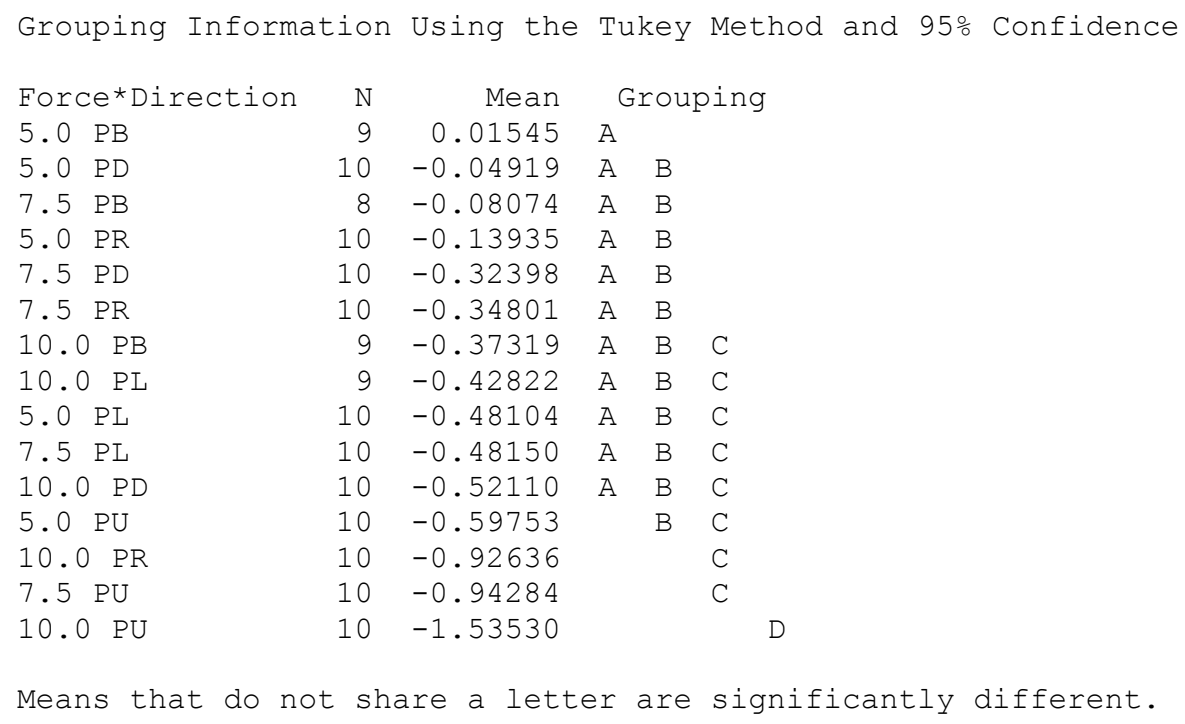

\section{Comparisons for MF (Post deltoid)}

Tukey Pairwise Comparisons: Response $=$ MF (Post deltoid), Term $=$ Force* Direction

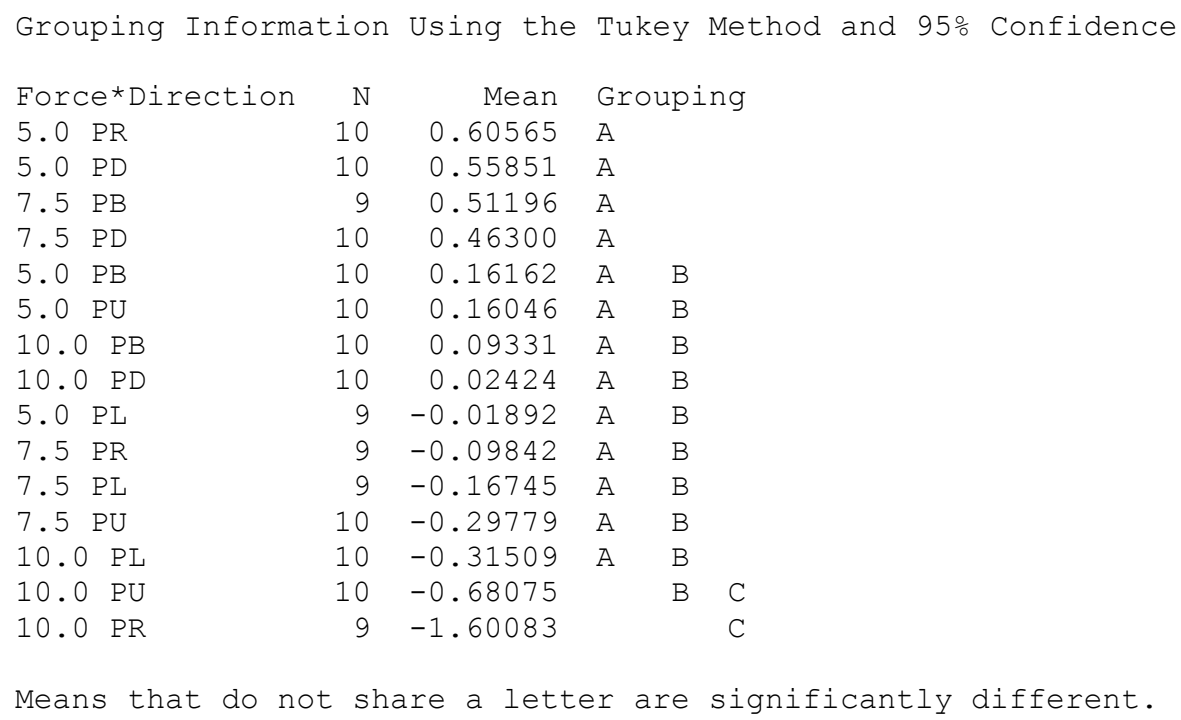


Comparisons for MF (Bicep)

Tukey Pairwise Comparisons: Response $=$ MF (Bicep), Term $=$ Force

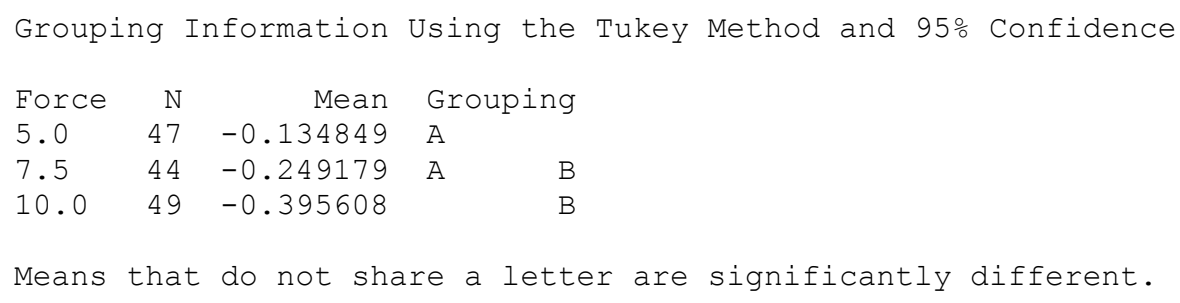

\section{Tukey Simultaneous 95\% Cls}

Tukey Pairwise Comparisons: Response $=$ MF (Bicep), Term $=$ Direction

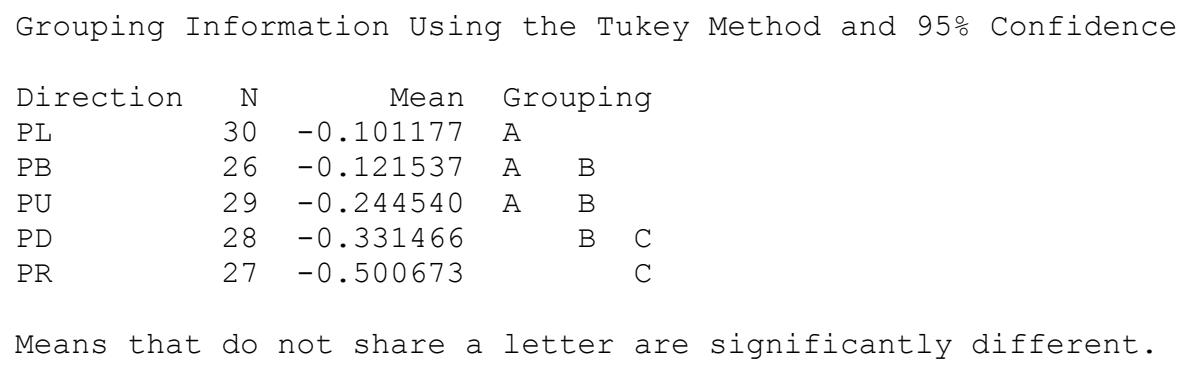

\section{Tukey Simultaneous 95\% Cls}

\section{Comparisons for MF (Tricep)}

Tukey Pairwise Comparisons: Response $=$ MF (Tricep), Term $=$ Force ${ }^{*}$ Direction

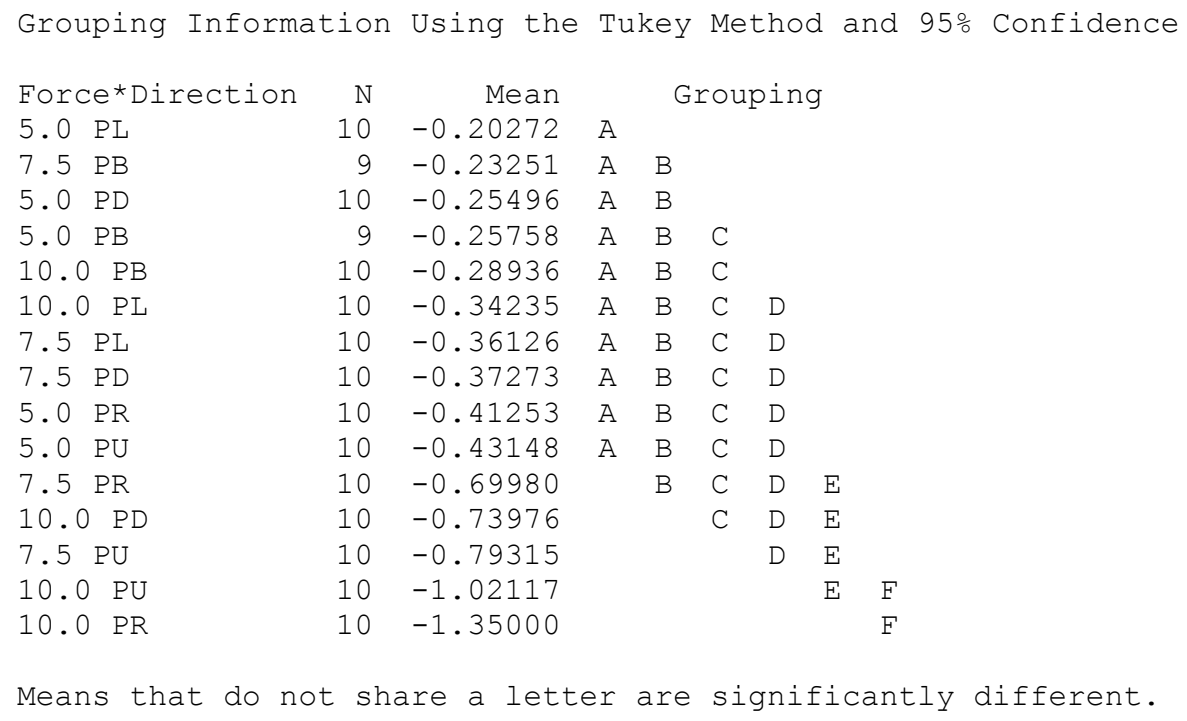


Comparisons for MF (Latissimus dorsi)

Tukey Pairwise Comparisons: Response = MF (Latissimus dorsi), Term = Force

Grouping Information Using the Tukey Method and 95\% Confidence

Force N Mean Grouping

$\begin{array}{llll}5.0 & 46 & -0.186679 \quad \mathrm{~A}\end{array}$

$\begin{array}{lll}7.5 & 46 & -0.285607 \quad \mathrm{~A}\end{array}$

$10.0 \quad 49-0.462065 \quad$ B

Means that do not share a letter are significantly different.

Tukey Simultaneous 95\% Cls

Tukey Pairwise Comparisons: Response = MF (Latissimus dorsi), Term = Direction

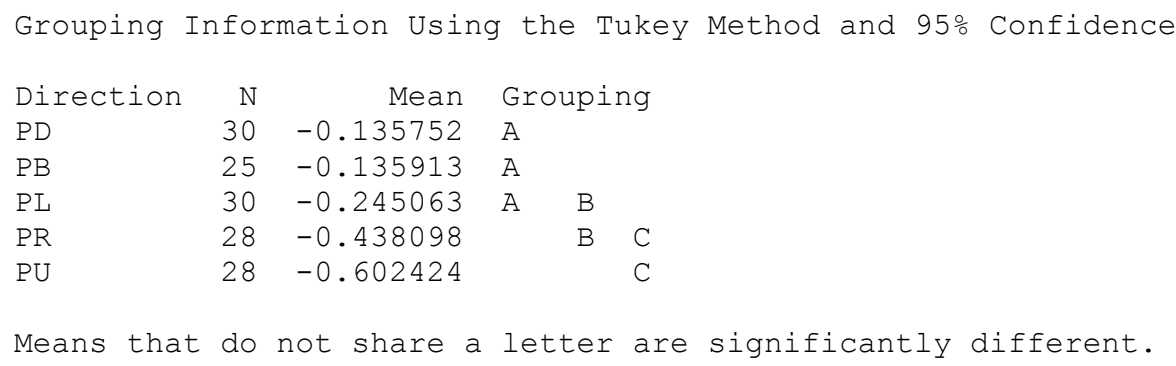

Tukey Simultaneous 95\% Cls 
Comparisons for TM

Tukey Pairwise Comparisons: Response = TM, Term = Force

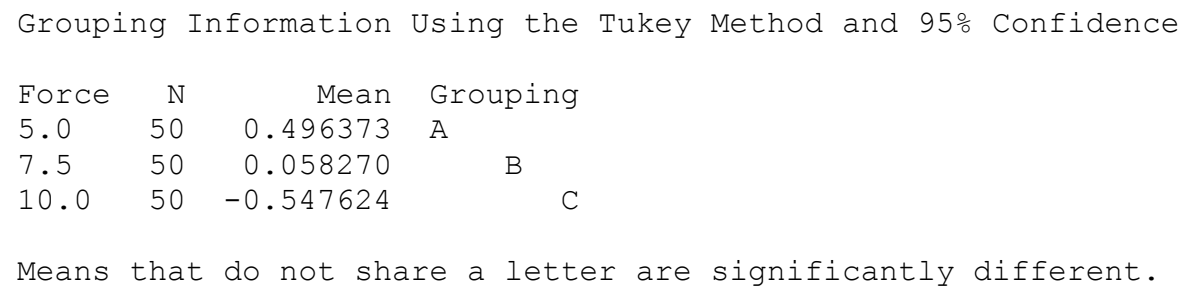

Tukey Simultaneous 95\% Cls

Tukey Pairwise Comparisons: Response = TM, Term = Direction

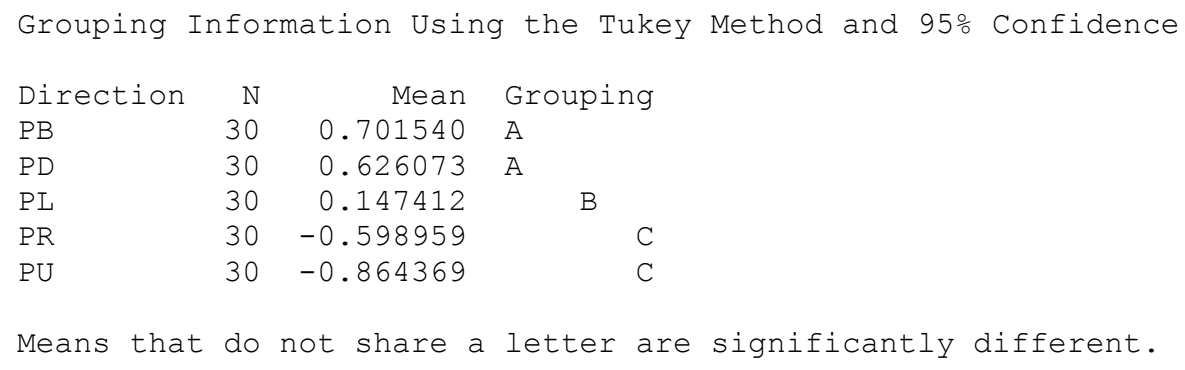

Tukey Simultaneous 95\% Cls

\section{Comparisons for NMAV (Supraspinatus)}

Tukey Pairwise Comparisons: Response $=$ NMAV (Supraspinatus), Term $=$ Force

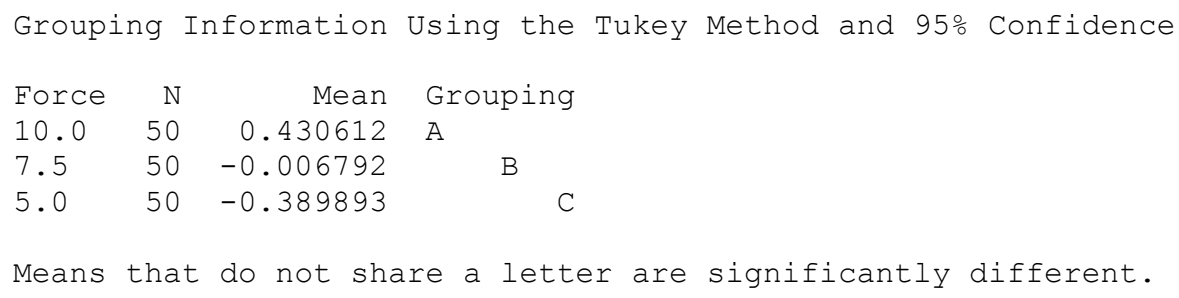

Tukey Simultaneous 95\% Cls 
Tukey Pairwise Comparisons: Response $=$ NMAV (Supraspinatus), Term $=$ Direction

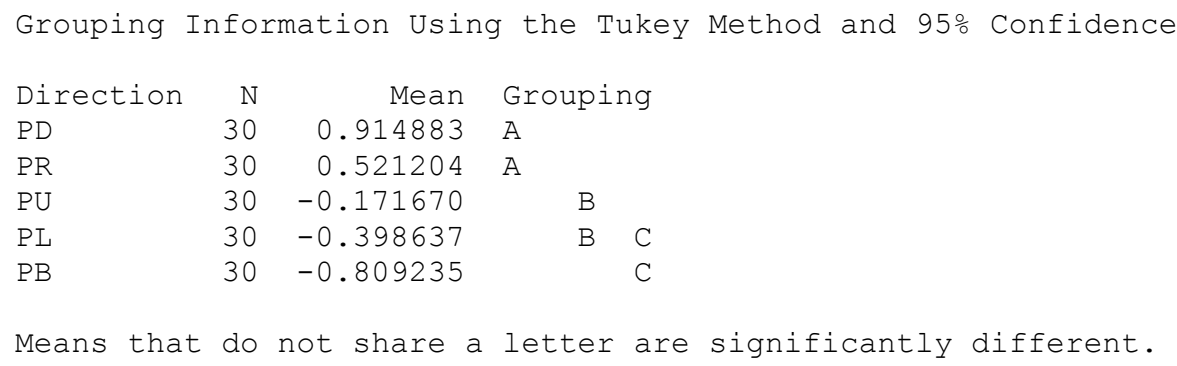

Tukey Simultaneous 95\% Cls

Comparisons for NMAV (Teres major)

Tukey Pairwise Comparisons: Response = NMAV (Teres major), Term = Force

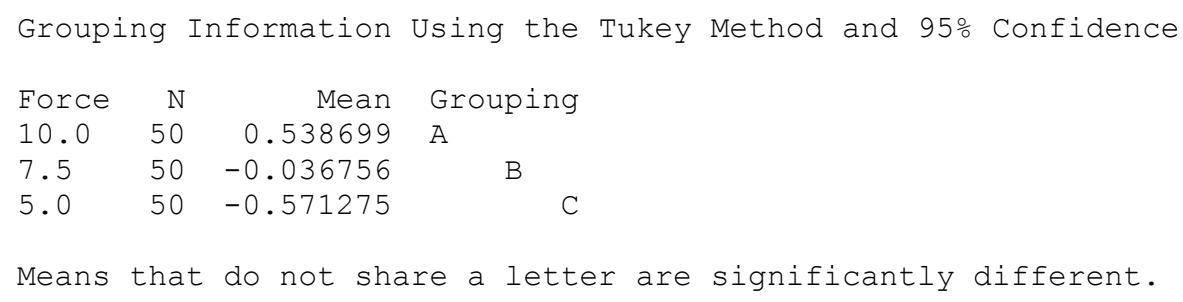

Tukey Simultaneous 95\% Cls

Tukey Pairwise Comparisons: Response $=$ NMAV (Teres major), Term $=$ Direction

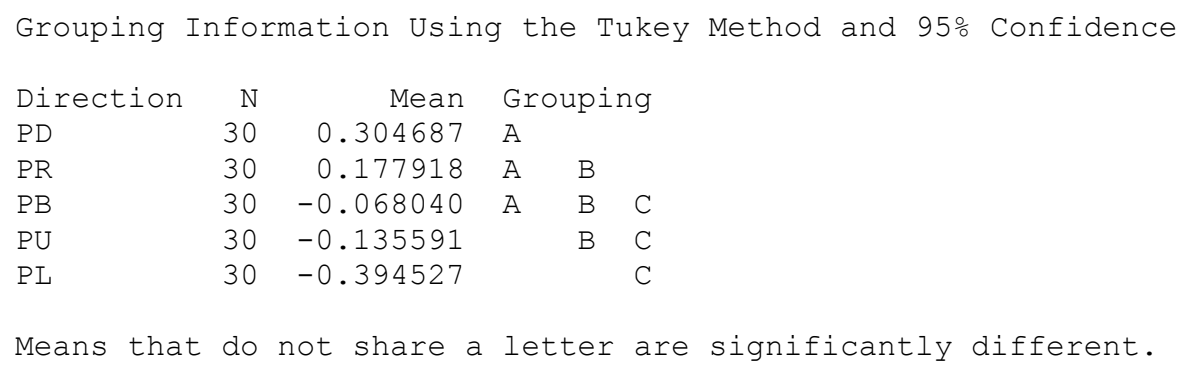

Tukey Simultaneous $95 \%$ Cls 
Comparisons for NMAV (Ant deltoid)

Tukey Pairwise Comparisons: Response = NMAV (Ant deltoid), Term = Force

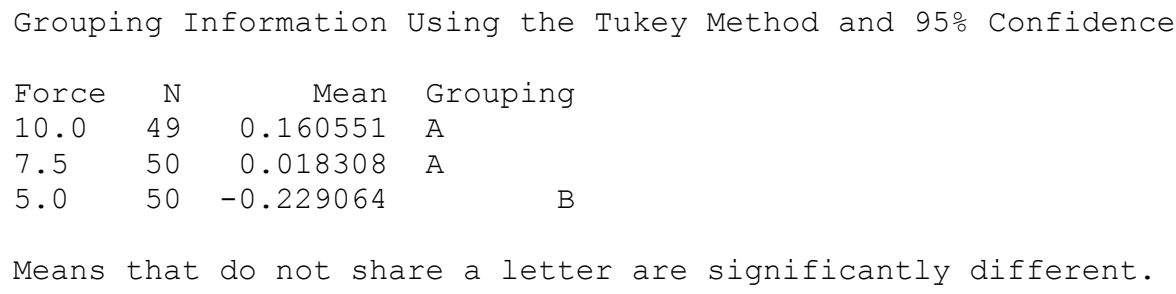

Tukey Simultaneous 95\% Cls

Tukey Pairwise Comparisons: Response $=$ NMAV $($ Ant deltoid), Term $=$ Direction

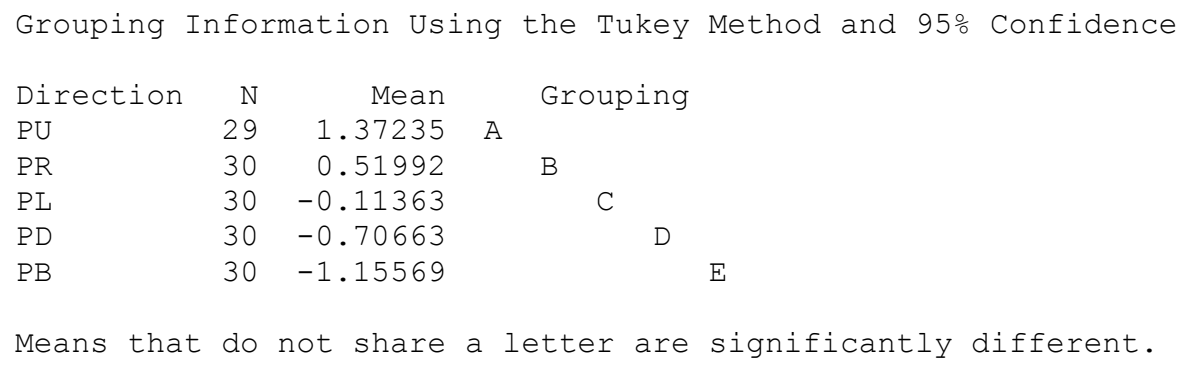

Tukey Simultaneous 95\% Cls

Comparisons for NMAV (Post deltoid)

Tukey Pairwise Comparisons: Response = NMAV (Post deltoid), Term = Force

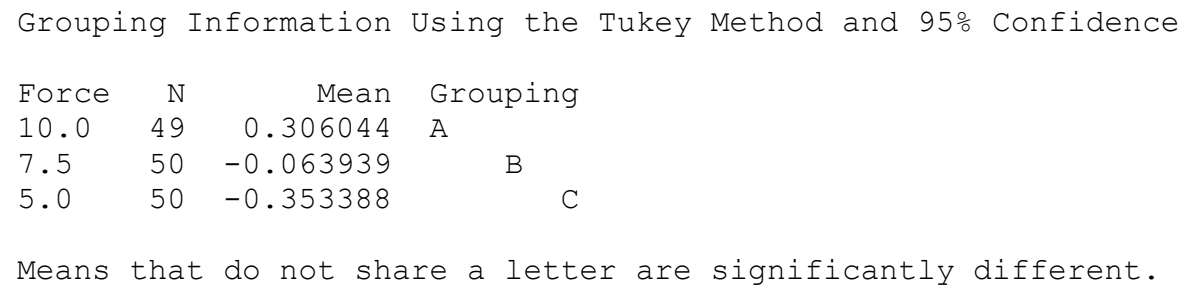

Tukey Simultaneous 95\% Cls 
Tukey Pairwise Comparisons: Response = NMAV (Post deltoid), Term $=$ Direction

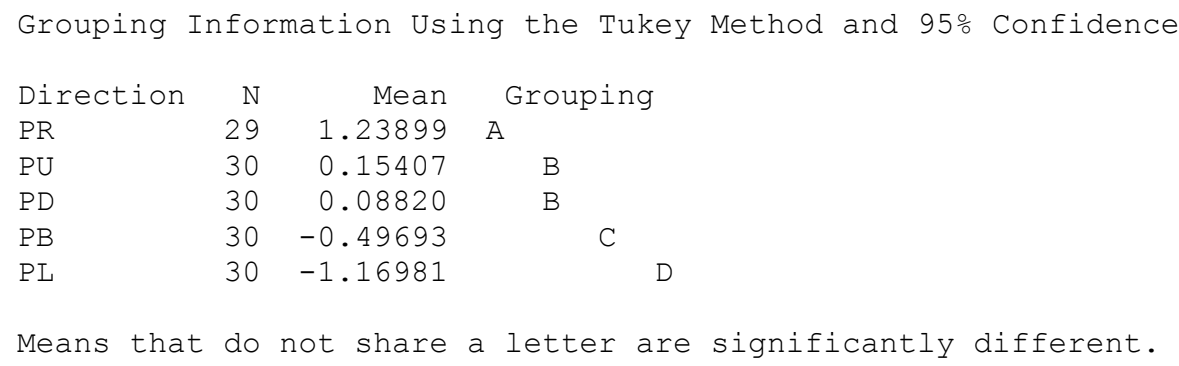

Tukey Simultaneous 95\% Cls

Comparisons for NMAV (Bicep)

Tukey Pairwise Comparisons: Response $=$ NMAV (Bicep), Term $=$ Force

Grouping Information Using the Tukey Method and 95\% Confidence

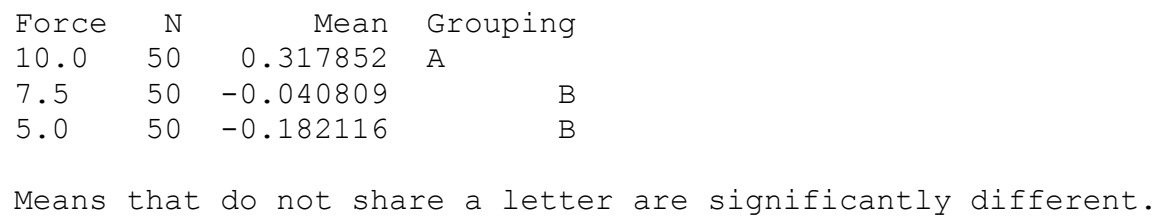

Tukey Simultaneous 95\% Cls

Tukey Pairwise Comparisons: Response $=$ NMAV (Bicep), Term $=$ Direction

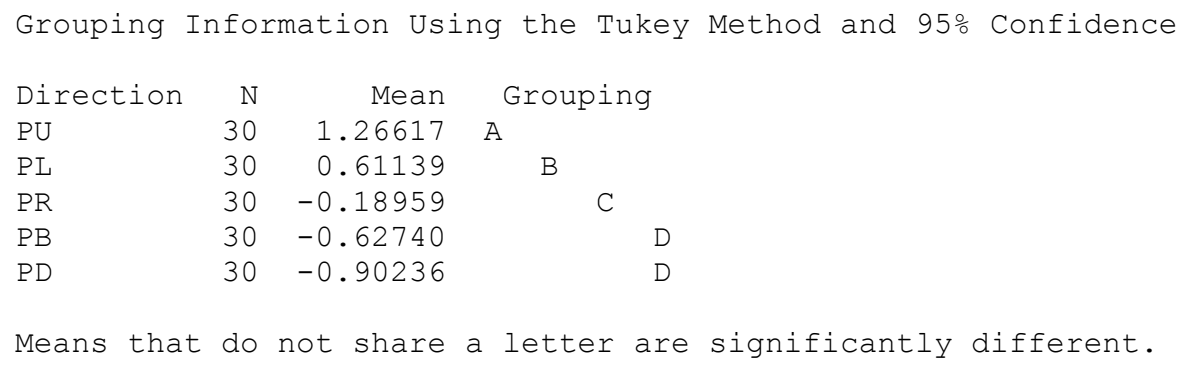

Tukey Simultaneous 95\% Cls 
Comparisons for NMAV (Tricep)

Tukey Pairwise Comparisons: Response $=$ NMAV (Tricep), Term $=$ Force*Direction

Grouping Information Using the Tukey Method and 95\% Confidence

\begin{tabular}{|c|c|c|c|c|c|c|c|c|c|c|}
\hline Force*Direction & $\mathrm{N}$ & Mean & & & & \multicolumn{5}{|c|}{ Grouping } \\
\hline $10.0 \mathrm{PL}$ & 10 & 1.33180 & A & & & & & & & \\
\hline $7.5 \mathrm{PL}$ & 10 & 1.04777 & A & B & & & & & & \\
\hline $10.0 \mathrm{~PB}$ & 10 & 0.98464 & A & B & $\mathrm{C}$ & & & & & \\
\hline $5.0 \mathrm{PL}$ & 10 & 0.65185 & A & $\mathrm{B}$ & $\mathrm{C}$ & D & & & & \\
\hline $7.5 \mathrm{~PB}$ & 10 & 0.36537 & & $\mathrm{~B}$ & $\mathrm{C}$ & $\mathrm{D}$ & $\mathrm{E}$ & & & \\
\hline $5.0 \mathrm{PD}$ & 10 & 0.21681 & & & $\mathrm{C}$ & $\mathrm{D}$ & E & $\mathrm{F}$ & & \\
\hline $10.0 \mathrm{PR}$ & 10 & 0.11908 & & & & $\mathrm{D}$ & E & F & G & \\
\hline $10.0 \mathrm{PD}$ & 10 & 0.06900 & & & & $\mathrm{D}$ & E & F & G & \\
\hline $5.0 \mathrm{~PB}$ & 10 & -0.10904 & & & & $\mathrm{D}$ & $\mathrm{E}$ & F & G & \\
\hline $7.5 \mathrm{PD}$ & 10 & -0.21854 & & & & & $\mathrm{E}$ & F & G & $\mathrm{H}$ \\
\hline $7.5 \mathrm{PR}$ & 10 & -0.36123 & & & & & E & F & G & $\mathrm{H}$ \\
\hline $10.0 \mathrm{PU}$ & 10 & -0.48143 & & & & & & F & G & $\mathrm{H}$ \\
\hline $5.0 \mathrm{PR}$ & 10 & -0.68027 & & & & & & & G & $\mathrm{H}$ \\
\hline $7.5 \mathrm{PU}$ & 10 & -0.98531 & & & & & & & & $\mathrm{H}$ \\
\hline $5.0 \mathrm{PU}$ & 10 & -1.31854 & & & & & & & & \\
\hline
\end{tabular}

Means that do not share a letter are significantly different.

Comparisons for NMAV (Latissimus dorsi)

Tukey Pairwise Comparisons: Response = NMAV (Latissimus dorsi), Term $=$ Force

Grouping Information Using the Tukey Method and 95\% Confidence

$\begin{array}{lrrrrr}\text { Force } & \text { N } & \text { Mean } & \text { Grouping } \\ 10.0 & 50 & 0.530913 & \text { A } & & \\ 7.5 & 50 & -0.040747 & & \text { B } & \\ 5.0 & 50 & -0.543134 & & & \text { C }\end{array}$

Means that do not share a letter are significantly different.

Tukey Simultaneous 95\% Cls

Tukey Pairwise Comparisons: Response = NMAV (Latissimus dorsi), Term = Direction

Grouping Information Using the Tukey Method and 95\% Confidence

\begin{tabular}{|c|c|c|c|}
\hline Direction & $\mathrm{N}$ & Mean & Grouping \\
\hline $\mathrm{PB}$ & 30 & 0.285739 & A \\
\hline PU & 30 & 0.251095 & A \\
\hline PR & 30 & 0.170686 & A \\
\hline $\mathrm{PD}$ & 30 & 0.100879 & A \\
\hline PL & 30 & -0.896679 & B \\
\hline
\end{tabular}

Tukey Simultaneous 95\% Cis 


\section{Comparisons for TNMAV}

Tukey Pairwise Comparisons: Response $=$ TNMAV, Term $=$ Force $*$ Direction

Grouping Information Using the Tukey Method and 95\% Confidence

Force*Direction

10.0 PR

$10.0 \mathrm{PU}$

$7.5 \mathrm{PU}$

$7.5 \mathrm{PR}$

$5.0 \mathrm{PU}$

$10.0 \mathrm{PD}$

$5.0 \mathrm{PR}$

$10.0 \mathrm{~PB}$

$10.0 \mathrm{PL}$

$7.5 \mathrm{PD}$

Mean

237.569 A

$216.100 \mathrm{~A}$

173.272

143.604

129.642

119.761

100.209

86.189

86.058

75.181

67.367

53.804

51.474

47.639

$7.5 \mathrm{~PB}$

5. $0 \mathrm{PL}$

40.429

Grouping

A

B

B C

C D

C D E

D $E$ F

E $\quad F \quad G$

$\begin{array}{lll}E & F & G \\ E & F & G\end{array}$

5. 0 PD
$5.0 \mathrm{~PB}$

10

Means that do not share a letter are significantly different. 
Appendix I: Subjective discomfort ratings raw data 


\begin{tabular}{|c|c|c|c|c|c|c|c|c|c|c|c|c|c|c|c|}
\hline Force & & & 0 lbs & & & & & $5 \mathrm{lbs}$ & & & & & 5lbs. & & \\
\hline Subject number & $\mathrm{PU}$ & PB & PR & PL & PD & $\mathrm{PU}$ & PB & PR & PL & $\mathrm{PD}$ & $\mathrm{PU}$ & $\mathrm{PB}$ & PR & PL & PD \\
\hline 1 & 10 & 2 & 10 & 4 & 7 & 10 & 3 & 9 & 3 & 5.5 & 7 & 1 & 7.5 & 2 & 2 \\
\hline 2 & 10 & 3.5 & 10 & 5.5 & 7 & 8 & 2 & 8 & 4.5 & 4 & 6.5 & 1 & 7 & 1.5 & 3 \\
\hline 3 & 9 & 3 & 8.5 & 5 & 6 & 5.5 & 2 & 6 & 4.5 & 5 & 5.5 & 1 & 4.5 & 2 & 1 \\
\hline 4 & 7.5 & 2.5 & 8 & 3 & 5 & 6 & 1.5 & 6 & 1 & 2.5 & 4 & 1 & 3.5 & 1 & 1 \\
\hline 5 & 7.5 & 2 & 7 & 2.5 & 3.5 & 5.5 & 2 & 5.5 & 2 & 2.5 & 4 & 1 & 4 & 1 & 1.5 \\
\hline 6 & 10 & 3 & 8.5 & 5 & 6 & 8.5 & 3 & 7.5 & 3 & 4.5 & 6 & 2.5 & 6 & 3 & 3 \\
\hline 7 & 8 & 1.5 & 7 & 4 & 4 & 5.5 & 1.5 & 4.5 & 1 & 1 & 2.5 & 1 & 1.5 & 1 & 1 \\
\hline 8 & 10 & 2 & 9 & 2 & 6 & 9 & 2 & 8 & 1 & 2 & 7 & 1 & 7 & 2 & 1 \\
\hline 10 & 10 & 4 & 9.5 & 6.5 & 7 & 7.5 & 3 & 8 & 4 & 4 & 6 & 2.5 & 6 & 2.5 & 3 \\
\hline 11 & 10 & 2 & 8 & 6 & 5 & 8.5 & 2 & 6.5 & 3.5 & 3.5 & 5.5 & 1 & 5 & 2.5 & 2 \\
\hline Avg. & 9.2 & 2.55 & 8.55 & 4.35 & 5.65 & 7.4 & 2.22 & 6.9 & 2.75 & 3.45 & 5.4 & 1.3 & 5.2 & 1.85 & 1.85 \\
\hline STD & 1.11 & 0.79 & 1.09 & 1.51 & 1.25 & 1.66 & 0.586 & 1.41 & 1.42 & 1.42 & 1.47 & 0.63 & 1.87 & 0.7 & 0.88 \\
\hline
\end{tabular}


Appendix J: Median frequency slope raw data 
S: Subject. F: Force. D: Direction. SS: Supraspinatus. IS: Infraspinatus. TM: Teres major. MD: Middle deltoid. AD: Anterior deltoid. PD: posterior deltoid. Bi: Bicep, Tri: Tricep. LD: Latissimus dorsi.

\begin{tabular}{|c|c|c|c|c|c|c|c|c|c|c|c|c|}
\hline $\mathbf{S}$ & $\mathbf{F}$ & D & SS & ID & $\mathbf{T M}$ & MD & AD & PD & $\mathbf{B i}$ & Tri & LD & TM \\
\hline 1 & 10 & $\mathrm{PU}$ & -0.7393 & -1.5786 & -2.9191 & -0.8274 & -2.3762 & -0.3560 & -0.4869 & -1.1822 & -1.9810 & -12.4465 \\
\hline 1 & 10 & $\mathrm{~PB}$ & 0.1909 & -0.1014 & -0.7007 & -0.7552 & $*$ & -0.3854 & -0.0021 & -0.2563 & -0.1413 & -2.1515 \\
\hline 1 & 10 & PR & -0.0764 & -1.2091 & -1.3313 & $*$ & 0.2091 & $*$ & $*$ & -0.8127 & $*$ & -3.2204 \\
\hline 1 & 10 & PL & -0.1175 & -0.3832 & 0.0354 & -0.1717 & -0.4990 & -0.1742 & -0.1749 & -0.3140 & -0.2713 & -2.0703 \\
\hline 1 & 10 & PD & $*$ & -0.0011 & -0.3144 & -0.4861 & -0.1336 & 0.1818 & -0.0755 & -0.1812 & -0.0518 & -1.0616 \\
\hline 1 & 7.5 & PU & -0.6893 & -1.2310 & -2.5762 & -0.2702 & -1.5405 & -0.5345 & -0.3560 & -1.4703 & $*$ & -8.6678 \\
\hline 1 & 7.5 & PB & 0.2252 & -0.2406 & 0.0853 & -0.2119 & $*$ & -0.1703 & $*$ & -0.3878 & 0.2395 & -0.4605 \\
\hline 1 & 7.5 & PR & -0.2580 & -1.1142 & $*$ & $*$ & -0.0476 & $*$ & -0.0109 & -0.2013 & $*$ & -1.6320 \\
\hline 1 & 7.5 & PL & $*$ & -0.2594 & 0.0679 & -0.3720 & -0.3336 & -0.2462 & 0.1241 & -0.3721 & -0.6895 & -2.0808 \\
\hline 1 & 7.5 & $\mathrm{PD}$ & -0.4416 & 0.1843 & 0.1322 & -0.0238 & 0.2598 & 0.1207 & -0.0521 & 0.2133 & 0.0853 & 0.4781 \\
\hline 1 & 5 & PU & 0.1039 & -0.2637 & -0.4584 & 0.0095 & -1.2563 & -0.1759 & -0.2899 & -0.3577 & -1.0906 & -3.7790 \\
\hline 1 & 5 & $\mathrm{~PB}$ & -0.0049 & -0.0615 & -0.0727 & -0.1469 & -0.0168 & -0.3182 & -0.2350 & -0.1175 & -0.2657 & -1.2392 \\
\hline 1 & 5 & PR & 0.0626 & -0.6853 & -0.9979 & 0.1102 & 0.1944 & -0.0934 & 0.1318 & -0.2664 & -0.2416 & -1.7857 \\
\hline 1 & 5 & PL & -0.3776 & -0.2025 & -0.5790 & -0.4178 & -0.5325 & -0.3717 & -0.0955 & 0.0469 & -0.1826 & -2.7122 \\
\hline 1 & 5 & PD & 0.1084 & -0.2035 & -0.4559 & -0.3423 & 0.1588 & -0.3738 & -0.1336 & -0.0755 & -0.5637 & -1.8811 \\
\hline 2 & 10 & $\mathrm{PU}$ & -1.2429 & -3.1571 & -2.8557 & -0.8500 & -2.0693 & -1.4536 & -0.4179 & -1.4936 & -2.1393 & -15.6793 \\
\hline 2 & 10 & $\mathrm{~PB}$ & -0.1347 & -0.1860 & -0.0825 & -0.0769 & -0.2308 & -0.0888 & -0.0948 & -0.2672 & 0.0601 & -1.1015 \\
\hline 2 & 10 & $\mathrm{PR}$ & -0.6867 & -1.0167 & -0.7455 & -1.4313 & -1.2567 & -1.6312 & -0.2418 & -0.9615 & -0.7703 & -8.7416 \\
\hline 2 & 10 & PL & -0.1469 & -0.8888 & -0.1168 & -0.4168 & -0.5878 & -0.4923 & -0.0815 & -0.3144 & -0.7007 & -3.7458 \\
\hline
\end{tabular}




\begin{tabular}{|c|c|c|c|c|c|c|c|c|c|c|c|c|}
\hline 2 & $10 \mathrm{I}$ & PD & -0.0238 & -0.1395 & -0.1752 & -0.1493 & -0.2714 & -0.1399 & -0.2577 & -0.4965 & 0.1423 & -1.5109 \\
\hline 2 & $7.5 \mathrm{I}$ & $\mathrm{PU}$ & -0.7131 & -1.8350 & -1.9901 & -0.8215 & -0.9575 & -0.8481 & -0.1675 & -1.2659 & $*$ & -8.5985 \\
\hline 2 & $7.5 \mathrm{I}$ & PB & -0.3227 & -0.2937 & -0.2595 & -0.0067 & -0.3559 & -0.1297 & -0.0521 & -0.4937 & 0.2091 & -1.7048 \\
\hline 2 & $7.5 \mid \mathrm{I}$ & PR & -0.2696 & -0.7689 & -0.8161 & -0.3616 & -0.2032 & -0.3256 & $*$ & -0.1934 & -0.6860 & -3.6243 \\
\hline 2 & $7.5 \mid \mathrm{I}$ & PL & -0.2315 & -0.3301 & -0.2913 & -0.4343 & -0.6322 & -0.1196 & -0.0920 & -0.4280 & -1.0357 & -3.5945 \\
\hline 2 & $7.5 \mathrm{I}$ & PD & -0.1808 & 0.0626 & 0.0465 & -0.1532 & -0.0339 & -0.0273 & -0.1581 & -0.2116 & -0.1490 & -0.8046 \\
\hline 2 & $5 \mathrm{H}$ & $\mathrm{PU}$ & -0.4039 & -1.0025 & -1.2007 & -0.7479 & -0.6734 & -0.5728 & -0.0444 & -0.7734 & -0.3910 & -5.8098 \\
\hline 2 & 5 | & PB & -0.2196 & -0.0322 & 0.2552 & -0.2084 & -0.5853 & -0.1084 & -0.0623 & -0.3266 & $*$ & -1.2876 \\
\hline 2 & 5 | & PR & -0.0042 & -0.8081 & -0.7140 & 0.0713 & -0.1252 & 0.0591 & 0.1738 & 0.1294 & -0.3514 & -1.5693 \\
\hline 2 & 5 | & PL & -0.2451 & 0.0612 & -0.0490 & -0.4860 & -0.6101 & -0.4248 & -0.0347 & -0.2290 & 0.1937 & -1.8238 \\
\hline 2 & 5 & PD & 0.1650 & $*$ & -0.1916 & -0.2727 & -0.0161 & -0.1021 & -0.5990 & -0.4559 & 0.0140 & -1.4584 \\
\hline 3 & $10 \mathrm{~F}$ & $\mathrm{PU}$ & -0.7070 & -1.5643 & -1.5577 & -1.7525 & -2.2189 & -0.3983 & -0.1469 & -1.1025 & -0.9413 & -10.3892 \\
\hline 3 & $10 \mathrm{~F}$ & PB & 0.1657 & -0.4203 & -0.4430 & -0.3290 & -0.6888 & -0.8231 & 0.3517 & -0.4143 & -0.5042 & -3.1053 \\
\hline 3 & $10 \mathrm{~F}$ & PR & -0.5801 & -1.1336 & -0.7441 & -1.1021 & -0.7073 & -1.1459 & -0.9259 & -0.8892 & -0.4434 & -7.6715 \\
\hline 3 & $10 \mathrm{~F}$ & PL & -0.2438 & -0.9909 & -0.2280 & -0.5846 & -0.5350 & -0.8189 & -0.3881 & -0.3196 & -0.0839 & -4.1927 \\
\hline 3 & $10 \mathrm{~F}$ & PD & -0.5070 & 0.1881 & -0.3650 & -0.4070 & -0.5238 & -0.5109 & -0.6298 & -0.7406 & -0.2220 & -3.7178 \\
\hline 3 & $7.5 \mathrm{~F}$ & $\mathrm{PU}$ & -0.5650 & -1.3738 & -1.2693 & -0.9728 & -1.0144 & -0.4112 & -0.0784 & -0.7458 & -0.1469 & -6.5774 \\
\hline 3 & $7.5 \mid \mathrm{F}$ & PB & -0.1906 & -0.7913 & -0.5238 & -0.3133 & -0.4361 & -0.3494 & 0.0455 & $*$ & 0.2140 & -2.3448 \\
\hline 3 & $7.5 \mathrm{~F}$ & PR & -0.2430 & -0.9903 & -1.1133 & -0.6777 & 0.1339 & -0.6707 & -1.1825 & -0.8007 & -0.3889 & -5.9330 \\
\hline 3 & $7.5 \mid \mathrm{I}$ & PL & -0.3619 & -0.2724 & 0.2291 & -0.6231 & -0.0200 & -0.8937 & -0.2336 & -0.2843 & -0.2168 & -2.6765 \\
\hline 3 & $7.5 \mathrm{~F}$ & PD & -0.6091 & -0.2455 & -0.2518 & -0.0871 & -0.7049 & -0.2227 & 0.1322 & -0.6472 & 0.1091 & -2.5269 \\
\hline 3 & $5 \mathrm{~F}$ & $\mathrm{PU}$ & -0.6374 & -0.6193 & -1.0382 & -0.6462 & -0.7699 & -1.1053 & 0.0518 & -0.2832 & -0.0682 & -5.1158 \\
\hline
\end{tabular}




\begin{tabular}{|c|c|c|c|c|c|c|c|c|c|c|c|c|}
\hline 3 & 5 & $\mathrm{~PB}$ & -0.8002 & -0.2500 & -0.0771 & $*$ & 0.0527 & -0.1079 & -0.0651 & -0.0354 & 0.3200 & -0.9628 \\
\hline 3 & 5 & PR & -0.1598 & -0.4766 & -0.6706 & -0.1511 & 0.3601 & -0.2962 & 0.1647 & -0.3126 & 0.0049 & -1.5371 \\
\hline 3 & 5 & PL & -0.0951 & -0.2028 & -0.3580 & -0.2350 & -0.3056 & $*$ & -0.2469 & -0.1755 & 0.0360 & -1.5829 \\
\hline 3 & 5 & PD & -0.2161 & 0.0678 & -0.0524 & -0.2238 & 0.2503 & -0.2615 & -0.3685 & -0.3420 & -0.8392 & -1.9854 \\
\hline 4 & 10 & PU & -0.1206 & -1.8636 & -2.6311 & -0.4053 & -0.9734 & -0.7081 & -0.9102 & -0.3850 & -0.4469 & -8.4441 \\
\hline 4 & 10 & $\mathrm{~PB}$ & 0.0958 & -0.6011 & -0.6574 & -0.4238 & -0.8140 & -0.4227 & -0.6899 & -0.7214 & -0.3731 & -4.6073 \\
\hline 4 & 10 & $\mathrm{PR}$ & -0.7556 & -2.5615 & -2.5049 & -0.9818 & -0.8434 & -0.7350 & -0.6909 & -1.6042 & -0.2860 & -10.9633 \\
\hline 4 & 10 & PL & -0.5983 & -2.1483 & 0.1028 & -0.1525 & -0.0483 & -0.4227 & 0.0437 & -0.3696 & -0.1329 & -3.7260 \\
\hline 4 & 10 & PD & -0.6322 & -0.1175 & -0.3654 & 0.0748 & -0.3280 & -0.2238 & -0.2011 & -0.7392 & -0.4063 & -2.9386 \\
\hline 4 & 7.5 & $\mathrm{PU}$ & -0.3147 & -1.5224 & -1.8542 & -0.3969 & 0.0476 & -0.7745 & -0.4193 & -0.3042 & -0.7658 & -6.3042 \\
\hline 4 & 7.5 & $\mathrm{~PB}$ & -0.4594 & 0.0797 & -0.3252 & -0.8025 & 0.0256 & -0.0633 & -0.2095 & -0.1140 & 0.2028 & -1.6657 \\
\hline 4 & 7.5 & $\mathrm{PR}$ & -0.5325 & -1.7249 & -1.7406 & -0.2542 & -0.5484 & -0.1182 & -0.4141 & -1.1652 & -0.2618 & -6.7598 \\
\hline 4 & 7.5 & PL & -0.3825 & $*$ & -0.1833 & -0.2458 & -0.8493 & -0.4333 & -0.1874 & -0.0997 & -0.1476 & -2.5288 \\
\hline 4 & 7.5 & PD & -0.5633 & -0.6122 & -0.3717 & -0.2532 & -0.6640 & -0.4329 & $*$ & -0.1906 & -0.2133 & -3.3011 \\
\hline 4 & 5 & $\mathrm{PU}$ & -0.2228 & -1.1539 & -0.9448 & -0.4214 & 0.2091 & -0.2846 & -0.0769 & 0.0633 & 0.1063 & -2.7256 \\
\hline 4 & 5 & $\mathrm{~PB}$ & -0.0937 & -0.3559 & 0.0853 & -0.0280 & 0.0413 & -0.1594 & 0.3545 & $*$ & -0.2280 & -0.3839 \\
\hline 4 & 5 & PR & -0.4004 & -1.2441 & -1.7266 & -0.2168 & -0.4665 & -0.2507 & -0.4389 & -0.2371 & -0.2811 & -5.2620 \\
\hline 4 & 5 & PL & -0.0434 & -0.7892 & -0.5909 & -0.1018 & -0.3993 & -0.4007 & 0.0574 & -0.4930 & -0.0679 & -2.8287 \\
\hline 4 & 5 & PD & -0.1920 & -0.0780 & 0.0797 & -0.0231 & -0.0014 & 0.1577 & -0.5280 & -0.1598 & -0.2693 & -1.0141 \\
\hline 5 & 10 & PU & -0.5748 & -1.3843 & -1.1682 & -0.2497 & -0.5902 & -0.1350 & -0.2329 & 0.0416 & -0.1217 & -4.4151 \\
\hline 5 & 10 & PB & -0.4350 & -0.1752 & -0.4090 & -0.2819 & 0.0260 & -0.7494 & -0.6497 & 0.0204 & 0.1149 & -2.5389 \\
\hline 5 & 10 & PR & -0.3769 & -1.0703 & -0.6336 & -0.9252 & -0.6745 & -0.9493 & -0.7497 & -1.0698 & -0.1418 & -6.5911 \\
\hline
\end{tabular}




\begin{tabular}{|c|c|c|c|c|c|c|c|c|c|c|c|c|}
\hline 5 & 10 & PL & -0.1374 & 0.2055 & -0.6650 & -0.1170 & -0.1126 & -0.9168 & 0.0073 & 0.2801 & -0.2564 & -1.7123 \\
\hline 5 & $10 \mathrm{I}$ & PD & 0.0294 & 0.0056 & 0.0336 & -0.1025 & -0.1126 & -0.2161 & -0.2920 & -0.3011 & -0.0133 & -0.9689 \\
\hline 5 & $7.5 \mathrm{I}$ & PU & -0.3560 & -1.0965 & -0.5920 & -0.2916 & -0.5056 & -0.2472 & 0.1549 & -0.0046 & -0.3007 & -3.2392 \\
\hline 5 & $7.5 \mid \mathrm{I}$ & PB & -0.6396 & -0.5199 & 0.1997 & 0.1119 & $*$ & $*$ & $*$ & 0.0744 & $*$ & -0.7735 \\
\hline 5 & $7.5 \mathrm{I}$ & PR & -0.1105 & -0.8028 & -0.4895 & -0.3969 & -0.3014 & -0.2839 & -0.7137 & -0.2374 & -0.2098 & -3.5458 \\
\hline 5 & $7.5 \mathrm{I}$ & PL & -0.2413 & -1.1427 & -0.3517 & 0.0748 & -0.2916 & $*$ & 0.2664 & 0.6371 & -0.1231 & -1.1721 \\
\hline 5 & $7.5 \mathrm{I}$ & PD & -0.1357 & 0.0399 & 0.1783 & -0.0343 & -0.0591 & -0.2637 & 0.1713 & -0.1948 & 0.4490 & 0.1511 \\
\hline 5 & $5 \mathrm{H}$ & $\mathrm{PU}$ & -0.2559 & -0.8032 & -0.3140 & -0.3402 & -0.3532 & -0.1713 & -0.2797 & -0.3707 & 0.0368 & -2.8513 \\
\hline 5 & 5 I & PB & -0.3119 & -0.4168 & 0.1797 & 0.2804 & $*$ & -0.4958 & $*$ & 0.2615 & $*$ & -0.5029 \\
\hline 5 & 5 | & PR & -0.1266 & -1.2217 & -0.4210 & -0.1955 & -0.1707 & -0.1574 & -0.4860 & -0.6413 & 0.1350 & -3.2850 \\
\hline 5 & 5 | & PL & 0.1804 & 0.1455 & -1.5248 & -0.0367 & -0.4700 & -0.8371 & -0.1269 & -0.0895 & -0.0098 & -2.7689 \\
\hline 5 & $5 \mathrm{~F}$ & PD & 0.0175 & 0.0154 & -0.0315 & -0.1899 & 0.0252 & -0.1231 & 0.1213 & 0.0843 & -0.0874 & -0.1681 \\
\hline 6 & $10 \mathrm{~F}$ & $\mathrm{PU}$ & -0.9500 & -1.6221 & -1.1976 & -1.2284 & -1.3689 & -0.8913 & -0.7151 & -1.4574 & -1.6311 & -11.0616 \\
\hline 6 & $10 \mathrm{~F}$ & PB & -0.2374 & -0.0938 & -0.0825 & -0.4951 & 0.0119 & -0.5168 & -0.3354 & -0.1168 & -0.5287 & -2.3945 \\
\hline 6 & $10 \mathrm{~F}$ & PR & -0.4682 & -1.1098 & -1.2560 & -1.6556 & -1.4133 & -1.7769 & -0.8196 & -1.3479 & -0.6039 & -10.4511 \\
\hline 6 & $10 \mathrm{H}$ & PL & -0.7615 & -0.4021 & -0.3899 & -0.5269 & -0.7546 & -0.4007 & -0.1598 & 0.1546 & 0.0399 & -3.2010 \\
\hline 6 & $10 \mathrm{~F}$ & PD & -0.3661 & 0.0699 & -0.5431 & -0.2871 & -0.5067 & -0.2577 & -0.8305 & -0.6032 & -0.6178 & -3.9421 \\
\hline 6 & $7.5 \mathrm{~F}$ & $\mathrm{PU}$ & -0.4804 & -0.9360 & -0.6007 & -0.8895 & -1.4811 & -0.8315 & -0.5277 & -0.6829 & -0.5682 & -6.9979 \\
\hline 6 & $7.5 \mathrm{H}$ & $\mathrm{PB}$ & -0.0221 & 0.0668 & -0.1091 & -0.3018 & -0.2997 & -0.1920 & -0.3616 & -0.2559 & -0.1567 & -1.6319 \\
\hline 6 & $7.5 \mathrm{~F}$ & PR & -0.3769 & -0.3734 & -0.2608 & -0.5909 & -0.7095 & -0.5920 & -0.0986 & -0.4643 & -0.5598 & -4.0261 \\
\hline 6 & $7.5 \mathrm{H}$ & PL & -0.6801 & -0.0091 & -0.3720 & -0.6256 & -0.2325 & -0.5451 & -0.2888 & -0.3472 & -1.6318 & -4.7322 \\
\hline 6 & $7.5 \mathrm{~F}$ & PD & -0.4423 & -0.2612 & -0.2203 & -0.3021 & -0.0577 & -0.2532 & -0.5028 & -0.1276 & 0.1088 & -2.0584 \\
\hline
\end{tabular}




\begin{tabular}{|c|c|c|c|c|c|c|c|c|c|c|c|c|}
\hline 6 & 5 & $\mathrm{PU}$ & -0.4804 & -1.1112 & -0.7046 & -0.7207 & -0.4941 & -0.2773 & -0.2962 & -0.1990 & -0.8896 & -5.1728 \\
\hline 6 & 5 & PB & -0.2696 & -0.1395 & -0.2290 & -0.3060 & -0.1930 & -0.4444 & -0.2934 & -0.4983 & -0.4357 & -2.8088 \\
\hline 6 & 5 & PR & -0.1014 & -0.5615 & -0.2888 & -0.3259 & -0.2221 & -0.1581 & -0.0199 & -0.2203 & -0.7119 & -2.6098 \\
\hline 6 & 5 & PL & $*$ & 0.2406 & -0.1895 & -0.2074 & -0.3290 & -0.1860 & -0.1493 & -0.3231 & -1.0451 & -2.1887 \\
\hline 6 & 5 & PD & -0.0203 & 0.1437 & -0.2095 & -0.0784 & -0.0035 & -0.1245 & $*$ & -0.1476 & 0.1280 & -0.3119 \\
\hline 7 & 10 & $\mathrm{PU}$ & -0.3231 & -0.9643 & -1.3147 & -0.5637 & -1.0343 & -1.0329 & -0.1741 & -0.9706 & -0.2780 & -6.6556 \\
\hline 7 & 10 & $\mathrm{~PB}$ & -0.4825 & -0.4881 & -0.3878 & 0.0004 & -0.3112 & 0.1479 & -0.3535 & -0.5731 & -0.4039 & -2.8518 \\
\hline 7 & 10 & PR & -0.7823 & -1.0294 & -1.7028 & -2.3014 & -1.8005 & -2.1330 & -1.5892 & -2.4449 & -0.5787 & -14.3622 \\
\hline 7 & 10 & PL & -0.5955 & -1.8294 & -0.3741 & -0.8741 & $*$ & -0.9514 & -0.2469 & -1.1084 & -0.0189 & -5.9986 \\
\hline 7 & 10 & $\mathrm{PD}$ & -0.8524 & -0.7456 & -0.6453 & -0.6021 & -0.6363 & -0.7877 & -0.1939 & -0.6637 & -0.7337 & -5.8605 \\
\hline 7 & 7.5 & $\mathrm{PU}$ & -0.6671 & -0.6609 & -1.2301 & -0.6238 & -0.8476 & -0.7969 & 0.0598 & -0.9221 & -0.5102 & -6.1986 \\
\hline 7 & 7.5 & $\mathrm{~PB}$ & -0.1595 & -0.3301 & 0.0742 & 0.0133 & 0.4343 & -0.3738 & $*$ & -0.3413 & -0.4276 & -1.1104 \\
\hline 7 & 7.5 & PR & -0.4309 & -1.5246 & -1.6518 & -1.1791 & -1.0528 & -0.8791 & -1.0127 & -1.6437 & -0.6327 & -10.0072 \\
\hline 7 & 7.5 & PL & -0.2647 & 0.0685 & -0.6088 & -0.6371 & -1.0629 & -0.6171 & -0.2682 & -0.9221 & 0.0329 & -4.2793 \\
\hline 7 & 7.5 & PD & -0.4826 & -0.2703 & -0.0990 & -0.0643 & -0.1063 & -0.2787 & 0.0531 & -0.6322 & -0.3339 & -2.2140 \\
\hline 7 & 5 & PU & -0.5049 & -0.4598 & -0.9427 & -0.3570 & -0.7039 & -0.5060 & $*$ & -0.5269 & -0.3171 & -4.3181 \\
\hline 7 & 5 & PB & -0.2283 & -0.5112 & -0.2598 & -0.1451 & 0.2532 & -0.4294 & -0.2794 & -0.4203 & $*$ & -2.0203 \\
\hline 7 & 5 & PR & -0.1483 & -0.8140 & -0.8602 & -0.8161 & -0.5206 & -0.6913 & -0.6269 & -1.0727 & -0.2406 & -5.7904 \\
\hline 7 & 5 & PL & -0.3343 & -0.4906 & -0.4413 & -0.5350 & -0.7241 & -0.6182 & -0.1542 & -0.4392 & -0.0955 & -3.8322 \\
\hline 7 & 5 & PD & -0.0049 & -0.0566 & 0.1028 & -0.0769 & -0.1028 & -0.5077 & 0.1231 & -0.3308 & -0.1322 & -0.9860 \\
\hline 8 & 10 & PU & -0.8067 & -1.5497 & -2.5689 & -0.8808 & -1.5518 & -1.5385 & -0.7958 & -1.5619 & -0.2832 & -11.5371 \\
\hline 8 & 10 & $\mathrm{~PB}$ & -0.0360 & -0.1186 & -0.0192 & -0.0759 & -0.1322 & 0.0650 & -0.0143 & -0.0819 & -0.3441 & -0.7570 \\
\hline
\end{tabular}




\begin{tabular}{|c|c|c|c|c|c|c|c|c|c|c|c|c|}
\hline 8 & $10 \mathrm{~F}$ & PR & -0.6651 & -1.6549 & -2.3511 & -1.6818 & -1.1958 & -1.8500 & -1.1336 & -1.7210 & -0.3385 & -12.5917 \\
\hline 8 & $10 \mathrm{I}$ & PL & 0.0017 & -0.8566 & -0.4675 & -0.6700 & -0.3811 & -0.9199 & -0.2154 & -0.4287 & 0.0133 & -3.9241 \\
\hline 8 & $10 \mathrm{~F}$ & PD & -0.3601 & 0.3028 & -0.2640 & -0.9182 & -0.7556 & -1.6203 & -0.6231 & -0.9472 & 0.1752 & -5.0105 \\
\hline 8 & $7.5 \mathrm{H}$ & PU & -0.7518 & -1.2427 & -1.2675 & -0.2780 & -1.2969 & -0.9116 & -0.6378 & -0.8490 & -0.1741 & -7.4091 \\
\hline 8 & $7.5 \mathrm{H}$ & $\mathrm{PB}$ & -0.1007 & -0.1490 & 0.2315 & -0.2154 & -0.0857 & -0.7011 & -0.0483 & -0.1706 & -0.1661 & -1.4052 \\
\hline 8 & $7.5 \mathrm{H}$ & PR & -0.1843 & -1.1199 & -1.6692 & -1.1196 & 0.2074 & -0.1552 & -0.5916 & -1.3853 & -0.2343 & -6.2521 \\
\hline 8 & $7.5 \mid \mathrm{I}$ & PL & -0.3060 & -0.1469 & 0.0916 & -0.4308 & -0.6563 & -0.5311 & -0.0423 & -0.3832 & 0.1112 & -2.2937 \\
\hline 8 & $7.5 \mathrm{H}$ & $\mathrm{PD}$ & -0.6091 & 0.1297 & -0.1913 & 0.2070 & -0.6130 & -0.5105 & -0.3455 & -0.5227 & 0.2825 & -2.1728 \\
\hline 8 & $5 \mathrm{H}$ & $\mathrm{PU}$ & -0.4591 & -0.3693 & -0.2755 & -0.1686 & -1.0570 & -0.6511 & -0.1403 & -0.5403 & -0.0864 & -3.7474 \\
\hline 8 & $5 \mathrm{H}$ & $\mathrm{PB}$ & -0.6119 & 0.1413 & -0.1049 & -0.1441 & 0.4091 & -0.7483 & 0.0329 & -0.4937 & $*$ & -1.5196 \\
\hline 8 & $5 \mathrm{H}$ & PR & -0.2171 & -0.9465 & $*$ & -0.2479 & 0.0042 & -0.1108 & -0.1710 & -0.6357 & 0.3608 & -1.9641 \\
\hline 8 & 5 | & PL & 0.1895 & 0.1056 & $*$ & -0.1801 & -0.7608 & -0.0514 & 0.5476 & -0.0581 & 0.0382 & -0.1695 \\
\hline 8 & $5 \mathrm{H}$ & $\mathrm{PD}$ & -0.0469 & -0.1399 & 0.1990 & 0.0336 & -0.4060 & -0.2535 & -0.2993 & -0.6196 & 0.4545 & -1.0780 \\
\hline 10 & $10 \mathrm{H}$ & PU & -0.7306 & -2.3167 & -1.7747 & -0.5434 & -1.3436 & -0.6588 & 0.2800 & -1.1594 & -0.6838 & -8.9309 \\
\hline 10 & $10 \mathrm{~F}$ & $\mathrm{~PB}$ & 0.0636 & -0.5822 & -0.7326 & -0.4259 & -0.6280 & -0.6175 & -0.2070 & -0.1140 & -0.1063 & -3.3497 \\
\hline 10 & $10 \mathrm{~F}$ & PR & -0.8195 & -2.5613 & -1.9424 & -1.3466 & -0.4114 & -1.5909 & 0.4933 & -1.6324 & -0.9912 & -10.8023 \\
\hline 10 & $10 \mathrm{I}$ & PL & -0.9326 & -2.2269 & -0.7049 & 0.5503 & -0.1846 & -0.0108 & 0.3636 & -0.4601 & -0.6378 & -4.2438 \\
\hline 10 & $10 \mathrm{~F}$ & $\mathrm{PD}$ & -0.7021 & -0.8556 & -0.9979 & -0.0035 & -1.0038 & -0.3011 & -0.8997 & -1.6553 & -0.2018 & -6.6206 \\
\hline 10 & $7.5 \mathrm{I}$ & $\mathrm{PU}$ & -0.2109 & -2.0305 & -1.2934 & -0.5605 & -0.6507 & -0.4486 & -0.0259 & -0.9871 & -0.7238 & -6.9311 \\
\hline 10 & $7.5 \mathrm{I}$ & $\mathrm{PB}$ & -0.3336 & -0.3063 & -0.6588 & 0.0476 & -0.1305 & -0.0294 & -0.0874 & -0.1046 & -0.5301 & -2.1330 \\
\hline 10 & $7.5 \mid \mathrm{H}$ & PR & -0.3769 & -1.9301 & -2.4888 & -0.6720 & -0.1168 & -0.5874 & $*$ & -0.7035 & -0.7105 & -7.5860 \\
\hline 10 & $7.5 \mid$ & PL & -0.1587 & -0.1930 & -0.0899 & -0.4486 & -0.0493 & -0.5934 & -0.0455 & -0.7252 & -0.0018 & -2.3053 \\
\hline
\end{tabular}




\begin{tabular}{|c|c|c|c|c|c|c|c|c|c|c|c|c|}
\hline 10 & 7.5 & PD & -0.2469 & -0.1333 & -0.4843 & -0.2238 & -0.6311 & -0.1514 & -0.4776 & -0.7091 & -0.3727 & -3.4301 \\
\hline 10 & 5 & $\mathrm{PU}$ & -0.0028 & -1.2365 & -0.9210 & -0.5145 & -0.0855 & -0.3381 & 0.2119 & -0.9334 & -0.3805 & -4.2002 \\
\hline 10 & 5 & $\mathrm{~PB}$ & -0.1287 & -0.1203 & 0.2706 & -0.0381 & -0.0538 & -0.1717 & 0.5238 & -0.5538 & -0.1140 & -0.3860 \\
\hline 10 & 5 & PR & 0.0203 & -1.6238 & -1.6539 & -0.2378 & -0.3892 & -0.0763 & -0.7759 & -0.6735 & -0.5584 & -5.9683 \\
\hline 10 & 5 & PL & -0.2962 & -0.0315 & -0.2591 & 0.3608 & -0.5332 & -0.0371 & -0.0776 & -0.2657 & -0.2042 & -1.3437 \\
\hline 10 & 5 & PD & $*$ & -0.4388 & -0.3742 & 0.0224 & -0.2664 & -0.1696 & -0.1028 & -0.1297 & 0.0657 & -1.3934 \\
\hline 11 & 10 & $\mathrm{PU}$ & -1.1350 & -1.3196 & -1.1503 & -1.1874 & -1.8266 & -0.6256 & -0.3249 & -0.9409 & -1.1182 & -9.6284 \\
\hline 11 & 10 & $\mathrm{~PB}$ & -0.8214 & -0.7713 & -0.4388 & -1.4969 & -0.6567 & -0.6378 & -0.4172 & -0.3692 & -0.6941 & -6.3032 \\
\hline 11 & 10 & PR & -1.1018 & -0.8913 & -0.6916 & -1.5277 & -1.1700 & -2.1608 & -0.9703 & -1.0165 & -0.7532 & -10.2829 \\
\hline 11 & 10 & PL & -0.5438 & -0.7755 & -0.5965 & -1.1135 & -0.6490 & -0.5161 & -0.2200 & -0.5434 & -0.3172 & -5.2748 \\
\hline 11 & 10 & PD & -0.8154 & -0.4210 & -0.8070 & -0.6192 & -0.9395 & -0.8301 & -1.1238 & -1.0700 & -0.6224 & -7.2482 \\
\hline 11 & 7.5 & $\mathrm{PU}$ & -0.8665 & -0.6416 & -0.3049 & -0.2871 & -1.1819 & 0.1867 & -0.2497 & -0.7000 & -0.4042 & -4.4490 \\
\hline$\left.11\right|^{7}$ & 7.5 & $\mathrm{~PB}$ & 0.1734 & -0.1322 & -0.2311 & -2.5168 & -0.1367 & -0.0549 & -0.2906 & -0.3305 & -0.3182 & -3.8375 \\
\hline$\left.11\right|^{7}$ & 7.5 & PR & 0.1878 & 0.2588 & -0.7011 & -0.8428 & -0.8418 & -0.5651 & -0.7591 & -0.2033 & -0.7240 & -4.1906 \\
\hline $11{ }^{7}$ & 7.5 & PL & -0.4333 & -0.3528 & -0.5315 & -1.5619 & -0.6874 & -0.2504 & -0.1860 & -0.6881 & 0.0350 & -4.6563 \\
\hline 11 & 7.5 & PD & -0.4909 & -0.1668 & -0.2224 & -0.3700 & -0.6298 & -0.3108 & -0.8668 & -0.7049 & -0.1749 & -3.9371 \\
\hline 11 & 5 & $\mathrm{PU}$ & -0.6629 & -0.4388 & -0.5105 & -0.3004 & -0.7913 & 0.3500 & -0.1067 & -0.3937 & -0.5206 & -3.3747 \\
\hline 11 & 5 & PB & 0.2538 & -0.3256 & -0.1626 & -1.0049 & -0.0420 & -0.3808 & -0.0035 & -0.2046 & -0.1944 & -2.0644 \\
\hline 11 & 5 & PR & -0.2846 & -0.5074 & -0.5126 & -0.5724 & -0.0581 & -0.1804 & -0.0790 & -0.1951 & -0.5315 & -2.9209 \\
\hline 11 & 5 & PL & -0.4567 & -0.4769 & -0.3413 & -2.1060 & -0.1458 & -0.8154 & -0.7304 & -0.0011 & 0.0182 & -5.0552 \\
\hline 11 & 5 & PD & 0.2731 & -0.0224 & -0.1164 & -0.1336 & -0.1301 & -0.2714 & -0.3315 & -0.3731 & -0.0825 & -1.1877 \\
\hline
\end{tabular}


Appendix K: Normalized mean absolute values raw data 
S: Subject. F: Force. D: Direction. SS: Supraspinatus. IS: Infraspinatus. TM: Teres major. MD: Middle deltoid. AD: Anterior deltoid. PD: posterior deltoid. Bi: Bicep, Tri: Tricep. LD: Latissimus dorsi.

\begin{tabular}{|c|c|c|c|c|c|c|c|c|c|c|c|c|}
\hline $\mathbf{S}$ & $\mathbf{F}$ & D & SS & IS & TM & MD & AD & PD & $\mathbf{B i}$ & Tri & LD & $\begin{array}{c}\text { TNMA } \\
\text { V }\end{array}$ \\
\hline 1 & 10 & PU & 11.2707 & 46.2376 & 38.5113 & 32.1507 & $*$ & 20.8333 & 36.7188 & 8.7735 & 24.8096 & $\begin{array}{c}219.305 \\
5\end{array}$ \\
\hline 1 & 10 & $\mathrm{~PB}$ & 3425 & 7.2772 & 21.0032 & 0.7665 & 0.7299 & 0.5585 & 5.6250 & 6.2320 & 21.5452 & 70.0801 \\
\hline 1 & 10 & PR & 14.4751 & 41.3366 & 38.5113 & 18.6765 & 11.5166 & 28.3918 & 10.5469 & 10.0442 & 23.2318 & $\begin{array}{c}196.730 \\
8\end{array}$ \\
\hline 1 & 10 & PL & 9.2044 & 4.8960 & 21.6181 & 2.3015 & 7.2275 & 1.1345 & 21.0156 & 5.7238 & 7.1328 & 80.2542 \\
\hline 1 & 10 & PD & 17.6796 & 11.4851 & 22.0388 & 1.8585 & 0.8412 & 5.2924 & 4.4043 & & 13.2699 & 83.4665 \\
\hline 1 & 7.5 & $\mathrm{PU}$ & 6.8177 & 36.3366 & 30.2265 & 21.4890 & 57.8199 & 13.6404 & 24.7266 & 3.1271 & 16.9750 & $\begin{array}{c}211.158 \\
7\end{array}$ \\
\hline 1 & 7.5 & PB & 9116 & 5.8960 & 19.6278 & & 2.6682 & & 5.6445 & 6.4862 & 10.7835 & 56.6249 \\
\hline 1 & 7.5 & PR & 7.7348 & 29.7525 & 31.1003 & 11.2684 & 6.8246 & 18.9474 & 8.4375 & 2.9061 & 22.1980 & $\begin{array}{c}139.169 \\
6\end{array}$ \\
\hline 1 & 7.5 & PL & 2707 & 3.3267 & 14.6764 & 1.6397 & 8.3531 & 0.7149 & 12.0313 & 8.7735 & 4.9238 & 57.7101 \\
\hline 1 & 7.5 & PD & 10.1436 & 7.1634 & 12.5566 & & & & & & 9.7443 & 53.7704 \\
\hline 1 & 5 & PU & 5.3481 & 24.4059 & 22.8155 & 18.1066 & 44.9052 & 9.7076 & 20.0586 & 1.6022 & 15.0163 & $\begin{array}{c}161.966 \\
1\end{array}$ \\
\hline 1 & 5 & $\mathrm{~PB}$ & 1878 & 5.4257 & 14.0777 & 0.9522 & 4.1588 & 0.4868 & 6.4063 & 3.6906 & 3.4712 & 40.8571 \\
\hline 1 & 5 & PR & 1657 & 20.9901 & 20.5825 & 7.6103 & 3.4479 & 13.3626 & & 2.3757 & 12.3504 & 90.6039 \\
\hline 1 & 5 & PL & & 2.1683 & 7.2977 & 1.2794 & & & 10.4297 & 5.7569 & & 38.3262 \\
\hline 1 & 5 & PD & 6.0331 & 3.0644 & 9.0291 & 1.0625 & 1.7014 & 1.6140 & 2.5391 & 8.3099 & 4.0424 & 37.3959 \\
\hline 2 & 10 & PU & 9.0845 & $*$ & 26.0749 & 31.8421 & 68.4028 & 39.8381 & 32.4380 & 2.6338 & 10.8037 & $\begin{array}{c}221.117 \\
9\end{array}$ \\
\hline 2 & 10 & PB & 2.8451 & 6.3938 & 6.1997 & 1.8158 & 0.8073 & 5.3198 & 7.3760 & 22.3944 & 15.3299 & 68.4819 \\
\hline 2 & 10 & PR & 27.1831 & 60.0237 & 41.6089 & 40.4135 & 32.6910 & $*$ & 8.0992 & 3.4577 & 10.7107 & $\begin{array}{c}224.187 \\
8\end{array}$ \\
\hline 2 & 10 & PL & 3.6761 & 5.5872 & 6.6782 & 4.0996 & 16.0590 & 3.1964 & 19.3802 & 17.1271 & 4.4078 & 80.2115 \\
\hline
\end{tabular}




\begin{tabular}{|c|c|c|c|c|c|c|c|c|c|c|c|c|}
\hline 2 & 10 & PD & 19.6479 & 7.4259 & 20.6657 & 1.3853 & 1.2049 & 2.8806 & 1.4773 & 4.6197 & 13.9594 & 73.2666 \\
\hline 2 & 7.5 & PU & 6.0000 & 49.3476 & 17.3370 & 19.1729 & 47.2222 & 22.8543 & 20.4752 & 1.7465 & 10.1354 & $\begin{array}{c}194.291 \\
1\end{array}$ \\
\hline 2 & 7.5 & PB & 3099 & 5.1186 & 6.6990 & 1.4323 & 0.6997 & 4.1316 & 6.2190 & 13.5211 & 7.9780 & 48.1092 \\
\hline 2 & 7.5 & PR & 13.7324 & 47.8055 & 30.6519 & 23.1391 & 21.4931 & 39.1700 & 5.0661 & 2.6338 & 8.8917 & $\begin{array}{c}192.583 \\
5\end{array}$ \\
\hline 2 & 7.5 & PL & 3.4507 & 7.6453 & 6.5742 & 6.3158 & 19.6354 & 5.4251 & 15.6198 & 13.2394 & 5.2876 & 83.1934 \\
\hline 2 & 7.5 & PD & 14.0845 & 3.8553 & 9.6879 & 0.9962 & 0.9045 & 2.0830 & 1.1260 & 3.9648 & 5.6684 & 42.3707 \\
\hline 2 & 5 & PU & 4.3099 & 40.6880 & 10.4022 & 15.2632 & 38.8889 & 18.8866 & 17.7479 & 1.5563 & 6.8782 & $\begin{array}{c}154.621 \\
2\end{array}$ \\
\hline 2 & 5 & PB & 1.7887 & 4.3060 & 6.3037 & 0.9098 & 0.5347 & 2.7611 & 4.0909 & 7.7465 & 7.0474 & 35.4889 \\
\hline 2 & 5 & PR & 8.2394 & 39.4425 & 14.7018 & 13.4774 & 12.9340 & 23.3401 & 3.3182 & 2.9507 & 6.9459 & $\begin{array}{c}125.350 \\
0\end{array}$ \\
\hline 2 & 5 & PL & 1268 & 4.6679 & 3.9667 & 7.1992 & 19.7917 & 7.2874 & 16.5083 & 7.9577 & 4.1709 & 74.6766 \\
\hline 2 & 5 & PD & 8732 & 2.8055 & 5.4785 & 0.7068 & 0.6510 & 1.1619 & 0.7748 & 7.9245 & 5.1269 & 33.5032 \\
\hline 3 & 10 & PU & 14.2138 & 51.7574 & 19.5413 & 30.1347 & 43.3884 & 7.7902 & 38.7847 & 2.7673 & 32.4332 & $\begin{array}{c}240.811 \\
1\end{array}$ \\
\hline 3 & 10 & PB & 7.9874 & 10.2970 & 14.5872 & 2.1094 & & 4.9888 & 4.2118 & 23.5849 & 32.9198 & $\begin{array}{c}101.843 \\
5\end{array}$ \\
\hline 3 & 10 & PR & 24.5283 & 50.6436 & 52.0183 & 50.3367 & 36.6116 & 53.7946 & 8.7500 & 8.4277 & 17.6718 & $\begin{array}{c}302.782 \\
6\end{array}$ \\
\hline 3 & 10 & PL & 4277 & 3.8540 & 10.3211 & 1.9731 & 5.7521 & 0.8415 & 23.5069 & 17.3944 & 19.1031 & 91.1737 \\
\hline 3 & 10 & PD & 40.5031 & 9.9257 & 30.2752 & 12.1549 & 3.1074 & 17.5000 & 3.8715 & 8.5535 & 40.9351 & $\begin{array}{c}166.826 \\
5\end{array}$ \\
\hline 3 & 7.5 & PU & 10.4403 & 37.8218 & 16.0550 & 22.6431 & 77.9339 & 5.7143 & 30.4861 & 1.9874 & 28.8168 & $\begin{array}{c}231.898 \\
7\end{array}$ \\
\hline 3 & 7.5 & PB & .0189 & 7.8960 & 9.6330 & 1.0488 & 0.9091 & 2.5536 & 5.4896 & 15.3459 & 15.0095 & 59.9045 \\
\hline 3 & 7.5 & PR & 17.1069 & 36.4604 & 32.5229 & 33.9394 & 26.7355 & 35.5357 & 5.1840 & 7.0440 & 13.9218 & $\begin{array}{c}208.450 \\
7\end{array}$ \\
\hline 3 & 7.5 & PL & 7.7987 & 3.3094 & 3.8106 & 1.7391 & 5.8182 & 0.8549 & 20.8681 & 23.2704 & 14.3130 & 81.7823 \\
\hline 3 & 7.5 & PD & 25.4088 & 8.8119 & 19.8165 & 7.8451 & 2.1777 & 12.8571 & 3.0104 & 6.2516 & 26.0496 & $\begin{array}{c}112.228 \\
8\end{array}$ \\
\hline 3 & 5 & PU & 6.7296 & 25.5198 & 11.8807 & 15.1684 & 63.5950 & 3.8460 & 24.4097 & 1.4151 & 20.6107 & $\begin{array}{c}173.175 \\
0\end{array}$ \\
\hline
\end{tabular}




\begin{tabular}{|c|c|c|c|c|c|c|c|c|c|c|c|c|}
\hline 3 & 5 & PB & 1.4340 & 4.7723 & 5.5688 & 0.7525 & 0.9380 & 2.2612 & 3.9722 & 7.0440 & 7.3092 & 34.0522 \\
\hline 3 & 5 & PR & 10.0000 & 25.6436 & 15.5963 & 17.0202 & 12.7273 & 15.0446 & 6.8299 & 4.1258 & 10.0477 & $\begin{array}{c}117.035 \\
4\end{array}$ \\
\hline 3 & 5 & PL & 4.3899 & 1.9010 & 2.3312 & 1.1953 & 3.1405 & 0.9844 & 16.9444 & 16.7296 & 11.8130 & 59.4293 \\
\hline 3 & 5 & PD & 19.0566 & 4.0446 & 11.8349 & 2.1700 & 1.2066 & 3.4509 & 2.8576 & 4.8102 & 11.4790 & 60.9104 \\
\hline 4 & 10 & PU & 5.7664 & 58.9200 & 5.7763 & 28.5714 & 53.9200 & 4.8753 & 23.6644 & 2.5036 & 29.4521 & $\begin{array}{c}213.449 \\
5\end{array}$ \\
\hline 4 & 10 & PB & 2.5036 & 4.8800 & 13.8584 & 3.1217 & 1.8120 & 6.2742 & 4.8288 & 9.1241 & 35.1884 & 81.5912 \\
\hline 4 & 10 & PR & 14.4526 & 62.8000 & 9.5205 & 45.9259 & 35.8000 & 39.4737 & 10.8390 & 3.3869 & 43.4932 & $\begin{array}{c}265.691 \\
8\end{array}$ \\
\hline 4 & 10 & PL & 3.8102 & 5.5280 & 5.6438 & 2.9339 & 12.0000 & 1.0928 & 14.0411 & 34.2138 & 5.0428 & 84.3065 \\
\hline 4 & 10 & PD & 26.4964 & 8.8440 & 14.8858 & 16.7989 & 5.7840 & 20.0000 & 1.7363 & 2.9197 & 29.6233 & $\begin{array}{c}127.088 \\
4\end{array}$ \\
\hline 4 & 7.5 & PU & 3.8978 & 40.6000 & 3.8014 & 16.8254 & 32.9200 & 2.7909 & 18.9384 & 1.6715 & 27.8168 & $\begin{array}{c}149.262 \\
1\end{array}$ \\
\hline 4 & 7.5 & PB & 1.7664 & 3.1400 & 4.2603 & 1.9868 & 1.7520 & 2.0512 & 3.5514 & 7.0292 & 18.3219 & 43.8592 \\
\hline 4 & 7.5 & PR & 7.5182 & 38.0000 & 4.7352 & 25.3439 & 23.9600 & 20.6510 & 3.4332 & 3.1387 & 21.5753 & $\begin{array}{c}148.355 \\
5\end{array}$ \\
\hline 4 & 7.5 & PL & 3.3212 & 3.5400 & 3.0068 & 2.1376 & 3.5440 & 0.8075 & 11.0616 & 23.5036 & 5.8990 & 56.8213 \\
\hline 4 & 7.5 & PD & 25.4015 & 4.8480 & 10.2740 & 11.0847 & 3.8680 & 14.2105 & 1.4229 & 2.7007 & 23.9726 & 97.7829 \\
\hline 4 & 5 & PU & 3.0438 & 33.3200 & 3.1393 & 13.4656 & 26.9200 & 2.2936 & 18.4247 & 1.8321 & 26.8836 & $\begin{array}{c}129.322 \\
6\end{array}$ \\
\hline 4 & 5 & PB & 2.2336 & 4.4760 & 6.8493 & 2.4497 & 1.5000 & 4.6537 & 2.7637 & 4.4161 & 24.2295 & 53.5716 \\
\hline 4 & 5 & PR & 5.1314 & 38.6000 & 4.3174 & 19.5767 & 20.9200 & 14.1551 & 6.5428 & 2.5839 & 22.6884 & $\begin{array}{c}134.515 \\
7\end{array}$ \\
\hline 4 & 5 & PL & 3.5839 & 3.0000 & 2.4795 & 3.3492 & 13.6600 & 0.9183 & 14.1438 & 14.0876 & 7.2517 & 62.4740 \\
\hline 4 & 5 & PD & 17.5912 & 4.4560 & 5.6826 & 5.5079 & 2.3160 & 9.1413 & 1.0445 & 4.3653 & 14.4606 & 64.5656 \\
\hline 5 & 10 & PU & 4.9461 & 31.5909 & 5.8116 & 14.0525 & 53.7267 & 12.6173 & 26.3324 & 3.1101 & 5.1392 & $\begin{array}{c}157.326 \\
8\end{array}$ \\
\hline 5 & 10 & PB & 3.6534 & 18.4091 & 24.4863 & 0.9662 & 1.0652 & 5.2963 & 0.8983 & 8.7963 & 31.4561 & 95.0272 \\
\hline 5 & 10 & PR & 11.3349 & 31.2879 & 8.6986 & 29.3058 & 18.1677 & 41.8765 & 1.6877 & 19.0164 & 10.5996 & $\begin{array}{c}171.975 \\
1\end{array}$ \\
\hline
\end{tabular}




\begin{tabular}{|c|c|c|c|c|c|c|c|c|c|c|c|c|}
\hline 5 & 10 & PL & 19.7658 & 3.6439 & 27.8082 & 1.3358 & 1.7391 & 2.2494 & 7.7650 & 24.1606 & 18.2441 & $\begin{array}{c}106.712 \\
1\end{array}$ \\
\hline 5 & 10 & PD & 33.9110 & 10.8333 & 22.5000 & 7.8612 & 2.7888 & 17.7284 & 0.9327 & 3.4567 & 23.4690 & $\begin{array}{c}123.481 \\
0\end{array}$ \\
\hline 5 & 7.5 & PU & 3.9719 & 25.8333 & 4.4075 & 12.4765 & 45.4658 & 11.3333 & 18.9398 & 2.3981 & 5.3961 & $\begin{array}{c}130.222 \\
6\end{array}$ \\
\hline 5 & 7.5 & PB & 5.9672 & 14.3939 & 16.6438 & 0.8630 & 0.9845 & 4.1235 & 1.6447 & 7.2787 & 11.0921 & 62.9914 \\
\hline 5 & 7.5 & PR & 9.3677 & 22.1212 & 5.2158 & 22.7580 & 11.0559 & 31.3086 & 1.2364 & 4.7588 & 5.5396 & $\begin{array}{c}113.361 \\
9\end{array}$ \\
\hline 5 & 7.5 & PL & .0211 & 2.6780 & 23.3562 & 0.9812 & 1.3851 & 2.4543 & 4.9857 & 26.0422 & 18.0086 & 88.9123 \\
\hline 5 & 7.5 & PD & 33.6300 & 8.5985 & 14.4521 & 4.6379 & 1.8261 & 12.0741 & 0.7736 & 2.7166 & 6.7024 & 85.4112 \\
\hline 5 & 5 & PU & 2.7541 & 21.4773 & 3.8082 & 10.2814 & 31.5217 & 9.5062 & 14.3266 & 1.9953 & 4.9422 & $\begin{array}{c}100.613 \\
1 \\
\end{array}$ \\
\hline 5 & 5 & PB & 2.0328 & 13.5985 & 10.3425 & 0.9118 & 0.8820 & 3.5580 & 1.4670 & 3.3349 & 8.9936 & 45.1211 \\
\hline 5 & 5 & PR & 7611 & 19.8864 & 4.5171 & 14.9343 & 8.0745 & 21.1852 & 0.9814 & 2.4075 & 4.9379 & 82.6854 \\
\hline 5 & 5 & PL & & & & & & & & 14.3326 & 3.8630 & 40.0305 \\
\hline 5 & 5 & PD & 17.1429 & 4.9583 & 6.5548 & 2.4146 & 1.1149 & 7.2099 & 0.7908 & 7.1250 & 5.2184 & 52.5296 \\
\hline 6 & 10 & PU & 7.5625 & 59.6667 & 27.6052 & 15.5130 & 52.2936 & 8.1849 & 44.3709 & 5.5500 & 10.2147 & $\begin{array}{c}230.961 \\
5\end{array}$ \\
\hline 6 & 10 & PB & 5625 & 12.3733 & 20.3407 & & 2.2018 & & 0.9056 & & 20.9509 & 89.7463 \\
\hline 6 & 10 & PR & 21.2500 & 65.4667 & 23.6974 & 19.9130 & 36.0321 & 29.2437 & 6.2748 & 7.0000 & 13.4356 & $\begin{array}{c}222.313 \\
3\end{array}$ \\
\hline 6 & 10 & PL & & & 19.5391 & & & & 11.8709 & & 8.5583 & 93.6289 \\
\hline 6 & 10 & PD & 16.0625 & 13.6000 & 23.7475 & 1.8452 & 2.7317 & 5.1681 & 2.1325 & 3.9688 & 13.2209 & 82.4770 \\
\hline 6 & 7.5 & PU & 5.9500 & 39.4000 & 16.1824 & 10.3913 & 34.6789 & 4.5546 & 34.6854 & 5.7813 & 9.5092 & $\begin{array}{c}161.133 \\
1 \\
\end{array}$ \\
\hline 6 & 7.5 & PB & 7.8750 & 14.1000 & 16.8337 & & & & & & 22.7301 & 84.6796 \\
\hline 6 & 7.5 & PR & 9.6875 & 39.2667 & 13.2265 & 9.3043 & 18.0275 & 14.0924 & 3.6093 & 4.2250 & 5.7301 & $\begin{array}{c}117.169 \\
3\end{array}$ \\
\hline 6 & 7.5 & PL & 4.3750 & 5.7133 & 12.6253 & 0.8209 & 3.6399 & 0.5655 & 8.6589 & 8.2500 & 5.7853 & 50.4341 \\
\hline 6 & 7.5 & PD & 11.3125 & 10.5067 & 15.5812 & 1.7748 & 2.2339 & 4.6723 & 1.4172 & 3.3438 & 12.0552 & 62.8975 \\
\hline
\end{tabular}




\begin{tabular}{|c|c|c|c|c|c|c|c|c|c|c|c|c|}
\hline 6 & 5 & PU & 3.5375 & 25.9333 & 11.0721 & 5.8783 & 27.3165 & 2.3950 & 24.1060 & 3.0250 & 5.6227 & $\begin{array}{c}108.886 \\
4\end{array}$ \\
\hline 6 & 5 & PB & 4.5000 & 9.7467 & 10.5461 & 1.0739 & 1.3280 & 3.0916 & 1.0596 & 5.8813 & 17.4847 & 54.7118 \\
\hline 6 & 5 & PR & 7.9375 & 29.6667 & 10.5711 & 6.3652 & 12.9587 & 9.6303 & 4.0894 & 2.4250 & 6.3865 & 90.0304 \\
\hline 6 & 5 & PL & 2.9625 & 3.7667 & 6.9790 & 0.5870 & 3.1422 & 0.4412 & 6.7053 & 7.5000 & 2.8773 & 34.9611 \\
\hline 6 & 5 & PD & 7.6875 & 8.0667 & 12.6253 & 1.1322 & 1.4404 & 3.1849 & 0.9983 & 4.4027 & 9.1411 & 48.6790 \\
\hline 7 & 10 & PU & 4.5734 & 18.5169 & 6.2264 & 5.9540 & 45.8861 & 3.4821 & 49.8599 & 0.8464 & 10.2574 & $\begin{array}{c}145.602 \\
7\end{array}$ \\
\hline 7 & 10 & PB & 0.8703 & 5.6271 & 9.7170 & 0.5818 & 0.6535 & 0.8584 & 6.8207 & 9.0102 & 18.9338 & 53.0729 \\
\hline 7 & 10 & PR & 9.3174 & 55.0847 & 10.7311 & 28.5349 & 21.5981 & 40.3061 & 6.8768 & 2.4642 & 21.5441 & $\begin{array}{c}196.457 \\
5\end{array}$ \\
\hline 7 & 10 & PL & 3.4812 & 8.8941 & 5.6604 & 2.0426 & 5.3639 & 2.1301 & 33.8375 & 15.4375 & 4.9853 & 81.8326 \\
\hline 7 & 10 & PD & 23.9932 & 8.5551 & 21.5330 & 3.4157 & 2.4652 & 7.9464 & 2.8852 & 2.8396 & 21.5441 & 95.1774 \\
\hline 7 & 7.5 & PU & 3.0068 & 18.4322 & 5.5967 & 5.4600 & 42.8006 & 3.6888 & 31.9328 & 0.6382 & 8.4926 & $\begin{array}{c}120.048 \\
7\end{array}$ \\
\hline 7 & 7.5 & PB & 0.7065 & 4.8729 & 6.3443 & 0.5187 & 0.7310 & 1.2844 & 4.7759 & 3.6519 & 10.9265 & 33.8122 \\
\hline 7 & 7.5 & PR & 7.4403 & 31.8220 & 6.1321 & 15.3578 & 12.0411 & 22.1556 & 3.8473 & 1.6519 & 12.8309 & $\begin{array}{c}113.279 \\
0\end{array}$ \\
\hline 7 & 7.5 & PL & 1.7816 & 4.0805 & 2.5495 & 1.3203 & 4.7152 & 1.1964 & 21.5126 & 9.7952 & 3.4007 & 50.3521 \\
\hline 7 & 7.5 & PD & 9.9659 & 5.0085 & 9.4575 & 1.1354 & 1.1693 & 2.9592 & 1.6008 & 1.9488 & 11.6912 & 44.9366 \\
\hline 7 & 5 & PU & 1.9590 & 16.5254 & 3.7830 & 5.2215 & 33.7025 & 3.4439 & 20.4202 & 0.4505 & 6.8162 & 92.3222 \\
\hline 7 & 5 & PB & 0.5870 & 4.6525 & 1.6509 & 0.4855 & 0.6408 & 1.6365 & 4.4958 & 2.8430 & 6.5993 & 23.5914 \\
\hline 7 & 5 & PR & 3.0648 & 19.7458 & 3.3703 & 9.3952 & 7.1203 & 13.1122 & 2.4202 & 1.1195 & 7.6985 & 67.0468 \\
\hline 7 & 5 & PL & 1.6007 & 2.3983 & 2.6014 & 0.8535 & 2.8022 & 0.7806 & 13.2493 & 3.1877 & 2.6875 & 30.1612 \\
\hline 7 & 5 & PD & 3.7201 & 2.0508 & 3.4104 & 0.4514 & 0.6772 & 0.9477 & 0.9468 & 2.6030 & 2.2537 & 17.0612 \\
\hline 8 & 10 & PU & 2.8464 & 46.3576 & 2.5606 & 15.3933 & 25.3036 & 4.5546 & 43.4870 & 0.4494 & 10.1244 & $\begin{array}{c}151.076 \\
9\end{array}$ \\
\hline 8 & 10 & PB & 0.9120 & 4.8013 & 6.2976 & 1.1133 & 0.3603 & 7.6580 & 0.6453 & 9.3446 & 12.3632 & 43.4956 \\
\hline
\end{tabular}




\begin{tabular}{|c|c|c|c|c|c|c|c|c|c|c|c|c|}
\hline 8 & 10 & PR & 11.6667 & 67.5497 & 4.3339 & 38.2022 & 16.7713 & 56.8966 & 4.5691 & 1.8071 & 8.9801 & $\begin{array}{c}210.776 \\
7\end{array}$ \\
\hline 8 & 10 & PL & 2.3034 & 1.7406 & 5.3806 & 1.2022 & 4.2206 & 1.4914 & 12.8357 & 16.6212 & 3.5050 & 49.3007 \\
\hline 8 & 10 & PD & 32.2097 & 7.3289 & 11.0813 & 7.3596 & 2.1660 & 20.3736 & 1.9339 & 1.7566 & 12.5871 & 96.7966 \\
\hline 8 & 7.5 & PU & 2.0787 & 32.3400 & 1.8962 & 10.9082 & 57.3887 & 3.2241 & 26.4529 & 0.6685 & 6.4925 & $\begin{array}{c}141.449 \\
8\end{array}$ \\
\hline 8 & 7.5 & PB & 1.6948 & 4.5585 & 4.5934 & 1.1863 & 0.3664 & 7.5862 & 0.3367 & 5.4869 & 9.7761 & 35.5853 \\
\hline 8 & 7.5 & PR & 6.5169 & 53.2009 & 2.7768 & 17.0412 & 9.1296 & 26.1207 & 2.0150 & 1.1479 & 6.4925 & $\begin{array}{c}124.441 \\
5\end{array}$ \\
\hline 8 & 7.5 & PL & 1.2903 & 1.2561 & 2.3875 & 0.9597 & 3.2389 & 1.0991 & 6.0721 & 13.9700 & 2.7960 & 33.0698 \\
\hline 8 & 7.5 & PD & 17.1348 & 4.2936 & 5.8910 & 5.0187 & 1.1235 & 12.8592 & 0.8287 & 1.1985 & 6.7910 & 55.1390 \\
\hline 8 & 5 & PU & 1.2416 & 16.6336 & 1.1782 & 6.6199 & 32.0850 & 2.2514 & 15.9920 & 0.2715 & 4.1269 & 80.4000 \\
\hline 8 & 5 & PB & 0.3427 & 4.1280 & 2.0502 & 0.8034 & 0.3239 & 5.1149 & 0.7285 & 3.4831 & 5.8706 & 22.8454 \\
\hline 8 & 5 & PR & 3.6330 & 31.7881 & 1.8287 & 10.9738 & 5.5870 & 15.2155 & 1.4529 & 1.0899 & 4.0498 & 75.6186 \\
\hline 8 & 5 & PL & 1.1948 & 0.9857 & 1.2820 & 0.8493 & 3.2186 & 1.0129 & 8.2565 & 8.9513 & 2.6244 & 28.3754 \\
\hline 8 & 5 & PD & 10.5993 & 2.9139 & 2.9585 & 2.7154 & 0.7004 & 8.4770 & 0.4960 & 10.0000 & 5.3980 & 44.2584 \\
\hline 10 & 10 & PU & 36.9565 & 60.4723 & 10.6494 & 20.9655 & 54.3253 & 4.5801 & 31.4953 & 3.4261 & 15.2212 & $\begin{array}{c}238.091 \\
6\end{array}$ \\
\hline 10 & 10 & PB & 5.7950 & 7.4025 & 12.5649 & 2.2897 & 0.7336 & 1.8268 & 6.2617 & 32.6957 & 16.7257 & 86.2954 \\
\hline 10 & 10 & PR & 41.4286 & 49.8973 & 16.2987 & 37.6897 & 15.8478 & 24.5144 & 10.1090 & 9.3913 & 16.8142 & $\begin{array}{c}221.990 \\
9\end{array}$ \\
\hline 10 & 10 & PL & 3.5714 & 6.3912 & 9.1916 & 5.2310 & 10.6903 & 1.5682 & 28.2710 & 28.2772 & 4.6681 & 97.8601 \\
\hline 10 & 10 & PD & 8.5714 & 14.1684 & 33.5065 & 10.3103 & 2.3201 & 7.6640 & 3.0078 & 7.8783 & 32.2124 & $\begin{array}{c}119.639 \\
2\end{array}$ \\
\hline 10 & 7.5 & PU & 29.7516 & 60.0103 & 8.2143 & 15.6552 & 36.5052 & 3.2415 & 20.4984 & 2.1043 & 12.6991 & $\begin{array}{c}188.679 \\
8 \\
\end{array}$ \\
\hline 10 & 7.5 & PB & 6.8323 & 5.9959 & 12.6623 & 1.7586 & 0.6886 & 1.1772 & 5.6698 & 15.6522 & 13.2301 & 63.6669 \\
\hline 10 & 7.5 & PR & 24.1615 & 39.2710 & 10.6818 & 20.3793 & 10.2076 & 12.6247 & 7.2586 & 4.1391 & 11.3717 & $\begin{array}{c}140.095 \\
3\end{array}$ \\
\hline 10 & 7.5 & PL & 2.6149 & 4.1632 & 4.2662 & 2.9241 & 6.0052 & 0.8753 & 19.0498 & 44.5217 & 3.3451 & 87.7658 \\
\hline
\end{tabular}




\begin{tabular}{|c|c|c|c|c|c|c|c|c|c|c|c|c|}
\hline 10 & 7.5 & PD & .7453 & 9.2864 & 22.0779 & 6.0276 & 1.3875 & 4.2257 & 3.9097 & 5.9739 & 14.7345 & 73.3686 \\
\hline 10 & 5 & PU & 23.4161 & 45.4312 & 7.0130 & 12.6897 & 26.4360 & 2.6614 & 14.4860 & 1.4957 & 11.0177 & $\begin{array}{c}144.646 \\
7\end{array}$ \\
\hline 10 & 5 & PB & 4845 & 4.0349 & 4.1591 & 1.2517 & 0.5796 & 0.6181 & 3.6044 & 6.9826 & 5.6018 & 32.3166 \\
\hline 10 & 5 & PR & 20.1863 & 31.9815 & 7.1591 & 12.8276 & 8.2180 & 7.2178 & 5.3427 & 4.0522 & 9.7788 & $\begin{array}{c}106.764 \\
0 \\
\end{array}$ \\
\hline 10 & 5 & PL & 6522 & 3.5883 & 2.3149 & 2.9828 & 10.9343 & 0.8097 & 16.7913 & 22.6957 & 3.7035 & 67.4726 \\
\hline 10 & 5 & PD & 6770 & 6.7710 & 11.6558 & 3.2138 & 0.8581 & 2.5696 & 0.9735 & 5.2016 & 8.8717 & 44.7922 \\
\hline 11 & 10 & PU & 5.8065 & 48.7023 & 15.6034 & 21.0811 & 48.4333 & 22.7461 & 56.0729 & 27.4597 & 72.8302 & $\begin{array}{c}343.257 \\
0\end{array}$ \\
\hline 11 & 10 & PB & 47.1774 & 16.5649 & 28.3333 & 8.3398 & 6.6000 & 23.0570 & 3.9615 & 31.8952 & 43.8994 & $\begin{array}{c}172.257 \\
1 \\
\end{array}$ \\
\hline 11 & 10 & PR & 32.2581 & 75.9542 & 18.3621 & 33.6486 & 40.7667 & 63.7306 & 16.4170 & 8.3468 & 64.0881 & $\begin{array}{c}362.784 \\
2 \\
\end{array}$ \\
\hline 11 & 10 & PL & 21.0484 & 6.4542 & 28.9368 & 1.8649 & 4.2067 & 2.3420 & 14.7368 & 78.8696 & 20.3145 & 95.3022 \\
\hline 11 & 10 & PD & 76.6129 & 21.2214 & 35.3448 & 8.8803 & 7.8000 & 22.2539 & 9.8583 & 76.6129 & 41.6352 & $\begin{array}{c}229.388 \\
1 \\
\end{array}$ \\
\hline 11 & 7.5 & PU & 4.0726 & 25.8397 & 9.0517 & 11.7375 & 27.4333 & 12.5648 & 37.8745 & 3.3185 & 44.4025 & $\begin{array}{c}204.570 \\
7\end{array}$ \\
\hline 11 & 7.5 & $\mathrm{~PB}$ & 4153 & 4.7481 & 9.1379 & 1.6583 & 1.3533 & 7.2539 & 1.2348 & 2.6169 & 18.6164 & 48.8085 \\
\hline 11 & 7.5 & PR & 14.2339 & 33.0916 & 6.2069 & 10.7915 & 12.1667 & 21.1658 & 5.5061 & 13.7097 & 29.1195 & $\begin{array}{c}139.135 \\
2 \\
\end{array}$ \\
\hline 11 & 7.5 & PL & 17.8629 & 4.6412 & 25.2011 & 1.9498 & 2.7267 & 1.7435 & 15.6275 & 11.4516 & 15.5975 & 83.6242 \\
\hline 11 & 7.5 & PD & 39.9597 & 11.1450 & 17.1552 & 4.2085 & 4.1933 & 14.5855 & 4.1134 & 38.4274 & 26.0377 & $\begin{array}{c}123.901 \\
4\end{array}$ \\
\hline 11 & 5 & PU & .3911 & 21.7557 & 7.2414 & 7.0849 & 19.9667 & 6.9171 & 23.1377 & 2.3427 & 36.0377 & $\begin{array}{c}150.469 \\
7\end{array}$ \\
\hline 11 & 5 & PB & 12.2581 & 4.3969 & 9.8276 & 1.8417 & 1.5067 & 8.3679 & 1.2510 & 2.8871 & 25.1572 & 61.7377 \\
\hline 11 & 5 & PR & 10.1210 & 30.1145 & 5.3017 & 7.8764 & 8.3867 & 17.0207 & 3.7166 & 7.4597 & 23.9623 & $\begin{array}{c}112.440 \\
9\end{array}$ \\
\hline 11 & 5 & PL & 17.9032 & 2.8359 & 12.8448 & 1.8224 & 1.9600 & 1.7746 & 27.2874 & 15.6855 & 12.5346 & 78.8301 \\
\hline 11 & 5 & PD & 24.4355 & 6.2786 & 8.2759 & 2.4749 & 2.5367 & 10.1036 & 2.3684 & 18.0242 & 17.0440 & 72.6954 \\
\hline
\end{tabular}

